\title{
Sarcopenia: a rising geriatric giant
}

Citation for published version (APA):

Mijnarends, D. M. (2016). Sarcopenia: a rising geriatric giant: health and economic outcomes of community-dwelling older adults with sarcopenia. [Doctoral Thesis, Maastricht University]. Maastricht University. https://doi.org/10.26481/dis.20160413dm

Document status and date:

Published: 01/01/2016

DOI:

10.26481/dis.20160413dm

Document Version:

Publisher's PDF, also known as Version of record

\section{Please check the document version of this publication:}

- A submitted manuscript is the version of the article upon submission and before peer-review. There can be important differences between the submitted version and the official published version of record.

People interested in the research are advised to contact the author for the final version of the publication, or visit the DOI to the publisher's website.

- The final author version and the galley proof are versions of the publication after peer review.

- The final published version features the final layout of the paper including the volume, issue and page numbers.

Link to publication

\footnotetext{
General rights rights.

- You may freely distribute the URL identifying the publication in the public portal. please follow below link for the End User Agreement:

www.umlib.nl/taverne-license

Take down policy

If you believe that this document breaches copyright please contact us at:

repository@maastrichtuniversity.nl

providing details and we will investigate your claim.
}

Copyright and moral rights for the publications made accessible in the public portal are retained by the authors and/or other copyright owners and it is a condition of accessing publications that users recognise and abide by the legal requirements associated with these

- Users may download and print one copy of any publication from the public portal for the purpose of private study or research.

- You may not further distribute the material or use it for any profit-making activity or commercial gain

If the publication is distributed under the terms of Article $25 \mathrm{fa}$ of the Dutch Copyright Act, indicated by the "Taverne" license above, 


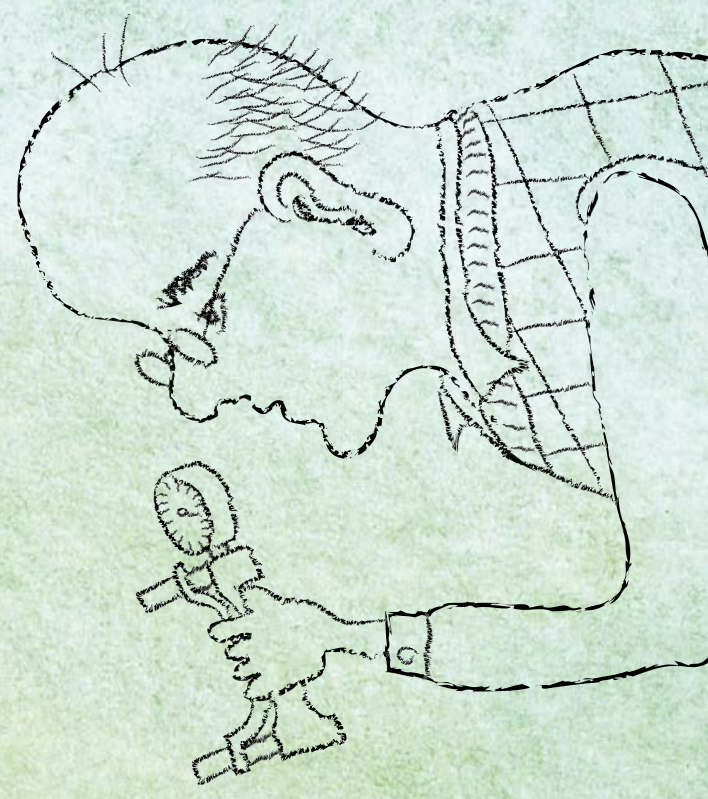

\section{Sarcopenia:} a Rising Geriatric Giant

Health and Economic Outcomes of Community-Dwelling Older Adults with Sarcopenia

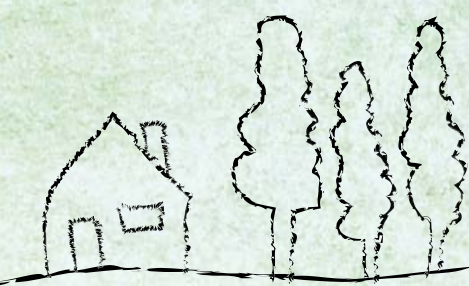





\section{Sarcopenia: a Rising Geriatric Giant}

Health and Economic Outcomes of CommunityDwelling Older Adults with Sarcopenia 
(c) Copyright Donja Mijnarends, Maastricht 2016

All rights reserved. No part of this thesis may be reproduced or transmitted in any form or by any means, electronic or mechanical, including photocopying, recording or any information storage or retrieval system without permission from the author, or when appropriate, from the publisher of the publications.

ISBN: $\quad$ 978-94-028-0084-5

Printing: $\quad$ Ipskamp Printing, Enschede

Cover design: $\quad$ Esther Ris, www.proefschriftomslag.nl

The studies presented in this thesis were performed at the Department of Health Services Research, School for Public Health and Primary Care (CAPHRI), Faculty of Health, Medicine and Life Sciences, Maastricht University. CAPHRI is part of the Netherlands School of Primary Care Research (CaRe), which has been acknowledged since 1995 by the Royal Netherlands Academy of Arts and Sciences (KNAW).

The MaSS study presented in this thesis has been supported by an unrestricted grant from Nutricia Research, Utrecht, the Netherlands. Printing of this thesis was financially supported by Danone Research - Centre for Specialised Nutrition. 


\title{
Sarcopenia: a Rising Geriatric Giant
}

\section{Health and Economic Outcomes of Community- Dwelling Older Adults with Sarcopenia}

\author{
DISSERTATION \\ to obtain the degree of Doctor at Maastricht University, \\ on the authority of the Rector Magnificus, Prof. Dr. L.L.G. Soete \\ in accordance with the decision of the Board of Deans, \\ to be defended in public \\ on Wednesday, 13 April 2016, at 14.00 hours
}

by

Donja Marita Mijnarends 


\section{Supervisor}

Prof. dr. J.M.G.A. Schols

\section{Co-supervisors}

Dr. R.J.G. Halfens

Dr. J.M.M. Meijers

\section{Assessment Committee}

Prof. dr. G.I.J.M. Kempen (chairman)

Prof. dr. R.A. de Bie

Prof. dr. O. Bruyère (University of Liège, Belgium)

Prof. dr. C.P.G.M. de Groot (Wageningen University)

Prof. dr. A.M.W.J. Schols 


\section{Contents}

$\begin{array}{lll}\text { Chapter } 1 & \text { General Introduction } & 7\end{array}$

Chapter 2 Validity and Reliability of Tools to Measure Muscle Mass, Strength 23 and Physical Performance in Community-Dwelling Older People: A Systematic Review

Chapter 3 Prevalence and Characterization of Sarcopenia in Older People

Living in the Community

Chapter 4 Instruments to Assess Sarcopenia and Physical Frailty in Older

People Living in a Community (Care) Setting: Similarities and

Discrepancies

Chapter 5 Burden-Of-IIlness of Dutch Community-Dwelling Older Adults with

Sarcopenia: Health Related Outcomes and Costs

Chapter 6 Physical Activity and Incidence of Sarcopenia: The Population-Based 105 AGES-Reykjavik Study

$\begin{array}{lll}\text { Chapter } 7 \quad \text { General Discussion } & 121\end{array}$

$\begin{array}{lll}\text { Chapter } 8 & \text { Valorisation } & 139\end{array}$

$\begin{array}{ll}\text { Summary } & 149\end{array}$

$\begin{array}{ll}\text { Samenvatting } & 153\end{array}$

$\begin{array}{ll}\text { Dankwoord } & 157\end{array}$

$\begin{array}{ll}\text { About the Author } & 163\end{array}$

$\begin{array}{ll}\text { Publications } & 165\end{array}$

$\begin{array}{lr}\text { Abbreviations } & 169\end{array}$ 



\section{CHAPTER 1}

General Introduction 



\section{Losing Muscle Mass: an Inevitable Consequence of Aging?}

Mrs. Jacobs is a 76-year old lady living independently. She loves to practice gardening and cooking using vegetables from her own garden. Once a week she takes care of her grandchildren and they play games together. Although she can still perform all activities of daily living herself she hired someone to support her with the housekeeping. She feels a bit sad that she cannot join her friends anymore on their weekly walks because she is getting too slow to keep up. Mrs. Jacobs' neighbour, Mr. Blom, visits Mrs. Jacobs for a cup of coffee. He tells her that he is a bit worried about her because he hasn't seen her work in her beloved garden for the last few weeks. Mrs. Jacobs tells him that lately she seems to have lost strength in her hands and she has difficulties getting up from a chair. Mr. Blom wonders whether she should go see a doctor to discuss her symptoms. But Mrs. Jacobs brushes his worries aside and does not see the need to visit a doctor, "those things are part of the aging process, aren't they?"

The human body is composed of more than 600 skeletal muscles, accounting for about $40 \%$ of body weight. ${ }^{1,2}$ In the early years of life muscle mass and function increase. This growth and strengthening of muscles continues for up to about 30 years, after which muscle mass and function slowly start to decrease (Figure 1). ${ }^{3,4}$ In 1989, Rosenberg came up with the term sarcopenia to describe the loss of muscle mass. ${ }^{5}$ Sarcopenia is derived from the Greek words 'sarx' (flesh) and 'penia' (loss). ${ }^{6}$ Sarcopenia occurs in $1-52 \%$ of the community-dwelling older adults, depending on definition, age group, measurement tool, and cut-off points used. ${ }^{7,8}$ Older adults with sarcopenia have a higher risk of disability, loss of independence, decreased quality of life, and an increased mortality risk. ${ }^{9-11}$ Sarcopenia has been recognized as a geriatric syndrome and fits within the list of geriatric giants (frequently occurring geriatric syndromes) such as immobility and instability. ${ }^{12,}{ }^{13}$ Early identification of sarcopenia followed by an appropriate intervention, such as exercise combined with nutritional advice, has the potential to delay or even reverse the loss of muscle mass and function. ${ }^{14}$ This thesis focuses on the prevalence of sarcopenia, characteristics of sarcopenic older adults, and health- and economic related outcomes. This first chapter introduces the topic, aims, and outline of the thesis.

\section{Mechanisms of Sarcopenia}

Human skeletal muscles are composed of two types of muscle fibers. ${ }^{2}$ Type I muscle fibres are called slow-twitch muscle fibres and are used for endurance exercise. ${ }^{2}$ Type II fasttwitch muscle fibres are able to supply great strength of contraction required for jumping for instance. ${ }^{2}$ As a person ages, the number of muscle fibres decreases and the size of the remaining muscle fibres reduces (atrophy). ${ }^{15}$ In older adults atrophy of type II fibres is seen most frequently. ${ }^{15}$ The exact causes of this process are multifactorial but not yet fully understood. ${ }^{16}$ Potential mechanisms that could explain the loss of muscle mass with aging are decreased activity of hormones that stimulate muscle synthesis (e.g. IGF-1, growth hormone, testosterone), increased activity of inflammatory factors that promote catabolism (e.g. TNF- $\alpha$, interleukin 6), and denervation of muscles. ${ }^{16-19}$ Furthermore, bed rest, disease, and lifestyle factors such as physical inactivity and an insufficient diet (e.g. low protein intake, vitamin D deficiency) may contribute to the loss of muscle mass. ${ }^{17,}{ }^{18}$

Studies show that the decline in muscle strength is even steeper than the decline in muscle mass. ${ }^{20-22}$ Muscle strength declines not only because of a reduction in muscle 
quantity but also due to decreased muscle quality (defined as strength corrected for size). Several mechanisms affecting muscle strength and quality are known, including impairments in neural (central) activation, changes in muscle protein structure and function, and fat infiltration. ${ }^{23}$ The latter, describing fat cells squeezing in between muscle cells, has been associated with both reduced muscle strength and impaired mobility. ${ }^{24-27}$

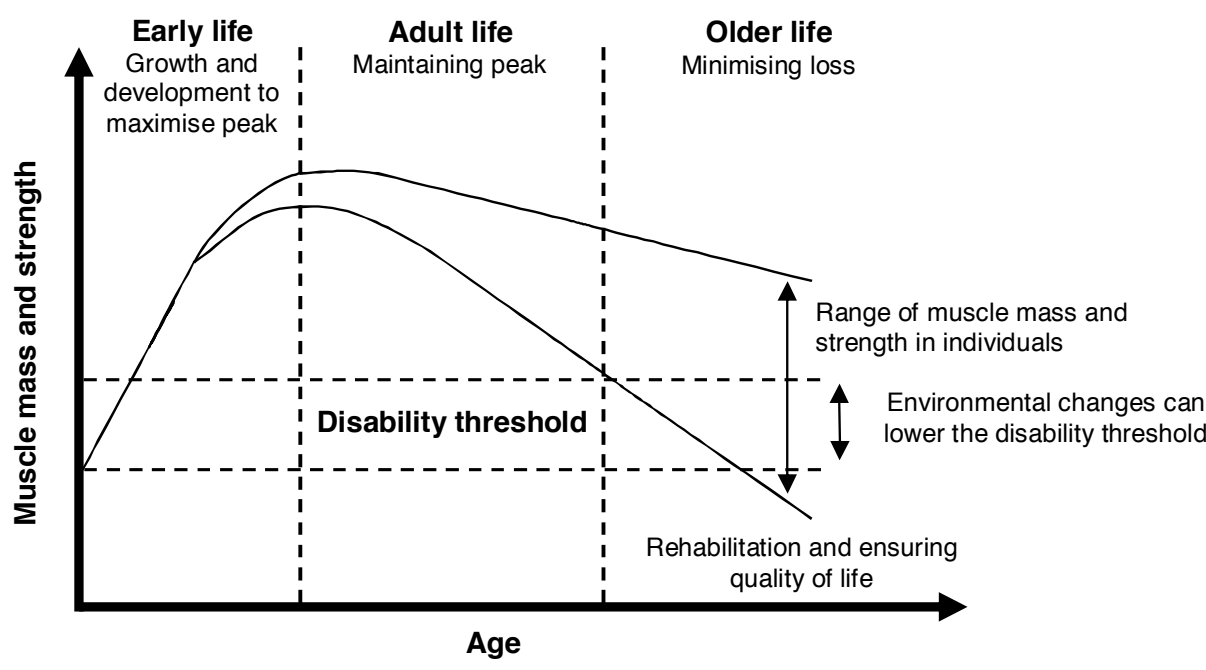

Figure 1 Life course model of sarcopenia based on the World Health Organization model of functional capacity ${ }^{3}$ (reproduced with permission of the $\mathrm{J}$ Nutr Health Aging)

\section{Prevalence of Sarcopenia}

The definition and cut-off points chosen to identify older adults with sarcopenia highly influence the prevalence of sarcopenia. ${ }^{28}$ In the last few years several researchers have tried to agree on a single definition of sarcopenia with appropriate cut-off points for low muscle mass. ${ }^{29-31}$ Originally, sarcopenia was defined as low muscle mass. For clinicians, the pharmaceutical industry, and regulatory agencies, this definition was not satisfying as muscle strength and function might be more clinically relevant (i.e. stronger predictors of adverse outcomes). ${ }^{32,33}$ Muscle strength does not depend solely on muscle mass and an increase in muscle mass does not necessarily lead to increased muscle strength and vice versa. $^{32}$ Therefore, international working groups presented consensus definitions on sarcopenia which in addition to low muscle mass include poor muscle function, ${ }^{34}$ weakness, ${ }^{35}$ limited mobility, ${ }^{36}$ or poor muscle strength and performance. ${ }^{37}$ Prevalence rates of sarcopenia vary highly, e.g. $3-52 \%$ (low muscle mass) ${ }^{38}$ and $1-29 \%$ (low muscle mass with poor muscle strength and/or performance $)^{39}$ in community-dwelling older adults. In long-term care institutions (e.g. nursing homes, care homes for disabled adults) reported prevalence rates range from $14-33 \% .{ }^{39}$ These ranges can be partly explained by age group (higher prevalence at higher ages), cut-off points for low muscle mass and function, and the chosen measurement tool. Although a growing number of studies on the prevalence of sarcopenia in community-dwelling and nursing home populations are 
published, studies in older adults receiving home care or living in an assisted or residential living facility (not being a nursing home) are scarce. Older adults in these settings might be at an early stage of dependency, which would make insight in the prevalence of sarcopenia and characteristics (like functional status) of this population valuable as it might facilitate early intervention against sarcopenia.

\section{Sarcopenia-Related Health Burden}

The main responsibility of skeletal muscles is to support standing balance and locomotion, which are needed for undertaking activities of daily living. A decline in skeletal muscle quantity and quality may result in mobility limitations, difficulties performing activities of daily living, and an increased risk of falls. ${ }^{40-43}$ The aforementioned physical limitations may affect quality of life and increase institutionalization, which in turn could lead to anxiety and increased risk of dependency. ${ }^{41,44}$ In addition, mortality rates for sarcopenic older adults have been reported to be 1.5 times higher than for non-sarcopenic older adults. ${ }^{41,45}$ The higher risk of mortality is mainly predicted by a decreased muscle strength. ${ }^{46}$

\subsection{Physical Frailty}

Sarcopenia has been designated as key pathway between physical frailty and disability or as key component of physical frailty. ${ }^{47-50}$ Frailty is a clinical state of increased vulnerability of an older person to a stressor. ${ }^{51}$ Frail older adults have a higher risk of falls and hospitalization, and their risk of mortality increases threefold compared to non-frail older adults. ${ }^{52}$ The Frailty Phenotype is one of the most well-known and often used definitions of frailty. ${ }^{53}$ The Frailty Phenotype consists of five criteria, (1) unintentional weight loss, (2) self-reported exhaustion, (3) weakness (poor grip strength), (4) slow walking speed, and (5) low physical activity. If three or more of these criteria are present the person is identified as frail. ${ }^{53}$ Although a variety of components shape the concepts of physical frailty and sarcopenia (e.g. weight loss, exhaustion, low physical activity versus low muscle mass), they share a core condition: impaired physical function. ${ }^{54}$ Therefore, several experts in the field have suggested combining frailty and sarcopenia to increase awareness among a broader public and to facilitate identification and treatment of both sarcopenia and frailty. ${ }^{10,49,55}$ Although it is clear that sarcopenia and frailty share common characteristics, studies reporting hard numbers on the overlap of the two conditions are limited.

\section{Economic Burden of Sarcopenia}

In the Netherlands about 18\% (3 million; year 2015) of the population is 65 years or older. $^{56}$ This percentage is expected to increase to more than $25 \%$ in the year $2035 .{ }^{57}$ Without intervention the ageing population will lead to an increased (and thus expensive) need for care in the future. ${ }^{58}$ Most older adults prefer to stay at home, in order to preserve their social network and because they are familiar with their environment. ${ }^{59}$ Nevertheless, institutionalization is not always preventable. About $20 \%$ of the older adults receive home care and $5-10 \%$ of the older adults are living in a residential care home or nursing home. $^{60,61}$ The main reasons for institutionalization are cognitive impairment and/or disability, and associated lack of support, and assistance in daily living. ${ }^{59}$

Sarcopenia has been associated with institutionalization and increased health care costs due to its link with physical disability, falls, and comorbidities such as osteoporosis, 
diabetes, and chronic kidney disease. ${ }^{44,62}$ In the United States sarcopenia alone was estimated to account for about $1.5 \%$ ( $\$ 18.5$ billions) of the direct total health care expenditures. $^{62}$ In that study costs were indirectly calculated. As far known there are no studies investigating the economic burden of sarcopenia using direct measures to estimate costs and there are no European studies on the economic burden of sarcopenia.

\section{Counteracting Sarcopenia}

Ageing inevitably leads to a loss of muscle mass and function; however, the rate of muscle loss is modifiable. Several researchers studied opportunities to prevent, delay or reverse the process of sarcopenia. Current recommendations to reverse or delay the progression of sarcopenia include resistance exercise and protein supplementation. ${ }^{14,63}$ Drug treatment is also being studied with regard to counteracting sarcopenia.

\subsection{Exercise}

Older adults tend to be less physically active than younger adults. ${ }^{64}$ Disuse of skeletal muscles contributes to loss of those muscles: "use it or lose it". ${ }^{65}$ Exercise-induced muscle contraction leads to hypertrophy (increase in volume) of muscle fibres, causing increased muscle mass and strength. ${ }^{15}$ Resistance exercise (Text Box 1 ) is the most promising intervention against sarcopenia. A meta-analysis of 47 studies on the effect of resistance exercise on muscle strength showed that older adults were able to gain up to $30 \%$ extra muscle strength. ${ }^{66}$ Greater improvement of muscle strength occurred with higher intensity training. ${ }^{66}$

Text Box 1 Definitions by the American College of Sports Medicine: ${ }^{58}$

- Exercise: planned, structured, and repetitive movement to improve or maintain one or more components of physical fitness. Exercise may include:

- Aerobic exercise: exercises in which the body's large muscles move in a rhythmic manner for sustained periods

- Resistance exercise: exercise that causes muscles to work or hold against an applied force or weight

- Physical activity: body movement that is produced by the contraction of skeletal muscles and that increases energy expenditure

Although the effect of (resistance) exercise on improvements in muscle mass and function is clear, studies on the effect of general physical activity on sarcopenia show inconsistent results. ${ }^{67}$ Murphy et al. ${ }^{68}$ showed that older adults with moderate physical activity were more likely to transition out of pre-sarcopenia. The LIFE-P study, a randomized-controlled trial with one year follow-up, investigated the effect of modest increases in physical activity on muscle strength in older adults with moderate functional limitations. ${ }^{69}$ Participants of the LIFE-P study received aerobic, strength, flexibility, and balance training, which turned out to prevent loss of muscle strength and improved physical performance. ${ }^{69,70}$ However, other studies did not find an association between physical activity and sarcopenia. ${ }^{71,72}$

It should be noted that older adults may take longer to reach the same level of improvement than younger adults and individual variation exists in the adaptive response to exercise training. ${ }^{64}$ In other words, in some older adults exercise may lead to great 
increases in muscle mass and function while in other older adults the effects of exercise may be minimal. ${ }^{64,65,73}$ However, in general, physical activity/exercise has a positive effect on muscle mass and function and is thus seen as an important remedy in the struggle against sarcopenia. ${ }^{74,75}$ Besides the positive effects of exercise on muscle mass and function exercise has additional benefits, such as improved health, reduced risk for chronic diseases, and increased average life expectancy in older adults. ${ }^{64,76,77}$

\subsection{Nutrition}

Without energy muscles don't work. Muscles need energy and nutrients for contraction, metabolism, and maintenance. ${ }^{78}$ Nutrient intake and dietary supplementation of amino acids and/or proteins stimulate protein synthesis and inhibit protein breakdown of skeletal muscles. ${ }^{79}$ As a result inadequate dietary intake may lead to weight loss (including loss of muscle mass), muscle fatigue, and weakness. ${ }^{78}$ Older adults are at risk of inadequate dietary intake, as they are more likely to experience e.g. loss of appetite (anorexia of aging/anorexia because of disease), problems with chewing or swallowing, altered hormonal responses, slower gastric emptying, pain, and depression. ${ }^{78}$ Hence, a nutritional intervention may have the potential to reduce the risk of (malnutrition-related) sarcopenia. Several studies have investigated the effects of protein, vitamin D, antioxidants, polyunsaturated fatty acids, magnesium, and fruit and vegetables consumption on muscle mass, strength, and performance. The findings show that so far the role of nutrition (supplementation) in counteracting sarcopenia remains equivocal, which could be partly attributed to a lack of large, well-designed studies on nutrition across healthcare settings. $^{13,79}$

Current nutritional recommendations for the prevention of sarcopenia stated by the Society for Sarcopenia, Cachexia and Wasting Disease include a protein intake between 1.0 and $1.5 \mathrm{~g}$ per $\mathrm{kg}$ body weight per day, and supplementation with vitamin $\mathrm{D}$ and a leucine enriched amino acid supplement. ${ }^{80}$ The effect of a nutritional intervention might be stronger in the presence of a (resistance) exercise component as exercise stimulates muscle protein synthesis. ${ }^{81-83}$ The Society for Sarcopenia, Cachexia and Wasting Disease therefore added 20-30 minutes per week of resistance and aerobic exercise to their nutritional recommendations for the management of sarcopenia. ${ }^{80}$

\subsection{Drug Treatment}

Up to now, (resistance) exercise combined with a nutritional intervention has been found most effective for the prevention and management of sarcopenia. However, applying such an intervention in (sarcopenic) older adults can be challenging. ${ }^{84}$ In case resistance exercise is not feasible, pharmacological agents may be of support in reducing functional decline. ${ }^{84}$ Some examples of pharmacological agents that have been tested in sarcopenia research are testosterone, growth hormone, creatine, and angiotensin-converting enzyme (ACE) inhibitors. ${ }^{84,85}$ Although pharmacological agents might be beneficial in treating sarcopenia, more research is needed to get insight in which agents are most appropriate.

\section{Identifying Older Adults with Sarcopenia}

Early identification of older adults with sarcopenia would be of great clinical relevance as it could reduce the substantial health and economic burden caused by sarcopenia. Especially in light of the current changes in the Dutch health care system, in which 
residential living facilities will disappear and older adults will have to be empowered to live independently as long as possible (aging in place), identification and management of sarcopenia is of importance. At the start of this thesis, as far known no systematic review on the psychometric properties of tools to measure sarcopenia in community-dwelling older adults was available. Identification of a set of valid, reliable, and feasible tools may support proper identification of sarcopenia in community-dwelling older adults.

To facilitate case finding of sarcopenic older adults the European Working Group of Sarcopenia in Older People (EWGSOP) provided an algorithm for identifying adults with sarcopenia (Figure 2). ${ }^{37}$ Several studies have been performed using this algorithm. ${ }^{7}$ The EWGSOP algorithm provides a clear view on which muscle parameters to include (muscle mass, grip strength, gait speed) in the assessment of sarcopenia. However, cut-off points for low muscle mass and assessment methods may differ. ${ }^{7,37}$

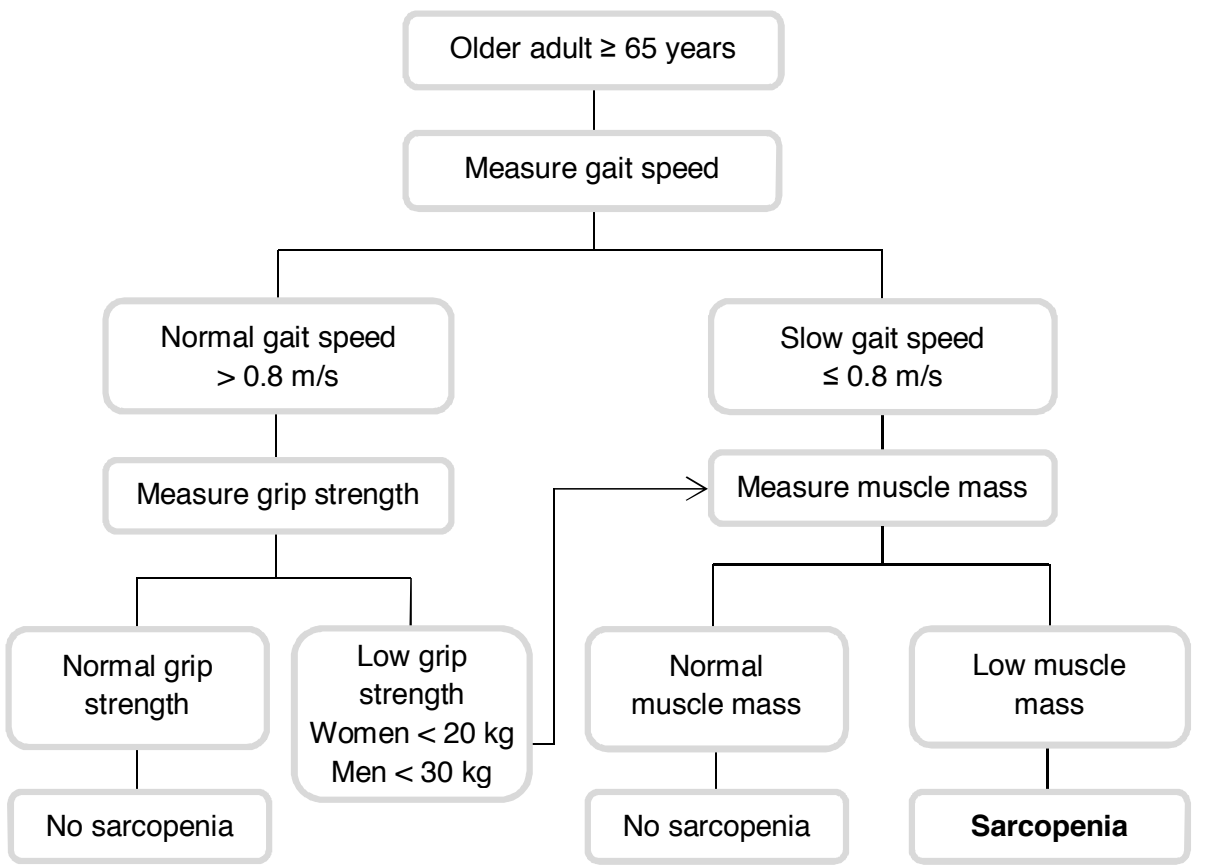

Figure 2 Algorithm for sarcopenia case finding as presented by the European Working Group on Sarcopenia in Older People ${ }^{37}$

Sarcopenia can be diagnosed via questionnaire or performance based measures. One questionnaire to diagnose sarcopenia is the SARC-F. It consists of the components strength, assistance with walking, rise from a chair, climb stairs, and falls. ${ }^{86}$ The advantage of this questionnaire is that sarcopenia can be rapidly diagnosed. Subjects may however over- or underestimate their physical capabilities. Most research into sarcopenia therefore makes use of performance-based measures. Several performance-based measures for muscle mass, strength, and physical performance are explained below. 


\subsection{Muscle Mass}

Muscle mass can be assessed by magnetic resonance imaging (MRI), computed tomography (CT), a 4-compartment model, ultrasonography, dual-energy X-ray (DXA), creatinine excretion, bio-electrical impedance analysis (BIA) or calf circumference ${ }^{87} \mathrm{MRI}$, $\mathrm{CT}$, and creatinine excretion are seen as gold standards to assess muscle mass, however, not always feasible due to their high costs or high radiation exposure. ${ }^{87,88} \mathrm{BIA}$ is a technique to measure muscle mass which is, in contrast to MRI, CT or DXA, feasible for application in a home-setting or by community medical services, relatively inexpensive, and does not expose the subject to radiation. ${ }^{89}$ Several population specific equations to estimate muscle mass by BIA have been proposed..$^{90}$ However, BIA should be interpreted with caution in subjects with an altered hydration status or with an extreme (low or high) BMI. $^{89}$ In addition to the availability of several techniques to assess muscle mass, which hampers comparison between studies, cut-off points for low muscle mass are not welldefined. ${ }^{37}$ Cut-off points for low muscle mass have be based on 1) a muscle mass lower than two standard deviations from a (healthy adult) reference population, 2) on the lowest sex-specific $20^{\text {th }}$ percentile of the sample under study or 3) on previously established associated health-risks such as disability. ${ }^{8,87,91}$ The EWGSOP prefers using a healthy young adult population as a reference population. ${ }^{37}$ The Foundation for the National Institutes of Health Biomarkers Consortium Sarcopenia Project defined low lean mass using DXA. ${ }^{35}$ They suggested cut-off points for appendicular lean mass adjusted for body mass index, based on the ability of the cut-off points to distinguish between presence or absence of weakness. ${ }^{35,92}$

\subsection{Muscle Strength}

The measurement of grip strength seems better defined, although for this muscle parameter differences in assessment protocols and cut-off points do persist. ${ }^{93}$ Most studies using the EWGSOP algorithm measure grip strength by a handheld dynamometer. ${ }^{7}$ For grip strength the EWGSOP provided cut-off points of $<30 \mathrm{~kg}$ for men and $<20 \mathrm{~kg}$ for women and BMI specific cut-off points. ${ }^{37}$ The Foundation for the National Institutes of Health Biomarkers Consortium Sarcopenia Project defined weakness as grip strength $<26$ $\mathrm{kg}$ for men and $<16 \mathrm{~kg}$ for women. ${ }^{35}$ While handheld dynamometry is a simple method to evaluate grip strength other techniques to assess muscle strength are available, such as an isokinetic dynamometer, vigorimeter, or leg press. ${ }^{94}$

\subsection{Physical Performance}

To assess physical performance the EWGSOP recommends usual gait speed. Gait speed is often assessed over a 4 or 6 meter track or by a 6 -minute walk test. ${ }^{95}$ Some researchers assess fast gait speed of their subjects, most researchers assess usual gait speed. ${ }^{96}$ Most studies using the EWGSOP algorithm apply cut-off points for slow gait speed of $\leq 0.8 \mathrm{~m} / \mathrm{s}$, which is predictive of reduced overall survival and disability. ${ }^{35,37,96}$ Another cut-off point for gait speed has been proposed by the International Working Group, consisting of researchers from America, Asia, and Europe. ${ }^{32}$ They recommend $\leq 1.0 \mathrm{~m} / \mathrm{s}$ as cut-off point for slow gait speed. ${ }^{36}$ This cut-off point was found to be predictive of poor outcomes, such as mobility disability, hospitalization, and mortality. ${ }^{96-98}$ 


\section{Aims and Outline of the Thesis}

In this introduction several gaps in knowledge have been presented, namely: a) No systematic review on the psychometric properties of tools to measure sarcopenia in community-dwelling older adults has been performed, b) Sarcopenia prevalence studies in older adults receiving home care or living in an assisted or residential living facility are scarce, c) Studies reporting hard numbers on the overlap between sarcopenia and frailty are limited, d) There are no studies investigating the economic burden of sarcopenia using direct measures to estimate costs, and e) The effect of general physical activity on the incidence of sarcopenia is unclear. Therefore, the overall aim of this thesis is to get more insight into the prevalence of sarcopenia and identify characteristics, health and economic outcomes of community-dwelling older adults with sarcopenia. To achieve this, the crosssectional Maastricht Sarcopenia Study was set up and a secondary data analysis was performed with data from the population-based Age, Gene/Environment, SusceptibilityReykjavik Study. A short summary of the MaSS and AGES-Reykjavik Study is presented below.

Chapters 3 to 5 of this thesis report on data from the Maastricht Sarcopenia Study (MaSS). This study included 247 community-dwelling older adults 1) without additional care, 2) living at home or in an assisted living facility with professional home care, or 3) living in a residential living facility. All participants were living in Maastricht, the Netherlands. Data was collected during a single 1-2 hour home visit, including measurements of height, weight, muscle mass, muscle strength, physical performance, comorbidities, cognitive function, physical activity, nutritional status (by a food frequency questionnaire and blood samples), frailty, functional status, and health care utilization.

Chapter 6 reports on a secondary data-analysis, using data from the populationbased Age, Gene/Environment, Susceptibility-Reykjavik Study (AGES-Reykjavik Study). The AGES-Reykjavik Study is a large cohort study with 5-year follow-up. ${ }^{99}$ The baseline examinations $(n=5,764)$ took place between 2002 and 2006 and the follow-up examinations took place between 2007 and $2011(n=3,316)$. The examinations consisted of several clinic visits and included numerous measurements on vascular, neurocognitive, and musculoskeletal health and questionnaires on physical, psychological, and social health. ${ }^{99}$ 


\subsection{Outline}

Below a short outline is given of the content of this thesis. This outline is also illustrated in Figure 3.

Chapter 1: General introduction of the thesis

Chapter 2: Describes the results of a systematic review on the validity and reliability of tools to measure muscle mass, strength, and physical performance

Chapter 3: Explores the prevalence of sarcopenia and characteristics of sarcopenic community-dwelling older adults, a) without additional care, b) living at home or in an assisted living facility with professional home care, and c) living in a residential living facility.

Chapter 4: Examines the relation between sarcopenia and frailty and the concurrent validity of two frailty tools (Fried criteria and FRAIL scale)

Chapter 5: Reports on the health (disability in activities of daily living, quality of life), and economic burden of sarcopenia in community-dwelling older adults

Chapter 6: Studies the relation between physical activity and the incidence of sarcopenia Chapter 7: General discussion, which reflects on the studies presented in this thesis

Chapter 8: Focuses on the societal value of the studies in this thesis

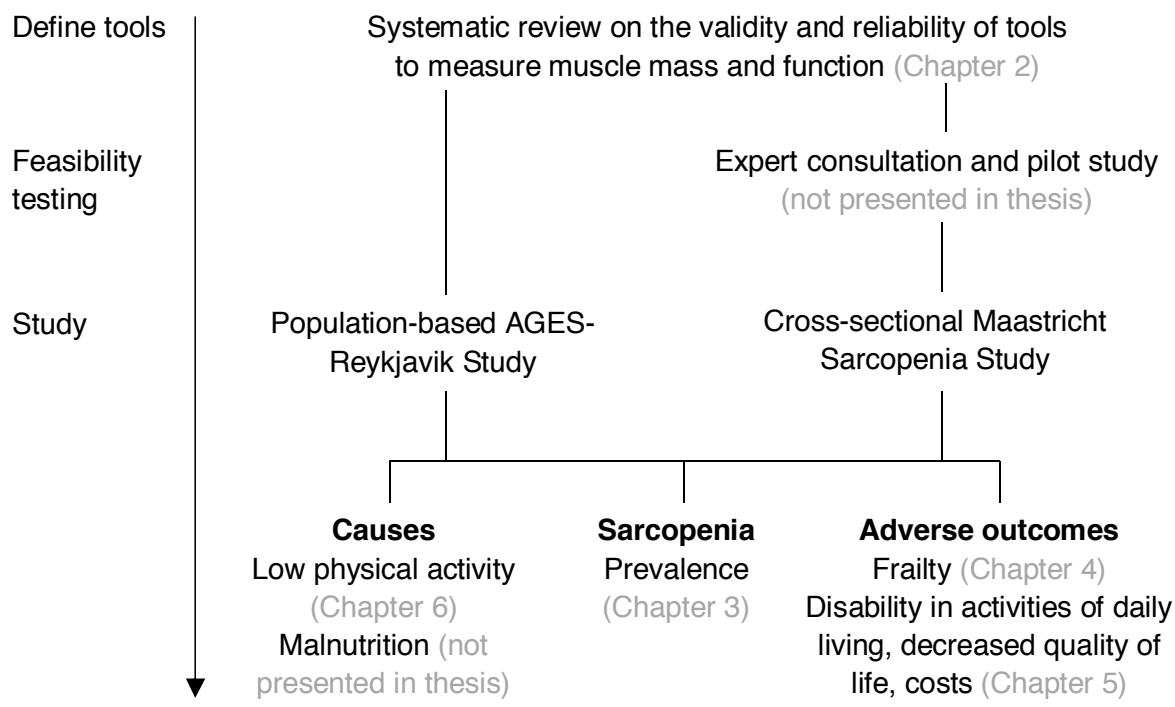

Figure 3 Flowchart of thesis outline 


\section{References}

1. McCann JAS. Anatomy \& physiology. 2nd ed. Philadelphia: Lippincott Williams \& Wilkins, 2002 (Chapter 4).

2. Guyton AC, Hall JE. Textbook of medical physiology. 11th ed. Philadelphia: Elsevier Saunders, 2005.

3. Sayer AA, Syddall H, Martin H, Patel H, Baylis D, Cooper C. The developmental origins of sarcopenia. J Nutr Health Aging 2008;12:427-432.

4. Mitchell WK, Williams J, Atherton P, Larvin M, Lund J, Narici M. Sarcopenia, dynapenia, and the impact of advancing age on human skeletal muscle size and strength: a quantitative review. Front Physiol 2012;3:260.

5. Rosenberg IH. Summary comments. Am J Clin Nutr 1989;50:1231-1233.

6. Rosenberg IH. Sarcopenia: origins and clinical relevance. J Nutr 1997;127:990S-991S.

7. Cruz-Jentoft AJ, Landi F, Schneider SM, et al. Prevalence of and interventions for sarcopenia in ageing adults: a systematic review: report of the International Sarcopenia Initiative (EWGSOP and IWGS). Age Ageing 2014;43:748-759.

8. Fielding RA, Vellas B, Evans WJ, et al. Sarcopenia: an undiagnosed condition in older adults: current consensus definition: prevalence, etiology, and consequences. International working group on sarcopenia. J Am Med Dir Assoc 2011;12:249-256.

9. Hairi NN, Cumming RG, Naganathan V, et al. Loss of muscle strength, mass (sarcopenia), and quality (specific force) and its relationship with functional limitation and physical disability: the Concord Health and Ageing in Men Project. J Am Geriatr Soc 2010;58:2055-2062.

10. Rizzoli R, Reginster JY, Arnal JF, et al. Quality of life in sarcopenia and frailty. Calcif Tissue Int 2013;93:101120.

11. Visser M, Schaap LA. Consequences of sarcopenia. Clin Geriatr Med 2011;27:387-399.

12. Cruz-Jentoft AJ, Landi F, Topinková E, Michel JP. Understanding sarcopenia as a geriatric syndrome. Curr Opin Clin Nutr Metab Care 2010;13:1-7.

13. Sayer AA. Sarcopenia the new geriatric giant: time to translate research findings into clinical practice. Age Ageing 2014;43:736-737.

14. Tieland M, Dirks ML, Van der Zwaluw N, et al. Protein supplementation increases muscle mass gain during prolonged resistance-type exercise training in frail elderly people: a randomized, double-blind, placebocontrolled trial. J Am Med Dir Assoc 2012;13:713-719.

15. Nilwik R, Snijders $T$, Leenders $M$, et al. The decline in skeletal muscle mass with aging is mainly attributed to a reduction in type II muscle fiber size. Exp Gerontol 2013;48:492-498.

16. Murton AJ. Muscle protein turnover in the elderly and its potential contribution to the development of sarcopenia. Proc Nutr Soc 2015;74(4):387-96.

17. Budui SL, Rossi AP, Zamboni M. The pathogenetic bases of sarcopenia. Clin Cases Miner Bone Metab 2015;12:22-26.

18. Drey M, Krieger B, Sieber CC, Bauer JM, Hettwer S, Bertsch T. Motoneuron loss is associated with sarcopenia. J Am Med Dir Assoc 2014;15:435-439.

19. Reid MB, Li YP. Tumor necrosis factor-alpha and muscle wasting: a cellular perspective. Respir Res 2001;2:269-272.

20. Auyeung TW, Lee SW, Leung J, Kwok T, Woo J. Age-associated decline of muscle mass, grip strength and gait speed: a 4-year longitudinal study of 3018 community-dwelling older Chinese. Geriatr Gerontol Int 2014;14:76-84.

21. Goodpaster BH, Park SW, Harris TB, et al. The loss of skeletal muscle strength, mass, and quality in older adults: the health, aging and body composition study. J Gerontol A Biol Sci Med Sci 2006;61:1059-1064.

22. Hughes VA, Frontera WR, Wood M, et al. Longitudinal muscle strength changes in older adults: influence of muscle mass, physical activity, and health. J Gerontol A Biol Sci Med Sci 2001;56:B209-217.

23. Clark BC, Manini TM. Functional consequences of sarcopenia and dynapenia in the elderly. Curr Opin Clin Nutr Metab Care 2010;13:271-276.

24. Koster A, Ding J, Stenholm S, et al. Does the amount of fat mass predict age-related loss of lean mass, muscle strength, and muscle quality in older adults? J Gerontol A Biol Sci Med Sci 2011;66:888-895.

25. Marcus RL, Addison O, Kidde JP, Dibble LE, Lastayo PC. Skeletal muscle fat infiltration: impact of age, inactivity, and exercise. J Nutr Health Aging 2010;14:362-366.

26. Miljkovic N, Lim JY, Miljkovic I, Frontera WR. Aging of skeletal muscle fibers. Ann Rehabil Med 2015;39:155162.

27. Visser M, Goodpaster BH, Kritchevsky SB, et al. Muscle mass, muscle strength, and muscle fat infiltration as predictors of incident mobility limitations in well-functioning older persons. J Gerontol A Biol Sci Med Sci 2005;60:324-333. 
28. Beaudart C, Reginster JY, Slomian J, et al. Estimation of sarcopenia prevalence using various assessment tools. Exp Gerontol 2015;61:31-37.

29. Cruz-Jentoft AJ, Landi F, Topinková E, Michel JP. Understanding sarcopenia as a geriatric syndrome. Curr Opin Clin Nutr Metab Care 2010;13:1-7.

30. Janssen I. Evolution of sarcopenia research. Appl Physiol Nutr Metab 2010;35:707-712.

31. Cederholm T, Morley JE. Sarcopenia: the new definitions. Curr Opin Clin Nutr Metab Care 2015;18:1-4.

32. Morley JE, Abbatecola AM, Argiles JM, et al. Sarcopenia with limited mobility: an international consensus. J Am Med Dir Assoc 2011;12:403-409.

33. Cruz-Jentoft AJ, Baeyens JP, Bauer JM, et al. Sarcopenia: European consensus on definition and diagnosis: report of the European Working Group on Sarcopenia in Older People. Age Ageing 2010;39:412-423.

34. Muscaritoli M, Anker SD, Argiles J, et al. Consensus definition of sarcopenia, cachexia and pre-cachexia: joint document elaborated by Special Interest Groups (SIG) "cachexia-anorexia in chronic wasting diseases" and "nutrition in geriatrics". Clin Nutr 2010;29:154-159.

35. Studenski SA, Peters KW, Alley DE, et al. The FNIH sarcopenia project: rationale, study description, conference recommendations, and final estimates. J Gerontol A Biol Sci Med Sci 2014;69:547-558.

36. Morley JE, Abbatecola AM, Argiles JM, et al. Sarcopenia with limited mobility: an international consensus. $J$ Am Med Dir Assoc 2011;12:403-409.

37. Cruz-Jentoft AJ, Baeyens JP, Bauer JM, et al. Sarcopenia: European consensus on definition and diagnosis: report of the European Working Group on Sarcopenia in Older People. Age Ageing 2010;39:412-423.

38. Fielding RA, Vellas B, Evans WJ, et al. Sarcopenia: an undiagnosed condition in older adults: current consensus definition: prevalence, etiology, and consequences. International working group on sarcopenia. J Am Med Dir Assoc 2011;12:249-256.

39. Cruz-Jentoft AJ, Landi F, Schneider SM, et al. Prevalence of and interventions for sarcopenia in ageing adults: a systematic review: report of the International Sarcopenia Initiative (EWGSOP and IWGS). Age Ageing 2014;43:748-759.

40. Da Silva AT, De Oliveira Duarte YA, Ferreira Santos JL, Wong R, Lebrao ML. Sarcopenia according to the european working group on sarcopenia in older people (EWGSOP) versus dynapenia as a risk factor for disability in the elderly. J Nutr Health Aging 2014;18:547-553.

41. Hirani V, Blyth F, Naganathan V, et al. Sarcopenia is associated with incident disability, institutionalization, and mortality in community-dwelling older men: the Concord Health and Ageing in Men Project. J Am Med Dir Assoc 2015;16:607-613.

42. Scott D, Hayes A, Sanders KM, Aitken D, Ebeling PR, Jones G. Operational definitions of sarcopenia and their associations with 5-year changes in falls risk in community-dwelling middle-aged and older adults. Osteoporos Int 2014;25:187-193.

43. Bischoff-Ferrari HA, Orav JE, Kanis JA, et al. Comparative performance of current definitions of sarcopenia against the prospective incidence of falls among community-dwelling seniors age 65 and older. Osteoporos Int 2015;26(12):2793-802.

44. Beaudart C, Rizzoli R, Bruyere O, Reginster JY, Biver E. Sarcopenia: burden and challenges for public health. Arch Public Health 2014;72:45.

45. Da Silva AT, Duarte YA, Santos JL, Wong R, Lebrao ML. Sarcopenia according to the European Working Group on Sarcopenia in Older People (EWGSOP) versus dynapenia as a risk factor for mortality in the elderly. J Nutr Health Aging 2014;18:751-756.

46. Newman AB, Kupelian V, Visser M, et al. Strength, but not muscle mass, is associated with mortality in the Health, Aging and Body Composition Study cohort. J Gerontol A Biol Sci Med Sci 2006;61:72-77.

47. Boirie Y. Fighting sarcopenia in older frail subjects: protein fuel for strength, exercise for mass [letter]. $\mathrm{J}$ Am Med Dir Assoc 2013;14:140-143.

48. Clegg A, Young J, lliffe S, Rikkert MO, Rockwood K. Frailty in elderly people. Lancet 2013;381:752-762.

49. Cruz-Jentoft AJ, Michel JP. Sarcopenia: a useful paradigm for physical frailty. Eur Geriatr Med 2013;4:102105.

50. Evans WJ, Paolisso G, Abbatecola AM, et al. Frailty and muscle metabolism dysregulation in the elderly. Biogerontology 2010;11:527-536.

51. Morley JE, Vellas B, Abellan van Kan G, et al. Frailty consensus: a call to action. J Am Med Dir Assoc 2013;14:392-397.

52. Lahousse L, Maes B, Ziere G, et al. Adverse outcomes of frailty in the elderly: the Rotterdam Study. Eur J Epidemiol 2014;29:419-427.

53. Fried LP, Tangen CM, Walston J, et al. Frailty in older adults: evidence for a phenotype. J Gerontol A Biol Sci Med Sci 2001;56:M146-156. 
54. Cesari M, Landi F, Vellas B, Bernabei R, Marzetti E. Sarcopenia and physical frailty: two sides of the same coin. Front Aging Neurosci 2014;6:192.

55. Morley JE, Von Haehling S, Anker SD, Vellas B. From sarcopenia to frailty: a road less traveled. J Cachexia Sarcopenia Muscle 2014;5:5-8.

56. Centraal Bureau voor de Statistiek. Bevolking: geslacht, leeftijd, burgerlijke staat en regio, 1 januari. Den Haag; Heerlen: CBS, 2015.

57. De Jong A, Van Duin C. Regionale prognose 2009-2040: vergrijzing en omslag van groei naar krimp. CBS Bevolkingstrends. 2009:35-44.

58. Centraal Bureau voor de Statistiek. Gezondheid en zorg in cijfers 2012. Den Haag: CBS, 2012.

59. Luppa M, Luck T, Weyerer S, Konig HH, Brahler E, Riedel-Heller SG. Prediction of institutionalization in the elderly: a systematic review. Age Ageing 2010;39:31-38.

60. Centraal Bureau voor de Statistiek, Van Hilten O, Mares AMHM. Gezondheid en zorg in cijfers 2009. Den Haag; Heerlen: CBS, 2009.

61. De Klerk M. Ouderen in instellingen: landelijk overzicht van de leefsituatie van oudere tehuisbewoners. Den Haag: Sociaal en Cultureel Planbureau, 2005.

62. Janssen I, Shepard DS, Katzmarzyk PT, Roubenoff R. The healthcare costs of sarcopenia in the United States. J Am Geriatr Soc 2004;52:80-85.

63. Tieland M, Van de Rest O, Dirks ML, et al. Protein supplementation improves physical performance in frail elderly people: a randomized, double-blind, placebo-controlled trial. J Am Med Dir Assoc 2012;13:720-726.

64. Chodzko-Zajko W, Proctor DN, Fiatarone Singh MA, et al. Exercise and physical activity for older adults Med Sci Sports Exerc 2009;41:1510-1530.

65. Marcell TJ. Sarcopenia: causes, consequences, and preventions. J Gerontol A Biol Sci Med Sci 2003;58:M911-916.

66. Peterson MD, Rhea MR, Sen A, Gordon PM. Resistance exercise for muscular strength in older adults: a meta-analysis. Ageing Res Rev 2010;9:226-237.

67. Scott D, Blizzard L, Fell J, Jones G. The epidemiology of sarcopenia in community living older adults: what role does lifestyle play? J Cachexia Sarcopenia Muscle 2011;2:125-134.

68. Murphy RA, Ip EH, Zhang Q, et al. Transition to sarcopenia and determinants of transitions in older adults: a population-based study. J Gerontol A Biol Sci Med Sci 2014;69:751-758.

69. Goodpaster BH, Chomentowski P, Ward BK, et al. Effects of physical activity on strength and skeletal muscle fat infiltration in older adults: a randomized controlled trial. J Appl Physiol (Bethesda, Md: 1985) 2008;105:1498-1503.

70. Pahor M, Blair SN, Espeland M, et al. Effects of a physical activity intervention on measures of physical performance: results of the lifestyle interventions and independence for Elders Pilot (LIFE-P) study. J Gerontol A Biol Sci Med Sci 2006;61:1157-1165.

71. Raguso CA, Kyle U, Kossovsky MP, et al. A 3-year longitudinal study on body composition changes in the elderly: role of physical exercise. Clin Nutr 2006;25:573-580.

72. Volpato S, Bianchi L, Cherubini A, et al. Prevalence and clinical correlates of sarcopenia in communitydwelling older people: application of the EWGSOP definition and diagnostic algorithm. J Gerontol A Biol Sci Med Sci 2014;69:438-46.

73. Bouchard C, Rankinen T. Individual differences in response to regular physical activity. Med Sci Sports Exerc 2001;33:S446-453.

74. Montero-Fernández N, Serra-Rexach JA. Role of exercise on sarcopenia in the elderly. Eur J Phys Rehabil Med 2013;49:131-143.

75. Landi F, Marzetti E, Martone AM, Bernabei R, Onder G. Exercise as a remedy for sarcopenia. Curr Opin Clin Nutr Metab Care 2014;17:25-31.

76. Hawley JA, Hargreaves M, Joyner MJ, Zierath JR. Integrative biology of exercise. Cell 2014;159:738-749.

77. Taylor D. Physical activity is medicine for older adults. Postgrad Med J 2014;90:26-32.

78. Volkert D. The role of nutrition in the prevention of sarcopenia. Wien Med Wochenschr 2011;161:409-415.

79. Evans WJ, Boccardi V, Paolisso G. Perspective: dietary protein needs of elderly people: protein supplementation as an effective strategy to counteract sarcopenia. J Am Med Dir Assoc 2013;14:67-69.

80. Morley JE, Argiles JM, Evans WJ, et al. Nutritional recommendations for the management of sarcopenia. $J$ Am Med Dir Assoc 2010;11:391-396.

81. Tieland M, Dirks ML, Van der Zwaluw N, et al. Protein supplementation increases muscle mass gain during prolonged resistance-type exercise training in frail elderly people: a randomized, double-blind, placebocontrolled trial. J Am Med Dir Assoc 2012;13:713-719. 
82. Kim H, Suzuki T, Saito K, Kojima N, Hosoi E, Yoshida H. Long-term effects of exercise and amino acid supplementation on muscle mass, physical function and falls in community-dwelling elderly Japanese sarcopenic women: a 4-year follow-up study. Geriatr Gerontol Int 2015;16(2):175-81.

83. Koopman R, Verdijk LB, Van Loon LJC. Exercise and nutritional interventions to combat age-related muscle loss. In: Lynch GS, ed. Sarcopenia: Age-related muscle wasting and weakness: mechanisms and treatments. Dordrecht etc.: Springer, 2010, pp. 289-315.

84. Rolland Y, Onder G, Morley JE, Gillette-Guyonet S, Abellan van Kan G, Vellas B. Current and future pharmacologic treatment of sarcopenia. Clin Geriatr Med 2011;27:423-447.

85. Martone AM, Lattanzio F, Abbatecola AM, et al. Treating sarcopenia in older and oldest old. Curr Pharm Des 2015;21:1715-1722.

86. Malmstrom TK, Morley JE. SARC-F: a simple questionnaire to rapidly diagnose sarcopenia. J Am Med Dir Assoc 2013;14:531-532.

87. Pahor M, Manini T, Cesari M. Sarcopenia: clinical evaluation, biological markers and other evaluation tools. J Nutr Health Aging 2009;13:724-728.

88. Chen Z, Wang Z, Lohman T, et al. Dual-energy X-ray absorptiometry is a valid tool for assessing skeletal muscle mass in older women. J Nutr 2007;137:2775-2780.

89. Kyle UG, Bosaeus I, De Lorenzo AD, et al. Bioelectrical impedance analysis: Part II: Utilization in clinical practice. Clin Nutr 2004;23:1430-1453.

90. Kyle UG, Bosaeus I, De Lorenzo AD, et al. Bioelectrical impedance analysis: Part I: Review of principles and methods. Clin Nutr 2004;23:1226-1243.

91. Janssen I, Baumgartner RN, Ross R, Rosenberg IH, Roubenoff R. Skeletal muscle cutpoints associated with elevated physical disability risk in older men and women. Am J Epidemiol 2004;159:413-421.

92. Cawthon PM, Peters KW, Shardell MD, et al. Cutpoints for low appendicular lean mass that identify older adults with clinically significant weakness. J Gerontol A Biol Sci Med Sci 2014;69:567-575.

93. Roberts HC, Denison HJ, Martin HJ, et al. A review of the measurement of grip strength in clinical and epidemiological studies: towards a standardised approach. Age Ageing 2011;40:423-429.

94. Mijnarends DM, Meijers JMM, Halfens RJG, et al. Validity and reliability of tools to measure muscle mass, strength, and physical performance in community-dwelling older people: a systematic review. J Am Med Dir Assoc 2013;14:170-178.

95. Mijnarends DM, Meijers JMM, Halfens RJG, et al. Validity and reliability of tools to measure muscle mass, strength, and physical performance in community-dwelling older people: a systematic review. J Am Med Dir Assoc 2013;14:170-178.

96. Abellan van Kan G, Rolland Y, Andrieu S, et al. Gait speed at usual pace as a predictor of adverse outcomes in community-dwelling older people: an International Academy on Nutrition and Aging (IANA) Task Force. J Nutr Health Aging 2009;13:881-889.

97. Blain $\mathrm{H}$, Carriere I, Sourial N, et al. Balance and walking speed predict subsequent 8-year mortality independently of current and intermediate events in well-functioning women aged 75 years and older. J Nutr Health Aging 2010;14:595-600.

98. Studenski S, Perera S, Patel K, et al. Gait speed and survival in older adults. JAMA 2011;305:50-58.

99. Harris TB, Launer LJ, Eiriksdottir G, et al. Age, gene/environment susceptibility: Reykjavik study: multidisciplinary applied phenomics. Am J Epidemiol 2007;165:1076-1087. 

CHAPTER 2

\section{Validity and Reliability of Tools to Measure Muscle Mass, Strength and Physical Performance in Community-Dwelling Older People: A Systematic Review}




\section{ABSTRACT}

Background: This study critically appraises the measurement properties of tools to measure muscle mass, strength and physical performance in community-dwelling older people. This study can support the selection of a valid and reliable set of tools that is feasible for future screening and identification of sarcopenia.

Methods: The databases Pubmed, Cumulative Index to Nursing and Allied Health Literature (CINAHL), and Cochrane were systematically searched (January 11, 2012). Studies were included if they investigated the measurement properties or feasibility, or both, of tools to measure muscle mass, strength, and physical performance in communitydwelling older people aged $\geq 60$ years. The consensus-based standards for the selection of health status measurement instruments (COSMIN) checklist was used for quality appraisal of the studies.

Results: Sixty-two publications were deemed eligible, including tools for muscle mass ( $\mathrm{n}=$ $16)$, muscle strength $(n=15)$, and physical performance $(n=31)$. Magnetic resonance imaging, computed tomography, and a 4-compartment model were used as gold standards for muscle mass assessment. Other frequently used measures of muscle mass are dualenergy $\mathrm{x}$-ray and the bioelectrical impedance (BIA); however, reliability data of the BIA are lacking. Hand-held dynamometry and gait speed or a short physical performance battery provide a valid and reliable measurement of muscle strength and physical performance, respectively.

Conclusions: It can be concluded that several tools are available for valid and reliable measurements of muscle mass, strength and performance in clinical settings. For a home setting BIA, handheld dynamometry and gait speed or a short physical performance battery are the most valid, reliable, and feasible. The combination of selected instruments and its use for the screening and identification of sarcopenia in community-dwelling older people need further evaluation. 


\section{Introduction}

The term sarcopenia was first introduced by Rosenberg ${ }^{1}$ in 1989 and literally means poverty (or deficiency) of flesh. The relevance of sarcopenia as a geriatric syndrome is indicated by the statement that "no decline with age is more dramatic or potentially more functionally significant than the decline in lean body mass". ${ }^{1}$ Over the last 6 years, several initiatives have been undertaken to find consensus on a proper definition of sarcopenia. ${ }^{2}$ Diagnosing sarcopenia by measuring only muscle mass appeared to be insufficient. Therefore, in 2009, two consensus definitions were proposed, adding loss of muscle function (International Working Group on Sarcopenia) or muscle strength and physical performance (European Working Group on Sarcopenia in Older People) to its definition. ${ }^{2}$ In 2010, another working group formulated sarcopenia as a reduced muscle mass with limited mobility. ${ }^{3}$ Depending on the definition used, prevalence rate estimates of sarcopenia in community-dwelling older people $>60$ years can vary between 3 and $52 \%$.,

With adequate screening for sarcopenia among community-dwelling older people, those with an increased risk for adverse outcomes, such as physical disability, and increased risk for falls, loss of independence, and death ${ }^{6-9}$ may be identified at an earlier stage. After this initial screening, diagnosis could take place in a clinical setting. Early identification of sarcopenia would be of great clinical relevance because the loss of muscle mass and strength with aging can be largely reversed by proper exercise and nutritional intervention. $^{8}$ The European Working Group on Sarcopenia in Older People introduced an algorithm for the identification of older people with sarcopenia based on their definition. ${ }^{10}$ For identification of sarcopenia in a research setting, several tools were stated to measure muscle mass, strength, and physical performance. However, those tools are not specifically focused on screening among community-dwelling older people, for whom case finding should be performed. Thus, exploring the measurement properties (validity and reliability) of tools feasible for measurements of muscle mass, strength, and performance is an important step for the future development of a set of tools to screen for or diagnose sarcopenia in a valid and reliable way among community-dwelling older people.

To the best of our knowledge, no systematic review on the measurement properties of tools to measure muscle mass, strength, and physical performance in communitydwelling older people has previously been published. The objective of this systematic literature review is to critically appraise the measurement properties of tools to measure muscle mass, strength, and physical performance. Moreover, the feasibility of such tools in community-dwelling older people will be evaluated. The identification of a set of most valid and reliable tools may support the future development of a screening tool for sarcopenia in community-dwelling older people.

\section{Methods}

Online databases PubMed, Cumulative Index to Nursing and Allied Health Literature, and Cochrane were systematically searched in title and abstract. The search was limited to publications in English and Dutch. Articles were searched up to January 11, 2012. Search terms were selected from literature and expert consultation, taking into account the three parameters of sarcopenia, that is, muscle mass, strength and performance, as mentioned in the consensus definition of the European Working Group. ${ }^{10}$ Backward citation tracking was performed to identify additional relevant articles. 
The final selection of search terms was: (1) construct of interest - muscle mass, fat free mass, skeletal muscle, muscle strength, lower limb strength, upper limb strength, lower extremity strength, upper extremity strength, grip strength, hand grip strength, elbow flexion strength, ankle strength, knee strength, maximal strength, physical performance, functional performance, muscle quality, muscle function, gait speed, walking speed; (2) target population - elderly, older adults, older people, older persons, sarcopeni*, community-dwelling, assisted living; (3) type of measurement instrument - tool*, instrument $^{\star}$, technique ${ }^{\star}$, measure ${ }^{*}$, assess ${ }^{\star}$, evaluat ${ }^{\star}$, test; and (4) measurement properties - reliab*, valid ${ }^{\star}$, feasib*, consistenc ${ }^{\star}$, accura*, agreement, precision, psychometric propert*. Asterisks indicate search for words with alternative ending, e.g. reliable, reliability etcetera.

\subsection{Study Eligibility Criteria}

The following inclusion criteria were used for the selection of relevant studies: The study had to evaluate the validity, reliability, and/or feasibility of a tool to measure muscle mass, strength, physical performance, or sarcopenia; focus on community-dwelling older people or people in assisted living facilities at age $\geq 60$ years; and provide a description of the method used to measure muscle mass, strength, physical performance, or sarcopenia.

Studies were excluded if they studied a specific patient population (e.g., patients with Parkinson disease) or if they measured only activities of daily living (e.g., Late Life Function and Disability Instrument), because those scales are focused on functional activities rather than on physical performance.

\subsection{Study Appraisal and Synthesis Methods}

The search hits were inserted in EndNote X2 and duplicates were removed. All titles and abstracts were independently screened by two authors (D.M. and S.t.B.) and scored as "relevant" or "not relevant" based on the inclusion and exclusion criteria mentioned earlier. The reviewers discussed their opinions to reach consensus if they disagreed about the inclusion of a study. A third reviewer (J.M.M. or Y.L.) was asked to participate in the final decision if disagreement persisted. Subsequently, full texts were assessed for inclusion by one reviewer (D.M.), according to the eligibility criteria mentioned earlier. After that, the methodological quality of the studies was assessed by the consensus-based standards for the selection of health status measurement instruments (COSMIN) checklist. ${ }^{11}$ The COSMIN checklist evaluates the methodologic quality of studies on measurement properties among others, content validity (evidence that the content of a test corresponds to the content of the construct it was designed to cover), construct validity (the degree to which the scores of a tool are consistent with hypotheses or are related to other variables and other tools measuring the same construct), and concurrent validity (evidence that scores from a tool correspond with the gold standard or concurrent external tools conceptually related to the measured construct). Criteria encompass, for example, handling of missing items, sample size, and appropriateness of statistical methods. A methodologic quality score (poor, fair, good, or excellent) per box was obtained by taking the lowest rating of any item in a box ("worse score counts"). One reviewer (D.M.) assessed the quality of all articles, and a second reviewer (D.S.) randomly assessed one third of the articles to validate the outcomes of the first reviewer. Studies with a poor quality score were excluded for this review; no weighting was applied to the studies rating fair, 
good, or excellent quality. The final selection of articles was checked by an expert in the field of sarcopenia (A.J.C.) who verified that relevant articles were included.

A tool is scored "+" when having a high reliability [intraclass correlation coefficient or weighted Kappa $\geq 0.70$ or Pearson correlation $(r) \geq 0.80$; high construct validity when correlation between constructs $\geq 0.50$, or high concurrent validity when Pearson/Spearman correlation or area under the curve $\geq 0.70]^{12}$

\section{Results}

An overview of the process of study selection and reasons for exclusion is shown in Figure 1. After title, abstract, and full-text screening, 135 studies were found eligible and assessed for quality. Of these 135 studies, 49 were appraised for quality by a second reviewer (D.S.); disagreement between the reviewers existed over four, because of lack of clarity of appropriate statistical methods $(n=2)$, choice of measurement property $(n=1)$, or interpretation of study results $(n=1)$. In a consensus meeting, the two reviewers discussed their opinions, after which agreement was reached.

A final selection of 62 studies was included in this review, classified as having fair ( $n$ $=61)$ or good $(n=1)$ quality. An overview of the characteristics of the individual studies is presented in Supplementary Data files. Table 1 provides an overview of the assessed measurement properties of the included studies. The tools are described in the following sections according to the parameter: muscle mass $(n=16)$, strength $(n=15)$, and performance $(n=31)$.

Table 1 Measurement Properties Assessed in the Included Studies (by the COSMIN Checklist)

\begin{tabular}{|c|c|c|c|c|c|c|c|c|c|}
\hline \multirow[t]{2}{*}{ Measurement Property } & \multicolumn{3}{|c|}{$\begin{array}{l}\text { Muscle } \\
\text { Mass }\end{array}$} & \multicolumn{3}{|c|}{$\begin{array}{l}\text { Muscle } \\
\text { Strength }\end{array}$} & \multicolumn{3}{|c|}{$\begin{array}{l}\text { Physical } \\
\text { Performance }\end{array}$} \\
\hline & $\mathrm{P}$ & $\mathrm{F}$ & $\mathrm{G}$ & $\mathrm{P}^{\star}$ & $\mathrm{F}$ & $\mathrm{G}$ & $\mathrm{P}^{\star}$ & $\mathrm{F}$ & $\mathrm{G}$ \\
\hline Box A Internal consistency ${ }^{30,35}$ & - & - & - & - & - & - & 2 & - & - \\
\hline Box B Reliability ${ }^{18,21-23,25-31,34,35,38,40,41,44-47,49-53,56,58,68-71}$ & - & - & - & - & 14 & - & - & 17 & - \\
\hline Box C Measurement error ${ }^{25,26,68}$ & - & - & - & 1 & 1 & - & - & 1 & - \\
\hline Box D Content validity ${ }^{58}$ & - & - & - & - & - & - & - & 1 & - \\
\hline Box F Hypothesis testing ${ }^{18-20,23,29,30,32-36,38,39,41-45,47,48,51,52,54,55,58,68,71,72}$ & - & - & - & - & 8 & - & 3 & 16 & 1 \\
\hline Box H Criterion validity ${ }^{13-17,20,21,24,37,41,51,53,57,69,73-83}$ & - & 16 & - & - & 5 & - & - & 4 & - \\
\hline Box I Responsiveness ${ }^{13,50}$ & - & 1 & - & - & - & - & - & 1 & - \\
\hline
\end{tabular}

\subsection{Validity, Reliability and Feasibility}

The validity and reliability of 10 different tools to assess muscle mass were reported (Table 2). The included studies evaluated mainly the concurrent validity, only one study assessed responsiveness, ${ }^{13}$ and no studies evaluated the reliability of the tools. As listed in Table 2, magnetic resonance imaging (MRI), computed tomography (CT), and a 4-compartment (4C) model were used as gold standards for assessment of muscle mass. The only study describing responsiveness showed that ultrasonography was able to detect changes in muscle mass before and after training. 


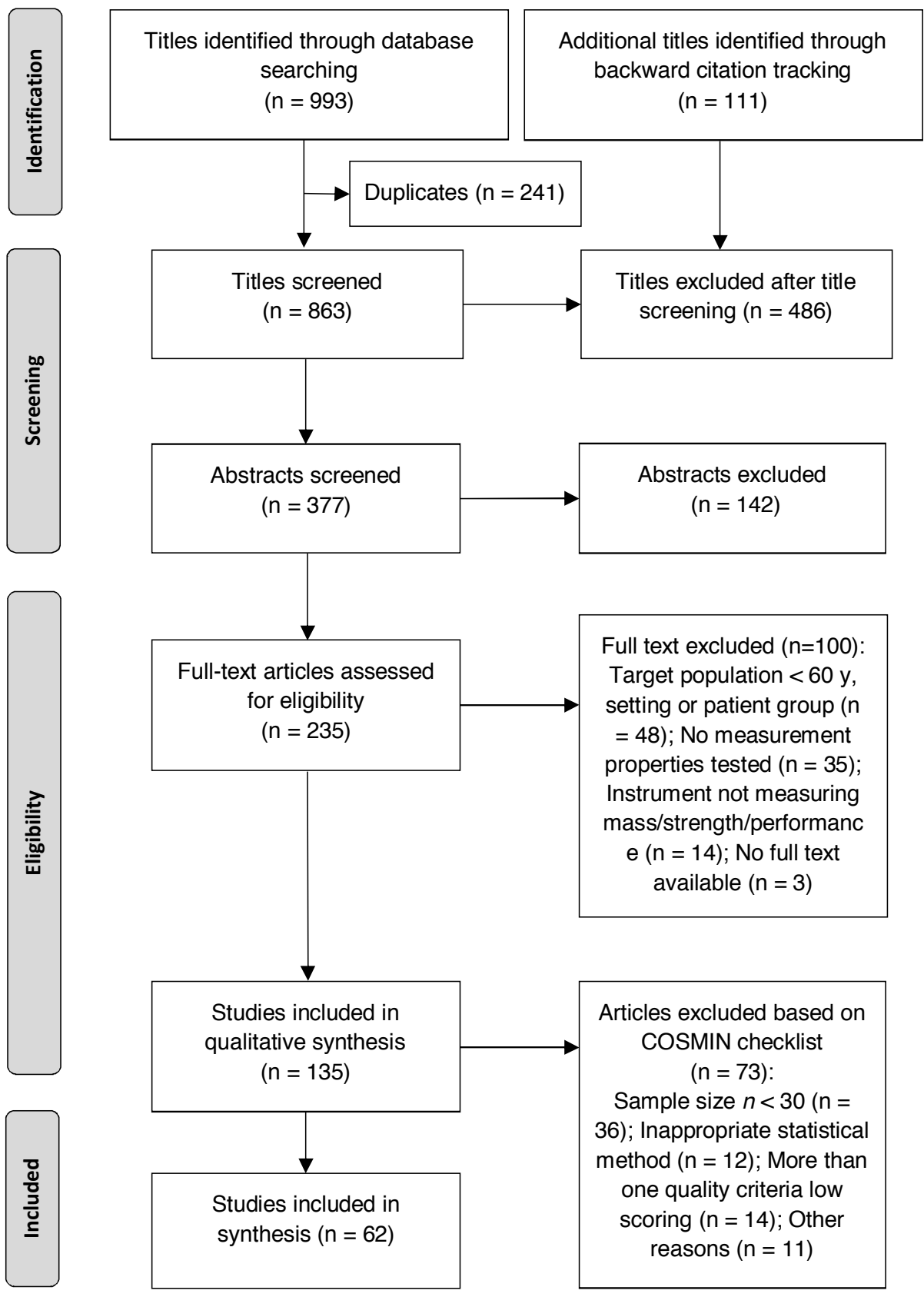

Figure 1 PRISMA (Preferred Reporting Items for Systematic Reviews and Meta-Analyses) flowchart showing selection procedure of articles 
Dual-energy X-ray (DXA) was found to be highly correlated with MRI, CT, and the 4-C model. Bioelectrical impedance (BIA) was found to have high concurrent validity; however, significant differences in estimation of mean fat-free mass between BIA and DXA were found. ${ }^{14}$ Furthermore, it was stated that its validity is questionable due to significant differences in the estimation of muscle mass by BIA compared with DXA, and reliability data are lacking. Calf circumference ${ }^{15}$ and skin-fold thickness ${ }^{16}$ both showed low correlations with DXA. Feasibility criteria discussed were exposure to radiation and costs. ${ }^{17}$

Table 2 Measurement Properties of Muscle Mass Tools in Community-Dwelling Older Persons

\begin{tabular}{|c|c|c|c|c|c|}
\hline \multirow[t]{2}{*}{ Instrument } & \multirow[t]{2}{*}{ Reliability } & \multicolumn{3}{|l|}{ Validity $^{*}$} & \multirow{2}{*}{$\begin{array}{l}\text { Portable and } \\
\text { Executable in a } \\
\text { Home Setting? }\end{array}$} \\
\hline & & Outcome & Concurrent & $\begin{array}{l}\text { Comparator } \\
\text { Instrument }\end{array}$ & \\
\hline $\begin{array}{l}\text { BIA } \\
\text { Single frequency } \\
14,16,73,75-77,80\end{array}$ & & $\begin{array}{l}r>0.79 \\
R^{2}=0.70 \\
\text { LOA } 12 \mathrm{~kg}^{\star \star}\end{array}$ & + & $\begin{array}{l}\text { TBW, 4-C model, } \\
\text { DXA }\end{array}$ & Yes \\
\hline Multifrequency $y^{73,74,78}$ & & $\begin{array}{l}I C C>0.95 \\
I C C>0.69\end{array}$ & + & $\begin{array}{l}\text { DXA whole body } \\
\text { DXA Segmental }\end{array}$ & \\
\hline BOD POD ${ }^{74}$ & & $\begin{array}{l}\text { LOA }-11.0 \\
\text { to } 2.4 \mathrm{~kg}^{\star \star}\end{array}$ & $?$ & DXA & No \\
\hline Calf circumference ${ }^{15}$ & & $r=0.63$ & - & DXA & Yes \\
\hline $\mathrm{CT}^{13,17,83}$ & & $\begin{array}{l}r>0.83 \\
R^{2}=0.96\end{array}$ & + & $\begin{array}{l}\text { Used as gold } \\
\text { standard vs. DXA } \\
\text { and } \\
\text { ultrasonography }\end{array}$ & No \\
\hline $\mathrm{DXA}^{14-17,78-81}$ & & $r>0.91$ & + & $\begin{array}{l}\text { MRI, CT, 4-C } \\
\text { model }\end{array}$ & No \\
\hline Equation for $\mathrm{LBW}^{79}$ & & $\begin{array}{l}\text { LOA } 0.65- \\
11.65 \mathrm{~kg}^{\star \star}\end{array}$ & + & DXA & Yes \\
\hline$M R I^{17}$ & & $r>0.91$ & + & $\begin{array}{l}\text { Used as gold } \\
\text { standard vs. DXA }\end{array}$ & No \\
\hline Skin fold thickness ${ }^{16}$ & & $R^{2}=0.62$ & - & DXA & Yes \\
\hline Ultrasonography ${ }^{13}$ & & $r>0.83$ & + & $\mathrm{CT}$ & Yes \\
\hline 4-C model ${ }^{76,83}$ & & $\begin{array}{l}R^{2}=0.98 \\
r=0.95\end{array}$ & + & $\begin{array}{l}\text { Used as gold } \\
\text { standard vs. DXA } \\
\text { and BIA }\end{array}$ & No \\
\hline
\end{tabular}

+ , high concurrent validity (Pearson/Spearman correlation or area under the curve (AUC) $\geq 0.70$ or responsiveness $\geq 0.50$ ); (-), low validity (Pearson/Spearman correlation or AUC $<0.70$ ); 4-C model, 4compartment model; BIA, bioelectrical impedance; BOD POD, measure of air displacement plethysmography; $\mathrm{CT}$, computed tomography; DXA, dual-energy $\mathrm{x}$-ray; ICC, intra-class correlation coefficient; LOA, limits of agreement; LBW, lean body weight; MRI, magnetic resonance imaging; TBW, total body water. *Only concurrent validity (evidence that scores from a tool correspond with the 'gold standard') was assessed in the included studies. ${ }^{* \star}$ LOA could not be interpreted, since no information was provided on the minimally important change.

Table 3 provides an overview of the tools to measure muscle strength and their validity and reliability. In the included studies, reliability, construct, and concurrent validity were assessed. The handheld dynamometer (HHD), by which measurements of hand grip, ankle, elbow, hip, and knee strength can be made, is valid and reliable. ${ }^{18-26}$ It showed both high interrater and intrarater reliability, and concurrent and construct validity were shown by comparison of several types of HHDs with an isokinetic dynamometer, ${ }^{24}$ a vigorimeter, ${ }^{20,23}$ and sit-to-stand testing. ${ }^{19}$ Other tools to assess muscle strength like the 
leg press, ${ }^{27}$ plate spring gauge, ${ }^{28}$ and pull down ${ }^{29}$ showed good reliability. However, no validity data were found for these specific tools. Feasibility criteria mentioned were rate of injuries, simplicity, time of the measurement, safety, and costs. ${ }^{29}$

Table 4 lists the validity and reliability of tools that can be used to measure physical performance. Most studies evaluated the intrarater reliability, construct and/or concurrent validity. Tools to assess physical performance comprised questionnaires, ${ }^{30,}{ }^{31}$ several performance-based tools, ${ }^{31-57}$ and a tool using video animation (the mobility assessment tool). ${ }^{58}$ Some tools measure single performance items, such as gait speed or standing balance, whereas other tools include multiple items. The latter was applied in, for example, the frequently used short physical performance battery (SPPB), which includes standing balance, gait speed, and chair rises (sit-to-stand). ${ }^{31,37,40,50}$ The mobility assessment tool is a tool that uses video clips of several types of performance, which subjects have to score as being able to do or not. Reliability and validity for gait speed measurements was confirmed in nine studies ${ }^{31,32,37,38,40,51,53,54,56}$ and it was found to have high construct validity, shown by correlations with SPPB and stair climb, and predictive validity for disability. ${ }^{37,42,53-55}$ Muscle soreness, safety, ease of administration, acceptability to patients, portability, time span, and ability to perform the test were mentioned with regard to feasibility. ${ }^{35,41,49,58}$

\section{Discussion}

Many tools are described that measure muscle mass, strength, and physical performance. MRI, CT, and a 4-C model were used as gold standards to measure muscle mass. Also, DXA, even though it is not the gold standard, was often used as reference method, because it is a cheaper and quicker option than the other gold standards for muscle mass. However, when comparing an instrument with a reference instrument that is not a gold standard, it is unknown to which degree the correlation between instruments is influenced by measurement errors of the reference instrument. A remarkable finding was the lack of studies examining the reliability of tools to measure muscle mass in older people. Reeves et $a l,{ }^{59}$ excluded from this review because of a small sample size, looked at the reliability of ultrasonography and its validity compared with MRI, and found good reliability and validity for ultrasonography. This adds to the evidence for high concurrent validity and responsiveness of ultrasound measurements found in this review. ${ }^{13}$

The leg press and HHD used on both upper and lower extremities are valid and reliable tools to measure muscle strength. The HHD is frequently used; however, Roberts et $\mathrm{al}^{60}$ concluded in their review that protocols to measure grip strength by HHD differ, which makes comparison between studies difficult. Stark et $\mathrm{al}^{61}$ reviewed the reliability and validity of HHD in young and older people, and also found that the various studies revealed a lack of homogeneity in methodology for the application of HHD, which underlines the need for using a standard protocol. They concluded that HHD cannot fully replace isokinetic measurements, but considering the costs of isokinetic devices and the impracticality, HHD is a good alternative. However, using hand grip strength as a predictor of overall strength seems unjustified in the healthy older adult. ${ }^{62}$ It can be argued that lower extremity strength might be even more relevant than upper extremity strength, because lower extremity strength is important for functional activities. ${ }^{62}$ 


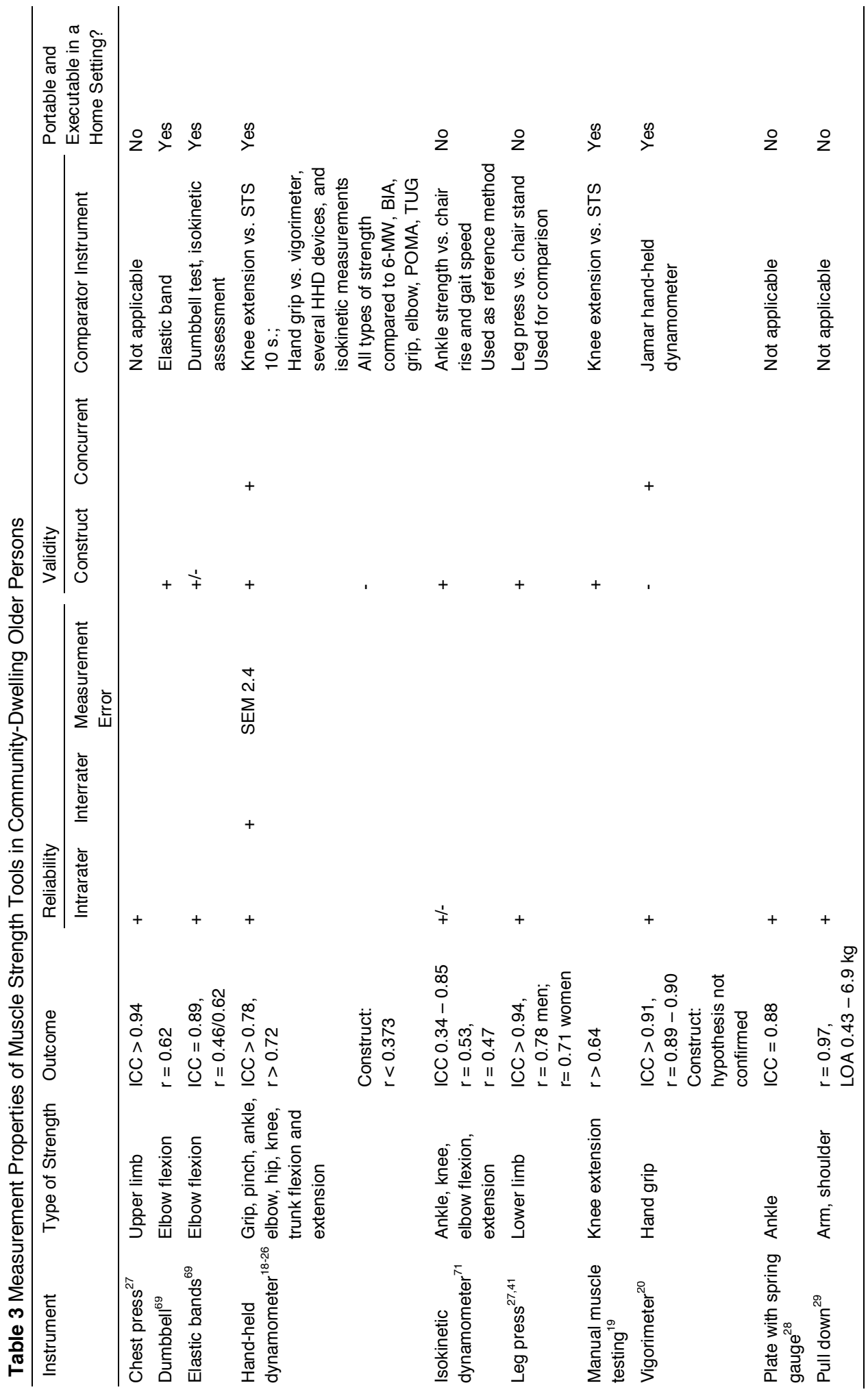




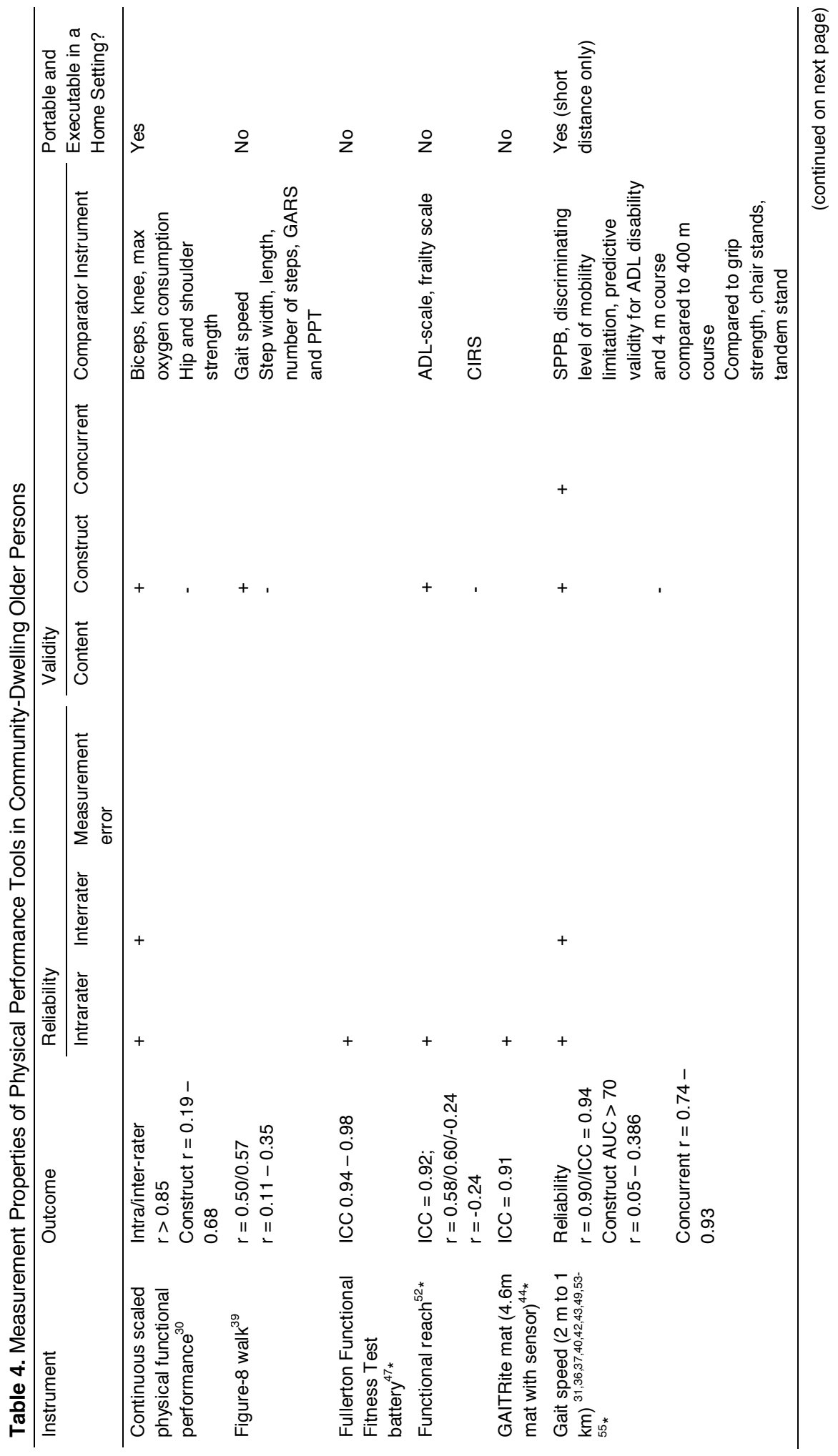




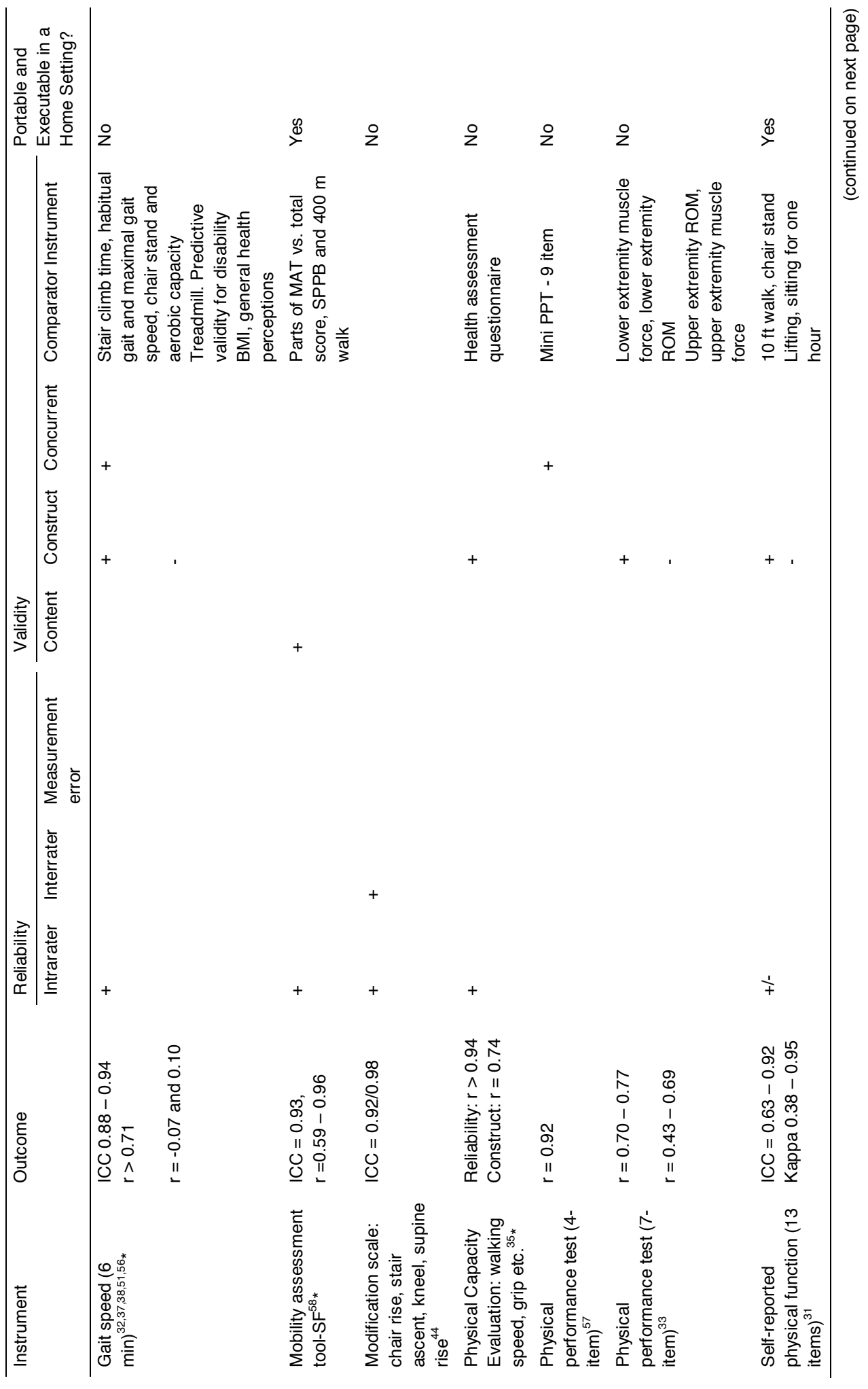




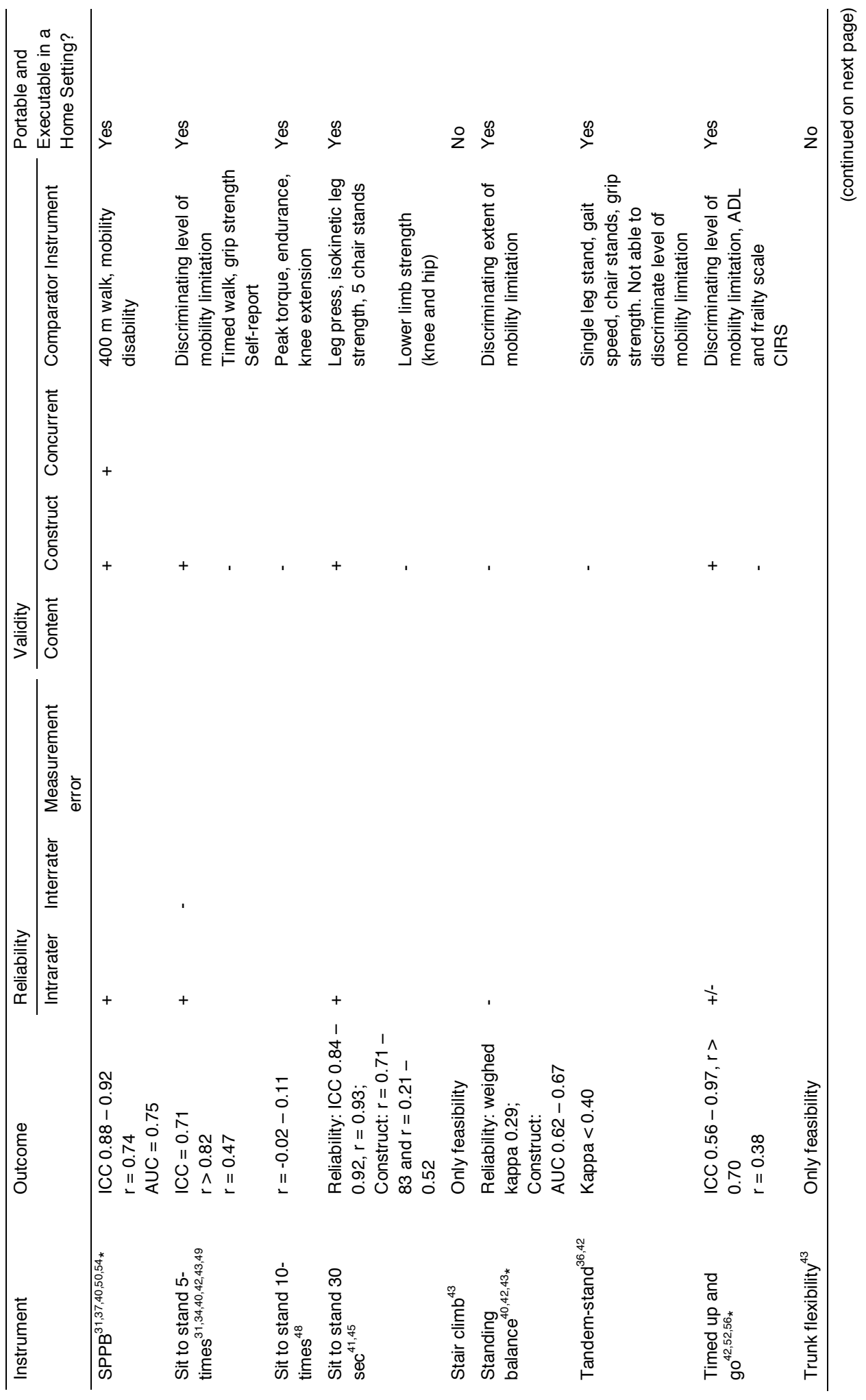




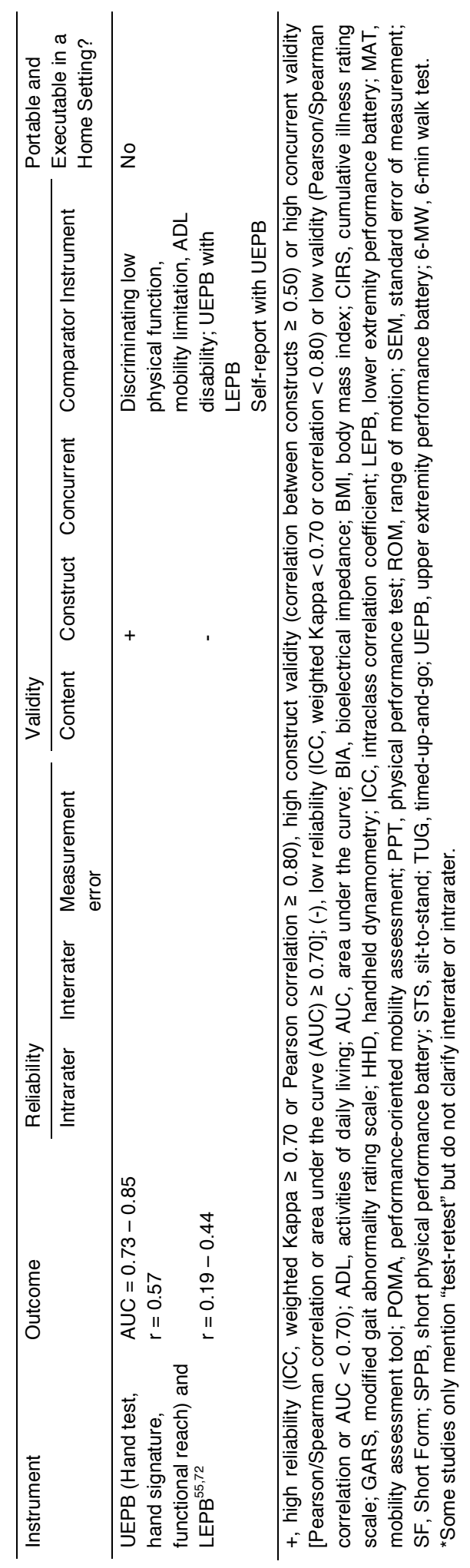


Many instruments have been applied to measure (aspects of) physical performance. Gait speed is a useful tool to assess physical performance given its high reliability and concurrent validity. Participants with SPPB scores $\leq 10$ at baseline had significantly higher odds of mobility disability at 3-year follow-up. ${ }^{63}$ Cooper et al's ${ }^{64}$ review concluded that walking speed, chair rises, and standing balance (components of the SPPB) were all associated with mortality. Those studies add to the clinical importance of the frequently used physical performance tools, namely, gait speed and the SPPB.

\subsection{Feasibility}

For quick screening of muscle mass, strength, and physical performance among community-dwelling older people, it would be beneficial if tools are feasible to apply in a general practitioner practice or in a home setting. With regard to muscle mass, many tools are available in clinical practice, but no well-validated and reliable tools are available for measurements of muscle mass in a home setting. BIA and the use of anthropometrics (such as calf circumference and skin-fold thickness measurements) were all found to be feasible for a home setting because the required equipment is portable. From those, BIA showed better evidence for validity, yet its validity is highly dependent on age, sex, and cultural influences, ${ }^{14}$ because, for example, oedema, diuretics and prosthesis hamper BIA measurements. Furthermore, it is likely that the use of different reference populations and cut-off points for muscle mass have large effects on the outcome. ${ }^{8,65,66}$ In a review on field and laboratory techniques to assess muscle mass, it is stated that 3-C and 4-C methods may be required and are usually recommended in older people, but $\mathrm{BIA}$ is put forward as the best option for field measurements. ${ }^{67}$ Ultrasound is a promising alternative to the BIA; however, for ultrasound to become a feasible and reliable alternative for BIA, work is warranted.

\subsection{Critical Appraisal of Methodology}

With regard to the methodology of this review, some aspects should be addressed. Most studies scored "fair" because they did not describe how missing items were handled. Studies were excluded when they had a sample size of less than 30 , which may have narrowed our results. In addition, a correlation of 0.69 is classified as low validity, whereas a correlation of 0.71 is classified as high, despite the marginal difference. For muscle strength and performance, gold standards are not available, which hampers assessment of proper concurrent validity. It should be taken into account that for some tools, only one study on validity and reliability was available.

\subsection{Conclusions and Implications of Key Findings}

For a valid and reliable screening or diagnosis of sarcopenia, firstly one has to agree on the combination of the parameters by which sarcopenia is measured. In this article, the European Working Group on Sarcopenia in Older People criteria were chosen, including muscle mass, muscle strength, and physical performance. Gold standards used for the assessment of muscle mass were $\mathrm{MRI}, \mathrm{CT}$, and a $4-\mathrm{C}$ model. A valid and reliable tool for muscle strength is the HHD; the SPPB and gait speed have good measurement properties with regard to the assessment of physical performance.

To measure muscle mass, strength and physical performance in a general practitioner practice or home setting, BIA, HHD and gait speed over a short distance or the 
SPPB can be used, since those measures are transportable and executable in those specific settings. However, because the validity of BIA is not optimal, it is debatable to measure only muscle strength and physical performance for a first screening, and when scores on these parameters are below normal, further assessment of muscle mass by, for example, DXA, as a more valid alternative for the measurement of muscle mass, could be used. The use of a combination of tools to measure muscle mass, strength, and physical performance for the screening and diagnosis of sarcopenia in community-dwelling older people, as well as predictive value, need further evaluation.

\section{Acknowledgments}

The authors thank Dr. C.B. Terwee from the VU University Medical Centre for her support with the correct interpretation and use of the COSMIN checklist. Furthermore, they thank M.J.H. Tilly for assisting with gathering the numerous references.

\section{Conflict of Interest}

This work was supported by Nutricia Advanced Medical Nutrition, Danone Research, Centre for Specialised Nutrition. Danone Research provided the salary and project support for D.M.M.

\section{Supplementary Data}

Supplementary data files can be found online or can be provided on request. As the supplementary data files are very large, these have not been added to this thesis. 


\section{References}

1. Rosenberg IH. Summary comments. Am J of Clin Nutr 1989; 50:1231-3.

2. Cederholm TE, Bauer JM, Boirie $Y$ et al. Toward a definition of sarcopenia. Clin Geriatr Med 2011;27(3):34153.

3. Morley JE, Abbatecola AM, Argiles JM et al. Sarcopenia With Limited Mobility: An International Consensus. J Am Med Dir Assoc 2011;12:403-409.

4. Fielding RA, Vellas B, Evans WJ et al. Sarcopenia: An Undiagnosed Condition in Older Adults. Current Consensus Definition: Prevalence, Etiology, and Consequences. International Working Group on Sarcopenia. J Am Med Dir Assoc 2011;12:249-256.

5. Landi F, Liperoti R, Russo A et al. Sarcopenia as a risk factor for falls in elderly individuals: Results from the iISIRENTE study. Clin Nutr 2012;31(5):652-8.

6. Cruz-Jentoft AJ, Landi $F$, Topinková $E$ et al. Understanding sarcopenia as a geriatric syndrome. Curr Opin Clin Nutr Metab Care 2010;13(1):1-7.

7. Narici MV, Maffulli N. Sarcopenia: Characteristics, mechanisms and functional significance. Br Med Bull 2010;95:139-59.

8. Rolland Y, Czerwinski S, Abellan Van Kan G et al. Sarcopenia: Its assessment, etiology, pathogenesis, consequences and future perspectives. J Nutr Health Aging 2008;12(7):433-50.

9. Roubenoff R, Hughes VA. Sarcopenia: Current concepts. J Gerontol A Biol Sci Med Sci 2000;55(12):M71624.

10. Cruz-Jentoft AJ, Baeyens JP, Bauer JM et al. Sarcopenia: European consensus on definition and diagnosis: Report of the european working group on sarcopenia in older people. Age Ageing 2010;39(4):412-23.

11. Mokkink LB, Terwee CB, Patrick DL et al. The COSMIN checklist for assessing the methodological quality of studies on measurement properties of health status measurement instruments: An international delphi study. Qual Life Res 2010;19(4):539-49.

12. Terwee CB, Bot SD, De Boer MR et al. Quality criteria were proposed for measurement properties of health status questionnaires. J Clin Epidemiol 2007;60(1):34-42.

13. Sipilä S, Suominen H. Quantitative ultrasonography of muscle: Detection of adaptations to training in elderly women. Arch Phys Med Rehabil 1996;77(11):1173-8.

14. Genton L, Karsegard VL, Kyle UG et al. Comparison of four bioelectrical impedance analysis formulas in healthy elderly subjects. Gerontology 2001;47(6):315-23.

15. Rolland $\mathrm{Y}$, Lauwers-Cances $\mathrm{V}$, Cournot $\mathrm{M}$ et al. Sarcopenia, calf circumference, and physical function of elderly women: A cross-sectional study. J Am Geriatr Soc 2003;51(8):1120-4.

16. Haapala I, Hirvonen A, Niskanen L et al. Anthropometry, bioelectrical impedance and dual-energy $x$-ray absorptiometry in the assessment of body composition in elderly finnish women. Clin Physiol Funct Imaging 2002;22(6):383-91.

17. Chen Z, Wang Z, Lohman $T$ et al. Dual-energy $x$-ray absorptiometry is a valid tool for assessing skeletal muscle mass in older women. J Nutr 2007;137(12):2775-80.

18. Abizanda P, Navarro JL, García-Tomás MI et al. Validity and usefulness of hand-held dynamometry for measuring muscle strength in community-dwelling older persons. Arch Gerontol Geriatr 2011;54(1):21-7.

19. Bohannon RW. Alternatives for measuring knee extension strength of the elderly at home. Clin Rehabil 1998;12(5):434-40.

20. Desrosiers J, Hebert R, Bravo G et al. Comparison of the Jamar dynamometer and the Martin vigorimeter for grip strength measurements in a healthy elderly population. Scand J Rehabil Med 1995;27(3):137-43.

21. Guerra RS, Amaral TF. Comparison of hand dynamometers in elderly people. J Nutr Health Aging 2009;13(10):907-12.

22. Ottenbacher KJ, Branch LG, Ray L et al. The reliability of upper- and lower-extremity strength testing in a community survey of older adults. Arch Phys Med Rehabil 2002;83(10):1423-7.

23. Payette $\mathrm{H}$, Hanusaik $\mathrm{N}$, Boutier $\mathrm{V}$ et al. Muscle strength and functional mobility in relation to lean body mass in free-living frail elderly women. Eur J Clin Nutr 1998;52(1):45-53.

24. Reed RL, Den Hartog R, Yochum $\mathrm{K}$ et al. A comparison of hand-held isometric strength measurement with isokinetic muscle strength measurement in the elderly. J Am Geriatr Soc 1993;41(1):53-6.

25. Wang $\mathrm{CY}$, Olson SL, Protas EJ. Test-retest strength reliability: Hand-held dynamometry in communitydwelling elderly fallers. Arch Phys Med Rehabil 2002;83(6):811-5.

26. Wang CY, Chen LY. Grip strength in older adults: Test-retest reliability and cutoff for subjective weakness of using the hands in heavy tasks. Arch Phys Med Rehabil 2010;91(11):1747-51. 
27. LeBrasseur NK, Bhasin S, Miciek R et al. Tests of muscle strength and physical function: Reliability and discrimination of performance in younger and older men and older men with mobility limitations. J Am Geriatr Soc 2008;56(11):2118-23.

28. Menz HB, Tiedemann A, Kwan MM et al. Reliability of clinical tests of foot and ankle characteristics in older people. J Am Podiat Med Assn 2003;93(5):380-7.

29. Rydwik E, Karlsson $\mathrm{C}$, Frändin $\mathrm{K}$ et al. Muscle strength testing with one repetition maximum in the arm/shoulder for people aged 75 + - test-retest reliability. Clin Rehabil 2007;21(3):258-65.

30. Cress ME, Buchner DM, Questad KA et al. Continuous-scale physical functional performance in healthy older adults: A validation study. Arch Phys Med Rehabil 1996;77(12):1243-50.

31. Tager IB, Swanson A, Satariano WA. Reliability of physical performance and self-reported functional measures in an older population. J Gerontol A Biol Sci Med Sci 1998;53(4):M295-300.

32. Bean JF, Kiely DK, Leveille SG et al. The 6-minute walk test in mobility-limited elders. J Gerontol A Biol Sci Med Sci 2002;57(11):M751-6.

33. Beissner $\mathrm{KL}$, Collins JE, Holmes $\mathrm{H}$. Muscle force and range of motion as predictors of function in older adults. Phys Ther 2000;80(6):556-63.

34. Bohannon RW, Shove ME, Barreca SR et al. Five-repetition sit-to-stand test performance by communitydwelling adults: A preliminary investigation of times, determinants, and relationship with self-reported physical performance. Isokinet Exerc Sci 2007;15:77-81.

35. Daltroy $\mathrm{LH}$, Phillips $\mathrm{CB}$, Eaton $\mathrm{HM}$, et al. Objectively measuring physical ability in elderly persons: The physical capacity evaluation. Am J Public Health 1995;85(4):558-60.

36. Guralnik JM, Seeman TE, Tinetti ME et al. Validation and use of performance measures of functioning in a non-disabled older population: Macarthur studies of successful aging. Aging Clin Exp Res 1994;6(6):410-9.

37. Guralnik JM, Ferrucci L, Pieper CF et al. Lower extremity function and subsequent disability: Consistency across studies, predictive models, and value of gait speed alone compared with the short physical performance battery. J Gerontol A Biol Sci Med Sci 2000;55(4):M221-31.

38. Harada ND, Chiu V, Stewart AL. Mobility-related function in older adults: Assessment with a 6-minute walk test. Arch Phys Med Rehabil 1999;80(7):837-41.

39. Hess RJ, Brach JS, Piva SR et al. Walking skill can be assessed in older adults: Validity of the figure-of-8 walk test. Phys Ther 2010;90(1):89-99.

40. Hoeymans N, Wouters ER, Feskens EJ et al. Reproducibility of performance-based and self-reported measures of functional status. J Gerontol A Biol Sci Med Sci 1997;52(6):M363-8.

41. Jones CJ, Rikli RE, Beam WC. A 30-s chair-stand test as a measure of lower body strength in communityresiding older adults. Res Q Exercise Sport 1999;70(2):113-9.

42. Kim MJ, Seino S, Kim MK et al. Validation of lower extremity performance tests for determining the mobility limitation levels in community-dwelling older women. Aging Clin Exp Res 2009;21(6):437-44.

43. Malmberg JJ, Miilunpalo SI, Vuori IM et al. A health-related fitness and functional performance test battery for middle-aged and older adults: Feasibility and health-related content validity. Arch Phys Med Rehabil 2002;83(5):666-77.

44. Manini TM, Cook SB, VanArnam T et al. Evaluating task modification as an objective measure of functional limitation: Repeatability and comparability. J Gerontol A Biol Sci Med Sci 2006;61(7):718-25.

45. McCarthy EK, Horvat MA, Holtsberg PA et al. Repeated chair stands as a measure of lower limb strength in sexagenarian women. J Gerontol A Biol Sci Med Sci 2004;59(11):1207-12.

46. Menz HB, Latt MD, Tiedemann A et al. Reliability of the gaitrite walkway system for the quantification of temporo-spatial parameters of gait in young and older people. Gait Posture 2004;20(1):20-5.

47. Miotto JM, Chodzko-Zajko WJ, Reich JL et al. Reliability and validity of the fullerton functional fitness test: An independent replication study. J Aging Phys Act 1999;7(4):339-53.

48. Netz Y, Ayalon M, Dunsky A et al. 'the multiple-sit-to-stand' field test for older adults: What does it measure? Gerontology 2004;50(3):121-6.

49. Ostchega $\mathrm{Y}$, Harris $\mathrm{TB}$, Hirsch $\mathrm{R}$ et al. Reliability and prevalence of physical performance examination assessing mobility and balance in older persons in the us: Data from the third national health and nutrition examination survey. J Am Geriatr Soc 2000;48(9):1136-41.

50. Ostir GV, Volpato S, Fried LP et al. Reliability and sensitivity to change assessed for a summary measure of lower body function: Results from the women's health and aging study. J Clin Epidemiol 2002;55(9):916-21.

51. Rikli RE, Jones CJ. The reliability and validity of a 6-minute walk test as a measure of physical endurance in older adults. J Aging Phys Act 1998;6(4):363-75.

52. Rockwood K, Awalt E, Carver D et al. Feasibility and measurement properties of the functional reach and the timed up and go tests in the canadian study of health and aging. J Gerontol A Biol Sci Med Sci 2000;55(2):M70-3. 
53. Rolland YM, Cesari M, Miller ME et al. Reliability of the 400-m usual-pace walk test as an assessment of mobility limitation in older adults. J Am Geriatr Soc 2004;52(6):972-6.

54. Sayers SP, Guralnik JM, Newman AB et al. Concordance and discordance between two measures of lower extremity function: 400 meter self-paced walk and sppb. Aging Clin Exp Res 2006;18(2):100-6.

55. Seino S, Kim MJ, Yabushita $\mathrm{N}$ et al. Is a composite score of physical performance measures more useful than usual gait speed alone in assessing functional status? Arch Gerontol Geriatr 2012;55(2):392-8.

56. Steffen TM, Hacker TA, Mollinger L. Age- and gender-related test performance in community-dwelling elderly people: Six-minute walk test, berg balance scale, timed up \& go test, and gait speeds. Phys Ther 2002;82(2):128-37.

57. Wilkins $\mathrm{CH}$, Roe $\mathrm{CM}$, Morris JC. A brief clinical tool to assess physical function: The mini-physical performance test. Arch Gerontol Geriatr 2010;50(1):96-100.

58. Rejeski WJ, Ip EH, Marsh AP et al. Development and validation of a video-animated tool for assessing mobility. J Gerontol A Biol Sci Med Sci 2010;65(6):664-71.

59. Reeves ND, Maganaris CN, Narici MV. Ultrasonographic assessment of human skeletal muscle size. Eur $\mathrm{J}$ Appl Physiol 2004;91(1):116-8.

60. Roberts HC, Denison HJ, Martin HJ et al. A review of the measurement of grip strength in clinical and epidemiological studies: Towards a standardised approach. Age Ageing 2011;40(4):423-9.

61. Stark T, Walker B, Phillips JK et al. Hand-held dynamometry correlation with the gold standard isokinetic dynamometry: A systematic review. Am Acad Phys Med Reh 2011;3(5):472-9.

62. Samuel D, Rowe P. An investigation of the association between grip strength and hip and knee joint moments in older adults. Arch Gerontol Geriatr 2012;54(2):357-60.

63. Vasunilashorn S, Coppin AK, Patel KV et al. Use of the short physical performance battery score to predict loss of ability to walk 400 meters: Analysis from the inchianti study. J Gerontol A Biol Sci Med Sci 2009;64(2):223-9.

64. Cooper R, Kuh D, Hardy R. Objectively measured physical capability levels and mortality: Systematic review and meta-analysis. BMJ 2010;341:c4467.

65. Bijlsma AY, Meskers CGM, Ling CHY et al. Defining sarcopenia: the impact of different diagnostic criteria on the prevalence of sarcopenia in a large middle aged cohort. Age 2013; 35(3):871-81.

66. Di Monaco, M, Vallero F, Di Monaco R et al. Prevalence of sarcopenia and its association with osteoporosis in 313 older women following a hip fracture. Arch Gerontol Geriatr 2011;52(1):71-4.

67. Norgan NG. Laboratory and field measurements of body composition. Public Health Nutr 2005;8(7A):110822.

68. Bautmans I, Jansen B, Van Keymolen B et al. Reliability and clinical correlates of 3d-accelerometry based gait analysis outcomes according to age and fall-risk. Gait Posture 2011;33(3):366-72.

69. Manor B, Topp R, Page P. Validity and reliability of measurements of elbow flexion strength obtained from older adults using elastic bands. J Geriatr Phys Ther 2006;29(1):16-9.

70. Spink MJ, Fotoohabadi MR, Menz HB. Foot and ankle strength assessment using hand-held dynamometry: Reliability and age-related differences. Gerontology 2010;56(6):525-32.

71. Suzuki T, Bean JF, Fielding RA. Muscle power of the ankle flexors predicts functional performance in community-dwelling older women. J Am Geriatr Soc 2001;49(9):1161-7.

72. Hazuda HP, Dhanda R, Owen SV et al. Development and validation of a performance-based measure of upper extremity functional limitation. Aging Clin Exp Res 2005;17(5):394-401.

73. Aleman-Mateo $\mathrm{H}$, Rush $\mathrm{E}$, Esparza-Romero $\mathrm{J}$ et al. Prediction of fat-free mass by bioelectrical impedance analysis in older adults from developing countries: A cross-validation study using the deuterium dilution method. J Nutr Health Aging 2010;14(6):418-26.

74. Bertoli S, Battezzati A, Testolin G et al. Evaluation of air-displacement plethysmography and bioelectrical impedance analysis vs dual-energy $x$-ray absorptiometry for the assessment of fat-free mass in elderly subjects. Eur J Clin Nutr 2008;62(11):1282-6.

75. Deurenberg $\mathrm{P}$, Van der Kooij K, Evers $\mathrm{P}$ et al. Assessment of body composition by bioelectrical impedance in a population aged greater than $60 \mathrm{y}$. Am J Clin Nutr 1990;51(1):3-6.

76. Dey DK, Bosaeus I, Lissner L et al. Body composition estimated by bioelectrical impedance in the swedish elderly: Development of population-based prediction equation and reference values of fat-free mass and body fat for 70- and 75-y olds. Eur J Clin Nutr 2003;57(8):909-16.

77. Dey DK, Bosaeus I. Comparison of bioelectrical impedance prediction equations for fat-free mass in a population-based sample of 75 y olds: The nora study. Nutr 2003;19(10):858-64.

78. Ling $\mathrm{CH}$, De Craen AJ, Slagboom PE et al. Accuracy of direct segmental multi-frequency bioimpedance analysis in the assessment of total body and segmental body composition in middle-aged adult population Clin Nutr 2011;30(5):610-5 
79. Mitchell SJ, Kirkpatrick CM, Le Couteur DG et al. Estimation of lean body weight in older communitydwelling men. Brit J Clin Pharmacol 2010;69(2):118-27.

80. Rech CR, Cordeiro BA, Petroski EL et al. Validation of bioelectrical impedance for the prediction of fat-free mass in brazilian elderly subjects. Brazil Arch Endocrinol Metab 2008;52(7):1163-71.

81. Roubenoff R, Baumgartner RN, Harris TB et al. Application of bioelectrical impedance analysis to elderly populations. J Gerontol A Biol Sci Med Sci 1997;52(3):M129-36.

82. Valencia ME, Aleman-Mateo $\mathrm{H}$, Salazar $\mathrm{G}$ et al. Body composition by hydrometry (deuterium oxide dilution) and bioelectrical impedance in subjects aged $>60$ y from rural regions of Cuba, Chile and Mexico. Int $J$ Obes Metab Dis 2003;27(7):848-55.

83. Visser $M$, Fuerst $T$, Lang $T$ et al. Validity of fan-beam dual-energy $x$-ray absorptiometry for measuring fatfree mass and leg muscle mass: Health, aging, and body composition study: Dual-energy $\mathrm{x}$-ray absorptiometry and body composition working group. J Appl Physiol 1999;87(4):1513-20. 



\section{CHAPTER 3}

\section{Prevalence and Characterization of Sarcopenia in Older People Living in the Community}

Submitted as: DM Mijnarends, RJG Halfens, JMGA Schols, FES Tan, ELA Lenaerts, S Verlaan, YC Luiking, JMM Meijers. 


\section{ABSTRACT}

Background: Sarcopenia negatively affects mobility and quality of life. Few studies exist on sarcopenia prevalence in older people receiving home care or living in an assisted or residential living facility. The objective of this study was to estimate the prevalence of sarcopenia in 1) those living independently at home without additional care, 2) those living at home or in an assisted living facility with professional home care, and 3) those living in a residential living facility with additional professional nursing care and/or meal service, and to characterize older people with sarcopenia.

Methods: The cross-sectional Maastricht Sarcopenia Study was undertaken in people $\geq$ 65 years. Sarcopenia was assessed according to the European Working Group on Sarcopenia in Older People algorithm, using skeletal muscle mass index (SMI; bioelectrical impedance), muscle strength (handheld dynamometer) and gait speed (as part of the short Physical Performance Battery - SPPB). Subjects were characterized for functional status (Groningen Activity Restriction Scale - GARS), number of comorbidities (Charlson Comorbidity Index), and cognitive status (Mini-Mental State Examination - MMSE). Differences in prevalence between the three groups and characteristics of sarcopenic versus non-sarcopenic older people were compared using Student's t-tests or Chi-square tests. Logistic regression was performed to assess the association of sarcopenia with functional status, number of comorbidities and cognitive status, controlling for age, sex and body mass index.

Results: 227 participants were included in the analyses, 157 without care, 41 living at home or in an assisted living facility with home care, and 29 living in a residential living facility. Sarcopenia was significantly more prevalent in people living in a residential living facility $(58.6 \%)$ compared to those receiving home care $(41.5 \%)$ and those living at home without care (12.1\%). Most sarcopenic older people had low SMI in combination with poor grip strength. People with sarcopenia had a significantly $(P<0.05)$ lower functional status, more comorbidities and a slightly lower cognitive function. After correcting for age, sex and BMI, sarcopenia was significantly associated with impaired functional status (OR 2.11, $95 \% \mathrm{Cl}: 1.43-3.12$ ), but not with the number of comorbidities and cognitive status.

Conclusions: Sarcopenia was more prevalent in older people with a care need, i.e. with home care or living in a residential living facility. The impaired functional status associated with sarcopenia underlines the need for early diagnosis and treatment of sarcopenia, to stimulate longer independence and prevent disability. 


\section{Introduction}

Sarcopenia, the age-related decline in muscle mass and function, negatively affects mobility and quality of life and is associated with increased nursing home admission in community-dwelling older people. ${ }^{1}$ Early identification of sarcopenia in older people is of clinical importance to enable early intervention. Interventions to improve muscle mass and function, such as exercise or nutrition, have the potential to delay the development of mobility difficulties related to sarcopenia. ${ }^{2}$

To facilitate early identification of sarcopenia in older people, the European Working Group on Sarcopenia in Older People (EWGSOP) developed an algorithm. ${ }^{1}$ This algorithm defines sarcopenia as low muscle mass with poor strength and/or performance. In the past years, several studies were performed to assess the prevalence of sarcopenia according to the EWGSOP criteria, in both the community and nursing home settings. ${ }^{3}$ Studies in community-dwelling older people using the EWGSOP definition have reported prevalence rates of sarcopenia between $1 \%$ and $29 \%{ }^{3}$ The huge variation between those studies, though using the same definition, can be partly explained by differences in group characteristics such as varying age groups, ${ }^{4}$ the use of different techniques to assess muscle mass, such as bio-electrical impedance (BIA) or dual-energy X-ray and various cutoff points to define low muscle mass. ${ }^{5-8}$

As one could expect, studies in participants with a need for care, like hospital patients or people in long-term care institutions, report on a higher prevalence of sarcopenia than studies in community-dwelling older people. ${ }^{3,9,10}$ Although several studies have assessed the prevalence rates of sarcopenia in the community and nursing homes, ${ }^{3}$ studies on the prevalence of sarcopenia in older people receiving other forms of care, e.g. professional home care or residential living facilities, are scarce. ${ }^{11,12}$ Especially people receiving home care or living in residential living facilities might be a good target population for an intervention to delay or prevent sarcopenia, as these people might be at an early stage of dependency.

Sarcopenia and/or its individual components (muscle mass, strength, performance) has been associated with functional status, the ability to perform activities of daily living (ADL). ${ }^{10,13-20}$ Gait speed seemed the strongest predictor of disability in both sexes, ${ }^{15,18,19}$ but also associations were found between disability and grip strength ${ }^{16,18,19}$ and between disability and low skeletal muscle mass. ${ }^{18,19}$ The association between low skeletal muscle mass and disability seems stronger in the presence of comorbidities. ${ }^{21}$ Next to impairments in functional status and the presence of comorbidities, sarcopenic individuals are more likely to have an impaired cognitive function. ${ }^{22}$

As studies on the prevalence of sarcopenia in older people receiving professional home care or living in a residential living facility are scarce, and these people might be at an early stage of dependency, insight in the prevalence of sarcopenia and characteristics (like functional status) of this population is valuable. Therefore this study aimed to estimate the prevalence of sarcopenia, using the EWGSOP algorithm, in 1) those living independently at home without additional care, 2) those living at home or in an assisted living facility with professional home care, and 3) those living in a residential living facility with additional professional nursing care and/or meal service. Moreover this study aimed to characterize older people with sarcopenia in terms of functional status, comorbidities, and cognitive status. 


\section{Methods}

\subsection{Design and Setting}

The cross sectional Maastricht Sarcopenia Study (MaSS) was undertaken in: 1) older people living independently at home without additional care, and 2) people living at home or in an assisted living facility with professional home care, and 3) older people living in a residential living facility with additional professional nursing care and/or meal service, in Maastricht, The Netherlands.

\subsection{Sample}

Eligibility criteria encompassed: people $\geq 65$ years with an understanding of the Dutch language, who gave written informed consent. Persons with an implantable cardiac defibrillator/pacemaker, persons in a wheelchair or bedridden, and those suffering from severe active rheumatoid arthritis, post stroke status with evident lingering symptoms, diseases of the nervous system, acute angina pectoris or dementia were excluded, because they would not have been able to perform the physical tests safely. ${ }^{23} \mathrm{~A}$ power calculation was made for the main outcomes of the MaSS study (difference in nutritional status in sarcopenic older people compared to non-sarcopenic older people; not reported here). The required sample size was calculated by means of $\mathrm{G}^{*}$ Power 3.1, a power analysis program that is commonly used in social sciences. ${ }^{24}$ The significance level was set to $\alpha=0.05$, the power $(1-\beta)$ to $=0.80$ and the estimated prevalence at $12.5 \%$, as being within the prevalence reported in other studies. ${ }^{25,26}$ This resulted in a required sample size (taking into account $10 \%$ drop out by coincidence) of 252 . This sample size provides sufficient power to compare characteristics between sarcopenic versus non-sarcopenic participants.

\subsection{Recruitment}

Participants were recruited between May 2013 and March 2014. The municipality of Maastricht randomly extracted 2448 addresses of people $\geq 65$ years. An information letter, informed consent form and stamped response envelope were sent to the selected addresses. After receiving the signed consent form, one of the researchers (D.M./E.L.) made a phone call to check for eligibility and a home visit was planned. To create awareness of the study, an interview was given to a local newspaper and a flyer with general information about the study was spread in all pharmacies and assisted and residential living facilities in Maastricht.

\subsection{Data Collection}

Data was collected during a single 1-2 hour home visit. A pilot study was performed to test the feasibility of this method of data collection. ${ }^{27}$ Standardized protocols were used to ensure conformity of data collection. Home visits were always performed in the morning because participants had to be in fasting state for the muscle mass measurement.

\subsection{Measures}

The prevalence of sarcopenia was assessed using the algorithm of the EWGSOP. ${ }^{1}$ According to this algorithm participants were categorized as sarcopenic when they had a low muscle mass and poor muscle strength and/or physical performance. The measures 
used for muscle mass, strength and performance were evaluated as valid and feasible for the measurement of sarcopenia in a home setting. ${ }^{28}$ Muscle mass was assessed by bioelectrical impedance (BIA AKERN 101, $50 \mathrm{kHz}$ ), according to the ESPEN guidelines. ${ }^{29}$ Muscle mass was calculated using the Janssen et al. ${ }^{6}$ equation: skeletal muscle mass $(\mathrm{kg})$ $=\left[\left(\right.\right.$ height $^{2} /$ resistance BIA analysis resistance $\left.{ }^{\star} 0.401\right)+\left(\right.$ gender $\left.^{\star} 3.825\right)+\left(\right.$ age $\left.\left.^{*}-0.071\right)\right]+$ 5.102 , where height is in centimetres, resistance in ohms, male gender is coded 1 , female 0 and age in years. This equation was developed in a population of 18-86 year olds and is applicable in a Caucasian population, ${ }^{6}$ like the Dutch population. Cut-off points for low muscle mass were based on the calculated skeletal muscle index (SMI); 1) in men SMI $\leq$ $8.50 \mathrm{~kg} / \mathrm{m}^{2}$ and in women $\leq 5.75 \mathrm{~kg} / \mathrm{m}^{2}$, also called severe sarcopenia and 2) SMI 8.51 $10.75 \mathrm{~kg} / \mathrm{m}^{2}$ (men) and $5.76-6.75 \mathrm{~kg} / \mathrm{m}^{2}$ (women) also called moderate sarcopenia. ${ }^{30}$

Muscle strength was assessed by a JAMAR hand-held dynamometer. Participants performed one try-out attempt with their arm in $90^{\circ}$ angle, followed by three attempts with each hand, alternating left and right. Participants were told to take a deep breath, and to start squeezing as they exhaled. Researchers encouraged the participants to squeeze as hard as possible. The maximum grip strength was used in the analyses, with cut-off points for poor muscle strength defined as $<20 \mathrm{~kg}$ for women and $<30 \mathrm{~kg}$ for men, as suggested by the EWGSOP. ${ }^{1}$ Physical performance was assessed using the short physical performance battery (SPPB) with a total score ranging from $0-12 .^{31}$ The SPPB includes normal gait speed over a four meter track (score 0-4), 5x chair stand (score 0-4) and a balance test (score 0-4); higher scores indicate better performance. For slow gait speed a cut-off point of $\leq 0.8 \mathrm{~m} / \mathrm{s}$ was used, as proposed by the EWGSOP. ${ }^{1}$ Furthermore, characteristics of participants were collected through a questionnaire that included age, sex, ethnicity, living situation i.e. type of care, comorbidities by the Charlson Comorbidity Index, ${ }^{32}$ functional status assessed by the validated Groningen Activity Restriction Scale $\left(\right.$ GARS) ${ }^{33}$ and cognitive function by the Mini-Mental State Examination (MMSE). ${ }^{34}$ Height (stadiometer type SECA 213) and weight (scale type SECA 877) were also measured with clothes, but without shoes, and BMI calculated as weight/height ${ }^{2}$. The BIAs, JAMARs and scales were regularly calibrated, every three weeks (BIA and JAMAR) and every three months (scales) respectively.

\subsection{Data Analysis}

SPSS version 21 (SPSS Inc, Chicago, IL) was used for statistical analyses. Means $( \pm S D)$ were used to summarize continuous variables. Chi-square test was used to compare the prevalence of sarcopenia in the three previously defined groups. Insight in the scores on individual parameters of the sarcopenia definition (i.e. SMI, grip strength, gait speed) and the SPPB was obtained by a descriptive analysis. Student's t-test (continuous variables) or Chi-square test (categorical variables) were used to compare the characteristics of sarcopenic versus non-sarcopenic older people. Logistic regression analysis was performed to assess the association of sarcopenia (dependent variable) with functional status (GARS score), number of comorbidities (Charlson Comorbidity Index) and cognitive status (MMSE score), controlling for age, sex and BMI. 


\subsection{Ethical Considerations}

The Medical Ethics Committee of the Academic Hospital Maastricht and Maastricht University approved the study after which the study was registered at http://www.clinicaltrials.gov (NCT01820988).

\section{Results}

A flow diagram of inclusion is shown in Supplementary Data, File 1. In total, 227 participants had complete data sets and were included in the analyses. Most participants were Caucasian (98\%), 6 participants were Asian. Analyses were performed with and without persons with oedema $(n=35)$. Excluding participants with oedema did not lead to significant differences in sarcopenia prevalence and outcomes between groups, therefore the analyses shown below include people with oedema.

\subsection{Prevalence of Sarcopenia}

Of the total sample, 53 participants $(23 \%)$ were classified as sarcopenic (Supplementary Data, File 2). Of those, 12 participants $(5 \%)$ had severe sarcopenia, while the others ( $\mathrm{n}=$ $41,18 \%$ ) had moderate sarcopenia. Sarcopenia was more prevalent in residential living facilities $(58.6 \%)$ compared to those receiving home care (at home or in an assisted living facility) $(41.5 \%)$ or those living at home without care $(12.1 \%)$ (Table 1$)$.

Of the 174 participants not identified as sarcopenic, $113(65 \%)$ had low SMI, but normal gait speed and grip strength (Figure 1, Part A). Of the 53 participants with sarcopenia, low SMI in combination with poor grip strength was present in 26 participants (49\%, Figure 1 - Part B). Of the 53 participants with sarcopenia, 18 participants (34\%) had low SMI combined with both poor strength and slow gait speed (Figure 1 - Part C), and low SMI in combination with slow gait speed was present in 9 participants (17\%, Figure 1 Part D). Moreover, 20 of the 174 non-sarcopenic participants (11\%) had low grip strength and/or slow gait speed, but normal muscle mass (Figure 1, parts E, F, G). Forty-one participants (18\%) did not have any muscle impairment.

\subsection{Characteristics of Sarcopenic Participants}

Participants with sarcopenia were significantly older $(P<0.001)$, had on average more comorbidities $(P=0.002)$, were more disabled in ADL $(P<0.001)$, had a lower cognitive function $(P=0.006)$ and had a lower $B M I(P=0.024)$ compared to their non-sarcopenic peers (Table 1). Sarcopenic participants scored lower on all performance measures, such as chair stand, balance score and total SPPB score (Table 1). Logistic regression analysis showed that there was a significant association between sarcopenia and functional status (OR 2.11, 95\% Cl: 1.43-3.12), but not with the number of comorbidities and cognitive status (Table 2). There was a significant (but small) interaction between age and functional status (interaction term OR 0.992, 95\% Cl: 0.987-0.996), i.e. the association between sarcopenia and functional status was stronger at younger age. Men more often had a low SMI compared to women, i.e. 106 out of 117 (91\%) versus 60 out of 110 (55\%) respectively $(P<0.001)$ (Table 1$)$. Women had more often poor grip strength, i.e. 35 out of $110(32 \%)$ women versus 24 out of 117 men $(21 \%)(P=0.052)$. 
Table 1 Participant Characteristics

\begin{tabular}{|c|c|c|c|c|c|c|}
\hline \multirow[t]{2}{*}{ Variable } & \multirow[t]{2}{*}{$\begin{array}{l}\text { Total } \\
(n=227)\end{array}$} & \multicolumn{2}{|c|}{$\begin{array}{l}\text { Characteristics of } \\
\text { Participants with/without } \\
\text { Sarcopenia }\end{array}$} & \multicolumn{3}{|c|}{$\begin{array}{l}\text { Characteristics of Participants Based on } \\
\text { Care Need }\end{array}$} \\
\hline & & $\begin{array}{l}\text { Non- } \\
\text { Sarcopenic } \\
(n=174)\end{array}$ & $\begin{array}{l}\text { Sarcopenic } \\
(n=53)\end{array}$ & $\begin{array}{l}\text { No Care } \\
(n=157)\end{array}$ & $\begin{array}{l}\text { Home Care at } \\
\text { Home/Assisted } \\
\text { Living }(n=41)\end{array}$ & $\begin{array}{l}\text { Residential } \\
\text { Living Facility } \\
(n=29)\end{array}$ \\
\hline \multicolumn{7}{|l|}{ General characteristics } \\
\hline Age in years, mean (SD) & $74.9(7.2)$ & $73.3(6.4)$ & $80.4(7.1)^{\star}$ & $72.1(4.9)$ & $80.7(7.1)$ & $82.3(8.2)$ \\
\hline \multicolumn{7}{|l|}{ Age category, n (\%) } \\
\hline 65-75 years & $135(59.5)$ & $123(70.7)$ & $12(22.6)^{\star}$ & $121(77.1)$ & $7(17.1)$ & $7(24.1)$ \\
\hline $76-85$ years & $67(29.5)$ & $40(23.0)$ & $27(50.9)^{\star}$ & $35(22.3)$ & $23(56.1)$ & $9(31.0)$ \\
\hline $86-95$ years & $25(11.0)$ & $11(6.3)$ & $14(26.4)^{\star}$ & $1(0.6)$ & $11(26.8)$ & $13(44.8)$ \\
\hline Sex, $\mathrm{n}$ female (\%) & $110(48.5)$ & $85(48.9)$ & $25(47.2)$ & $73(46.5)$ & $22(53.7)$ & $15(51.7)$ \\
\hline \multicolumn{7}{|l|}{ Comorbidities, n (\%) } \\
\hline Cancer & $14(6.2)$ & $8(4.6)$ & $6(11.3)$ & $5(3.2)$ & $4(9.8)$ & $5(17.2)$ \\
\hline Chronic lung disease & 45 (19.9) & 32 (18.3) & $13(24.5)$ & $21(13.4)$ & 15 ( 36.6$)$ & $8(27.6)$ \\
\hline Diabetes & $26(11.5)$ & $18(10.3)$ & $8(15.1)$ & $8(5.1)$ & $10(24.4)$ & $8(27.6)$ \\
\hline Heart attack/infarct & $26(11.5)$ & $17(9.8)$ & $9(17.0)$ & $16(10.2)$ & $4(9.8)$ & $6(20.7)$ \\
\hline Heart failure & $22(9.7)$ & $15(8.6)$ & 7 (13.2) & $11(7.0)$ & $6(14.6)$ & $5(17.2)$ \\
\hline Hypertension & $100(44.1)$ & $71(40.8)$ & $29(54.7)$ & $65(41.4)$ & $18(43.9)$ & $17(58.6)$ \\
\hline $\begin{array}{l}\text { Gastro-intestinal } \\
\text { disease }\end{array}$ & $21(9.3)$ & $17(9.8)$ & $4(7.5)$ & $11(7.0)$ & $3(7.3)$ & $7(24.1)$ \\
\hline $\begin{array}{l}\text { Peripheral arterial } \\
\text { disease }\end{array}$ & $43(18.9)$ & $31(17.8)$ & $12(22.6)$ & $23(14.6)$ & $15(36.6)$ & $5(17.2)$ \\
\hline Rheumatic disorder & $72(31.7)$ & $54(31.0)$ & $18(34.0)$ & $43(27.4)$ & $18(43.9)$ & $10(34.5)$ \\
\hline Stroke $e^{\star \star}$ & $13(5.7)$ & $5(2.9)$ & $8(15.1)^{\star}$ & $5(3.2)$ & $5(12.2)$ & $3(10.3)$ \\
\hline Other** & $63(27.8)$ & $41(23.6)$ & $21(41.5)^{\star}$ & $41(26.1)$ & $15(36.6)$ & $13(44.8)$ \\
\hline $\begin{array}{l}\text { Number of comorbidities, } \\
\text { mean (SD) }\end{array}$ & $2.1(1.8)$ & $1.9(1.8)$ & $2.7(1.7)^{\star}$ & $1.6(1.4)$ & $2.9(2.0)$ & $3.2(2.1)$ \\
\hline $\mathrm{BMI}$, mean kg/m² (SD) & $27.1(3.9)$ & $27.5(4.0)$ & $26.1(3.3)^{\star}$ & $26.9(3.6)$ & $27.7(4.5)$ & $27.6(4.8)$ \\
\hline MMSE score, mean (SD) & $28.7(1.3)$ & $28.9(1.3)$ & $28.3(1.4)^{\star}$ & $28.9(1.2)$ & $28.2(1.6)$ & $28.4(1.4)$ \\
\hline \multicolumn{7}{|l|}{ Level of care, n (\%) } \\
\hline No care & $157(69.1)$ & $138(79.3)$ & $19(35.8)^{\star}$ & $157(100.0)$ & $0(0.0)$ & $0(0.0)$ \\
\hline $\begin{array}{l}\text { Home care at home/ } \\
\text { assisted living }\end{array}$ & $41(18.1)$ & $24(13.8)$ & $17(32.1)^{\star}$ & $0(0.0)$ & $41(100.0)$ & $0(0.0)$ \\
\hline $\begin{array}{l}\text { Residential living } \\
\text { facility }\end{array}$ & $29(12.8)$ & $12(6.9)$ & $17(32.1)^{\star}$ & $0(0.0)$ & $0(0.0)$ & $29(100.0)$ \\
\hline GARS score, mean (SD) & $23.4(9.0)$ & $21.6(7.3)$ & $29.4(11.3)^{\star}$ & $20.0(4.3)$ & $29.5(10.7)$ & $33.2(12.9)$ \\
\hline \multicolumn{7}{|l|}{ Muscle characteristics } \\
\hline \multicolumn{7}{|l|}{ SMI, mean kg/m² (SD) } \\
\hline Men (total $n=117$ ) & $9.5(0.9)$ & $9.5(0.9)$ & $9.3(0.8)$ & $9.5(0.8)$ & $9.3(1.0)$ & $9.6(0.9)$ \\
\hline Women (total $n=110$ ) & $6.8(1.0)$ & $7.0(0.9)$ & $6.0(0.5)^{\star}$ & $6.8(0.8)$ & $6.9(1.1)$ & $6.7(1.3)$ \\
\hline \multicolumn{7}{|l|}{$\begin{array}{l}\text { Low SMI, sex-specific } \\
\text { proportion }\end{array}$} \\
\hline Men (total $n=117$ ) & 106 out of 117 & 78 out of 89 & 28 out of $28^{\star}$ & 75 out of 84 & 18 out of 19 & 13 out of 14 \\
\hline Women (total $n=110$ ) & 60 out of 110 & 35 out of 85 & 25 out of $25^{\star}$ & 37 out of 73 & 13 out of 22 & 10 out of 15 \\
\hline
\end{tabular}




\begin{tabular}{lllll}
\hline Variable & $\begin{array}{l}\text { Total } \\
(n=227)\end{array}$ & $\begin{array}{l}\text { Characteristics of } \\
\text { Participants with/without } \\
\text { Sarcopenia }\end{array}$ & $\begin{array}{l}\text { Characteristics of Participants Based on } \\
\text { Care Need }\end{array}$ \\
\cline { 2 - 3 } & $\begin{array}{l}\text { Non- } \\
\text { Sarcopenic } \\
(n=174)\end{array}$ & $\begin{array}{l}\text { Sarcopenic } \\
(n=53)\end{array}$ & $\begin{array}{l}\text { No Care } \\
(n=157)\end{array}$ & $\begin{array}{l}\text { Home Care at Residential } \\
\text { Home/Assisted Living Facility } \\
\text { Living }(n=41) \quad(n=29)\end{array}$
\end{tabular}

Muscle mass as \% of total

body weight, mean (SD)

$\begin{array}{lllllll}\text { Men (total } n=117) & 35.1(3.1) & 35.4(3.0) & 34.0(3.1)^{\star} & 35.2(3.1) & 34.4(3.2) & 35.1(2.7) \\ \begin{array}{l}\text { Women (total } \mathrm{n}=110) \\ \text { rip strength, mean kg (SD) }\end{array} & 25.4(3.0) & 25.6(2.8) & 24.7(3.4) & 25.7(3.0) & 24.9(2.8) & 24.5(3.0) \\ \quad & & & & & \\ \quad \text { Men } & 36.2(8.0) & 39.1(6.4) & 26.9(5.0)^{\star} & 38.2(7.5) & 31.4(6.9) & 30.1(6.8) \\ \text { Women } & 21.8(6.3) & 23.8(5.3) & 15.1(4.5)^{\star} & 24.0(5.1) & 17.9(6.3) & 17.1(7.0)\end{array}$

Poor grip strength, $\mathrm{n}$ (sexspecific \%)

$\begin{array}{lllllll}\text { Men (total } \mathrm{n}=117) & 24(20.5) & 3(2.6) & 21(17.9)^{\star} & 10(11.9) & 7(36.8) & 7(50.0) \\ \text { Women (total } \mathrm{n}=110) & 35(31.8) & 12(10.9) & 23(20.9)^{\star} & 11(15.1) & 15(68.2) & 9(60.0) \\ \text { it speed, mean m/s (SD) } & 1.0(0.3) & 1.1(0.2) & 0.8(0.2)^{\star} & 1.1(0.2) & 0.9(0.2) & 0.7(0.2) \\ \text { ance score, mean (SD) } & 3.6(0.8) & 3.8(0.6) & 3.2(1.1)^{\star} & 3.8(0.5) & 3.4(1.0) & 2.9(1.2) \\ \text { air stand score, mean } & 2.6(1.3) & 2.9(1.4) & 1.6(1.2)^{\star} & 3.0(1.0) & 1.9(1.3) & 1.3(1.4)\end{array}$

$\begin{array}{lllllll}\text { Chair stand } 5 \mathrm{x} \text {, mean s } 13.3(4.4) & 12.5(3.2) & 16.7(6.4)^{*} & 12.3(3.0) & 15.2(4.2) & 18.3(8.9) \\ (\mathrm{SD})^{\mathrm{a}} & & & & & \end{array}$

$\begin{array}{llllll}\text { SPPB score, mean (SD) } \quad 9.9(2.4) & 10.5(1.9) & 7.8(2.6)^{\star} & 10.7(1.5) & 8.7(2.6) & 7.1(3.1)\end{array}$

Prevalence of sarcopenia, $53(23.3) \quad 0(0.0) \quad 53(100.0) \quad 19(12.1) \quad 17(41.5) \quad 17(58.6)$

$\mathrm{n}(\%)$

$\begin{array}{lllllll}\text { Moderate sarcopenia } & 41(18.1) & 0(0.0) & 41(77.4) & 14(8.9) & 12(29.3) & 15(51.7) \\ \text { Severe sarcopenia } & 12(5.3) & 0(0.0) & 12(22.6) & 5(3.2) & 5(12.2) & 2(6.9)\end{array}$

BMI, body mass index; GARS, Groningen Activity Restriction Scale (total score range 18-72, higher scores indicate more restriction in ADL); MMSE, Mini-Mental State Examination; SMI, skeletal muscle index; SPPB, short physical performance battery. Low SMI defined as $\leq 10.75 \mathrm{~kg} / \mathrm{m}^{2}$ (men) and $\leq 6.75 \mathrm{~kg} / \mathrm{m}^{2}$ (women); Poor grip strength $<30 \mathrm{~kg}$ men, $<20 \mathrm{~kg}$ women. *Significant difference between sarcopenic and non-sarcopenic participants $(P$-value $<0.05)$. Significant differences in age category and level of care were found comparing the 3 groups. ${ }^{*}$ Stroke without evident lingering symptoms; Other, kidney, liver disease, etc. ${ }^{a} \mathrm{n}=205$, since not all participants were able to perform the $5 x$ chair stand.

\section{Discussion}

Sarcopenia was more prevalent in older people receiving professional home care or living in a residential living facility. This result is in line with previous research in communitydwelling older people versus a long-term care setting, which showed that the prevalence of sarcopenia is higher in people with a need for care. ${ }^{3}$ Only two publications were found on the prevalence of sarcopenia in an assisted living or residential living population. A study by Krause $^{12}$ reported a $54.5 \%$ (men) and $36.3 \%$ (women) prevalence of sarcopenia in people living in the community or an assisted living facility. The higher prevalence found compared to our study might be because they did not use the EWGSOP algorithm and their sample size was rather small $(n=33)$. The other publication was a protocol article of a study on sarcopenia prevalence in residential care, but this study did not publish results yet. $^{11}$

Our study showed that poor grip strength and slow gait speed were not always coincided by low SMI, meaning that also non-sarcopenic older people might have impaired 
muscle function. Grip strength and gait speed have been shown to be good predictors of negative health outcomes like accelerated dependency in ADL, and they are easy to measure in clinical geriatric practice. ${ }^{15,16,18,35,36}$ Therefore, the first steps in the EWGSOP (gait speed and grip strength) are of clinical relevance, also in non-sarcopenic older people.

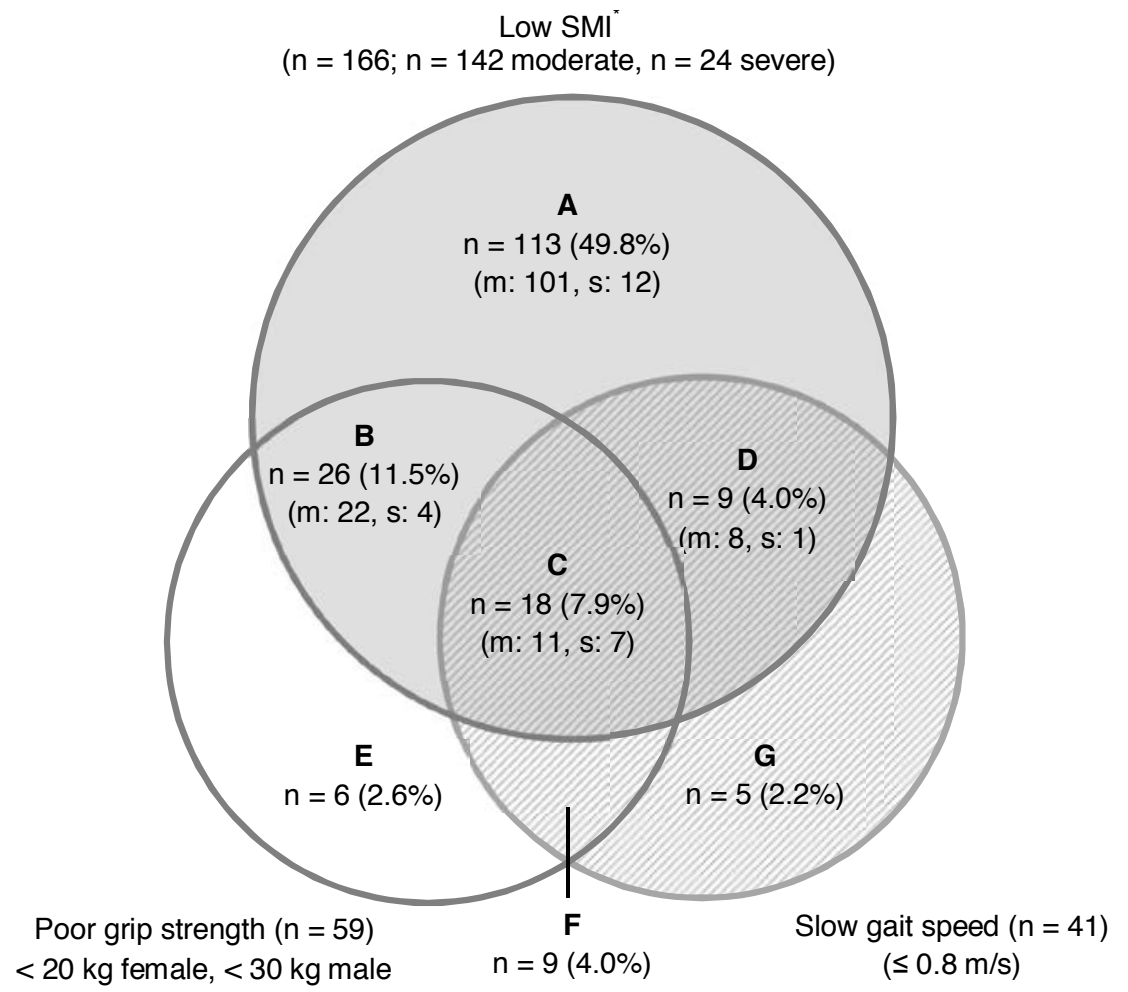

Figure 1 Prevalence of Muscle Impairments as Percentage of the Total Population

Part A: people with low SMI, Part B: people with low SMI and poor grip strength, Part C: people with low SMI, poor grip strength and slow gait speed, Part D: people with low SMI and slow gait speed, Part E: People with only poor grip strength, Part F: People with both poor grip strength and slow gait speed, but normal SMI, Part G: people with only slow gait speed. Parts B, C and D are persons with sarcopenia according to the EWGSOP definition. Percentages are calculated based on the total sample $(n=227)$. *SMI, skeletal muscle index; $m$, moderately low SMI, low skeletal muscle index $8.51-10.75 \mathrm{~kg} / \mathrm{m}^{2}$ (men), 5.76-6.75 kg/m² (women); s, severely low SMI, low skeletal muscle index $\leq$ $8.50 \mathrm{~kg} / \mathrm{m}^{2}$ (men) and $\leq 5.75 \mathrm{~kg} / \mathrm{m}^{2}$ (women).

Low SMI was more prevalent in men than in women; however a study by Volpato et al., ${ }^{4}$ also using BIA but using slightly different cut-off points, shows that low SMI is more prevalent in women. As our results and the study by Volpato et al. ${ }^{4}$ show, it seems that a notable number of people with low SMI are not sarcopenic, because their grip strength and gait speed are within the normal range. The number of people found with low SMI is influenced by the cut-off points used. In our study, we corrected SMI for height squared. Other ways of classifying low SMI are by correcting for body weight, BMI or fat mass. ${ }^{37,38}$ Cut-off points are based on $<2 S D$ of a reference population, the lowest $20^{\text {th }}$ percentile or 
based on e.g. association with physical disability. Differences in cut-off points lead to differences in prevalence of low SMI and sarcopenia. ${ }^{37}$

Besides a difference in sarcopenia prevalence depending on the care need, we observed that sarcopenia was associated with an impaired functional status. Body composition and muscle performance influence functional status. But whether low muscle mass, ${ }^{19}$ poor muscle strength, ${ }^{15,20}$ slow gait speed, ${ }^{15}$ fat mass, ${ }^{39-41}$ or a combination of these factors is mostly affecting functional status is not fully understood yet. Martien et al. ${ }^{42}$ showed that older people in an assisted living facility have a better functional status (assessed by the modified Physical Performance Test, which includes a range of functional items) than nursing home residents. Our study shows that people receiving home care and living in a residential living facility score lower on functional status (mean GARS score 3033) compared to independently living older people (GARS score 20), but all groups still have (some) independence in ADL, as the maximum GARS score (indicating total dependency in $A D L$ ) is 72 . People receiving home care or living in a residential living facility were not yet totally care dependent, though sarcopenia was more prevalent in these groups compared to independently living older people. Therefore empowerment of this group to maintain or improve their physical performance by e.g. (resistance) exercise, is thought to contribute to better functional outcomes, such as longer independence in ADL. 2, 43, 44 Besides, early diagnosis of sarcopenia in independently living older people might prevent or delay the onset of sarcopenia.

Table 2 Association of Sarcopenia with Functional Status, Comorbidities and Cognitive Status

\begin{tabular}{lll}
\hline Variable & Unadjusted Model OR $(95 \% \mathrm{Cl})$ & Model 1 OR $(95 \% \mathrm{Cl})$ \\
\hline Functional status (GARS score) & $1.09(1.05-1.13)$ & $2.11(1.43-3.12)$ \\
\# of comorbidities & Not significant & Not significant \\
Cognitive status (MMSE score) & Not significant & Not significant \\
Age & - & $1.40(1.21-1.62)$ \\
Age ${ }^{\star}$ Functional status & - & $0.99(0.99-1.00)$ \\
Sex & - & Not significant \\
BMI & - & $0.82(0.73-0.91)$ \\
\hline
\end{tabular}

GARS, Groningen Activity Restriction Scale; MMSE, Mini-Mental State Examination.

Although previous studies showed an association between cognitive function ${ }^{22}$ and the number of comorbidities ${ }^{19}$ with sarcopenia, these were not significantly associated with sarcopenia in our model. That we did not find an association with cognitive status might be explained by the fact that our study sample had in general a high cognitive status and there was only a marginal (potentially not clinically relevant) difference in cognitive status between the groups. The number of comorbidities might drop from our model due to the stronger association of sarcopenia with functional status.

A limitation of our study is that only $12 \%$ of the invited participants were willing to participate. A comparison between those who enrolled in the study and those who rejected or did not respond could not be made, since we were not allowed to ask participants their reasons for non-participation. Another study in the residential care setting reported that $67 \%$ of the randomized subjects declined participation, stating reasons like a lack of interest, a fear of something new, and/or cognitive wellbeing. ${ }^{11}$ Arguing that our sample is likely healthier than the general target population, the 'real' prevalence of sarcopenia in the 
community might be higher than presented. Furthermore the residential care group is rather small, therefore the 'real' prevalence in that group might deviate from the prevalence that we found in our sample. We did not include persons with a diagnosis of dementia, because of the expected burden of the home visit. This might limit the generalizability of our results. A methodological limitation is the bio-electrical impedance, which was selected as a measure for muscle mass for feasibility reasons, but might have overestimated or underestimated muscle mass. ${ }^{45}$ Persons with oedema, which might have interfered with the validity of the BIA measurement, ${ }^{23}$ were included in the analyses. Excluding those participants led to a sarcopenia prevalence of $26 \%$.

In conclusion, this study showed that sarcopenia was more prevalent in older people with a care need, i.e. with home care or living in a residential living facility. The impaired functional status associated with sarcopenia underlines the need for early diagnosis and treatment of sarcopenia, to stimulate longer independence and prevent disability.

\section{Acknowledgements}

We greatly appreciate the willingness and enthusiasm of the participants. We would like to thank Prof. dr. Luc van Loon for his constructive feedback and Suzanne Rijcken, Saskia Wolters and the municipality of Maastricht for their support.

\section{Funding}

This work was supported by Nutricia Research, Nutricia Advanced Medical Nutrition, Utrecht, the Netherlands. All authors declare that they have no conflict of interest. 


\section{References}

1. Cruz-Jentoft AJ, Baeyens JP, Bauer JM, Boirie Y, Cederholm T, Landi F, et al. Sarcopenia: European consensus on definition and diagnosis: report of the European Working Group on Sarcopenia in Older People. Age Ageing 2010;39(4):412-23.

2. Waters DL, Baumgartner RN, Garry PJ, Vellas B. Advantages of dietary, exercise-related, and therapeutic interventions to prevent and treat sarcopenia in adult patients: an update. Clin Interv Aging 2010;5:259-70.

3. Cruz-Jentoft AJ, Landi F, Schneider SM, Zuniga C, Arai H, Boirie Y, et al. Prevalence of and interventions for sarcopenia in ageing adults: a systematic review: report of the International Sarcopenia Initiative (EWGSOP and IWGS). Age Ageing 2014;43(6):748-59.

4. Volpato S, Bianchi L, Cherubini A, Landi F, Maggio M, Savino E, et al. Prevalence and clinical correlates of sarcopenia in community-dwelling older people: application of the EWGSOP definition and diagnostic algorithm. J Gerontol A Biol Sci Med Sci 2014;69(4):438-46.

5. Chien MY, Huang TY, Wu YT. Prevalence of sarcopenia estimated using a bioelectrical impedance analysis prediction equation in community-dwelling elderly people in Taiwan. J Am Geriatr Soc 2008;56(9):1710-5.

6. Janssen I, Heymsfield SB, Baumgartner RN, Ross R. Estimation of skeletal muscle mass by bioelectrical impedance analysis. J Appl Physiol 2000;89(2):465-71.

7. Janssen I, Heymsfield SB, Ross R. Low relative skeletal muscle mass (sarcopenia) in older persons is associated with functional impairment and physical disability. J Am Geriatr Soc 2002;50(5):889-96.

8. Studenski SA, Peters KW, Alley DE, Cawthon PM, McLean RR, Harris TB, et al. The FNIH sarcopenia project: rationale, study description, conference recommendations, and final estimates. J Gerontol A Biol Sci Med Sci 2014;69(5):547-58.

9. Sipers WMWH, Meijers JMM, Van Dijk RB, Halfens RJG, Schols JMGA. Impact of different diagnostic criteria on the prevalence of sarcopenia in an acute care geriatric ward. J Frailty Aging 2014;3(4):222-9.

10. Sousa AS, Guerra RS, Fonseca I, Pichel F, Amaral TF. Sarcopenia among hospitalized patients: a crosssectional study. Clin Nutr 2015;34(6):1239-44.

11. Henwood TR, Keogh JW, Reid N, Jordan W, Senior HE. Assessing sarcopenic prevalence and risk factors in residential aged care: methodology and feasibility. J Cachexia Sarcopenia Muscle 2014;5(3):229-36.

12. Krause KE, Mclntosh El, Vallis LA. Sarcopenia and predictors of the fat free mass index in communitydwelling and assisted living older men and women. Gait Posture 2012;35(2):180-5.

13. Hirani V, Blyth F, Naganathan V, Le Couteur DG, Seibel MJ, Waite LM, et al. Sarcopenia is associated with incident disability, institutionalization, and mortality in community-dwelling older men: the Concord Health and Ageing in Men Project. J Am Med Dir Assoc 2015;16(7):607-13.

14. Janssen I. Influence of sarcopenia on the development of physical disability: the Cardiovascular Health Study. J Am Geriatr Soc 2006;54(1):56-62.

15. Cesari M, Rolland Y, Abellan van Kan G, Bandinelli S, Vellas B, Ferrucci L. Sarcopenia-related parameters and incident disability in older persons: results from the "Invecchiare in Chianti" study. J Gerontol A Biol Sci Med Sci 2015;70(4):457-63.

16. Hairi NN, Cumming RG, Naganathan V, Handelsman DJ, Le Couteur DG, Creasey H, et al. Loss of muscle strength, mass (sarcopenia), and quality (specific force) and its relationship with functional limitation and physical disability: the Concord Health and Ageing in Men Project. J Am Geriatr Soc 2010;58(11):2055-62.

17. Tanimoto $Y$, Watanabe M, Sun W, Sugiura Y, Tsuda $Y$, Kimura M, et al. Association between sarcopenia and higher-level functional capacity in daily living in community-dwelling elderly subjects in Japan. Arch Gerontol Geriatr 2012;55(2):e9-e13.

18. Tyrovolas S, Koyanagi A, Olaya B, Ayuso-Mateos JL, Miret M, Chatterji S, et al. The role of muscle mass and body fat on disability among older adults: a cross-national analysis. Exp Gerontol 2015;69:27-35.

19. Amigues I, Schott AM, Amine M, Gelas-Dore B, Veerabudun K, Paillaud E, et al. Low skeletal muscle mass and risk of functional decline in elderly community-dwelling women: the prospective EPIDOS study. J Am Med Dir Assoc 2013;14(5):352-7.

20. Da Silva AT, De Oliveira Duarte YA, Ferreira Santos JL, Wong R, Lebrao ML. Sarcopenia according to the european working group on sarcopenia in older people (EWGSOP) versus dynapenia as a risk factor for disability in the elderly. J Nutr Health Aging 2014;18(5):547-53.

21. Li Cl, Li TC, Lin WY, Liu CS, Hsu CC, Hsiung CA, et al. Combined association of chronic disease and low skeletal muscle mass with physical performance in older adults in the Sarcopenia and Translational Aging Research in Taiwan (START) study. BMC Geriatr 2015;15:11.

22. Tolea MI, Galvin JE. Sarcopenia and impairment in cognitive and physical performance. Clin Interv Aging 2015;10:663-71. 
23. Kyle UG, Bosaeus I, De Lorenzo AD, Deurenberg P, Elia M, Manuel Gomez J, et al. Bioelectrical impedance analysis: Part II: Utilization in clinical practice. Clin Nutr 2004;23(6):1430-53.

24. Faul F, Erdfelder E, Lang AG, Buchner A. G*Power 3: a flexible statistical power analysis program for the social, behavioral, and biomedical sciences. Behav Res Methods 2007;39(2):175-91.

25. Arango-Lopera VE, Arroyo P, Gutiérrez-Robledo RM, Pérez-Zepeda MU. Prevalence of sarcopenia in Mexico City. Eur Geriatr Med 2012;3(3):157-60.

26. Patil R, Uusi-Rasi K, Pasanen M, Kannus P, Karinkanta S, Sievanen H. Sarcopenia and osteopenia among 70-80-year-old home-dwelling Finnish women: prevalence and association with functional performance. Osteoporos Int 2013;24(3):787-96.

27. Mijnarends D, Meijers J, Halfens R et al. Rationale and design of a cross-sectional study of the prevalence, characterization and health and economic consequences of sarcopenia in community-dwelling older people in the Netherlands [abstract]. J Nutr Health Aging 2013;17(supplement 1):S245.

28. Mijnarends DM, Meijers JMM, Halfens RJG et al. Validity and reliability of tools to measure muscle mass, strength, and physical performance in community-dwelling older people: a systematic review. J Am Med Dir Assoc 2013;14(3):170-8.

29. Kyle UG, Bosaeus I, De Lorenzo AD et al. Bioelectrical impedance analysis: Part I: Review of principles and methods. Clin Nutr 2004;23(5):1226-43.

30. Janssen I, Baumgartner RN, Ross R, Rosenberg IH, Roubenoff R. Skeletal muscle cutpoints associated with elevated physical disability risk in older men and women. Am J Epidemiol 2004;159(4):413-21.

31. Guralnik JM, Simonsick EM, Ferrucci $L$ et al. A short physical performance battery assessing lower extremity function: association with self-reported disability and prediction of mortality and nursing home admission. $J$ Gerontol 1994;49(2):M85-94.

32. Charlson ME, Pompei P, Ales KL, MacKenzie CR. A new method of classifying prognostic comorbidity in longitudinal studies: development and validation. J Chronic Dis 1987;40(5):373-83.

33. Kempen GIJM, Miedema I, Ormel J, Molenaar W. The assessment of disability with the Groningen Activity Restriction Scale: conceptual framework and psychometric properties. Soc Sci Med 1996;43(11):1601-10.

34. Kok RM, Verhey FRJ. Gestandaardiseerde MMSE (Dutch translation of the Mini Mental State Examination). 2002.

35. Abellan van Kan G, Rolland Y, Andrieu S et al. Gait speed at usual pace as a predictor of adverse outcomes in community-dwelling older people: an International Academy on Nutrition and Aging (IANA) Task Force. J Nutr Health Aging 2009;13(10):881-9.

36. Norman K, Stobäus N, Gonzalez MC, Schulzke JD, Pirlich M. Hand grip strength: outcome predictor and marker of nutritional status. Clin Nutr 2011;30(2):135-42.

37. Bijlsma AY, Meskers CG, Ling CH et al. Defining sarcopenia: the impact of different diagnostic criteria on the prevalence of sarcopenia in a large middle aged cohort. Age 2013;35(3):871-81.

38. Bosy-Westphal A, Muller MJ. Identification of skeletal muscle mass depletion across age and BMI groups in health and disease: there is need for a unified definition. Int J Obes 2015;39(3):379-86.

39. Batsis JA, Mackenzie TA, Barre LK, Lopez-Jimenez F, Bartels SJ. Sarcopenia, sarcopenic obesity and mortality in older adults: results from the National Health and Nutrition Examination Survey III. Eur J Clin Nutr 2014;68(9):1001-7.

40. Bouchard DR, Dionne IJ, Brochu M. Sarcopenic/obesity and physical capacity in older men and women: data from the Nutrition as a determinant of successful aging (NuAge): the Quebec longitudinal study. Obesity 2009;17(11):2082-8.

41. Lebrun CE, van der Schouw YT, de Jong FH, Grobbee DE, Lamberts SW. Fat mass rather than muscle strength is the major determinant of physical function and disability in postmenopausal women younger than 75 years of age. Menopause 2006;13(3):474-81.

42. Martien S, Delecluse C, Boen F, Seghers J, Pelssers J, Van Hoecke AS, et al. Is knee extension strength a better predictor of functional performance than handgrip strength among older adults in three different settings? Arch Gerontol Geriatr 2015;60(2):252-8.

43. Koopman R, Verdijk LB, Van Loon LJC. Exercise and nutritional interventions to combat age-related muscle loss. In: Lynch GS, editor. Sarcopenia: age-related muscle wasting and weakness: mechanisms and treatments. Dordrecht: Springer; 2010. p. 289-315.

44. Tieland M, Dirks ML, Van der Zwaluw N, Verdijk LB, Van de Rest O, De Groot LC, et al. Protein supplementation increases muscle mass gain during prolonged resistance-type exercise training in frail elderly people: a randomized, double-blind, placebo-controlled trial. J Am Med Dir Assoc 2012;13(8):713-9.

45. Genton L, Karsegard VL, Kyle UG, Hans DB, Michel JP, Pichard C. Comparison of four bioelectrical impedance analysis formulas in healthy elderly subjects. Gerontology 2001;47(6):315-23. 


\section{Supplementary Data Chapter 3 - File 1}

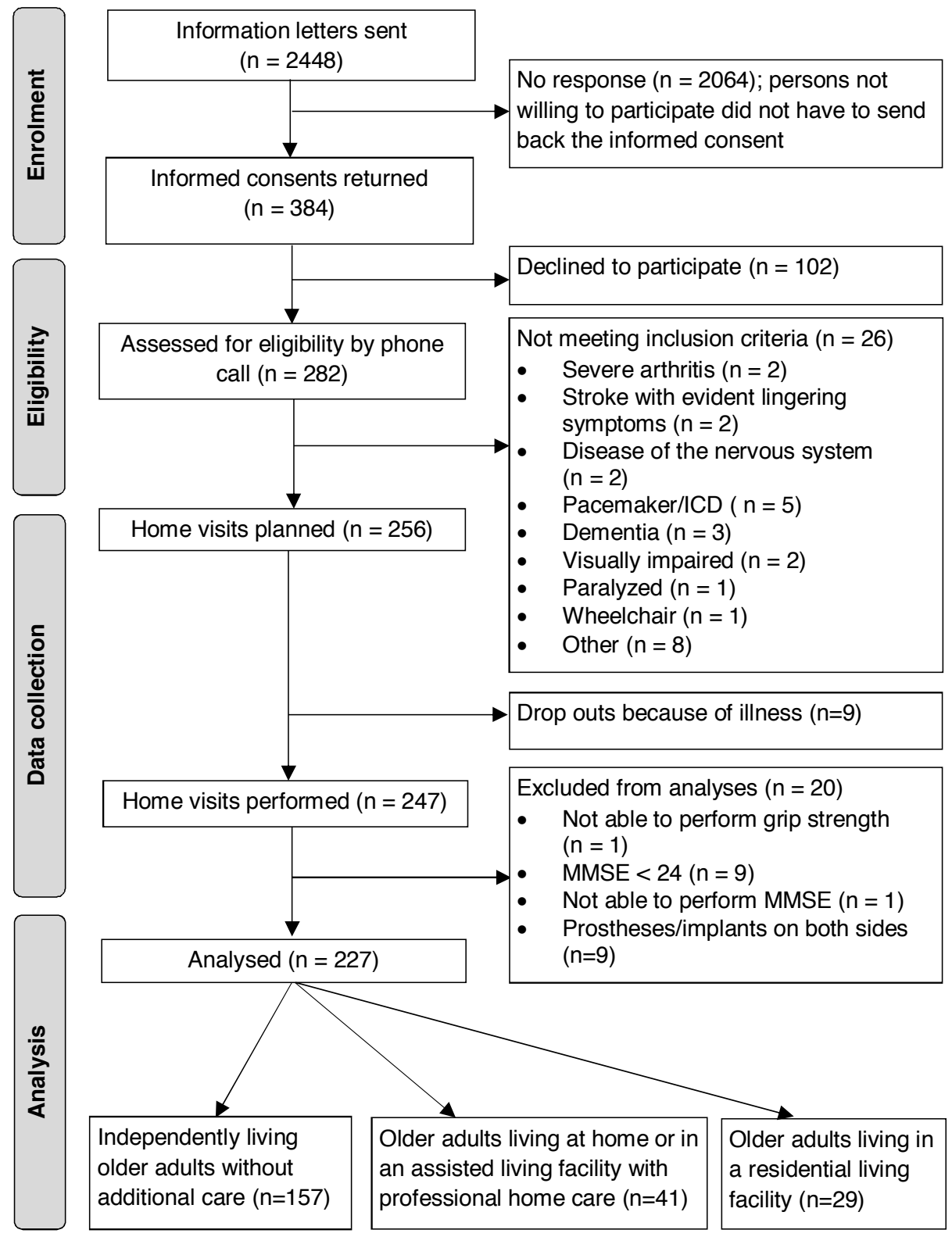

Supplementary Figure 1 Adapted CONSORT flow diagram of inclusion 


\section{Supplementary Data Chapter 3 - File 2}

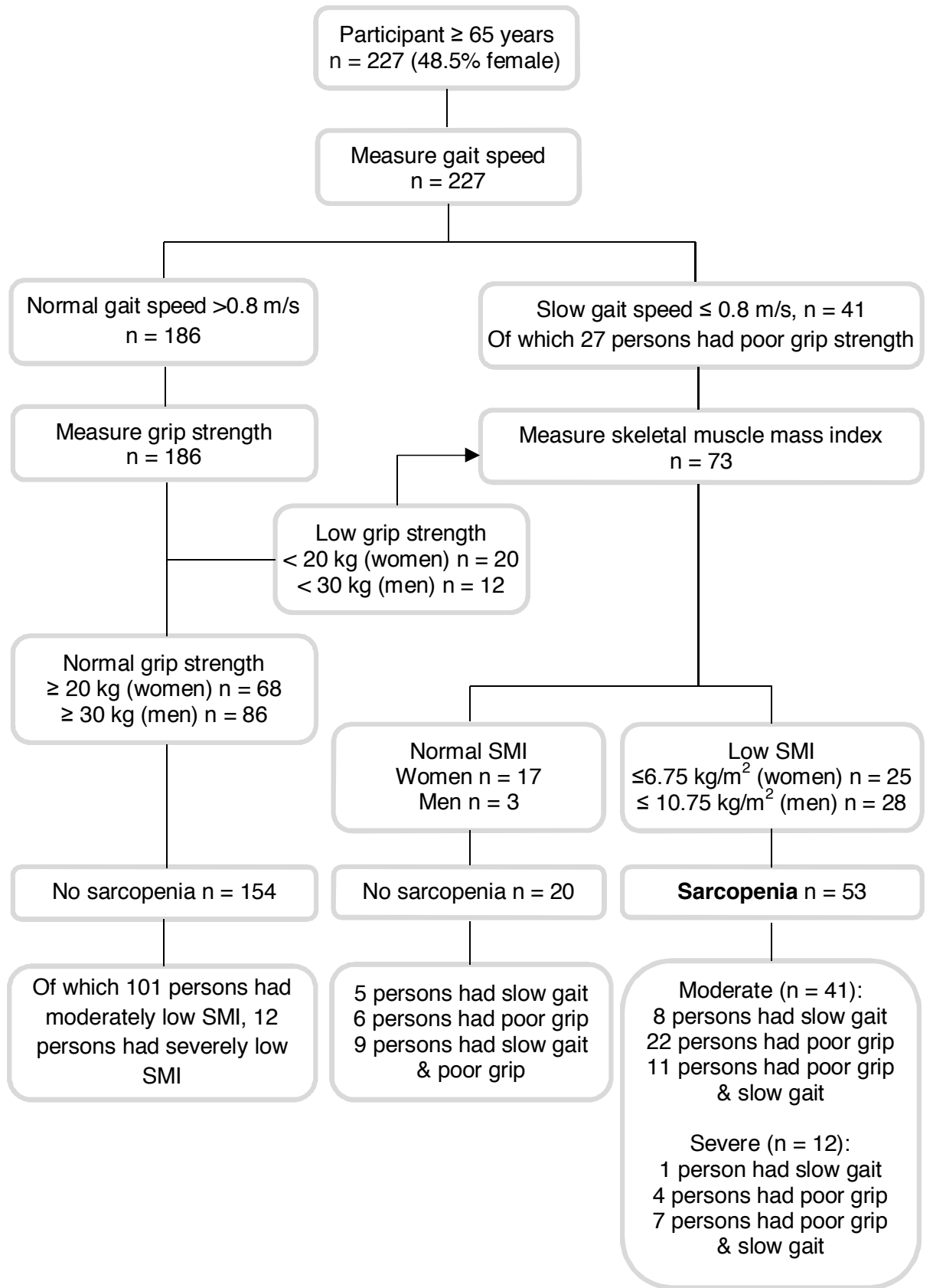

Supplementary Figure 2 Identification of sarcopenia according to the EWGSOP algorithm ${ }^{1}$ 



\section{CHAPTER 4}

\section{Instruments to Assess Sarcopenia and Physical Frailty in Older People Living in a Community (Care) Setting: Similarities and Discrepancies}

This chapter was published as: DM Mijnarends, JMGA Schols, JMM Meijers, FES Tan, S Verlaan, YC Luiking, JE Morley, RJG Halfens. J Am Med Dir Assoc 2015;6(4):301-8. 


\section{ABSTRACT}

Objectives: Both sarcopenia and physical frailty are geriatric syndromes causing loss of functionality and independence. This study explored the association between sarcopenia and physical frailty and the overlap of their criteria in older people living in different community (care) settings. Moreover, it investigated the concurrent validity of the FRAIL scale to assess physical frailty, by comparison with the widely used Fried criteria.

Design: Data were retrieved from the cross-sectional Maastricht Sarcopenia Study (MaSS).

Setting: The study was undertaken in different community care settings in an urban area (Maastricht) in the South of the Netherlands.

Participants: People were 65 years or older, gave written informed consent, were able to understand Dutch language and were not wheelchair bound or bedridden.

Intervention: Not applicable.

Measurements: Sarcopenia was identified using the algorithm of the European Working Group on Sarcopenia in Older People. Physical frailty was assessed by the Fried criteria and by the FRAIL scale. Logistic regression was performed to assess the association between sarcopenia and physical frailty measured by the Fried criteria. Spearman correlation was performed to assess the concurrent validity of the FRAIL scale compared with the Fried criteria.

Results: Data from 227 participants, mean age 74.9 years, was analysed. Sarcopenia was identified in $23.3 \%$ of the participants, when using the cut-off points for moderate sarcopenia. Physical frailty was identified in $8.4 \%$ ( $\geq 3$ Fried criteria) and $9.3 \%$ ( $\geq 3$ FRAIL scale criteria) of the study population. Sarcopenia and physical frailty were significantly associated $(P=0.022)$. Frail older people were more likely to be sarcopenic than those who were not frail. In older people who were not frail, the risk of having sarcopenia increased with age. Next to poor grip strength (78.9\%) and slow gait speed $(89.5 \%)$, poor performance in other functional tests was common in frail older people. The two physical frailty scales were significantly correlated $(r=0.617, P<0.001)$.

Conclusion: Sarcopenia and physical frailty were associated and partly overlap, especially on parameters of impaired physical function. Some evidence for concurrent validity between the FRAIL scale and Fried criteria was found. Future research should elicit the value of combining sarcopenia and frailty measures in preventing disability and other negative health outcomes. 


\section{Introduction}

In the past two decades, the concepts and definitions of the geriatric syndromes sarcopenia and frailty have been frequently revised. In addition, their application in clinical practice for diagnosis and therapy has been challenged. ${ }^{1,2}$ This has resulted in prevalence rates varying between $0.9 \%$ and $50 \%$ for sarcopenia ${ }^{3}$ and between $4.0 \%$ and $59.1 \%$ for frailty ${ }^{4}$ in the older community-dwelling population. The concept of sarcopenia partly overlaps with the concept of physical frailty (Supplementary Data, File 1), and therefore they might cover the same population. Sarcopenia was defined by the European Working Group on Sarcopenia in Older Persons (EWGSOP) as a loss of muscle mass in combination with a loss of muscle strength and/or physical performance. ${ }^{5}$ Frailty is defined as a clinical state of increased vulnerability of an older person to a stressor, ${ }^{6}$ such as pain or a psychologically stressful event. Therefore, a holistic approach of frailty encompasses a physical, psychological, and social domain; however, most frailty instruments focus on physical frailty only. ${ }^{7}$ Experts consider sarcopenia as a key component of physical frailty ${ }^{8-10}$ or as a key pathway between physical frailty and disability. ${ }^{11}$ However, little is currently known about the association between the criteria of sarcopenia and physical frailty. ${ }^{12}$

Although valid models of (physical) frailty exist in epidemiological research, more efficient models need to be developed to detect frailty in clinical practice. ${ }^{9}$ One of the most known and validated operational definitions of physical frailty in older people is the frailty phenotype. ${ }^{13,14}$ Fried et al. ${ }^{14}$ defined physical frailty as the presence of three or more of the following criteria (Supplementary Data, File 1): (1) unintentional weight loss, (2) selfreported exhaustion, (3) weakness (grip strength), (4) slow walking speed, and (5) low physical activity. Although the criteria are easy to perform, their assessment is not always doable in clinical practice because of a lack of resources, such as dynamometers, lack of space for a walk test, or lack of time to perform multiple measurements. ${ }^{13} \mathrm{~A}$ simple and rapid screening test, the FRAIL scale, has recently been developed and validated by Morley et al. ${ }^{15}$ It consists of five simple questions to assess physical frailty, related to (1) Fatigue, (2) Resistance, (3) Ambulation, (4) Illnesses, and (5) Loss of Weight. Such a rapid test might be more feasible for physicians to assess physical frailty in clinical practice and thus might facilitate diagnosis and treatment.

Unravelling the association of the concepts and criteria of sarcopenia and physical frailty is needed to boost the development and implementation of an efficient screening tool. This study explored the association between the concepts of sarcopenia (by the EWGSOP, including both moderate and severely low skeletal muscle index) and physical frailty (by the Fried criteria with $\geq 3$ positive criteria), and the overlap between their indicators in older people living in different community (care) settings. It is hypothesized that frail older people are more likely to be sarcopenic than those who are not frail. Our secondary aim was to examine the concurrent validity of the FRAIL scale to assess physical frailty compared with the Fried criteria. The Fried criteria will be used as comparison instrument, because it is widely known, validated, and commonly used. ${ }^{13,14,16,17}$

\section{Methods}

\subsection{Design and Setting}

Data were retrieved from the Maastricht Sarcopenia Study (MaSS), which was undertaken in older people in different community care settings in an urban area (Maastricht) in the 
south of the Netherlands. MaSS is a cross-sectional study aiming to characterize sarcopenia by measuring the prevalence; associated factors, such as nutritional status, physical activity, and health; and economic consequences of sarcopenia. More information on study design and recruitment can be found at http://www.clinicaltrials.gov (NCT01820988).

\subsection{Participants}

The study was conducted in 247 participants aged 65 years or older in the following community settings: independently living without home care, older people receiving home care, and older people residing in an assisted or residential living facility. On request, the municipality of Maastricht provided a random sample of older people. An information letter and informed consent form were sent. Participants were included when they gave written informed consent, were able to understand the Dutch language, and were not wheelchair bound or bedridden. Participants with an implantable cardiac defibrillator/pacemaker, or suffering from a severe heart, joint, or nervous system disease or dementia were excluded, because of safety reasons and/or incapability of performing the physical tests.

\subsection{Measures}

Sarcopenia was assessed according to the EWGSOP algorithm, including muscle mass, strength, and physical performance. ${ }^{5}$ Muscle mass was assessed by bioelectrical impedance (BIA Akern Srl, Florence, Italy 101, $50 \mathrm{kHz}$ ), complying with the European Society for Clinical Nutrition and Metabolism Guidelines. ${ }^{18}$ Skeletal muscle mass was calculated using the equation developed by Janssen et $\mathrm{al}^{19}{ }^{19}$ because this equation is applicable in an older Caucasian population: skeletal muscle mass $(\mathrm{kg})=$ $\left(\left[\right.\right.$ height $^{2} /$ resistance BIA analysis $\left.{ }^{\star} 0.401\right]+\left[\right.$ gender $\left.^{\star} 3.825\right]+\left[\right.$ age $\left.\left.^{\star}-0.071\right]\right)+5.102$, where height is in centimetres, resistance in ohms, male gender is coded 1 and female 0 , and age in years. Muscle mass was then converted to skeletal muscle index (SMI) by dividing muscle mass by height (in $\mathrm{m}$ ) squared. Muscle strength was assessed by a JAMAR handheld dynamometer (Sammons Preston, Inc, Warrenville, IL) to measure grip strength. Participants performed one try-out attempt followed by alternately three attempts with their left hand and three attempts with their right hand. Physical performance was assessed by normal walking speed $(\mathrm{m} / \mathrm{s})$ over a 4-meter track. These measures for muscle mass, strength, and performance were found to be valid and feasible in community-dwelling older people. ${ }^{20,21}$ Participants were classified as sarcopenic when they had a low muscle mass, defined as a low $\mathrm{SMI} \leq 10.75 \mathrm{~kg} / \mathrm{m}^{2}$ (in men) and $\leq 6.75 \mathrm{~kg} / \mathrm{m}^{2}$ (in women), ${ }^{22}$ and low muscle strength (men $<30 \mathrm{~kg}$; women $<20 \mathrm{~kg}$ ), and/or low physical performance (walking speed $\leq 0.8 \mathrm{~m} / \mathrm{s}$ ). The cut-off points for low muscle mass include both moderate and severe low muscle mass. ${ }^{22}$ Other performance measures included balance testing and a five times chair stand, as part of the Short Physical Performance Battery (SPPB). ${ }^{23}$

Physical frailty was assessed by the previously validated Fried criteria ${ }^{14}$ and the FRAIL scale. ${ }^{15,24}$ The 5 Fried criteria were assessed as follows: (1) a question about unintentional weight loss of more than $4.5 \mathrm{~kg}$ in the past year $(0=\mathrm{no}, 1=$ yes) and (2) a question about self-reported exhaustion $(0=$ rarely or a little of the time, $1=$ a moderate amount of the time or most of the time). Both questions were available in the Dutch language. The third Fried criterion is weakness, measured by a hand-held dynamometer, with normal grip strength $=0$, low grip strength $=1$; cut-off points were stratified by gender 
and body mass index according to Fried et al ${ }^{14}$ (Supplementary Data, File 2). The fourth criterion, walking speed, was measured by timing the participants' normal walking speed over a 4-m track. Normal walking speed $=0$, slow walking speed $=1$; cut-off points were stratified by gender and height ${ }^{14}$ (Supplementary Data, File 2). The fifth and last Fried criterion is physical activity, measured by the Minnesota Leisure Time Physical Activity Questionnaire. ${ }^{25}$ Normal physical activity $=0$, low physical activity = 1; cut-off points for low physical activity are less than $383 \mathrm{kcal} /$ week (men) or less than $270 \mathrm{kcal} / \mathrm{week}$ (women). Participants were considered pre-frail or frail when they scored 1 to 2 or 3 to 5 points, respectively. The FRAIL scale ${ }^{15}$ consists of 5 questions: (1) fatigue $(0=$ none of the time, a little of the time, some of the time; $1=$ most of the time, all of the time), (2) resistance (difficulty walking up 10 steps; $0=$ no, 1 = yes), (3) ambulation (difficulty walking several hundred yards; 0 = no, 1 = yes), (4) illnesses (hypertension, diabetes, cancer, chronic lung disease, heart attack, congestive heart failure, angina pectoris, asthma, arthritis, stroke, and kidney disease; $0=0-4$ illnesses, $1=5-11$ illnesses), and (5) loss of weight (current weight minus weight 1 year ago; $0=$ less than $5 \%$ change, $1=$ change $5 \%$ or more). Subjects were considered pre-frail or frail when they scored 1 to 2 or 3 to 5 points on the FRAIL scale, respectively. The original FRAIL scale was translated from English to Dutch, with permission, by a native Dutch speaker. Backward translation was performed by a native English speaker. Afterward, the backward translation was compared with the original English version by another native English speaker. No differences were found between the original and the backward translated versions.

Furthermore, characteristics of participants were collected through a questionnaire that recorded, among others, age, sex, community (care) setting (community-dwelling with/without home care, assisted living, residential living facility), chronic diseases (by the FRAIL scale and Charlson Comorbidity Index ${ }^{26}$ ), depression, and cognitive function (MiniMental State Examination [MMSE] ${ }^{27}$ ). Height and weight were assessed by respectively a stadiometer (type SECA 213, Seca, Hamburg, Germany) and scale (type SECA 877). Both were measured with clothes, but without shoes, and body mass index (BMI) calculated as weight/height ${ }^{2}$. The validated Groningen Activity Restriction Scale (GARS), consisting of 18 questions, was used to assess disability in (instrumental) activities of daily living. ${ }^{28}$ Answer categories range from "fully independently without any difficulty" (1) to "can only do it with someone's help" (4), leading to a total score between 18 and 72.

\subsection{Statistical Analysis}

Data were analysed using SPSS version 21 (SPSS Inc, Chicago, IL). Logistic regression was performed to assess the association between the EWGSOP definition of sarcopenia and the Fried criteria. The association of sarcopenia (yes/no; dependent variable), the dichotomized frailty score (frail yes/no), as well as the total frailty score (score 0-5) derived from the physical frailty criteria, were studied in older people living in different community (care) settings. Age, sex, and BMI were included in the model as covariates. Chi-square tests were performed to assess differences in frail scores (0-5) and pre-frail status in the sarcopenic versus non-sarcopenic group. Concurrent validity, the extent to which a measure (FRAIL scale) is consistent with a gold standard (Fried criteria) was assessed by calculating bivariate (Spearman) correlations. 
Table 1 Participant Characteristics

\begin{tabular}{|c|c|c|c|c|c|c|}
\hline \multirow[t]{2}{*}{ Variable } & \multirow[t]{2}{*}{$\begin{array}{l}\text { Sarcopenic } \\
(n=53)\end{array}$} & \multicolumn{2}{|c|}{$\begin{array}{l}\text { Frail } \\
\text { (Fried criteria) }\end{array}$} & \multicolumn{2}{|c|}{$\begin{array}{l}\text { Frail } \\
\text { (FRAIL scale) }\end{array}$} & \multirow[t]{2}{*}{$\begin{array}{l}\text { Total } \\
(n=227)\end{array}$} \\
\hline & & $\begin{array}{l}\text { Pre-frail } \\
(n=81)\end{array}$ & $\begin{array}{l}\text { Frail } \\
(n=19)\end{array}$ & $\begin{array}{l}\text { Pre-frail } \\
(n=57)\end{array}$ & $\begin{array}{l}\text { Frail } \\
(n=21)\end{array}$ & \\
\hline Age in years, mean (SD) & $80.4(7.1)$ & $77.1(7.3)$ & $85.5(8.6)$ & $75.3(7.4)$ & $83.9(7.6)$ & $74.9(7.2)$ \\
\hline \multicolumn{7}{|l|}{ Age in categories, $\mathrm{n}(\%)$} \\
\hline $65-74$ & $12(22.6)$ & $33(40.7)$ & $4(21.1)$ & $30(52.6)$ & $4(19.0)$ & $122(53.7)$ \\
\hline $75-84$ & $23(43.4)$ & $33(40.7)$ & $3(15.8)$ & $18(31.6)$ & $5(23.8)$ & $75(33.0)$ \\
\hline 85-95 & $18(34.0)$ & $15(18.5)$ & $12(63.2)$ & $9(15.8)$ & $12(57.1)$ & $30(13.2)$ \\
\hline Sex, n female (\%) & $25(47.2)$ & $43(53.1)$ & $13(68.4)$ & $31(54.4)$ & $14(66.7)$ & $110(48.5)$ \\
\hline BMI, mean kg/m² (SD) & $26.1(3.3)$ & $27.9(4.6)$ & $28.6(5.1)$ & $27.4(4.9)$ & $28.8(5.4)$ & $27.1(3.9)$ \\
\hline Comorbidities, mean (SD) & $2.7(1.7)$ & $2.8(1.9)$ & $3.5(1.3)$ & $2.7(1.9)$ & $4.1(1.7)$ & $2.1(1.8)$ \\
\hline \multicolumn{7}{|l|}{ Most prevalent comorbidities, n (\%) } \\
\hline Chronic lung disease & $13(24.5)$ & $25(30.8)$ & $6(31.6)$ & $17(29.9)$ & $10(47.6)$ & 45 (19.9) \\
\hline Diabetes & $8(15.1)$ & $15(18.5)$ & $5(26.3)$ & $9(15.8)$ & $6(28.6)$ & $26(11.5)$ \\
\hline Heart attack/infarct & $9(17.0)$ & $12(14.8)$ & $3(15.8)$ & $5(8.8)$ & $3(14.3)$ & $26(11.5)$ \\
\hline Hypertension & $29(54.7)$ & $44(54.3)$ & $11(57.9)$ & $28(49.1)$ & $15(71.4)$ & $100(44.1)$ \\
\hline Peripheral arterial disease & $12(22.6)$ & $22(27.2)$ & $5(26.3)$ & $15(26.3)$ & $6(28.6)$ & $43(18.9)$ \\
\hline Rheumatic disorder & $18(34.0)$ & $35(43.2)$ & $9(47.4)$ & $20(35.1)$ & $12(57.7)$ & $72(31.7)$ \\
\hline Depression, n (\%) & $5(9.4)$ & $8(9.9)$ & $3(15.8)$ & $9(15.8)$ & $2(9.5)$ & $17(7.5)$ \\
\hline MMSE score, mean (SD) & $28.3(1.4)$ & $28.7(1.4)$ & $28.7(1.4)$ & $28.9(1.3)$ & $27.7(1.6)$ & $28.7(1.3)$ \\
\hline \multicolumn{7}{|l|}{ Community (care) setting, $\mathrm{n}(\%)$} \\
\hline Independently living & 19 (35.9) & $44(54.3)$ & $3(15.8)$ & $31(54.4)$ & $3(14.3)$ & $157(69.2)$ \\
\hline Home care & $11(20.8)$ & $18(22.2)$ & $4(21.1)$ & $13(22.8)$ & $5(23.8)$ & $28(12.3)$ \\
\hline Assisted living & $6(11.3)$ & $6(7.4)$ & $4(21.1)$ & $2(3.5)$ & $4(19.0)$ & $13(5.7)$ \\
\hline Residential living facility & $17(32.1)$ & $13(16.0)$ & $8(42.1)$ & $11(19.3)$ & $9(42.9)$ & $29(12.8)$ \\
\hline \multicolumn{7}{|l|}{$\mathrm{SMI}$, mean $\mathrm{kg} / \mathrm{m}^{2}(\mathrm{SD})$} \\
\hline Men & $9.3(0.8)$ & $9.5(1.0)$ & $9.7(1.3)$ & $9.6(1.1)$ & $9.3(1.2)$ & $9.5(0.9)$ \\
\hline Women & $6.0(0.5)$ & $6.9(1.2)$ & $6.6(1.2)$ & $6.8(1.2)$ & $7.1(1.3)$ & $6.8(1.0)$ \\
\hline Low skeletal muscle index, $\mathrm{n}(\%)$ & $53(100.0)$ & $58(71.6)$ & $12(63.2)$ & $40(70.2)$ & $11(52.4)$ & $166(73.1)$ \\
\hline Poor grip strength, n (\%) & $44(83.0)$ & $43(53.1)$ & $15(78.9)$ & $21(36.8)$ & $16(76.2)$ & $59(26.0)$ \\
\hline Slow gait speed, n (\%) & $27(50.9)$ & $21(25.9)$ & $17(89.5)$ & $13(22.8)$ & $20(95.2)$ & $41(18.1)$ \\
\hline Gait speed, mean m/s (SD) & $0.8(0.2)$ & $0.9(0.2)$ & $0.5(0.2)$ & $0.9(0.2)$ & $0.5(0.2)$ & $1.0(0.3)$ \\
\hline Balance score, mean (SD) & $3.2(1.1)$ & $3.6(0.7)$ & $2.2(1.4)$ & $3.6(0.7)$ & $2.5(1.5)$ & $3.6(0.8)$ \\
\hline Chair stand $5 \mathrm{x}$, mean $\mathrm{s}(\mathrm{SD})^{*}$ & $16.7(6.4)$ & $14.9(5.2)$ & $18.0(5.5)$ & $15.5(5.9)$ & $19.4(5.8)$ & $13.3(4.4)$ \\
\hline SPPB score, mean (SD) & $7.8(2.6)$ & $9.3(1.9)$ & $4.6(2.7)$ & $9.4(1.9)$ & $4.8(2.7)$ & $9.9(2.4)$ \\
\hline GARS score, mean (SD) & $29.4(11.3)$ & $25.0(8.1)$ & $43.5(10.2)$ & $25.4(6.9)$ & $44.3(10.3)$ & $23.4(9.0)$ \\
\hline \multicolumn{7}{|l|}{ Fried criteria, n positive score (\%) } \\
\hline Weight loss & $0(0.0)$ & $4(4.9)$ & $1(5.3)$ & $4(7.0)$ & $1(4.8)$ & $5(2.2)$ \\
\hline Exhaustion & $12(22.6)$ & $20(24.7)$ & $13(68.4)$ & $17(29.8)$ & $10(47.6)$ & $33(14.5)$ \\
\hline Weakness (grip) & $43(81.1)$ & $52(64.2)$ & $18(94.7)$ & $21(36.8)$ & $18(85.7)$ & $70(30.8)$ \\
\hline Slow walking speed & $20(37.7)$ & $15(18.5)$ & $17(89.5)$ & $7(12.3)$ & $19(90.5)$ & $32(14.1)$ \\
\hline Low physical activity & $17(32.1)$ & $16(19.8)$ & $17(89.5)$ & $13(22.8)$ & $13(61.9)$ & $33(14.5)$ \\
\hline \multicolumn{7}{|l|}{ FRAIL scale, n positive score (\%) } \\
\hline Fatigue & $13(24.5)$ & $19(23.5)$ & $11(57.9)$ & $17(29.8)$ & $17(81.0)$ & $34(15.0)$ \\
\hline Resistance & $25(47.2)$ & $22(27.2)$ & $18(94.7)$ & $27(47.4)$ & $21(100.0)$ & $48(21.1)$ \\
\hline Ambulation & $18(34.0)$ & $19(23.5)$ & $16(84.2)$ & $16(28.1)$ & $21(100.0)$ & $37(16.3)$ \\
\hline Illnesses & $1(1.9)$ & $1(1.2)$ & $2(10.5)$ & $0(0.0)$ & $3(14.3)$ & $3(1.3)$ \\
\hline Loss of weight & 7 (13.2) & $9(11.1)$ & $3(15.8)$ & $15(26.3)$ & $4(19.0)$ & $19(8.4)$ \\
\hline
\end{tabular}

Sarcopenia as defined by the EWGSOP: low muscle mass, cut-off point $\leq 10.75 \mathrm{~kg} / \mathrm{m}^{2}$ (in men) and $\leq 6.75 \mathrm{~kg} / \mathrm{m}^{2}$, and low muscle strength (men $<30 \mathrm{~kg}$; women $<20 \mathrm{~kg}$ ) and/or low physical performance (walking speed $<0.8$ $\mathrm{m} / \mathrm{s}$ ). Subjects are considered frail by the Fried criteria when they score 3-5 points; idem for the FRAIL scale.

${ }^{*} n=205$, since not all participants were able to perform the $5 x$ chair stand. 
No official gold standard for physical frailty exists; the Fried criteria were used as comparison instrument because it is widely known, validated, and commonly used. Concurrent validity was rated positive when the correlation was 0.70 or higher. $^{29}$

\subsection{Ethical Considerations}

The Medical Ethics Committee of the Academic Hospital Maastricht and Maastricht University approved the MaSS study.

\section{Results}

Of the 384 people who returned the informed consent form, 282 people were willing to participate, of which 256 participants met the inclusion criteria (Supplementary Data, File 3: flow diagram of inclusion). Of those 256 people, 9 participants dropped out due to illness and 20 people were excluded from the analyses because of the following: prosthesis on both sides that might have influenced muscle mass measurement $(n=9)$, not able to perform the grip strength test $(n=1)$, or not able to perform the MMSE $(n=1)$ or MMSE score less than $24(n=9)$. The other 227 participants had complete data. The total sample included 157 independently living older people, and 70 participants receiving care $(n=28$ home care, $n=13$ assisted living, $n=29$ residential living).

The participants' characteristics are shown in Table 1. Sarcopenia was identified in 53 participants $(23.3 \%)$ and physical frailty in $8.4 \%(n=19)$ and $9.3 \%(n=21)$ according to the Fried criteria and FRAIL scale, respectively. Of the participants, $35.7 \%$ and $25.1 \%$ were pre-frail according to, respectively, the Fried criteria and FRAIL scale. Most of the sarcopenic $(64.1 \%)$ and frail $(84.2 \%$ by Fried and $85.7 \%$ by the FRAIL scale) older people received some form of care services. Both sarcopenic and frail older people have higher GARS scores than people without sarcopenia or frailty, indicating more disability in activities of daily living. For all functional parameters, the frail group seemed to score lower than the pre-frail group and the sarcopenic group.

Table 2 Sarcopenia Versus Frailty

\begin{tabular}{llll}
\hline Variable & Sarcopenic $(n=53)$ & Not Sarcopenic $(n=174)$ & $P_{-v a l u e}$ \\
\hline Fried criteria, $n(\%)$ & & $124(71.3)$ & $<0.001$ \\
0 points (not frail; $n=127)$ & $3(5.7)$ & $43(24.7)$ & \\
1-2 points (pre-frail; $n=81)$ & $38(71.7)$ & $7(4.0)$ & $<0.001$ \\
3-5 points (frail; $n=19)$ & $12(22.6)$ & & \\
FRAIL scale, $n(\%)$ & & $127(73.0)$ & \\
0 points (not frail; $n=149)$ & $22(41.5)$ & $39(22.4)$ & \\
1-2 points (pre-frail; $n=57)$ & $18(34.0)$ & $8(4.6)$ & \\
3-5 points (frail; $n=21)$ & $13(24.5)$ & & \\
\hline
\end{tabular}

Percentages are calculated by dividing the number of (not/pre)frail older people by the number of (not) sarcopenic older people. E.g. sarcopenic participants that are not frail $=3 / 53=5.7 \%$. ${ }^{\star} P$-value Chi-square test: comparison between not sarcopenic and sarcopenic participants.

In frail older people (Fried criteria $\geq 3$ ), the percentage of low SMI was $63.2 \%$, whereas poor grip strength (78.9\%) and slow gait speed $(89.5 \%)$ were even more prevalent. Furthermore, frail older people most often had a positive score on the frailty indicators weakness or resistance and slow walking speed and ambulation, whereas a positive score on weight loss or illnesses was less frequent (Table 1). Sarcopenic and frail older people have significantly (all $\mathrm{P}$ values $<0.05$ ) lower short physical performance battery (SPPB) 
and balance scores, slower gait speed, and a longer chair stand time than their peers who are not sarcopenic or not frail (Table 1).

\subsection{Overlap between Sarcopenia and Physical Frailty}

Of the sarcopenic older participants $(n=53), 3$ participants were not frail $(5.7 \%), 38$ participants were pre-frail $(71.7 \%)$, and 12 participants $(22.6 \%)$ were frail according to the three positive Fried criteria (Table 2). In participants without sarcopenia $(n=174)$, most were not frail $(71.3 \%), 43$ participants were pre-frail $(24.7 \%)$, and 7 participants were frail $(4.0 \%)$. Of the frail older people $(n=19), 12$ participants had sarcopenia, whereas of the non-frail older people $(n=127)$, only three participants had sarcopenia (Table 2). Sarcopenia was associated with the dichotomized score (frail yes/no; $P=0.022$ ) and with the total score $(0-5)$ of the Fried criteria $(P<0.001)$.

Results of the final regression model are shown in Figure 1, revealing that frail older people have a $60 \%$ risk of having sarcopenia. In older people who were not frail, the risk of having sarcopenia increased with age. Additionally, looking at the individual criteria of sarcopenia, $12(7.2 \%)$ of 166 individuals with low muscle mass, $15(25.4 \%)$ of 59 individuals with poor grip strength, and 17 (41.5\%) of 41 individuals with slow gait speed were classified as physically frail.

\subsection{Concurrent Validity of the FRAIL Scale Versus the Fried Criteria}

Thirteen participants were classified as physically frail by both scales, 14 participants were classified as physically frail by one scale but not by the other (Figure 2). The Spearman correlation between the scales using a dichotomized outcome (frail yes/no) was $r=0.617$, $P<0.001$. The correlation between both scales using the total score $(0-5)$, was $r=0.601$, $P<0.001$.

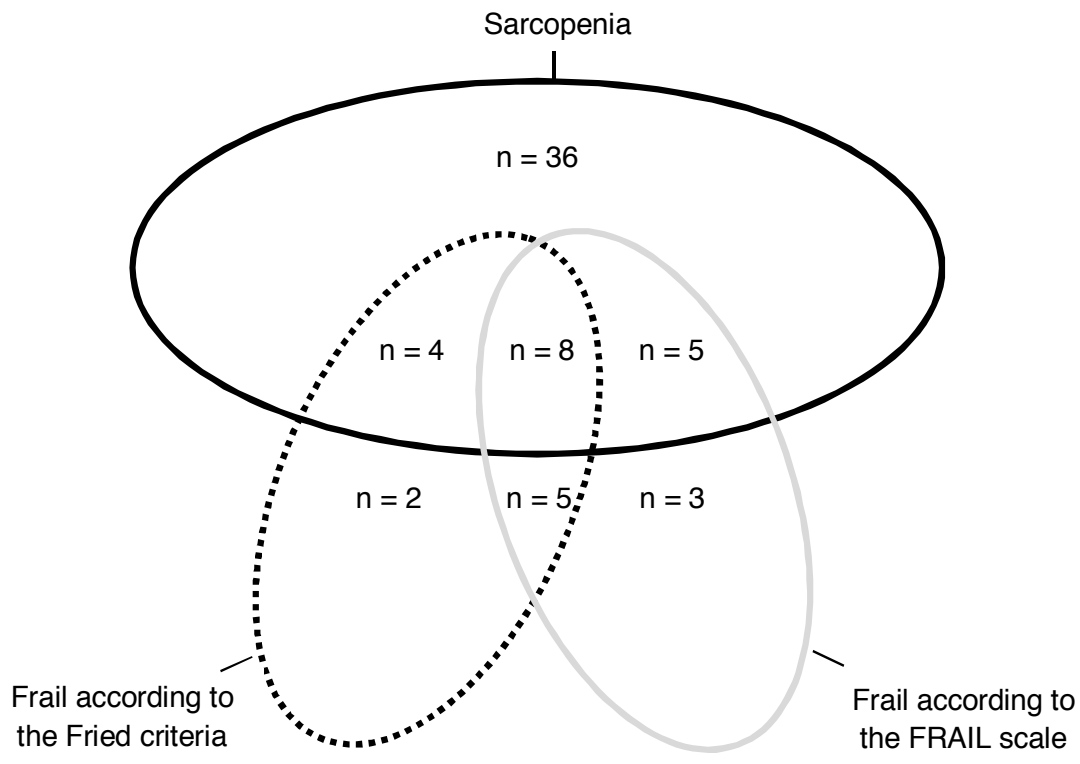

Figure 1 Overlap between sarcopenia (EWGSOP criteria) and frailty 


\section{Discussion}

This study showed that sarcopenia and physical frailty, identified in older people living in different community (care) settings, were significantly associated. Frail older people had a higher risk of having sarcopenia than older people who were not frail. In frail older people, next to the criteria poor grip strength and slow gait speed, which are determinants for both frailty and sarcopenia, poor performance in other functional tests was common. Furthermore, some evidence was found supporting concurrent validity between the FRAIL scale and the Fried criteria. A notable finding is that both scales identified an almost similar number of frail people, but partly different individuals.

Physical frailty and sarcopenia share to some extent the same criteria, such as loss of strength and decreased physical performance. Based on the data from our study, it seems that most sarcopenic individuals are pre-frail or frail, whereas most of the non-sarcopenic individuals are not (pre)-frail. The overlap that we found might be influenced by the measurement method (BIA, cut-off points low SMI) and definition of sarcopenia ${ }^{30-32}$ (e.g., the EWGSOP criteria have different cut-off points for muscle mass and strength compared with the recently published Foundation for the National Institutes of Health criteria, which define sarcopenia based on muscle mass corrected for BMI and poor grip strength). ${ }^{33}$ Using uncorrected cut-off points for SMI could have led to an overestimation of sarcopenia status. On the other hand, the overlap with sarcopenia is larger when pre-frail individuals are also taken into account. Frail older people were more disabled in activities of daily living; however, looking at frail older people without disability was not possible because of the small sample size. Furthermore, the pre-frail group was bigger than the frail group, which should be kept in mind when interpreting the percentage overlap with sarcopenia.

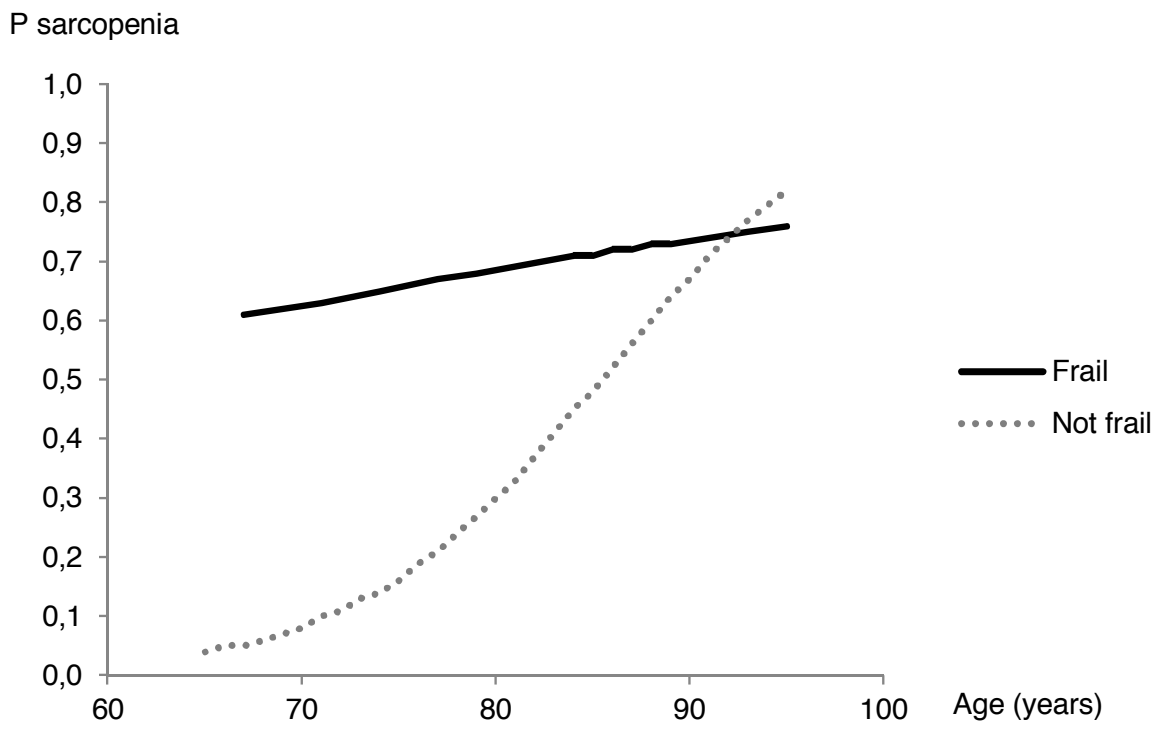

Figure 2 Association of frailty (yes/no) by the Fried criteria in terms of risk is based on the logistic model logit $(p)=-8.68+12.03{ }^{*}$ Fried $+0.16^{\star}$ Age $+0.13^{*}$ Age ${ }^{\star}$ Fried $-0.17^{\star}$ BMl. Sex was not significant and therefore not included in the final model. BMI was set at 27.1 (mean of total sample). 
The concurrent occurrence of frailty and sarcopenia is likely to increase due to the aging population. ${ }^{34}$ Frisoli et $\mathrm{al}^{35}$ found that almost $53 \%$ of the frail older people were also sarcopenic, whereas $42 \%$ of the older people who were not frail had sarcopenia. Our study confirms their results (i.e., frail older people have a higher risk of sarcopenia compared with the older people who were not frail). For the older people who were not frail, the risk of having sarcopenia was age-dependent. This means that frail older people aged 60 to 70 years have a higher risk of sarcopenia of about $60 \%$, compared with a risk of approximately $10 \%$ in people who are not frail. However, at ages 80 to 90 years, the risk of having sarcopenia does not differ between frail and non-frail older people, and is about $60 \%$ in both groups. This might be explained by the fact that, although overlap is found between the concepts of sarcopenia and frailty, the concepts are not equivalent (e.g., at older ages muscle loss might become more severe, leading to a diagnosis of sarcopenia in older people who are not frail). Looking at the individual criteria of sarcopenia and frailty, it seems that especially parameters of physical function, such as poor strength and slow gait speed, overlap. Recent studies ${ }^{36,37}$ show that grip strength and gait speed might be promising measures for those who want to use sarcopenia as a paradigm for frailty. Our results show that poor grip strength and slow gait speed are highly prevalent in frail older people. Screening for sarcopenia might therewith also identify a considerable number of people with (a risk of) frailty. Moreover, both sarcopenic and frail groups have low SPPB, balance, and chair stand scores.

In our study, we found a low number of frail older people with weight loss. Other studies found slightly higher percentages of weight loss, namely $8.5 \%{ }^{38}$ and $9.3 \%$ in men, and $17.2 \%$ in women, ${ }^{39}$ whereas Subra et $\mathrm{al}^{37}$ and Tavassoli et $\mathrm{al}^{40}$ found much higher rates of weight loss (24.4\%-32.9\%) in patients screened for frailty by their general practitioner. This might be explained by other characteristics of their study population, such as a higher mean age, a larger number of people receiving care (household support; $66 \%$ ) and inclusion of people with low MMSE scores. Also, the methodology for determining weight loss (i.e., by actually measuring or via a questionnaire), as well as the time period for such weight loss (e.g., several months up to 1 year) might lead to variation.

The physical frailty scales used in this study were both previously validated, ${ }^{14,15,23,41,42}$ and found to be feasible to assess physical frailty in community-dwelling older people in different care settings. Although both scales identified almost the same number of physically frail older people, partly different individuals were identified, as also is indicated by a moderate correlation between the scales. The reason for this might be because only the FRAIL scale includes a question about illnesses, whereas only the Fried criteria include a physical activity criterion. Another reason could be that the FRAIL scale consists only of questions, whereas the Fried criteria also include performance-based measures. When responding to questions, older people might over- or underestimate their own abilities. Furthermore, the absence of a gold standard impedes evidence-based statements over what frailty is exactly and what its consequences are; this hampers the comparison of studies using different tools. In a recent study by Rodríguez-Mañas et al, ${ }^{2}$ several experts tried to reach consensus regarding a frailty definition. They reached agreement on the main dimensions of frailty (physical performance, including gait speed and mobility, nutritional status, mental health, cognition), but not yet on its operational definition. Cooper et $\mathrm{al}^{43}$ state that evidence-based knowledge on assessment techniques for sarcopenia and frailty is missing (e.g., no accepted end points for intervention trials targeting at sarcopenia 
and frailty exist). Operational definitions for frailty seem to focus on the consequences of sarcopenia. ${ }^{44}$ Cesari et $\mathrm{al}^{45}$ proposed that the assessment of sarcopenia and frailty should be refined by putting more focus on physical function impairment, as a precursor of disability. Recently, Cruz Jentoft and Michel ${ }^{11}$ suggested that diagnostic criteria for sarcopenia may be used to measure physical frailty in research and practice, as sarcopenia might be easier to operationalize than physical frailty for clinical prevention, diagnosis, and treatment. This seems logical, as many of the adverse outcomes of frailty are probably mediated by sarcopenia. ${ }^{11}$ Recently, several experts reached consensus over the importance of screening all older people for frailty when visiting a health care provider. ${ }^{46,47}$ In the Netherlands, this idea is currently being reconsidered due to the substantial number of false positives that are detected. ${ }^{48}$ It should be recognized that at present we lack intervention studies demonstrating that interventions for frailty improve health outcomes. ${ }^{6}$ Adding sarcopenia-related measures to frailty screening, or focusing on physical function ${ }^{45}$ might enhance the identification of the number of people at high risk of negative adverse outcomes. There is a reasonable amount of data suggesting that exercise and/or protein supplementation enhances physical function and, therefore, might prevent disability in people with sarcopenia. ${ }^{45,49,50}$

Preventing sarcopenia and frailty seems most beneficial in community settings in which people do not receive care yet. Screening seems most important in settings in which people receive care, like home care, assisted living facilities, and residential living facilities, as our results indicate that in those settings the prevalence of sarcopenia and frailty seems highest. Screening might be extended to acute care settings, nursing homes, and hospitals, because in those settings sarcopenia was identified in at least 1 of 3 patients. ${ }^{51-53}$

Some limitations of this study should be addressed. Because of the cross-sectional nature of this study, no firm conclusions with regard to cause and consequences can be drawn. The overlap found between sarcopenia and frailty is related to the chosen definitions and cut-off points for sarcopenia and frailty. Bioelectrical impedance was used to assess muscle mass, which is not a gold standard and might have led to an over- or underrepresentation of people with low muscle mass. Also, 15\% responded to the invitation to participate. No information was collected about the group not willing to participate, because they did not have to send back the informed consent form. Therefore, a healthier group might have been included because people in better physical condition might be more inclined to participate compared with people with a poorer physical condition. As the sample of frail older people is rather small, the corresponding percentages should be interpreted with caution. The correlation found between the two frailty scales is a lower bound, because the underlying (true) correlation is attenuated because these measurement instruments are not perfectly measuring the latent trait physical frailty. In other words, the Fried criteria are not officially a "gold" standard. No correction for this attenuation could be made because no data are available about the reliability of the Fried criteria. ${ }^{54}$

In conclusion, sarcopenia and physical frailty were associated and partly overlap, especially on parameters of impaired physical function. Some evidence for concurrent validity between the FRAIL scale and Fried criteria was found. Future research should elicit the value of combining sarcopenia and frailty measures in preventing disability and other negative health outcomes. 


\section{Acknowledgments}

We greatly appreciate the time, efforts and enthusiasm of the participants in this study. We thank Elles Lenaerts for her tremendous help with the data collection. Furthermore, we express our gratitude to the municipalities of Maastricht for their support with the recruitment of participants. 


\section{References}

1. Gobbens RJ, Luijkx KG, Wijnen-Sponselee MT, Schols JM. In search of an integral conceptual definition of frailty: opinions of experts. J Am Med Dir Assoc 2010;11:338-343.

2. Rodríguez-Mañas L, Feart C, Mann G, et al. Searching for an operational definition of frailty: a Delphi method based consensus statement: the frailty operative definition-consensus conference project. J Gerontol A-Biol 2013;68:62-67.

3. Fielding RA, Vellas B, Evans WJ, et al. Sarcopenia: an undiagnosed condition in older adults: current consensus definition: prevalence, etiology, and consequences. International working group on sarcopenia. J Am Med Dir Assoc 2011;12:249-256.

4. Collard RM, Boter H, Schoevers RA, Oude Voshaar RC. Prevalence of frailty in community-dwelling older persons: a systematic review. J Am Geriatr Soc 2012;60:1487-1492.

5. Cruz-Jentoft AJ, Baeyens JP, Bauer JM, et al. Sarcopenia: European consensus on definition and diagnosis: report of the European Working Group on Sarcopenia in Older People. Age Ageing 2010;39:412-423.

6. Morley JE, Vellas B, Abellan van Kan G, et al. Frailty consensus: a call to action. J Am Med Dir Assoc 2013;14:392-397.

7. Gobbens RJ, van Assen MA. Frailty and its prediction of disability and health care utilization: the added value of interviews and physical measures following a self-report questionnaire. Arch Gerontol Geriat 2012;55:369-379.

8. Boirie Y. Fighting sarcopenia in older frail subjects: protein fuel for strength, exercise for mass [letter]. J Am Med Dir Assoc 2013;14:140-143.

9. Clegg A, Young J, lliffe S, et al. Frailty in elderly people. Lancet 2013;381:752-762.

10. Evans WJ, Paolisso G, Abbatecola AM, et al. Frailty and muscle metabolism dysregulation in the elderly. Biogerontology 2010;11:527-536.

11. Cruz-Jentoft AJ, Michel JP. Sarcopenia: a useful paradigm for physical frailty. Eur Geriatr Med 2013;4:102105.

12. Viana JU, Silva SL, Torres JL, et al. Influence of sarcopenia and functionality indicators on the frailty profile of community-dwelling elderly subjects: a cross-sectional study. Braz J Phys Ther 2013;17:373-381.

13. Cesari M, Gambassi G, Abellan van Kan G, Vellas B. The frailty phenotype and the frailty index: different instruments for different purposes. Age Ageing 2014;43:10-12.

14. Fried LP, Tangen CM, Walston J, et al. Frailty in older adults: evidence for a phenotype. J Gerontol A-Biol 2001;56:M146-156.

15. Morley JE, Malmstrom TK, Miller DK. A simple frailty questionnaire (FRAIL) predicts outcomes in middle aged African Americans. J Nutr Health Aging 2012;16:601-608.

16. Fried LP, Ferrucci L, Darer J, et al. Untangling the concepts of disability, frailty, and comorbidity: implications for improved targeting and care. J Gerontol A-Biol 2004;59:255-263.

17. Rockwood K, Andrew M, Mitnitski A. A comparison of two approaches to measuring frailty in elderly people. J Gerontol A-Biol 2007;62:738-743.

18. Kyle UG, Bosaeus I, De Lorenzo AD, et al. Bioelectrical impedance analysis: Part II: Utilization in clinical practice. Clin Nutr 2004;23:1430-1453.

19. Janssen I, Heymsfield SB, Baumgartner RN, Ross R. Estimation of skeletal muscle mass by bioelectrical impedance analysis. J Appl Physiol 2000;89:465-471.

20. Mijnarends D, Meijers J, Halfens R, et al. Rationale and design of a cross-sectional study of the prevalence, characterization and health and economic consequences of sarcopenia in community-dwelling older people in the Netherlands [abstract]. J Nutr Health Aging 2013;17:S245.

21. Mijnarends DM, Meijers JMM, Halfens RJG, et al. Validity and reliability of tools to measure muscle mass, strength, and physical performance in community-dwelling older people: a systematic review. J Am Med Dir Assoc 2013;14:170-178.

22. Janssen I, Baumgartner RN, Ross R, et al. Skeletal muscle cutpoints associated with elevated physical disability risk in older men and women. Am J Epidemiol 2004;159:413-421.

23. Guralnik JM, Simonsick EM, Ferruci L, et al. A short physical performance battery assessing lower extremity function: assocation with self-reported disability and prediction of mortality and nursing home admission. $J$ Gerontol Med Sci 1994;49:M85-M94.

24. Lopez D, Flicker L, Dobson A. Validation of the frail scale in a cohort of older Australian women. J Am Geriatr Soc 2012;60:171-173.

25. Richardson MT, Leon AS, Jacobs Jr. DR, et al. Comprehensive evaluation of the Minnesota Leisure Time Physical Activity Questionnaire. J Clin Epidemiol 1994;47:271-281. 
26. Charlson ME, Pompei P, Ales KL, MacKenzie CR. A new method of classifying prognostic comorbidity in longitudinal studies: development and validation. J Chron Dis 1987;40:373-383.

27. Kok RM, Verhey FRJ. Gestandaardiseerde MMSE (Dutch translation of the Mini Mental State Examination). 2002.

28. Kempen GIJM, Miedema I, Ormel J, Molenaar W. The assessment of disability with the Groningen Activity Restriction Scale: conceptual framework and psychometric properties. Soc Sci Med 1996;43:1601-1610.

29. Terwee CB, Bot SD, De Boer MR, et al. Quality criteria were proposed for measurement properties of health status questionnaires. J Clin Epidemiol 2007;60:34-42.

30. Landi F, Martone AM, Calvani R, Marzetti E. Sarcopenia risk screening tool: a new strategy for clinical practice. J Am Med Dir Assoc 2014;15:613-614.

31. Michel JP. Sarcopenia: there is a need for some steps forward. J Am Med Dir Assoc 2014;15:379-380.

32. Woo J, Leung J, Morley JE. Validating the SARC-F: a suitable community screening tool for sarcopenia? $\mathrm{J}$ Am Med Dir Assoc 2014;15:630-634.

33. Studenski SA, Peters KW, Alley DE, Cawthon PM, McLean RR, Harris TB, et al. The FNIH sarcopenia project: rationale, study description, conference recommendations, and final estimates. J Gerontol A: Biol 2014;69:547-558.

34. Litchford MD. Counteracting the trajectory of frailty and sarcopenia in older adults. Nutr Clin Pract 2014;29:428-434.

35. Frisoli Jr. A, Chaves PH, Ingham SJ, Fried LP. Severe osteopenia and osteoporosis, sarcopenia, and frailty status in community-dwelling older women: results from the Women's Health and Aging Study (WHAS) II. Bone. 2011;48:952-957.

36. Auyeung TW, Lee JS, Leung J, Kwok T, Woo J. The selection of a screening test for frailty identification in community-dwelling older adults. J Nutr Health Aging 2014;18:199-203.

37. Subra J, Gillette-Guyonnet S, Cesari M, et al. The integration of frailty into clinical practice: preliminary results from the Gerontopole. J Nutr Health Aging 2012;16:714-720.

38. Garcia-Garcia FJ, Gutierrez Avila G, Alfaro-Acha A, et al. The prevalence of frailty syndrome in an older population from Spain: the Toledo Study for Healthy Aging. J Nutr Health Aging 2011;15:852-856.

39. Ávila-Funes JA, Helmer C, Amieva $\mathrm{H}$, et al. Frailty among community-dwelling elderly people in France: the three-city study. J Gerontol A-Biol 2008;63:1089-1096.

40. Tavassoli N, Guyonnet S, Abellan Van Kan G, et al. Description of 1,108 older patients referred by their physician to the "Geriatric Frailty Clinic (G.F.C) for Assessment of Frailty and Prevention of Disability" at the gerontopole. J Nutr Health Aging 2014;18:457-464.

41. Ravindrarajah $\mathrm{R}$, Lee $\mathrm{DM}$, Pye $\mathrm{SR}$, et al. The ability of three different models of frailty to predict all-cause mortality: results from the European Male Aging Study (EMAS). Arch Gerontol Geriat. 2013;57:360-368.

42. Woo J, Leung J, Morley JE. Comparison of frailty indicators based on clinical phenotype and the multiple deficit approach in predicting mortality and physical limitation. J Am Geriatr Soc 2012;60:1478-1486

43. Cooper C, Dere W, Evans W, et al. Frailty and sarcopenia: definitions and outcome parameters. Osteoporosis Int 2012;23:1839-1848.

44. Gielen E, Verschueren S, O'Neill TW, et al. Musculoskeletal frailty: a geriatric syndrome at the core of fracture occurrence in older age. Calcified Tissue Int 2012;91:161-177.

45. Cesari M, Landi F, Vellas B, Bernabei R, Marzetti E. Sarcopenia and physical frailty: two sides of the same coin. Front Aging Neurosci 2014;6:192.

46. Morley JE, Von Haehling S, Anker SD, Vellas B. From sarcopenia to frailty: a road less traveled. J Cachexia Sarcopenia Muscle 2014;5:5-8.

47. Vellas B, Cestac P, Morley JE. Implementing frailty into clinical practice: we cannot wait. J Nutr Health Aging 2012;16:599-600.

48. Pijpers E, Ferreira I, Stehouwer CD, et al. The frailty dilemma: review of the predictive accuracy of major frailty scores. Eur J Intern Med 2012;23:118-123.

49. Bauer J, Biolo G, Cederholm T, et al. Evidence-based recommendations for optimal dietary protein intake in older people: a position paper from the PROT-AGE Study Group. J Am Med Dir Assoc 2013;14:542-559.

50. Cadore EL, Izquierdo M. New strategies for the concurrent strength-, power-, and endurance-training prescription in elderly individuals. J Am Med Dir Assoc 2013;14:623-624.

51. Landi F, Cruz-Jentoft AJ, Liperoti R, Russo A, Giovannini S, Tosato M, et al. Sarcopenia and mortality risk in frail older persons aged 80 years and older: results from ilSIRENTE study. Age Ageing 2013;42:203-209.

52. Rossi AP, Fantin F, Micciolo R, Bertocchi M, Bertassello P, Zanandrea V, et al. Identifying sarcopenia in acute care setting patients. J Am Med Dir Assoc 2014;15:303.e307-e312.

53. Smoliner C, Sieber CC, Wirth R. Prevalence of sarcopenia in geriatric hospitalized patients. J Am Med Dir Assoc 2014;15:267-272. 
54. De Vries NM, Staal JB, Van Ravensberg CD, et al. Outcome instruments to measure frailty: a systematic review. Ageing Res Rev 2011;10:104-114. 


\section{Supplementary Data Chapter 4 - File 1}

Supplementary Table 1 Concepts of Physical Frailty and Sarcopenia

\begin{tabular}{llll}
\hline Criteria & Sarcopenia $^{5}$ & Fried Criteria $^{14}$ & FRAIL Scale $^{15}$ \\
\hline Muscle mass & Physical examination & No & No \\
Muscle strength/weakness/resistance & Physical examination & Physical examination & Questionnaire \\
Physical performance (e.g. walk test) & Physical examination & Physical examination & Questionnaire \\
Physical activity level & No $^{*}$ & Questionnaire & No \\
Weight loss & No $^{*}$ & Question or physical Questionnaire \\
Self-reported exhaustion & No & examination & No \\
Fatigue & No & Questionnaire & Questionnaire \\
Illnesses & $N^{\star}$ & No & Questionnaire \\
\hline
\end{tabular}

${ }^{\star}$ Those factors are not included in sarcopenia assessment but are involved in the onset and progression of sarcopenia. $^{5}$ 


\section{Supplementary Data Chapter 4 - File 2}

\section{Cut-off Points for Grip Strength and Walking Speed}

Cut-off points for grip strength criterion for frailty, stratified by gender and body mass index according to Fried et al. ${ }^{14}$

Low grip strength if:

Males

$$
\begin{array}{ll}
\mathrm{BMI} \leq 24 \mathrm{~kg} / \mathrm{m}^{2} & \text { and grip strength } \leq 29 \mathrm{~kg} \\
\mathrm{BMI} \leq 24.1-26 \mathrm{~kg} / \mathrm{m}^{2} & \text { and grip strength } \leq 30 \mathrm{~kg} \\
\mathrm{BMI} \leq 26.1-28 \mathrm{~kg} / \mathrm{m}^{2} & \text { and grip strength } \leq 30 \mathrm{~kg} \\
\mathrm{BMI}>28 \mathrm{~kg} / \mathrm{m}^{2} & \text { and grip strength } \leq 32 \mathrm{~kg}
\end{array}
$$

\section{Females}

$$
\begin{aligned}
& \mathrm{BMl} \leq 23 \mathrm{~kg} / \mathrm{m}^{2} \quad \text { and grip strength } \leq 17 \mathrm{~kg} \\
& \mathrm{BMI} \leq 23.1-26 \mathrm{~kg} / \mathrm{m}^{2} \text { and grip strength } \leq 17.3 \mathrm{~kg} \\
& \mathrm{BMI} \leq 26.1-29 \mathrm{~kg} / \mathrm{m}^{2} \text { and grip strength } \leq 18 \mathrm{~kg} \\
& \mathrm{BMI}>29 \mathrm{~kg} / \mathrm{m}^{2} \quad \text { and grip strength } \leq 21 \mathrm{~kg}
\end{aligned}
$$

Cut-off points for walking speed, stratified by gender and height according to Fried et al. ${ }^{14}$

\section{Slow walking speed if:}

Males

Height $\leq 173 \mathrm{~cm}$ and walking speed $\leq 0.65 \mathrm{~m} / \mathrm{s}$

Height $>173 \mathrm{~cm}$ and walking speed $\leq 0.76 \mathrm{~m} / \mathrm{s}$

\section{Females}

Height $\leq 159 \mathrm{~cm}$ and walking speed $\leq 0.65 \mathrm{~m} / \mathrm{s}$

Height $>159 \mathrm{~cm}$ and walking speed $\leq 0.76 \mathrm{~m} / \mathrm{s}$ 


\section{Supplementary Data Chapter 4 - File 3}

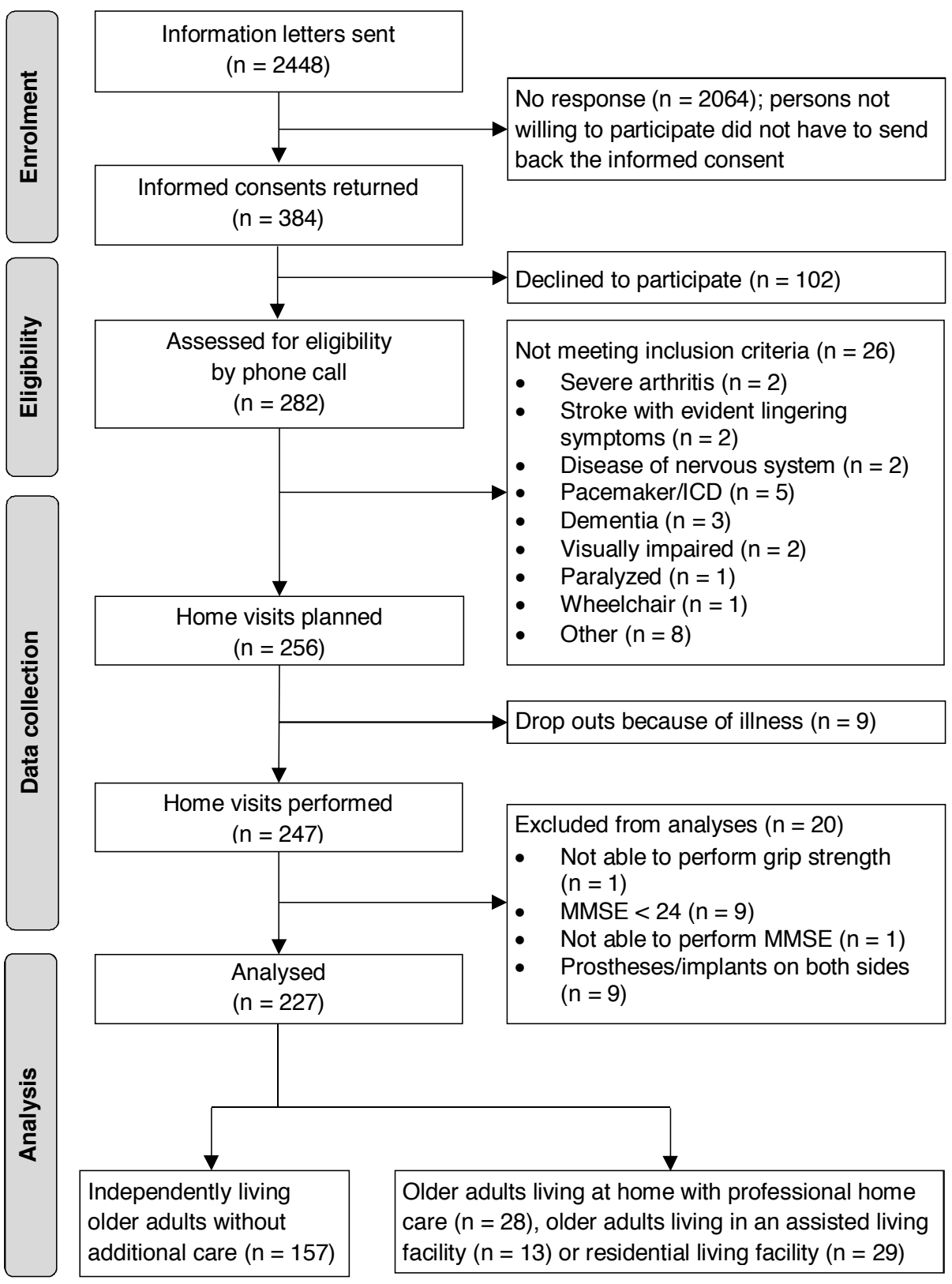

Supplementary Figure 1 Adapted CONSORT flow diagram of inclusion 


CHAPTER 5

\section{Burden-Of-IIIness of Dutch Community-Dwelling Older Adults with Sarcopenia: Health Related Outcomes and Costs}

Published as: DM Mijnarends, JMGA Schols, RJG Halfens, JMM Meijers, YC Luiking, S Verlaan, SMAA Evers. Eur Geriatr Med 2016; [Epub ahead of print] http://dx.doi.org/10.1016/j.eurger.2015.12.011. 


\section{ABSTRACT}

Objective: To explore the burden-of-illness of Dutch community-dwelling older adults with sarcopenia, in terms of disability in activities of daily living (ADL), quality of life (QoL) and costs from a societal perspective.

Methods: The Maastricht Sarcopenia Study (MaSS) was performed in adults $\geq 65 \mathrm{y}$ receiving 1) no care, 2) home care/assisted living facility, or 3) care in a residential living facility. Sarcopenia was defined according to the European Working Group on Sarcopenia algorithm. Disability in ADL was measured with the Groningen Activity Restriction Scale (GARS); QoL with the EQ-5D-5L. Subjects were questioned about their health care use and health-related costs (societal perspective). Data are presented for sarcopenic and (age and sex matched) non-sarcopenic subjects. Bootstrapping was performed to estimate $95 \% \mathrm{Cl}$ around the mean costs. Several subgroup (age, sex, living situation, comorbidities) and sensitivity analyses were performed.

Results: Sarcopenic subjects $(n=53)$ scored significantly worse on health-related outcomes compared with non-sarcopenic subjects ( $n=174$; GARS $29 \pm 11.3$ vs. $22 \pm 7.3$, $P$ $<0.001$, QoL $0.78 \pm 0.2$ vs. $0.86 \pm 0.2, P=0.001$ ). This difference was, except for the subscale ADL, no longer significant when compared with age and sex matched nonsarcopenic subjects (GARS $27 \pm 10.6, P=0.097$, QoL $0.81 \pm 0.2, P=0.362$ ). Mean health care costs of sarcopenic subjects $(€ 4325,95 \% \mathrm{Cl}: € 3198-€ 5471)$ were significantly higher than those of non-sarcopenics (€1533, 95\% Cl: $€ 1153-€ 1912)$, and higher, i.e. $€ 1557$ per three months (though not significant) compared with age and sex matched nonsarcopenics (€2768, 95\% Cl: €1914-€3743). Living situation (residential care) was a main driver of costs.

Conclusions: Community-dwelling sarcopenic older adults had a higher health and economic burden than non-sarcopenic older adults. This was importantly driven by the living situation - keeping older adults independent and out of care-dependent settings may contribute to a reduction of health care costs. 


\section{Introduction}

Sarcopenia, the loss of muscle mass and function, is associated with poor health outcomes, such as a lower quality of life (QoL) and an increased risk of disability in activities of daily living (ADL), institutionalization and mortality. ${ }^{1-5} \ln 2010$, the European Working Group on Sarcopenia in Older People (EWGSOP) suggested an algorithm to identify sarcopenia, based on low muscle mass in combination with poor strength or performance. ${ }^{6}$ Using this algorithm, about $1-29 \%$ of the community-dwelling older adults and $14-33 \%$ of older adults living in a long-term care institution have sarcopenia. ${ }^{7}$

In addition to being associated with negative health outcomes, sarcopenia could lead to a potential economic burden due to the related costs of disability, falls, institutionalization and comorbidities. ${ }^{8,9}$ Despite the fact that knowing the costs of a disease is important for policy makers, ${ }^{10,11}$ only one study was found estimating the costs of sarcopenia in non-institutionalized adults aged $\geq 60 \mathrm{y} .{ }^{8}$ This study defined sarcopenia as low muscle mass, and found that sarcopenia alone accounted for about $1.5 \%(\$ 18.5$ billions) of the direct total health care expenditures in the United States. ${ }^{8}$ This equals about an extra $\$ 900$ (about $€ 677$ ) per (sarcopenic) person per year. In that study, costs were indirectly calculated, using relative risk estimates of sarcopenia-related physical disability, previously reported costs of disability (from two national surveys conducted in 1980-1995) and previously reported prevalence rates of sarcopenia. ${ }^{8,} 12$ They did not compare sarcopenic with (matched) non-sarcopenic older adults, and to the best of our knowledge there are no studies that have measured actual health care costs in sarcopenic older adults in a European setting.

With an ageing population and the current pressure on health care systems and government budgets, it is relevant to get insight in the burden of sarcopenia in terms of health-related outcomes and costs. Early identification and management of sarcopenia (by e.g. resistance exercise combined with nutritional supplementation ${ }^{13}$ ) could reduce the impact of sarcopenia on both the individual (health related outcomes) as well as the society (costs of health care). Evidence for a substantial burden of disease strengthens the need for interventions and may support policy decisions with regard to prevention, diagnosis and treatment. ${ }^{10,11}$

The overall aim of this paper is to explore the burden-of-illness of Dutch communitydwelling older adults with sarcopenia, in terms of disability in ADL, quality of life, and costs, from a societal perspective. Older adults with sarcopenia were identified using the EWGSOP algorithm. ${ }^{6}$

\section{Methods}

This manuscript follows the Consolidated Health Economic Evaluation Reporting Standards (CHEERS) and the Dutch guideline for costing research. ${ }^{14,15}$

\subsection{Target Population and Subgroups}

The Maastricht Sarcopenia Study (MaSS) was performed in community-dwelling adults aged $\geq 65$ years. Community-dwelling older adults were included when they were living:

- Independently at home without additional care;

- At home or in an assisted living facility with professional home care;

- In a residential living facility. 
In group 3 meal service, household and personal support were included as standard care, contrary to nursing homes where medical and paramedical care are also offered. ${ }^{16}$ The base case sample existed of all subjects with complete data. Subgroups were made for age (65-80 years/80+ years), sex (male/female), living situation (no care/home care \& assisted living/residential living) and number of comorbidities (no comorbidities/1-3 comorbidities/3+ comorbidities), as these variables were expected to influence the costs. Subjects with oedema were included in the base case, although oedema might influence the measurement of muscle mass. As the reliability of the answers on the questionnaires might be affected in people with poor cognitive function, these subjects were excluded in the base case. To assess the impact of including subjects with oedema and excluding subjects with low cognitive function, these subjects were included and excluded, respectively, in the sensitivity analyses. Furthermore, as some other researchers use low muscle mass as sole criterion for sarcopenia, we also explored the costs of subjects with low versus normal muscle mass.

\subsection{Study Perspective and Time Horizon}

A societal perspective was chosen, meaning that all health-related costs for society were included, no matter who paid for it. ${ }^{17}$ In this study, a time horizon of three months was chosen. To prevent recall bias, the measurement period is ideally no longer than three months, although patients might remember specific forms of health care for a longer period. ${ }^{14}$ To further improve the completeness of the data, subjects were asked to check their agenda or calendar for appointments with a health care provider in the previous three months.

\subsection{Sarcopenia Measures}

Sarcopenia was assessed according to the algorithm of the European Working Group on Sarcopenia in Older People (EWGSOP). ${ }^{6}$ Muscle mass was assessed by bioelectrical impedance analysis (BIA Akern Srl, Florence, Italy 101, $50 \mathrm{kHz}$ ), muscle strength by a JAMAR handheld dynamometer (Sammons Preston, Inc, Warrenville, IL) and physical performance by normal gait speed over four meters, as described in a previous paper. ${ }^{18}$ These measures were found to be valid and feasible for identifying sarcopenia in a homesetting. ${ }^{19}$ Cut-off points for low skeletal muscle index (SMI) were $\leq 10.75 \mathrm{~kg} / \mathrm{m}^{2}$ (in men) and $\leq 6.75 \mathrm{~kg} / \mathrm{m}^{2}$ (in women), reflecting those with moderate and severely low SMI. Cut-off points for poor grip strength were $<30 \mathrm{~kg}$ for men, $<20 \mathrm{~kg}$ for women, and for performance low gait speed $\leq 0.8 \mathrm{~m} / \mathrm{s}$, as derived from the EWGSOP. ${ }^{6}$ Subjects were classified as sarcopenic when they had low muscle mass in combination with poor grip strength and/or low physical performance. ${ }^{6}$

\subsection{Health Outcomes Measures}

Disability in ADL was measured by the validated Groningen Activity Restriction Scale (GARS). ${ }^{20}$ This questionnaire consists of 11 questions about ADL and 7 questions about instrumental ADL, such as being able to do grocery shopping or prepare a meal. ${ }^{20}$ Answer categories range from "fully independent without any difficulty" (score 1) to "fully dependent" (score 4). This leads to a total score between 18 and 72, with higher scores indicating more disability in ADL. ${ }^{20}$ 
QoL was assessed by the generic, validated EQ-5D-5L questionnaire. ${ }^{21,}{ }^{22}$ The EQ-5D-5L questionnaire consists of 5 questions corresponding to the dimensions mobility, self-care, usual activities, pain/discomfort and anxiety. ${ }^{23}$ The dimension scores $(1=$ no problems at all to 5 = extreme problems) are combined into a health state score (e.g. 11111 for a patient that has no problems at all on any of the five dimensions) and subsequently converted into an index value between $0-1$ using a country specific value set. ${ }^{23,24}$ Furthermore, the EQ-5D-5L includes a single question about self-rated overall health, with scores ranging from 0 (worst imaginable health state) to 100 (best imaginable health state). ${ }^{21,23,25}$

\subsection{Economic Outcome Measure}

Health care utilization was assessed bottom-up, by asking subjects about their health care use in the past three months (18 questions). The questionnaire was developed for the purpose of this study, taking into consideration the steps in developing a cost questionnaire stated by Thorn et al., ${ }^{26}$ and was tested for feasibility in a pilot study. ${ }^{27}$ Questions were asked regarding costs within the health care sector (e.g. visits to a general practitioner, hospital, paramedical staff, psychological support) and costs for the patient/family (e.g. medication, travelling costs to health facility, purchase of medical aids, in-house adjustments, use of foodservice and nutritional supplements, unpaid support by family or friends), Supplementary Data, Table 1. A societal perspective also takes into account costs of productivity losses, but this was not applicable here, since this study only included older adults who had passed the retirement age of 65 years.

\subsubsection{Estimating Costs}

The Dutch costing guideline was used for methodological standardization and to obtain cost prices of health care utilization. ${ }^{14}$ Costs of medication were retrieved from the Drug Information System of the National Health Care Institute (http://www.medicijnkosten.nl) and the website of the Dutch Healthcare Authority (http://www.nza.nl). Delivery costs for the medication (assuming that medication is prescribed at least once per three months) were included in the total costs of medication, as recommended by the Dutch costing guideline. ${ }^{14}$ In case the manufacturer of medication was unknown, the lowest price for that specific medicine was taken. Market prices were used to estimate costs of vitamin supplements. Costs of external food service and in-house adjustments were based on selfreport by the participant. Travel costs were based on the mean distance to a health care provider and mean transportation costs per $\mathrm{km}$, as stated in the Dutch costing guideline. ${ }^{14}$

\subsubsection{Currency, Price Date and Conversion}

Unit prices are shown in euros. The year 2014 (end of the data collection) was taken as reference year. All unit prices were converted to 2014 using price index data from Statistics Netherlands. ${ }^{28}$ Total costs of health care use (Supplementary Data, Table 3) were obtained by multiplying the volumes of health care use (Supplementary Data, Table 1) by the corresponding unit prices (Supplementary Data, Table 2).

\subsection{Recruitment and Data Collection}

Enrolment took place from May 2013 until February 2014. The municipality of Maastricht randomly selected 2448 addresses of adults older than 65 years, who were invited to 
participate. Inclusion criteria encompassed: given written informed consent, able to understand the Dutch language, not wheelchair bound or bedridden. Subjects with an implantable cardiac defibrillator/pacemaker were excluded since the measurement of muscle mass by bioelectrical impedance forms a potential hazard in these conditions. ${ }^{29}$ Subjects with severe heart, joint or nervous system diseases or dementia were excluded, due to reasons of safety, burden and ethical accountability. Data of subjects who met the inclusion criteria $(n=256)$ were collected by two trained researchers during a two-hour home visit. All questionnaires were administered face-to-face. In addition to the sarcopenia, health and economic measures described above, data collection included assessment of height, weight, cognitive function, ${ }^{30}$ and chronic diseases, ${ }^{31}$ as described previously. $^{18}$

\subsection{Statistical Methods}

Data was analysed using SPSS version 22 (SPSS Inc, Chicago, IL). Disability in ADL, QoL and cost data are presented for sarcopenic and (age and sex matched) non-sarcopenic subjects. A manually, randomly selected age and sex matched non-sarcopenic group was created, as health care utilization is age and sex dependent, and these two factors are unchangeable. $^{32}$ Differences between sarcopenic and (age and sex matched) nonsarcopenic subjects regarding age, sex, BMI, cognitive function, QoL and disability in ADL were assessed by Student's t-test (continuous variables), Chi-square (categorical variables) or Mann-Whitney $U$ tests (non-normally distributed continuous variables). Even though the cost data turned out to be skewed, arithmetic means are presented, being generally the preferred way of reporting cost differences. ${ }^{33}$ Non-parametric bootstrapping with 1000 replications was performed to estimate $95 \%$ confidence intervals $(\mathrm{Cl})$ around the mean costs and to assess significant differences in costs between sarcopenic and nonsarcopenic subjects and between subgroups. Data are presented as means \pm SD or means with $95 \% \mathrm{Cl}$. A P value of $<0.05$ was considered significant.

\section{Results}

Of the 256 older adults who agreed to participate in the MaSS study and met the inclusion criteria, 9 subjects dropped out due to illness and 20 subjects were excluded from the analyses because of missing data for grip strength $(n=1)$ or cognitive function $(n=1)$, poor cognitive function $(n=8)$, invalid muscle mass measurement $(n=9)$ or both $(n=1)$. Therefore, the total analytical sample was 227.

\subsection{Characteristics of the Study Population}

Characteristics of subjects are shown in Table 1. Mean age of the subjects was $74.9 \pm 7.2 y$. The prevalence of sarcopenia was $12.1 \%$ in community-dwelling, $41.5 \%$ in home care/assisted living, and $58.6 \%$ in residential living subjects. Sarcopenic subjects $(n=53)$ were significantly older, had more comorbidities and were more often living in a residential living facility compared with non-sarcopenic subjects $(n=174$; Table 1$)$. When comparing sarcopenic with age and sex matched non-sarcopenic subjects $(n=53)$, only BMI differed significantly $(P=0.001)$. 
Table 1 Characteristics of the Study Sample

\begin{tabular}{llll}
\hline Variable & $\begin{array}{l}\text { Sarcopenic } \\
(\mathrm{n}=53)\end{array}$ & $\begin{array}{l}\text { Non-Sarcopenic, } \\
\text { Age and Sex Matched } \\
(\mathrm{n}=53)\end{array}$ & $\begin{array}{l}\text { Non-Sarcopenic } \\
(\mathrm{n}=174)\end{array}$ \\
\hline $\begin{array}{l}\text { Age in years, mean (SD) } \\
\text { Sex, } \mathrm{n} \text { female (\%) }\end{array}$ & $80.4(7.1)$ & $79.7(7.0)$ & $73.3(6.4)^{\star}$ \\
Body mass index, mean $\mathrm{kg} / \mathrm{m}^{2}$ (SD) & $25(47.2)$ & $25(47.2)$ & $85(48.9)$ \\
\# of comorbidities, mean (SD) & $2.1(3.3)$ & $28.8(4.6)^{\star}$ & $27.5(4.0)^{\star}$ \\
MMSE score, mean (SD) & $28.3(1.4)$ & $2.4(1.9)$ & $1.9(1.7)^{*}$ \\
Living situation, $\mathrm{n}(\%)$ & $28.3(1.4)$ & $28.9(1.3)^{\star}$ \\
$\quad$ No care & $19(35.8)$ & $29(54.7)$ & $*$ \\
$\quad$ Home care/assisted living & $17(32.1)$ & $16(30.2)$ & $138(79.3)$ \\
$\quad$ Residential living facility & $17(32.1)$ & $8(15.1)$ & $12(13.8)$ \\
\hline
\end{tabular}

${ }^{*}$ Significantly $(P$-value $<0.05)$ different compared with people with sarcopenia based on Mann-Whitney $U$ test (Age, BMI, MMSE, Number of comorbidities) or Chi-square test (Sex, Living situation).

Table 2 Disability in ADL

\begin{tabular}{|c|c|c|c|}
\hline GARS Items & $\begin{array}{l}\text { Sarcopenia, } \\
\mathrm{n}=53\end{array}$ & $\begin{array}{l}\text { No Sarcopenia, Age and } \\
\text { Sex Matched, } n=53\end{array}$ & $\begin{array}{l}\text { No Sarcopenia, } \\
n=174\end{array}$ \\
\hline Mean GARS score (SD)* ${ }^{\star}$ & $29.4(11.3)$ & $26.6(10.6)$ & $21.6(7.3)^{\star \star}$ \\
\hline Subscale basic ADL & $16.6(5.4)$ & $14.9(5.5)^{\star \star}$ & $12.6(3.6)^{\star \star}$ \\
\hline \multicolumn{3}{|l|}{ Items basic ADL, mean score (SD) } & $9.0(4.0)^{\star \star}$ \\
\hline Dressing & $1.5(0.7)$ & $1.4(0.9)$ & $1.2(0.5)^{\star \star}$ \\
\hline Get in/out of bed & $1.3(0.5)$ & $1.2(0.5)$ & $1.1(0.3)^{\star \star}$ \\
\hline Stand up from a chair & $1.4(0.6)$ & $1.2(0.4)$ & $1.1(0.3)^{\star \star}$ \\
\hline Wash hands/face & $1.0(0.3)$ & $1.0(0.1)$ & $1.0(0.1)$ \\
\hline Wash/dry body & $1.5(0.9)$ & $1.6(1.1)$ & $1.2(0.7)^{\star \star}$ \\
\hline Get on/off toilet & $1.1(0.4)$ & $1.1(0.3)$ & $1.0(0.2)^{\star \star}$ \\
\hline Eat and drink & $1.1(0.4)$ & $1.0(0.0)$ & $1.0(0.0)^{\star \star}$ \\
\hline Get around inside house & $1.2(0.5)$ & $1.1(0.4)$ & $1.0(0.2)^{\star \star}$ \\
\hline Go up/down stairs & $2.2(1.2)$ & $1.6(1.0)$ & $1.3(0.7)^{\star \star}$ \\
\hline Walk outdoors & $1.6(1.0)$ & $1.3(0.8)^{\star \star}$ & $1.1(0.5)^{\star \star}$ \\
\hline Take care of feet/toenails & $2.7(1.3)$ & $2.4(1.3)$ & $1.6(1.1)^{\star \star}$ \\
\hline \multicolumn{4}{|c|}{ Items instrumental $A D L$, mean score (SD) } \\
\hline Prepare breakfast/lunch & $1.2(0.7)$ & $1.1(0.5)$ & $1.0(0.2)^{\star \star}$ \\
\hline Prepare dinner & $1.8(1.3)$ & $1.5(1.0)$ & $1.2(0.7)^{\star \star}$ \\
\hline Do light cleaning & $1.4(0.9)$ & $1.3(0.8)$ & $1.1(0.5)^{\star \star}$ \\
\hline Do heavy cleaning & $2.5(1.4)$ & $2.4(1.3)$ & $1.7(1.1)^{\star \star}$ \\
\hline Wash/iron clothes & $2.0(1.3)$ & $1.7(1.2)$ & $1.3(0.8)^{\star \star}$ \\
\hline Make beds & $2.2(1.2)$ & $2.1(1.2)$ & $1.5(0.9)^{\star \star}$ \\
\hline Go shopping & $1.7(1.2)$ & $1.6(1.1)$ & $1.2(0.7)^{\star \star}$ \\
\hline
\end{tabular}

${ }^{*}$ GARS total score may range from 18-72, subscale ADL may range from 11-44, subscale instrumental ADL (IADL) may range from 7-28, higher scores indicate more disability in ADL. Item scores range from "fully independent without any difficulty" (score 1 ) to "fully dependent" (score 4). **Significantly (P-value < 0.05 ) different compared with people with sarcopenia based on Mann-Whitney $U$ test (mean GARS score and subscale scores) or Chi-square test (items scores).

\subsection{Burden of Sarcopenia in Terms of Health Outcomes}

The GARS score was significantly $(P<0.001)$ different between sarcopenic $(29.4 \pm 11.3)$ versus non-sarcopenic subjects $(21.6 \pm 7.3)$. This difference was not significant between sarcopenic versus age and sex matched non-sarcopenic subjects $(26.6 \pm 10.6 ; p=0.097)$, except for the subscale basic ADL and the item 'walk outdoors' (Table 2). Subjects 
indicated that they had most difficulty on the GARS items 'go up/down stairs', 'take care of feet/toenails' and the instrumental GARS items 'do heavy cleaning' and 'make beds'.

As with the GARS score, the overall EQ-5D-5L utility score was significantly $(P<$ $0.001)$ lower in sarcopenic $(0.78 \pm 0.2)$ compared with non-sarcopenic subjects $(0.86 \pm 0.2)$, but not significantly different from the age and sex matched non-sarcopenic subjects $(0.81 \pm 0.2 ; P=0.362)$. In general, subjects reported most problems in the domains mobility and pain (Figure 1). Subjects with sarcopenia reported more problems with mobility and usual ADL compared with non-sarcopenics $(P<0.05)$, but not compared with age and sex matched non-sarcopenic subjects. Self-rated health of sarcopenic subjects $(72 \pm 16)$ tended to be lower compared with age and sex matched non-sarcopenic $(77 \pm 13, P=0.071)$ and was lower compared with the total sample of non-sarcopenic subjects $(80 \pm 12, P<0.001)$.

\subsection{Burden of Sarcopenia in Terms of Costs}

The volumes of resource use, unit prices and mean total costs per person are shown in Supplementary Data, Tables 1-3. As depicted in Figure 2, average costs of health care per person per three months were significantly higher in sarcopenic subjects (€4325, 95\% Cl: $€ 3198-€ 5471$ ), compared with non-sarcopenic subjects (€1533, 95\% Cl: €1153-€1912). The mean difference in total costs was $€ 2792$. The age and sex matched non-sarcopenic subjects also showed lower costs (€2768, 95\% Cl: $€ 1914-€ 3743)$ than sarcopenic subjects, though the difference was not significant.

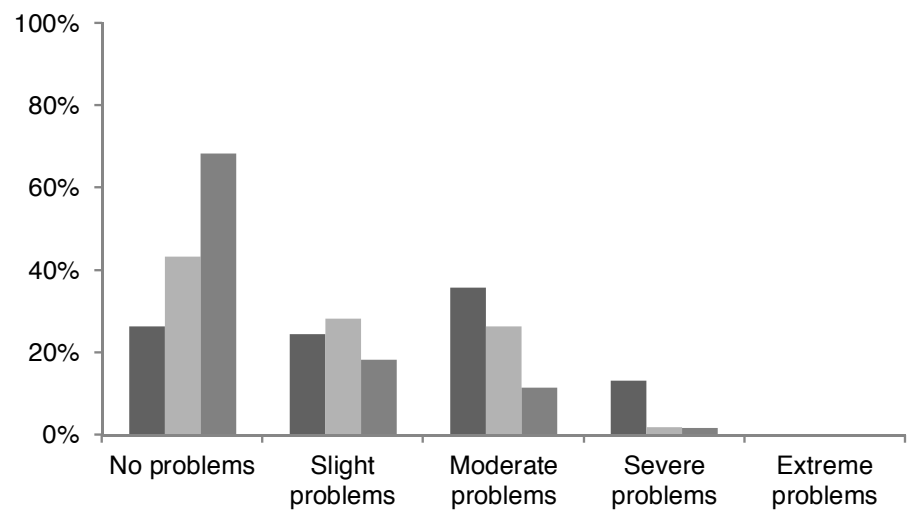

Figure 1a Dimension: mobility

Sarcopenic older adults $(n=53)$

Age and sex matched non-sarcopenic older adults $(n=53)$

Non sarcopenic older adults $(n=174)$ 

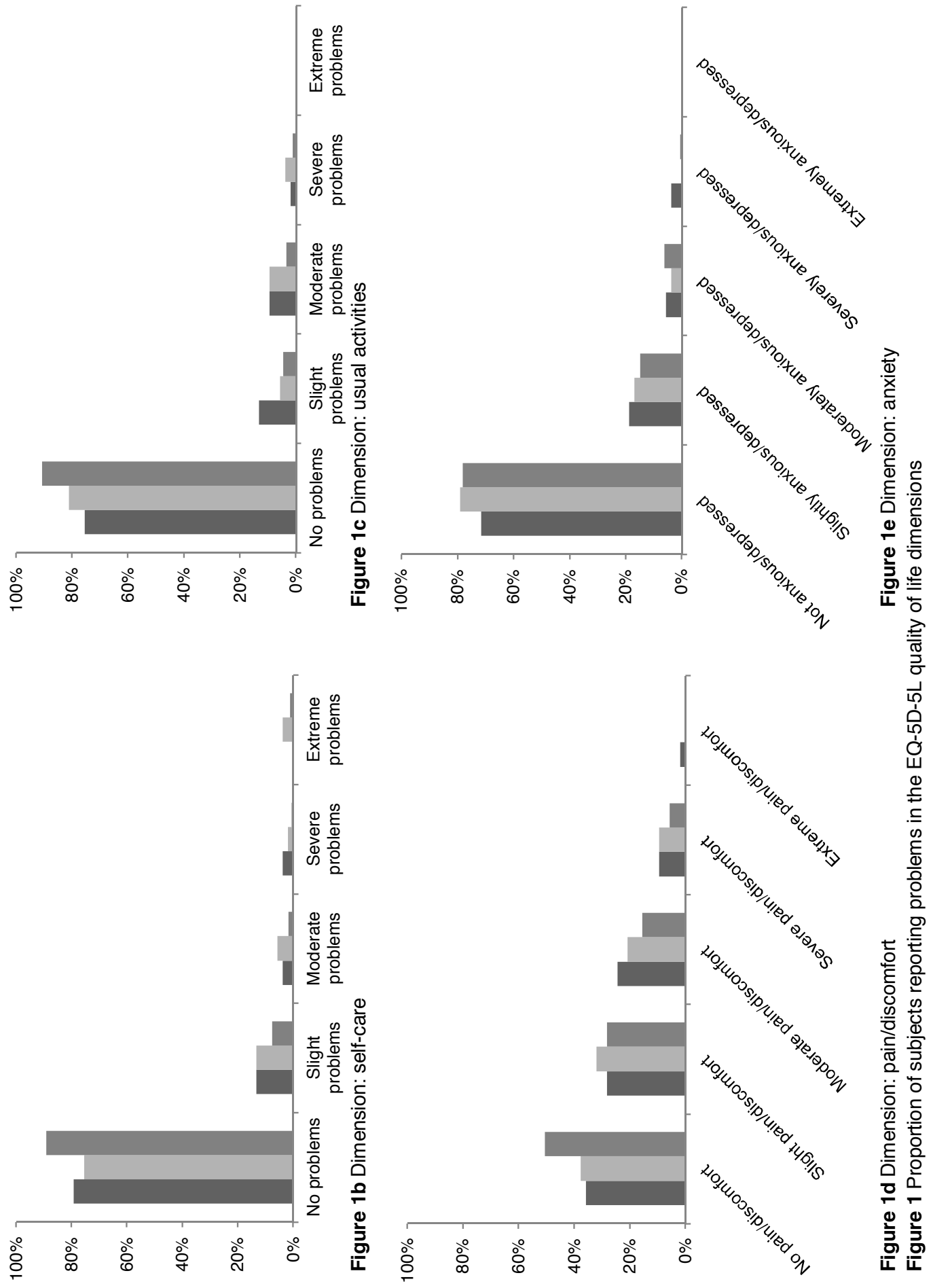
The highest proportion of costs was attributable to costs of care in a residential living facility, followed by support at home and hospital services. Except for costs of care in a residential living facility, no significant cost differences were found for the individual cost categories (Figure 2) between sarcopenic and non-sarcopenic subjects.

\subsection{Subgroup and Sensitivity Analyses}

Subgroup analyses showed that subjects with higher age, more comorbidities and more care dependency had lower utility scores and higher GARS scores, but not by definition lower self-rated health (Tables 3 and 4). Furthermore, though differences were not significant, higher age, more comorbidities and more care dependency yielded higher costs. There were no significant differences in costs between sarcopenic vs. nonsarcopenic subjects living in the same setting (Table 4). A remarkable finding in the sensitivity analysis is that subjects with solely low SMI, scored better on QoL and disability in ADL (Table 3), compared to subjects with a normal SMI. Furthermore, excluding subjects with oedema $(n=35)$ did not lead to significantly lower costs, and including subjects with low cognitive function $(n=8)$ did not lead to significantly higher costs. No cost difference was found between subjects with low versus normal SMI.

\section{Discussion}

The aim of this study was to explore the burden-of-illness of Dutch community-dwelling older adults with sarcopenia, in terms of disability in ADL, QoL and costs, from a societal perspective. In this study, a higher health burden (in terms of disability in ADL and QoL) was seen in sarcopenic versus non-sarcopenic subjects. No evidence was found for a higher health burden in sarcopenic versus age and sex matched non-sarcopenic subjects, except for the subscale basic ADL. The total health care costs of community-dwelling sarcopenic subjects ( $n=53$, mean total costs per person per three months $€ 4325$ ) were about three times higher than the health care costs observed in non-sarcopenic subjects ( $\mathrm{n}$ $=174, € 1533$ ), and 1.5 times higher (although not significantly) compared with the age and sex matched non-sarcopenic subjects $(n=53, € 2768)$. This means that sarcopenic subjects had an extra annual health care spending of $€ 11168$ compared with nonsarcopenic subjects and an extra $€ 6228$ compared with matched controls. Costs of care in a residential living facility constituted the highest proportion of costs.

The GARS scores in our sample are comparable with previous GARS data in a community-dwelling population aged 65 and older. ${ }^{34-36}$ Chan et al. ${ }^{37}$ found higher disability scores, but investigated an older population than ours. Two other studies on disability in sarcopenia used different tools (e.g. Katz ADL scale) to assess disability, and also found an association between sarcopenia and disability, ${ }^{1,38}$ however, one other study did not find such an association. ${ }^{9}$ The study design, definition of sarcopenia and gender of subjects can influence the association between sarcopenia and disability, ${ }^{39-41}$ which may explain the difference in observations. It should also be noted that the GARS measures the competence of a person in the ADL domains, but not actual performance. Bootsma et al. ${ }^{42}$ showed that discrepancies exist between the two, i.e. some older adults could perform ADL activities, but did not perform them regularly. Therefore, in our study, subjects could possibly have overestimated their abilities. This might partly explain why we did not find a significantly different GARS score in sarcopenic versus age and sex matched nonsarcopenic subjects. Moreover, subjects in the age and sex matched group were living in a 
residential living facility (more disabled compared with total group of non-sarcopenic subjects) relatively more often and the sample size of the matched controls might have been too small to detect significant differences.

The mean QoL scores of both sarcopenic and non-sarcopenic subjects were in line with previous studies using the EQ-5D in sarcopenia research. Previous studies on the association between QoL and (domains of) sarcopenia using the Short-Form $36^{43-47}$ and/or the $E Q-5 D^{37,43,48,49}$ to assess QoL, reported inconsistent results. Some researchers did find a significant association between quality of life and sarcopenia, ${ }^{44}$ muscle mass, ${ }^{46,} 48$ hand grip strength, ${ }^{37,43-47}$ or physical performance, ${ }^{43-47}$ others did partly find an association, e.g. only in men ${ }^{49}$ or did find an association using the SF-36, but not when using the EQ$5 \mathrm{D} .{ }^{43}$ In a review on QoL in sarcopenia and frailty, Rizzoli and colleagues ${ }^{3}$ underline the challenge of attributing QoL merely to sarcopenia, as comorbidities are often present and might also have an impact on QoL.

In our study, we found that sarcopenia accounted for an extra annual health care spending of $€ 11168$ compared with non-sarcopenic subjects and an extra (although not significant) $€ 6228$ compared with matched controls. Looking at the cost difference per person, the health care costs for the total population are expected to be substantial. The health care costs of matched controls were expected to be higher than the total group of non-sarcopenic subjects, as the matched controls were older, and the oldest subjects were more likely to reside in a (relatively expensive) residential living facility and had more comorbidities. However, the wide confidence intervals around the costs and the small sample size of the matched controls might have hampered detection of significant differences between sarcopenic and matched non-sarcopenic subjects. There were no significant differences in costs between sarcopenic vs. non-sarcopenic subjects living in the same setting. However, sarcopenic older adults might be more prone to be admitted to residential care as previous research indicated that sarcopenia is associated with institutionalization. ${ }^{1}$ Therefore it can be argued that correcting for living situation when comparing costs of sarcopenic vs. non-sarcopenic older adults is not justified. The cost difference between sarcopenic and non-sarcopenic subjects that we found was larger than found by Janssen et al., who found about an extra $\$ 900$ (about $€ 677$ ) per sarcopenic person per year. ${ }^{8}$ Four reasons could underlie this difference. Firstly, Janssen et al. ${ }^{8}$ defined sarcopenia as low muscle mass, while we also included muscle strength and/or performance. But when using their definition of sarcopenia in our sensitivity analyses, the cost difference between sarcopenic and non-sarcopenic subjects was not significant. Secondly, they indirectly calculated costs of health care, using relative risk estimates of sarcopenia-related physical disability and previously calculated costs of disability ${ }^{8}$ and it is unclear whether costs of a residential living facility were included. The bottom-up approach that we used to estimate health care utilization, as well as the high proportion of costs from living in a residential living facility, could have led to cost differences between studies. Thirdly, Janssen et al. ${ }^{8}$ calculated costs of sarcopenia based on costs of disability. Although disability has been shown to be a large health care burden, ${ }^{50}$ physical disability is not the only driver of costs in older adults with sarcopenia. ${ }^{9}$ The association of sarcopenia with falls, institutionalization and comorbidities, such as osteoporosis, diabetes, and chronic kidney disease, could also lead to substantially increased costs. ${ }^{2,9,51-56}$ Fourthly, differences in costs might emerge from differences in the healthcare systems of the Netherlands and the U.S. 

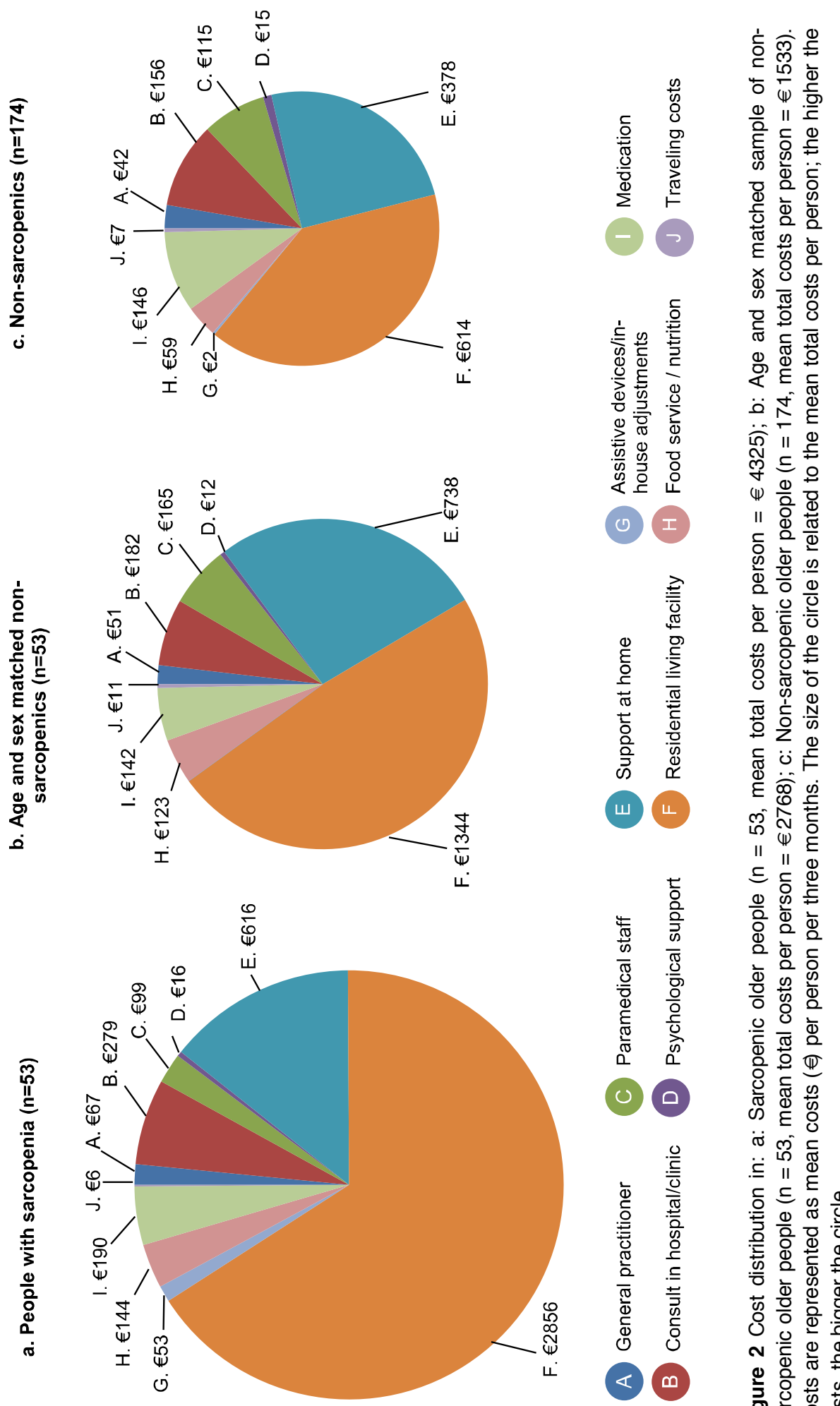

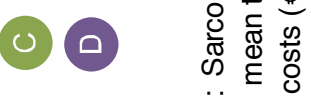

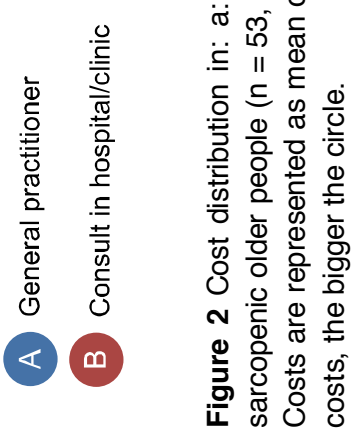




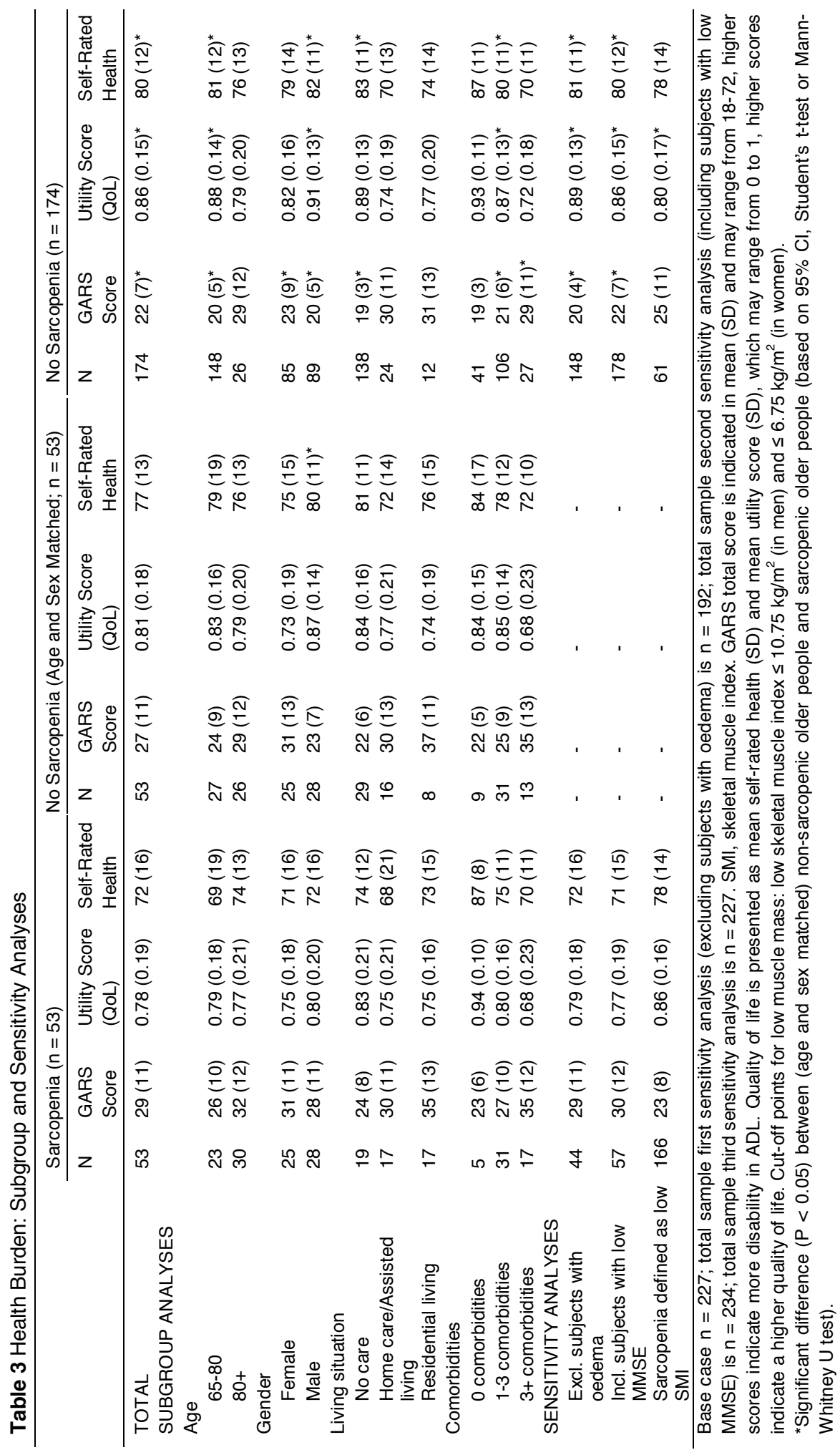




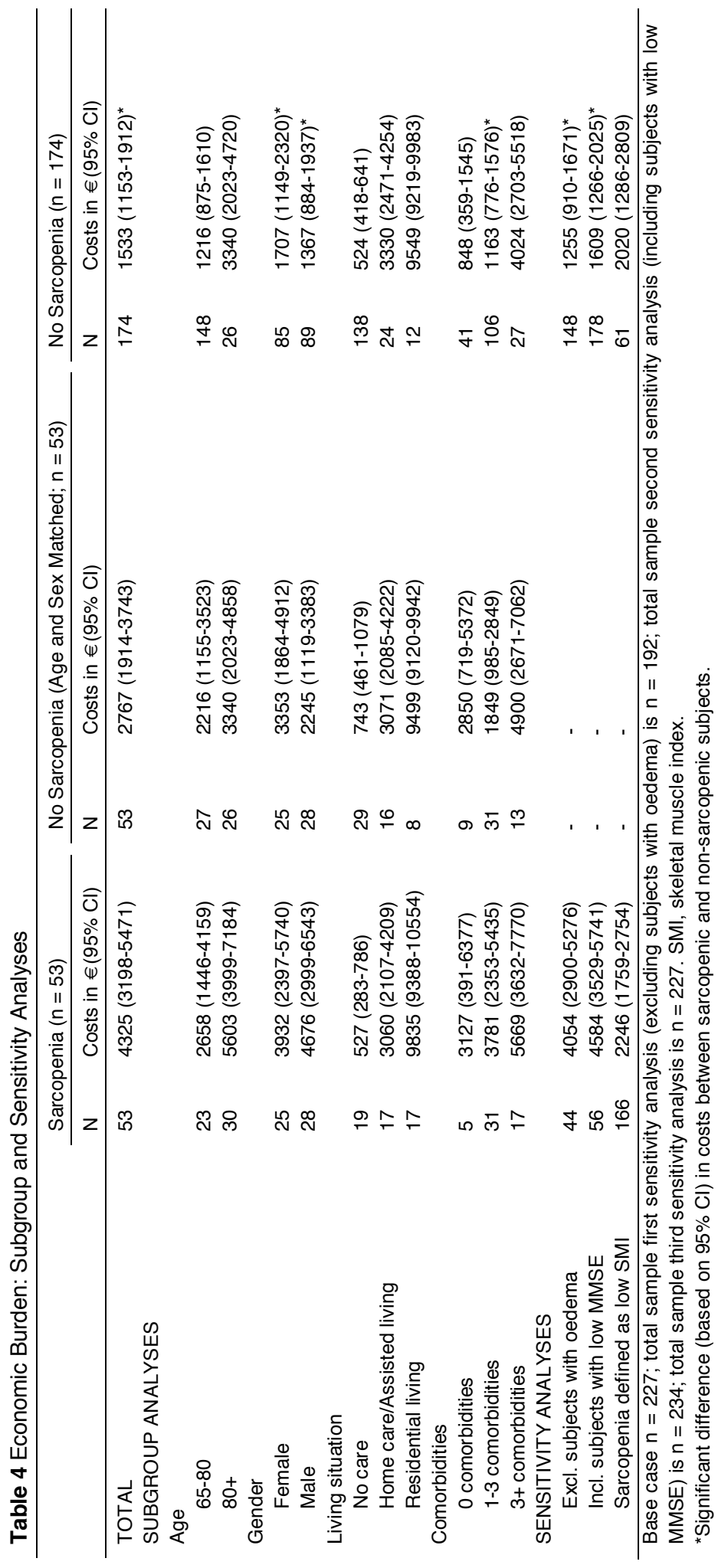




\subsection{Strengths and Weaknesses}

A strength of this study is its bottom-up approach to identify volumes of health care use by measuring actual costs in a cross-sectional study. In addition, standardized unit prices based on national guidelines were used, facilitating comparison with other Dutch studies. Health outcomes were assessed using sufficiently tested instruments. ${ }^{20,} 22$ Although no existing cost questionnaire was used that would have simplified consistency across studies, ${ }^{26}$ existing questionnaires were consulted during the development of the cost questionnaire and the questionnaire was tested for feasibility in a pilot study. Although the advantage of a generic quality of life instrument such as the EQ-5D-5L that was used in this study is that one can compare the burden of different diseases, it may be argued that a sarcopenia-specific QoL instrument (such as the recently developed SarQoL) ${ }^{57}$ might be of added value. Furthermore, the cross-sectional design of the study does not allow causeconsequence comparison. The time frame of health care utilization was three months, which might have been too short to identify all cost sources. Finally, generalizability of the results may be limited to some extent due to the fact that the response rate was about $15 \%$ and a selection bias in participation may have occurred. As illness might be a reason for non-participation, and subjects needed to be able to undergo several physical tests during a two-hour home visit, our sample might have been healthier than the general Dutch 65+ population.

\subsection{Implications and Future Research}

Our results indicate that the health and economic burden of sarcopenia seems mainly driven by living situation. Prevention and treatment of sarcopenia, especially communitydwelling older adults living independently at home, might alleviate its health and economic burden, for example by delaying the onset of disability and the need for care and institutionalization. However, research is needed to confirm this. To help policy makers and health care professionals make a well-informed decision about whether or not to implement a strategy to reduce the burden of sarcopenia (e.g. resistance exercise combined with nutrition), they should have more information than on the sarcopenia burden alone. It can be recommended to also provide information on the costs and savings of such a strategy. ${ }^{11}$

\section{Conclusions}

Community-dwelling sarcopenic subjects had a higher health and economic burden than non-sarcopenic subjects. This was importantly driven by the living situation. Although differences in health and economic outcomes between sarcopenic and age and sex matched non-sarcopenic subjects were not significant, the same trend was seen. Keeping older adults independent and out of care-dependent settings may contribute to a reduction of health care costs.

\section{Ethical Statement}

The MaSS study was approved by the Medical Ethics Committee of the Academic Hospital Maastricht and Maastricht University and registered at http://www.clinicaltrials.gov (NCT01820988). 


\section{Funding}

This study was funded by Nutricia Research, Utrecht, the Netherlands.

\section{Contributors}

Study concept and design: RH, JM, JS, SE, YL, SV, DM. Data acquisition, statistical analyses and manuscript preparation: DM. Interpretation of data and critical revising: all. All authors read and approved the final manuscript.

\section{Disclosure of Interest}

SV and YL are employees of Nutricia Research. The other authors declare that they have no competing interest.

\section{Acknowledgments}

We are grateful to all subjects of the MaSS study for their cooperation and Elles Lenaerts for her help with the data collection. We would like to thank Ruben Drost, Mitchel van Eeden and Mike Wallace for their advice with regard to the cost calculations and Frans Tan for his advice regarding the statistical analyses. The support of the municipality of Maastricht with the recruitment of subjects has been greatly appreciated. 


\section{References}

1. Hirani V, Blyth F, Naganathan V, Le Couteur DG, Seibel MJ, Waite LM, et al. Sarcopenia is associated with incident disability, institutionalization, and mortality in community-dwelling older men: the Concord Health and Ageing in Men Project. J Am Med Dir Assoc 2015;16(7):607-13.

2. Luppa M, Luck T, Weyerer S, Konig HH, Brahler E, Riedel-Heller SG. Prediction of institutionalization in the elderly: a systematic review. Age Ageing 2010;39(1):31-8.

3. Rizzoli R, Reginster JY, Arnal JF, Bautmans I, Beaudart C, Bischoff-Ferrari H, et al. Quality of life in sarcopenia and frailty. Calcif Tissue Int. 2013;93(2):101-20.

4. Visser M, Schaap LA. Consequences of sarcopenia. Clin Geriatr Med 2011;27(3):387-99.

5. Woo J, Leung J, Morley JE. Defining sarcopenia in terms of incident adverse outcomes. J Am Med Dir Assoc 2015;16(3):247-52.

6. Cruz-Jentoft AJ, Baeyens JP, Bauer JM, Boirie Y, Cederholm T, Landi F, et al. Sarcopenia: European consensus on definition and diagnosis: report of the European Working Group on Sarcopenia in Older People. Age Ageing 2010;39(4):412-23.

7. Cruz-Jentoft AJ, Landi F, Schneider SM, Zuniga C, Arai H, Boirie Y, et al. Prevalence of and interventions for sarcopenia in ageing adults: a systematic review: report of the International Sarcopenia Initiative (EWGSOP and IWGS). Age Ageing 2014;43(6):748-59.

8. Janssen I, Shepard DS, Katzmarzyk PT, Roubenoff R. The healthcare costs of sarcopenia in the United States. J Am Geriatr Soc 2004;52(1):80-5.

9. Beaudart C, Rizzoli R, Bruyere O, Reginster JY, Biver E. Sarcopenia: burden and challenges for public health. Arch Public Health 2014;72(1):45.

10. Tarricone R. Cost-of-illness analysis: what room in health economics? Health Policy 2006;77(1):51-63.

11. World Health Organization. WHO guide to identifying the economic consequences of disease and injury. Geneva: WHO, 2009.

12. Janssen I, Baumgartner RN, Ross R, Rosenberg IH, Roubenoff R. Skeletal muscle cutpoints associated with elevated physical disability risk in older men and women. Am J Epidemiol 2004;159(4):413-21.

13. Tieland M, Dirks ML, Van der Zwaluw N, Verdijk LB, Van de Rest O, De Groot LC, et al. Protein supplementation increases muscle mass gain during prolonged resistance-type exercise training in frail elderly people: a randomized, double-blind, placebo-controlled trial. J Am Med Dir Assoc 2012;13(8):713-9.

14. Hakkaart-van Roijen L, Tan SS, Bouwmans CAM. Handleiding voor kostenonderzoek: methoden en standaard kostprijzen voor economische evaluaties in de gezondheidszorg: geactualiseerde versie 2010 Diemen: CVZ, January 2011.

15. Husereau D, Drummond M, Petrou S, Carswell C, Moher D, Greenberg D, et al. Consolidated Health Economic Evaluation Reporting Standards (CHEERS) statement. BMC Med 2013;11:80.

16. Schols JMGA. De toekomst van de chronische zorg, ... ons een zorg?: van oude structuren, de dingen, die voorbijgaan ... [Oration]. Tilburg: Universiteit van Tilburg; 2004.

17. Drummond MF, Sculpher MJ, Torrance GW, O'Brien BJ, Stoddart GL. Methods for the economic evaluation of health care programme. 3rd ed. Oxford: Oxford University Press; 2005.

18. Mijnarends DM, Schols JM, Meijers JM, Tan FE, Verlaan S, Luiking YC, et al. Instruments to assess sarcopenia and physical frailty in older people living in a community (care) setting: similarities and discrepancies. J Am Med Dir Assoc 2015;16(4):301-8.

19. Mijnarends DM, Meijers JMM, Halfens RJG, Ter Borg S, Luiking YC, Verlaan S, et al. Validity and reliability of tools to measure muscle mass, strength, and physical performance in community-dwelling older people: a systematic review. J Am Med Dir Assoc 2013;14(3):170-8.

20. Kempen GIJM, Miedema I, Ormel J, Molenaar W. The assessment of disability with the Groningen Activity Restriction Scale: conceptual framework and psychometric properties. Soc Sci Med 1996;43(11):1601-10.

21. EuroQol Group. EuroQol: a new facility for the measurement of health-related quality of life. Health Policy 1990;16(3):199-208.

22. Janssen MF, Birnie E, Haagsma JA, Bonsel GJ. Comparing the standard EQ-5D three-level system with a five-level version. Value Health 2008;11(2):275-84.

23. Rabin R, Oemar M, Oppe M, Janssen B, Herdman M. EQ-5D-5L user guide: basic information on how to use the EQ-5D-5L instrument: version 1.0. Rotterdam: EuroQol Group, April 2011.

24. Van Hout B, Janssen MF, Feng YS, Kohlmann T, Busschbach J, Golicki D, et al. Interim scoring for the EQ5D-5L: mapping the EQ-5D-5L to EQ-5D-3L value sets. Value Health 2012;15(5):708-15.

25. Herdman M, Gudex C, Lloyd A, Janssen M, Kind P, Parkin D, et al. Development and preliminary testing of the new five-level version of EQ-5D (EQ-5D-5L). Qual Life Res 2011;20(10):1727-36. 
26. Thorn JC, Coast J, Cohen D, Hollingworth W, Knapp M, Noble SM, et al. Resource-use measurement based on patient recall: issues and challenges for economic evaluation. Appl Health Econ Health Policy 2013;11(3):155-61.

27. Mijnarends D, Meijers J, Halfens R, Ter Borg S, Luiking Y, Verlaan S, et al. Rationale and design of a crosssectional study of the prevalence, characterization and health and economic consequences of sarcopenia in community-dwelling older people in the Netherlands [abstract]. J Nutr Health Aging 2013;17(supplement 1):S245.

28. Centraal Bureau voor de Statistiek. Consumentenprijzen: prijsindex $2006=100$. Den Haag; Heerlen: CBS; 2015 Available from:

http://statline.cbs.nl/Statweb/publication/?DM=SLNL\&PA=71311ned\&D1=0,4\&D2=0\&D3=142,155,168,181,1 94,219,232,245,I\&HDR=G1,T\&STB=G2\&VW=T, last access September 2015.

29. Kyle UG, Bosaeus I, De Lorenzo AD, Deurenberg P, Elia M, Manuel Gomez J, et al. Bioelectrical impedance analysis: Part II: Utilization in clinical practice. Clin Nutr 2004;23(6):1430-53.

30. Folstein MF, Folstein SE, McHugh PR. "Mini-mental state": a practical method for grading the cognitive state of patients for the clinician. J Psychiatr Res 1975;12(3):189-98.

31. Charlson ME, Pompei P, Ales KL, MacKenzie CR. A new method of classifying prognostic comorbidity in longitudinal studies: development and validation. J Chron Dis 1987;40(5):373-83

32. Alemayehu B, Warner KE. The lifetime distribution of health care costs. Health Serv Res 2004 Jun;39(3):627-42.

33. Ramsey S, Willke R, Briggs A, Brown R, Buxton M, Chawla A, et al. Good research practices for costeffectiveness analysis alongside clinical trials: the ISPOR RCT-CEA Task Force report. Value Health 2005;8(5):521-33.

34. Gobbens RJ, van Assen MA. Frailty and its prediction of disability and health care utilization: the added value of interviews and physical measures following a self-report questionnaire. Arch Gerontol Geriatr 2012;55(2):369-79.

35. Gobbens RJ, Van Assen MA, Schalk MJ. The prediction of disability by self-reported physical frailty components of the Tilburg Frailty Indicator (TFI). Arch Gerontol Geriatr 2014;59(2):280-7.

36. Kempen GIJM, Doeglas DM, Suurmeijer TPMB. Het meten van problemen met zelfredzaamheid op verzorgend en huishoudelijk gebied met de Groningen Activity Restriction Scale (GARS): een handleiding. Groningen: Noordelijk Centrum voor Gezondheidsvraagstukken, 2012 ISBN 90-72156-58-7.

37. Chan OY, Van Houwelingen AH, Gussekloo J, Blom J, Den Elzen W. Comparison of quadriceps strength and handgrip strength in their association with health outcomes in older adults in primary care. Age 2014;36(5):9714.

38. Janssen I, Heymsfield SB, Ross R. Low relative skeletal muscle mass (sarcopenia) in older persons is associated with functional impairment and physical disability. J Am Geriatr Soc. 2002;50(5):889-96.

39. Cesari M, Rolland Y, Abellan van Kan G, Bandinelli S, Vellas B, Ferrucci L. Sarcopenia-related parameters and incident disability in older persons: results from the "Invecchiare in Chianti" study. J Gerontol A Biol Sci Med Sci 2015;70(4):457-63.

40. Janssen I. Influence of sarcopenia on the development of physical disability: the Cardiovascular Health Study. J Am Geriatr Soc. 2006;54(1):56-62.

41. Rolland Y, Czerwinski S, Abellan Van Kan G, Morley JE, Cesari M, Onder G, et al. Sarcopenia: its assessment, etiology, pathogenesis, consequences and future perspectives. J Nutr Health Aging 2008;12(7):433-50.

42. Bootsma-van der Wiel A, Gussekloo J, De Craen AJ, Van Exel E, Knook DL, Lagaay AM, et al. Disability in the oldest old: "can do" or "do do"? J Am Geriatr Soc 2001;49(7):909-14.

43. Beaudart C, Reginster JY, Petermans J, Gillain S, Quabron A, Locquet M, et al. Quality of life and physical components linked to sarcopenia: the SarcoPhAge study. Exp Gerontol 2015;69:103-10.

44. Patel HP, Syddall HE, Jameson K, Robinson S, Denison H, Roberts HC, et al. Prevalence of sarcopenia in community-dwelling older people in the UK using the European Working Group on Sarcopenia in Older People (EWGSOP) definition: findings from the Hertfordshire Cohort Study (HCS). Age Ageing 2013;42(3):378-84.

45. Sayer AA, Syddall HE, Martin HJ, Dennison EM, Roberts HC, Cooper C. Is grip strength associated with health-related quality of life?: findings from the Hertfordshire Cohort Study. Age Ageing 2006;35(4):409-15.

46. Trombetti A, Reid KF, Hars M, Herrmann FR, Pasha E, Phillips EM, et al. Age-associated declines in muscle mass, strength, power, and physical performance: impact on fear of falling and quality of life. Osteoporos Int 2016;27(2):463-71. 
47. Wanderley FA, Silva G, Marques E, Oliveira J, Mota J, Carvalho J. Associations between objectively assessed physical activity levels and fitness and self-reported health-related quality of life in communitydwelling older adults. Qual Life Res 2011;6:6.

48. Go SW, Cha YH, Lee JA, Park HS. Association between sarcopenia, bone density, and health-related quality of life in Korean men. Korean J Fam Med 2013;34(4):281-8.

49. Kim YP, Joh JY, Kim S, Hwang HS, Shin IS. The application of different appendicular skeletal muscle cutoff points and research definitions associated with health-related quality of life in Korean older people: data from KNHANES 2008-2011. BMC Geriatr 2014;14:144.

50. Fried TR, Bradley EH, Williams CS, Tinetti ME. Functional disability and health care expenditures for older persons. Arch Intern Med 2001;161(21):2602-7.

51. Cawthon PM, Fox KM, Gandra SR, Delmonico MJ, Chiou CF, Anthony MS, et al. Do muscle mass, muscle density, strength, and physical function similarly influence risk of hospitalization in older adults? J Am Geriatr Soc 2009;57(8):1411-9.

52. Davis JC, Robertson MC, Ashe MC, Liu-Ambrose T, Khan KM, Marra CA. International comparison of cost of falls in older adults living in the community: a systematic review. Osteoporos Int 2010;21(8):1295-306.

53. Heinrich S, Rapp K, Rissmann U, Becker C, Konig HH. Cost of falls in old age: a systematic review. Osteoporos Int 2010;21(6):891-902.

54. Hernlund E, Svedbom A, Ivergard M, Compston J, Cooper C, Stenmark J, et al. Osteoporosis in the European Union: medical management, epidemiology and economic burden. Arch Osteoporos 2013;8(12):136.

55. Scott D, Hayes A, Sanders KM, Aitken D, Ebeling PR, Jones G. Operational definitions of sarcopenia and their associations with 5-year changes in falls risk in community-dwelling middle-aged and older adults. Osteoporos Int 2014;25(1):187-93.

56. Svedbom A, Ivergard M, Hernlund E, Rizzoli R, Kanis JA. Epidemiology and economic burden of osteoporosis in Switzerland. Arch Osteoporos 2014;9(1):187.

57. Beaudart C, Biver E, Reginster JY, Rizzoli R, Rolland Y, Bautmans I, et al. Development of a selfadministrated quality of life questionnaire for sarcopenia in elderly subjects: the SarQoL. Age Ageing 2015;44(6):960-6. 


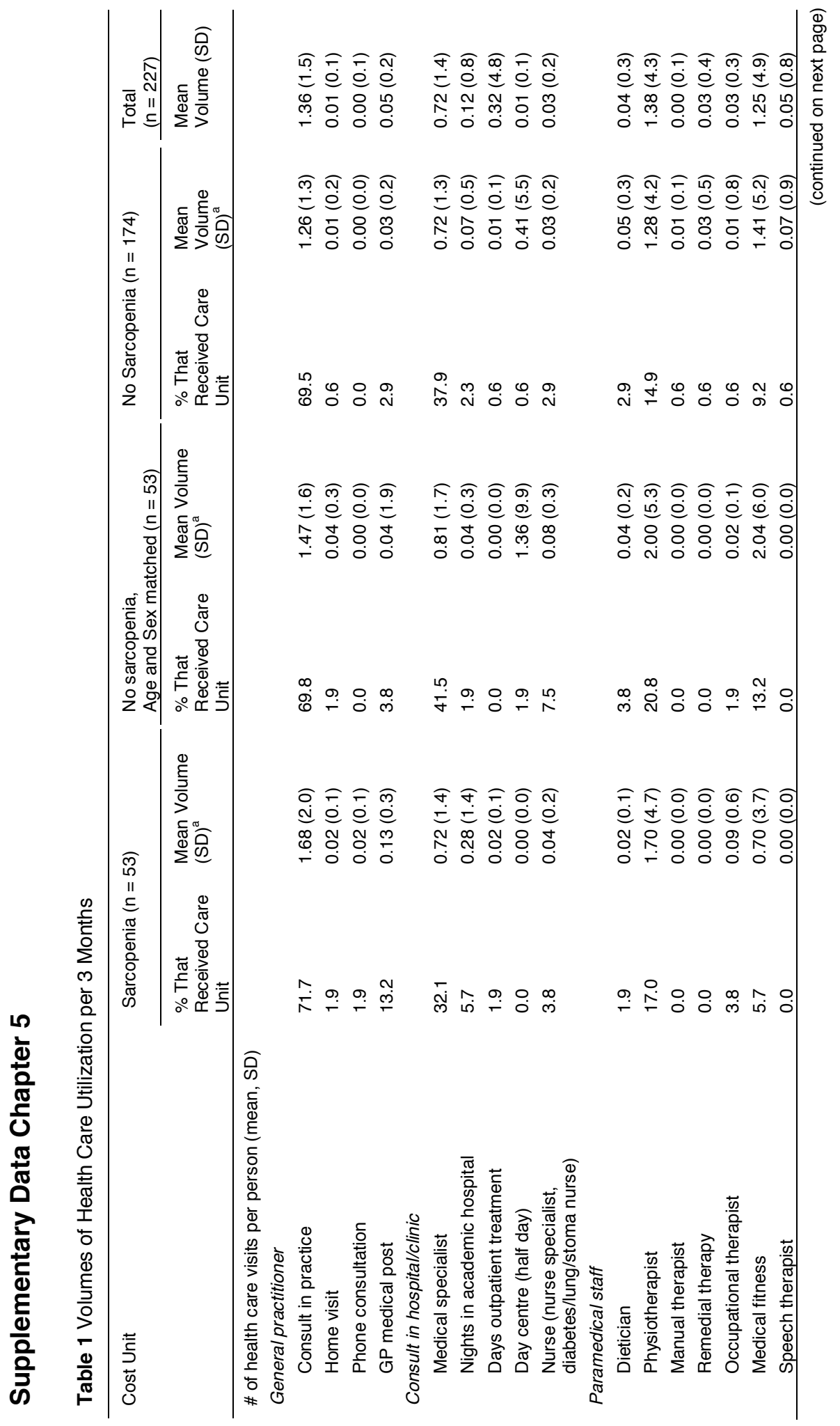




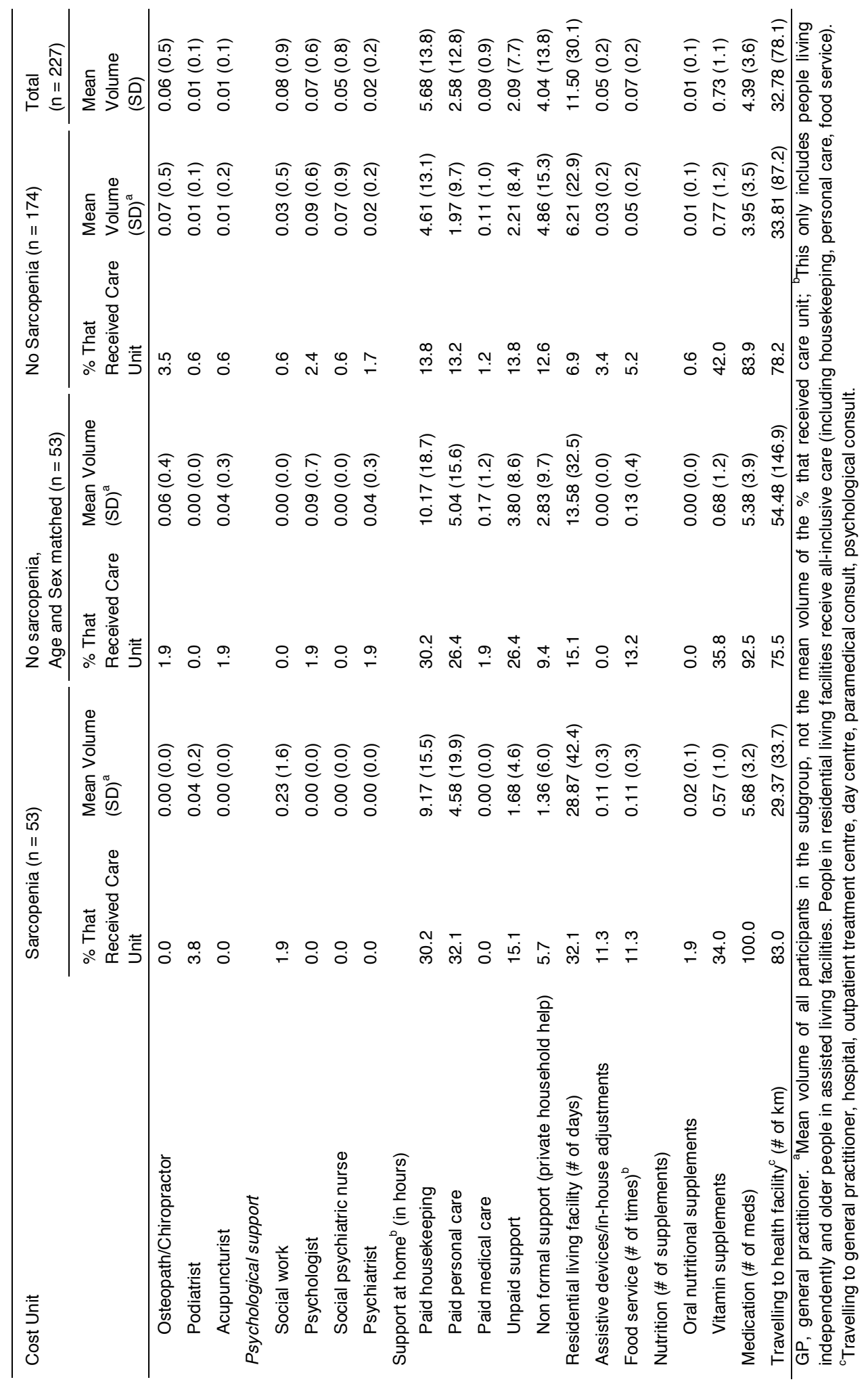




\section{Supplementary Data Chapter 5}

Table 2 Cost Prices of Health Care Services

\begin{tabular}{|c|c|c|}
\hline Cost Category & $\begin{array}{l}\text { Price Year } \\
2014 \text { (in €) }\end{array}$ & Source $^{\mathrm{a}}$ and Original Year \\
\hline \multicolumn{3}{|l|}{ Health care visit (costs/consult) } \\
\hline \multicolumn{3}{|l|}{ General practitioner } \\
\hline Consult in practice & 30.78 & Guideline National Health Care Institute - 2009 \\
\hline Home visit & 47.26 & Guideline National Health Care Institute - 2009 \\
\hline Phone consultation & 15.39 & Guideline National Health Care Institute - 2009 \\
\hline GP medical post & 103.68 & The Dutch Healthcare Authority - 2014 \\
\hline \multicolumn{3}{|l|}{ Consult in hospital/clinic } \\
\hline Medical specialist & 131.08 & Guideline National Health Care Institute - 2009 \\
\hline Night in academic hospital & 632.02 & Guideline National Health Care Institute - 2009 \\
\hline Days outpatient treatment & 275.89 & Guideline National Health Care Institute - 2009 \\
\hline Daily period in day centre & 36.34 & The Dutch Healthcare Authority - 2014 \\
\hline $\begin{array}{l}\text { Nurse (nurse specialist, diabetes/lung/ } \\
\text { stoma nurse) }\end{array}$ & 33.52 & Guideline National Health Care Institute - 2009 \\
\hline \multicolumn{3}{|l|}{ Paramedical staff } \\
\hline Consult: Dietician & 29.68 & Guideline National Health Care Institute - 2009 \\
\hline Consult: Physiotherapist & 39.57 & Guideline National Health Care Institute - 2009 \\
\hline Consult: Manual therapist & $39.57^{\mathrm{b}}$ & Guideline National Health Care Institute - 2009 \\
\hline Consult: Remedial therapist & 38.47 & Guideline National Health Care Institute - 2009 \\
\hline Consult: Occupational therapist & 24.18 & Guideline National Health Care Institute - 2009 \\
\hline Consult: Activity therapist & 38.47 & Guideline National Health Care Institute - 2009 \\
\hline Consult: Medical fitness & $39.57^{\mathrm{b}}$ & Guideline National Health Care Institute - 2009 \\
\hline Consult: Speech therapist & 36.27 & Guideline National Health Care Institute - 2009 \\
\hline Consult: Osteopath/chiropractor & $33.63^{c}$ & Guideline National Health Care Institute - 2009 \\
\hline Consult: Podiatrist & $33.63^{\mathrm{c}}$ & Guideline National Health Care Institute - 2009 \\
\hline Consult: Acupuncturist & $33.63^{c}$ & Guideline National Health Care Institute - 2009 \\
\hline \multicolumn{3}{|l|}{ Psychological support } \\
\hline Consult: Social work & 71.45 & Guideline National Health Care Institute - 2009 \\
\hline Consult: Psychologist & 86.28 & Guideline National Health Care Institute - 2009 \\
\hline Consult: Social psychiatric nurse & $33.52^{d}$ & Guideline National Health Care Institute - 2009 \\
\hline Consult: Psychiatrist & 113.21 & Guideline National Health Care Institute - 2009 \\
\hline \multicolumn{3}{|l|}{ Support at home (costs/hour) } \\
\hline Paid housekeeping & 38.47 & Guideline National Health Care Institute - 2009 \\
\hline Paid personal care & 48.36 & Guideline National Health Care Institute - 2009 \\
\hline Paid medical care & 71.45 & Guideline National Health Care Institute - 2009 \\
\hline Unpaid support & 13.74 & Guideline National Health Care Institute - 2009 \\
\hline Non formal support & $13.74^{\mathrm{e}}$ & Guideline National Health Care Institute - 2009 \\
\hline Residential living facility (costs/day) & 98.92 & Guideline National Health Care Institute - 2009 \\
\hline \multicolumn{3}{|l|}{ Assistive devices/in-house adjustments } \\
\hline Arch support & 146.42 & The Drug Information System - 2013 \\
\hline Orthopaedic shoes & 1363.18 & The Drug Information System - 2013 \\
\hline Toilet raiser & 48.47 & The Drug Information System - 2013 \\
\hline Rollator & 124.21 & The Drug Information System - 2009 \\
\hline Crutches & 50.56 & The Drug Information System - 2009 \\
\hline Cane & 6.06 & Self-report \\
\hline Special chair & 383.71 & The Drug Information System - 2009 \\
\hline Ankle brace & 59.95 & Market price \\
\hline Antiskid mat & 5.05 & Self-report - 2013 \\
\hline Stair handrails & 807.81 & Self-report - 2013 \\
\hline
\end{tabular}

(continued on next page) 


\begin{tabular}{|c|c|c|}
\hline Cost Category & $\begin{array}{l}\text { Price Year } \\
2014 \text { (in €) }\end{array}$ & Source $^{a}$ and Original Year \\
\hline \multicolumn{3}{|l|}{ Food service (price per meal) } \\
\hline Food delivery ('Tafeltje-dekje') & 5.77 & Self-report - 2013/2014 \\
\hline Restaurant residential home & 17.17 & Self-report - 2013/2014 \\
\hline \multicolumn{3}{|l|}{ Nutrition } \\
\hline Oral nutritional supplements & Varies & Market price \\
\hline Vitamin supplements & Varies & Market price \\
\hline Vitamin B injection (price/per $500 \mu \mathrm{g}$ ) & 0.65 & National Health Care Institute - 2013/2014 \\
\hline \multicolumn{3}{|l|}{ Medication-related } \\
\hline Medication & Varies & National Health Care Institute - 2013/2014 \\
\hline Delivery costs (price/medicine) & 5.55 & Guideline National Health Care Institute - 2009 \\
\hline $\begin{array}{l}\text { Prescription costs (per medicine/ week) } \\
\text { in residential living facility }\end{array}$ & 3.03 & Guideline National Health Care Institute - 2009 \\
\hline Travelling to health facility $(€ / \mathrm{km})$ & 0.20 & Guideline National Health Care Institute - 2009 \\
\hline \multicolumn{3}{|c|}{ 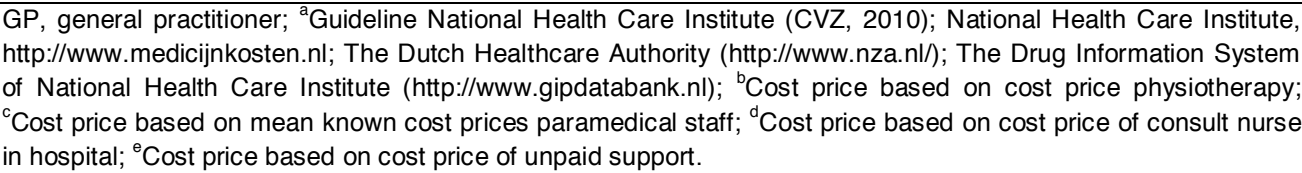 } \\
\hline
\end{tabular}




\section{Supplementary Data Chapter 5}

Table 3 Total Costs of Health Care Utilization

\begin{tabular}{|c|c|c|c|c|}
\hline \multirow[t]{2}{*}{ Cost Category } & \multicolumn{4}{|c|}{ Total Costs (in €) Per Person (Mean, SD) } \\
\hline & $\begin{array}{l}\text { Sarcopenia } \\
(n=53)\end{array}$ & $\begin{array}{l}\text { No Sarcopenia, Age } \\
\text { and Sex Matched } \\
(n=53)\end{array}$ & $\begin{array}{l}\text { No Sarcopenia } \\
(n=174)\end{array}$ & $\begin{array}{l}\text { Total } \\
(n=227)\end{array}$ \\
\hline \multicolumn{5}{|l|}{ Health care visit } \\
\hline \multicolumn{5}{|l|}{ General practitioner } \\
\hline Consult in practice & $51.69(60.3)$ & $45.30(48.9)$ & $38.74(39.9)$ & $41.76(45.7)$ \\
\hline Home visit & $0.89(6.5)$ & $1.78(13.0)$ & $0.54(7.2)$ & $0.62(7.0)$ \\
\hline Phone consultation & $0.29(2.1)$ & $0.00(0.0)$ & $0.00(0.0)$ & $0.07(1.0)$ \\
\hline GP medical post & $13.69(35.4)$ & $3.91(19.9)$ & $2.98(17.4)$ & $5.48(23.3)$ \\
\hline Subtotal GP & $66.56(77.3)$ & $50.99(55.05)$ & $42.26(44.8)$ & $47.94(54.9)$ \\
\hline \multicolumn{5}{|l|}{ Consult in hospital/clinic } \\
\hline Medical specialist & $93.98(184.3)$ & $106.35(219.7)$ & $94.9(176.2)$ & $94.70(177.7)$ \\
\hline Night in academic hospital & $178.87(853.2)$ & $23.85(173.6)$ & $43.59(337.0)$ & $75.17(507.6)$ \\
\hline Days outpatient treatment & $5.21(37.9)$ & $0.00(0.0)$ & $1.59(20.9)$ & $2.4(25.8)$ \\
\hline Daily period in day centre & $0.0(0.0)$ & $49.37(359.4)$ & $15.04(198.4)$ & $11.53(173.7)$ \\
\hline Nurse & $1.26(6.4)$ & $2.52(8.9)$ & $0.96(5.6)$ & $1.03(5.8)$ \\
\hline Subtotal hospital & $279.33(904.0)$ & $182.10(463.41)$ & $156.09(447.8)$ & $184.87(586.71)$ \\
\hline \multicolumn{5}{|l|}{ Paramedical staff } \\
\hline Consult: Dietician & $0.56(4.1)$ & $1.12(5.7)$ & $1.36(8.9)$ & $1.18(8.05)$ \\
\hline $\begin{array}{l}\text { Consult: Physiotherapist/ } \\
\text { manual therapist }\end{array}$ & $67.19(186.0)$ & $79.14(209.4)$ & $50.94(167.5)$ & $54.74(171.8)$ \\
\hline Consult: Remedial therapist & $0.00(0.0)$ & $0.00(0.0)$ & $1.33(17.5)$ & $1.02(15.3)$ \\
\hline $\begin{array}{l}\text { Consult: Occupational } \\
\text { therapist }\end{array}$ & $2.28(13.6)$ & $0.00(0.0)$ & $0.14(1.8)$ & $0.64(6.8)$ \\
\hline Consult: Medical fitness & $27.62(144.7)$ & $80.63(237.3)$ & $55.94(207.1)$ & $49.33(194.4)$ \\
\hline Consult: Speech therapist & $0.00(0.0)$ & $0.00(0.0)$ & $2.50(33.0)$ & $1.92(28.9)$ \\
\hline $\begin{array}{l}\text { Consult: Osteopath/ } \\
\text { chiropractor }\end{array}$ & $0.00(0.0)$ & $1.90(13.9)$ & $2.51(17.7)$ & $1.93(15.5)$ \\
\hline Consult: Podiatrist & $1.27(6.5)$ & $0.00(0.0)$ & $0.19(2.5)$ & $0.44(3.8)$ \\
\hline Consult: Acupuncturist & $0.00(0.0)$ & $1.26(9.2)$ & $0.39(5.1)$ & $0.30(4.5)$ \\
\hline $\begin{array}{l}\text { Subtotal paramedical staff } \\
\text { Psychological support }\end{array}$ & $98.93(227.2)$ & $164.52(308.0)$ & $115.31(261.3)$ & $111.48(253.4)$ \\
\hline Consult: Social work & $16.18(117.8)$ & $0.00(0.0)$ & $2.46(32.5)$ & $5.67(63.5)$ \\
\hline Consult: Psychologist & $0.00(0.0)$ & $8.14(59.3)$ & $7.44(54.8)$ & $5.70(48.0)$ \\
\hline $\begin{array}{l}\text { Consult: Social psychiatric } \\
\text { nurse }\end{array}$ & $0.00(0.0)$ & $0.00(0.0)$ & $2.31(30.5)$ & $1.77(26.7)$ \\
\hline Consult: Psychiatrist & $0.00(0.0)$ & $4.27(31.1)$ & $2.60(20.9)$ & 1.99 (18.3) \\
\hline Subtotal psychological support & $16.18(117.8)$ & $12.41(66.4)$ & $14.82(72.6)$ & $15.13(85.0)$ \\
\hline Support at home & & & & \\
\hline Paid housekeeping & $352.76(596.0)$ & 391.09 (719.4) & $177.49(503.5)$ & $218.41(530.7)$ \\
\hline Paid personal care & $221.35(964.6)$ & $243.53(753.0)$ & $95.27(467.5)$ & $124.71(619.9)$ \\
\hline Paid medical care & $0.00(0.0)$ & $12.13(88.3)$ & $8.01(74.7)$ & $6.14(65.4)$ \\
\hline Unpaid support & $23.12(63.5)$ & $52.17(118.0)$ & $30.38(115.7)$ & $28.69(105.8)$ \\
\hline Non formal support & $18.67(81.9)$ & $38.89(133.9)$ & $66.80(210.6)$ & $55.57(189.5)$ \\
\hline Subtotal support at home & $615.89(1284.0)$ & $737.81(1332.4)$ & $377.97(903.0)$ & $433.52(1006.9)$ \\
\hline
\end{tabular}




\begin{tabular}{lllll}
\hline Cost Category & \multicolumn{3}{l}{ Total Costs (in €) Per Person (Mean, SD) } \\
\cline { 2 - 5 } & $\begin{array}{l}\text { Sarcopenia } \\
(\mathrm{n}=53)\end{array}$ & $\begin{array}{l}\text { No Sarcopenia, Age } \\
\text { and Sex Matched } \\
(\mathrm{n}=53)\end{array}$ & $\begin{array}{l}\text { No Sarcopenia } \\
(\mathrm{n}=174)\end{array}$ & $\begin{array}{l}\text { Total } \\
(\mathrm{n}=227)\end{array}$ \\
\hline Residential living facility & $2855.62(4195.3)$ & $1343.82(3217.6)$ & $613.99(2262.4)$ & $1137.36(2978.5)$ \\
Assistive devices/in-house & $53.16(220.7)$ & $0.00(0.0)$ & $1.98(14.8)$ & $13.93(108.8)$ \\
adjustments & & & & \\
Food service & $138.0(651.5)$ & $116.85(344.4)$ & $50.39(239.2)$ & $70.84(377.9)$ \\
Nutrition & $5.79(9.9)$ & $6.02(12.0)$ & $8.15(13.3)$ & $7.60(12.6)$ \\
Medication & $189.78(202.7)$ & $142.06(145.4)$ & $145.60(469.2)$ & $155.92(421.5)$ \\
Travel costs to health facility & $5.87(6.7)$ & $10.90(29.4)$ & $6.76(17.4)$ & $6.56(15.6)$ \\
TOTAL COSTS & $4325.1(4240.8)$ & $2767.5(3366.9)$ & $1533.3(2607.3)$ & $2185.1(3277.6)$ \\
\hline
\end{tabular}

GP, general practitioner. Exchange rate 2014: 1 EUR = 1.33 USD (European Central Bank, retrieved March 16, 2015, from https://www.ecb.europa.eu/stats/exchange/eurofxref/html/eurofxref-graph-usd.en.html). 



\section{CHAPTER 6}

\section{Physical Activity and Incidence of Sarcopenia: The Population-Based AGES-Reykjavik Study}

Submitted as: DM Mijnarends, A Koster, JMGA Schols, JMM Meijers, RJG Halfens, V Gudnason, G Eiriksdottir, K Siggeirsdottir, S Sigurdsson, PV Jonsson, O Meirelles, TB Harris. 


\section{ABSTRACT}

Background: The prevalence of sarcopenia increases with age. Physical activity might slow the rate of muscle loss and therewith the incidence of sarcopenia.

Objective: To examine the association of physical activity with incident sarcopenia over a five year period.

Design: Data from the population-based Age, Gene/Environment, Susceptibility-Reykjavik Study (AGES-Reykjavik Study) were used.

Setting: People residing in the Reykjavik area at the start of the study.

Subjects: The study included people aged 66-93 years old.

Methods: The amount of moderate-vigorous physical activity (MVPA) was assessed by a self-reported questionnaire. Sarcopenia was identified using the European Working Group on Sarcopenia in Older People (EWGSOP) algorithm. Muscle mass was assessed by computed tomography imaging of the thigh, grip strength by a computerized dynamometer affixed to a chair and gait speed by a $6-\mathrm{m}$ walk.

Results: 2,309 participants (mean age $74.9 \pm 4.7$ years; $58 \%$ female) had complete data and were included in the analyses. The prevalence of sarcopenia was $7.3 \%$ at baseline and $16.8 \%$ at follow-up. The incidence proportion of sarcopenia over five years was $14.8 \%$ in the least active individuals and $9.0 \%$ in the most active individuals. Compared to participants who reported that they never participated in MVPA, those reporting a moderate-high amount of MVPA had a significantly lower likelihood of incident sarcopenia (OR: 0.64; 95\% Cl: 0.45-0.91).

Conclusion: A higher amount of MVPA seems to contribute to counteracting the development of sarcopenia. To delay the onset of sarcopenia and its potential adverse outcomes, attention should be paid to increasing physical activity levels in older adults. 


\section{Introduction}

Sarcopenia, defined as the loss of muscle mass and function, affects quality of life and increases the risk of physical limitations and disability in older adults. ${ }^{1,2}$ Depending on the definition used, the prevalence of sarcopenia in community-dwelling older adults ranges from $1 \%$ to $50 \%$, with higher prevalence rates in older age groups. ${ }^{3,4}$ Although the loss of muscle mass appears to be an inevitable part of the aging process, the rate of muscle loss is modifiable. ${ }^{5}$ For instance, resistance training interventions have shown to be effective in reversing losses of skeletal muscle mass and function. ${ }^{6}$ Aiming to delay the onset of disability and progression of chronic diseases and to gain other health benefits, current recommendations for physical activity are set at 150 minutes per week for moderateintensity aerobic activity and two or more days per week for muscle strengthening activities. ${ }^{7,8}$ Moderate-intensity activity noticeably accelerates the heart rate and includes activities like brisk walking or dancing. ${ }^{7}$ In industrialized countries physical activity levels in older adults are low, with $40-60 \%$ of the older adults not meeting the recommendations for physical activity. ${ }^{7,9}$ Although exercise has been proven to be effective in reversing losses of muscle mass, ${ }^{6,10}$ studies investigating the effect of general physical activity on the prevention of sarcopenia show inconsistent results. ${ }^{11}$ For example, Ryu and colleagues, using data from a cross-sectional Korea National Health and Nutrition Examination Survey, report that being physically active is associated with a reduced risk of sarcopenia. ${ }^{12}$ On the contrary, Volpato et al. ${ }^{13}$ did not find an association between physical activity and sarcopenia. Raguso et al. ${ }^{14}$ performed a 3-year longitudinal study and found that leisure time physical activity did not seem to prevent the loss of muscle mass.

In addition to the issue of inconsistent findings of the effect of general physical activity on sarcopenia, only a few studies have examined the incidence of sarcopenia. ${ }^{15-17}$ The aim of this study, then, was to examine the association of physical activity with the incidence of sarcopenia over a five year period in a large population-based cohort study of older adults, the AGES-Reykjavik Study. ${ }^{18}$ To identify people with sarcopenia, the algorithm of the European Working Group on Sarcopenia in Older People (EWGSOP) was used. ${ }^{19}$ This algorithm includes measurements of muscle mass (computed tomography of the midthigh), isometric muscle strength of the hand (computerized dynamometer) and gait speed (6 m walk).

\section{Methods}

\subsection{Design and Study Population}

This paper describes a secondary data analysis using data of the Age, Gene/Environment, Susceptibility-Reykjavik (AGES-Reykjavik) Study. ${ }^{18}$ AGES-Reykjavik is a population-based study undertaken in survivors of the Reykjavik Study. ${ }^{18,20,21}$ The Reykjavik Study, established in 1967 and followed by the Icelandic Heart Association, aimed to prospectively study cardiovascular disease in people born between 1907 and 1935 and residing in Reykjavik. ${ }^{18,20,21}$ Between 2002 and 2006 the AGES-Reykjavik Study reexamined 5764 survivors of the original cohort who had participated in the Reykjavik Study (T1). The second examination (T2) took place between 2007 and 2011 ( $n=3,316$ ). All participants signed informed consent. The National Bioethics Committee in Iceland and the National Institute on Aging Intramural Institutional Review Board in Bethesda, USA, approved the study (approval number VSN-00-063). 


\subsection{Measurements}

The baseline examination consisted of three clinic visits within four to six weeks. ${ }^{18}$ It included, among others, vascular, neurocognitive and musculoskeletal components and questionnaires on physical, psychological and social health. An overview of all examinations included in the AGES-Reykjavik Study has been previously published. ${ }^{18}$ For this paper, relevant measurements are described below. The included measurements were performed at both baseline (T1) and follow-up (T2).

\subsection{Identification of Sarcopenia}

Sarcopenia was identified using the algorithm of the European Working Group on Sarcopenia in Older People (EWGSOP). ${ }^{19}$ According to this algorithm, sarcopenia is present in older adults with low muscle mass in combination with poor muscle strength and/or performance. Muscle mass was assessed by computed tomography imaging (CT), using a four-detector CT system (Sensation, Siemens Medical Systems, Erlangen, Germany). ${ }^{22}$ Average thigh total muscle cross-sectional area $\left(\mathrm{cm}^{2}\right)$ was obtained from a single axial $10-\mathrm{mm}$-thick section in both legs. ${ }^{23}$ To our knowledge, this is the first study to apply the EWGSOP definition using a CT image-based measure for muscle mass. ${ }^{3}$ The EWGSOP does not provide CT cut-off points for low muscle mass, therefore the lowest gender-specific $20^{\text {th }}$ percentile of the thigh total muscle cross sectional area $\left(<83.2 \mathrm{~cm}^{2}\right.$ in females, $<116.5 \mathrm{~cm}^{2}$ in males) was used in the main analyses and the lowest genderspecific $10^{\text {th }}$ percentile $\left(<78.2 \mathrm{~cm}^{2}\right.$ in females, $<108.2 \mathrm{~cm}^{2}$ in males) in the sensitivity analyses. The $20^{\text {th }}$ percentile method has been used before in sarcopenia research using DXA. ${ }^{24,25}$ Maximum grip strength of the dominant hand was measured by a computerized dynamometer affixed to an adjustable special chair (Good Strength software, Metitur, Finland), with the elbow flexed at $90^{\circ}$ and armrests adjusted for height so that the shoulders were relaxed. ${ }^{26}$ Participants performed three trials, each lasting four to five seconds, and after each exam they rested for half a minute. Participants were provided with standardized verbal encouragement throughout the testing protocol. EWGSOP cut-off points for poor grip strength are $<20 \mathrm{~kg}$ (women) and $<30 \mathrm{~kg}$ (men). ${ }^{19}$ Usual walking speed $(\mathrm{m} / \mathrm{s})$ was assessed over a 6 meter track. ${ }^{27}$ The EWGSOP cut-off point for slow gait speed is $\leq 0.8 \mathrm{~m} / \mathrm{s}^{19}$

\subsection{Physical Activity Assessment}

Physical activity was assessed by a self-reported questionnaire. Participants were asked, among others, how many hours per week they participated in moderate to vigorous intensity physical activity (MVPA) in the past 12 months (one question). Provided examples of MVPA were badminton, golf, biking, swimming, heavy gardening, weight lifting, hiking/mountain climbing, fast walking/heavy housework, rowing, aerobics, jogging and running. Pre-defined answer categories were never, rarely, occasionally (weekly but less than one hour), moderate (1-3 hours per week) and high (more than 4 hours per week). In the final analyses the MVPA categories were combined into 1. Never, 2. Rarelyoccasionally, 3. Moderate-high.

\subsection{Covariates}

Age, sex, education (primary, secondary, college, university), marital status (married/living together, widow/widower, divorced, single), smoking status (never, previous, current) and 
$>5 \mathrm{~kg}$ weight loss in the past 12 months were assessed by a questionnaire. BMI was calculated by dividing body weight in $\mathrm{kg}$ by height in meters squared. The total number of comorbidities was obtained by self-report, medication assessment and clinical assessment, and included cancer, chronic lung disease, asthma, dementia, diabetes, heart attack, congestive heart failure, hypertension, rheumatic disorder and stroke. Depressive symptoms were assessed by the validated 15-item Geriatric Depression Scale (GDS). ${ }^{28,} 29$ The total score of the GDS ranges from zero (no depressive symptoms), to 15 (high number of depressive symptoms), with 6 or more depressive symptoms as a cut-off point for depression. ${ }^{29}$ Cognitive function was assessed by the Mini-Mental State Examination, with scores ranging from $0-30$, where higher scores indicate better cognitive function. ${ }^{30}$

\subsection{Statistical analysis}

To compare baseline characteristics of people with and without sarcopenia, Chi-square tests (categorical variables) and Student's t-tests (continuous variables) were used. Multinomial regression was used to examine differences in the amount of MVPA between participants with and without sarcopenia at T1. Model 1 was adjusted for age, sex, education and marital status. Model 2 further included BMI, smoking status, total number of comorbidities, depressive symptoms, weight loss, and cognitive function.

To assess the association between baseline physical activity and incidence of sarcopenia, logistic regression was used. For this analysis, only people without sarcopenia at baseline were included $(n=2140)$. As above, model 1 was adjusted for age, sex, education and marital status. Model 2 additionally included BMI, smoking status, total number of comorbidities, depressive symptoms, weight loss, and cognitive function.

\section{Results}

Between baseline $(n=5,764)$ and follow-up (mean follow-up $5.2 \pm 0.3$ years, range 4.2-8.2 years), 1,039 participants died and 1,409 were lost to follow-up or refused to participate, leaving a total sample at follow-up of 3,316 participants (Supplementary Data, Figure 1). Of these 3,316 participants, 1,007 were excluded due to missing data on muscle parameters ( $n=670)$, physical activity $(n=66)$ or baseline covariates $(n=271)$, leaving a total analytical sample of 2,309 participants. Characteristics of participants who participated at baseline only and characteristics of participants excluded because of missing data are shown in Supplementary Data, Table 1. Participants that dropped out between T1 and T2 were at baseline significantly older, had a lower BMI, more comorbidities, a lower educational level, were more often living alone, were less active and were more often sarcopenic compared to participants that did not drop out.

Characteristics of the 2,309 included participants are shown in Table 1. The mean age of the participants was 74.9 years at baseline and the majority were female $(57.8 \%)$, which reflects the gender distribution of this age group in the general population. The prevalence of sarcopenia was $7.3 \%(n=169)$ at baseline (see sarcopenia identification in Supplementary Data, Figure 2$)$ and $16.8 \%(n=389)$ at follow-up. At baseline, significant differences between sarcopenic and non-sarcopenic older adults were found for all characteristics except smoking status and weight loss. At baseline $38.5 \%$ of the participants did not engage in MVPA, which was $47.7 \%$ at follow-up. 


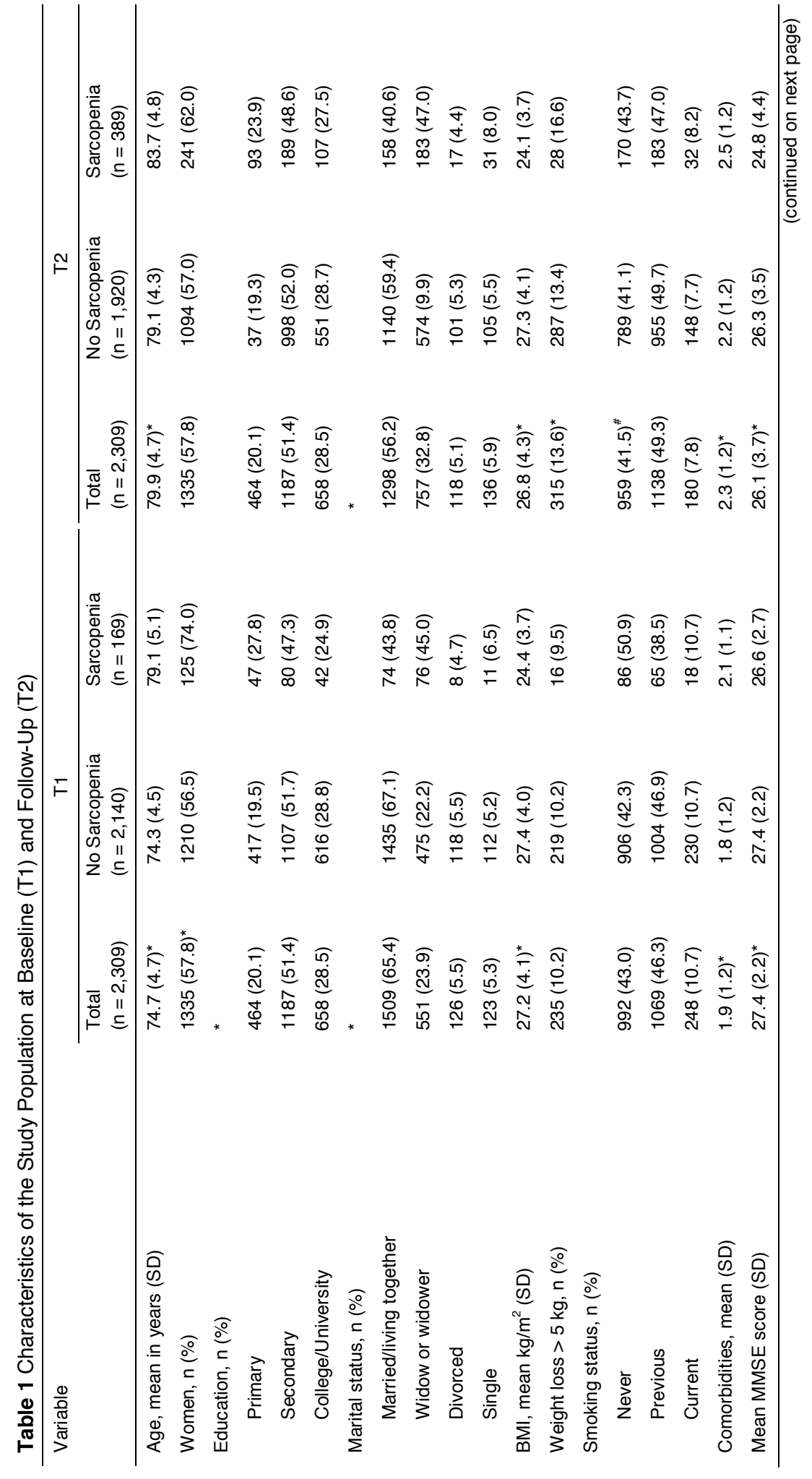




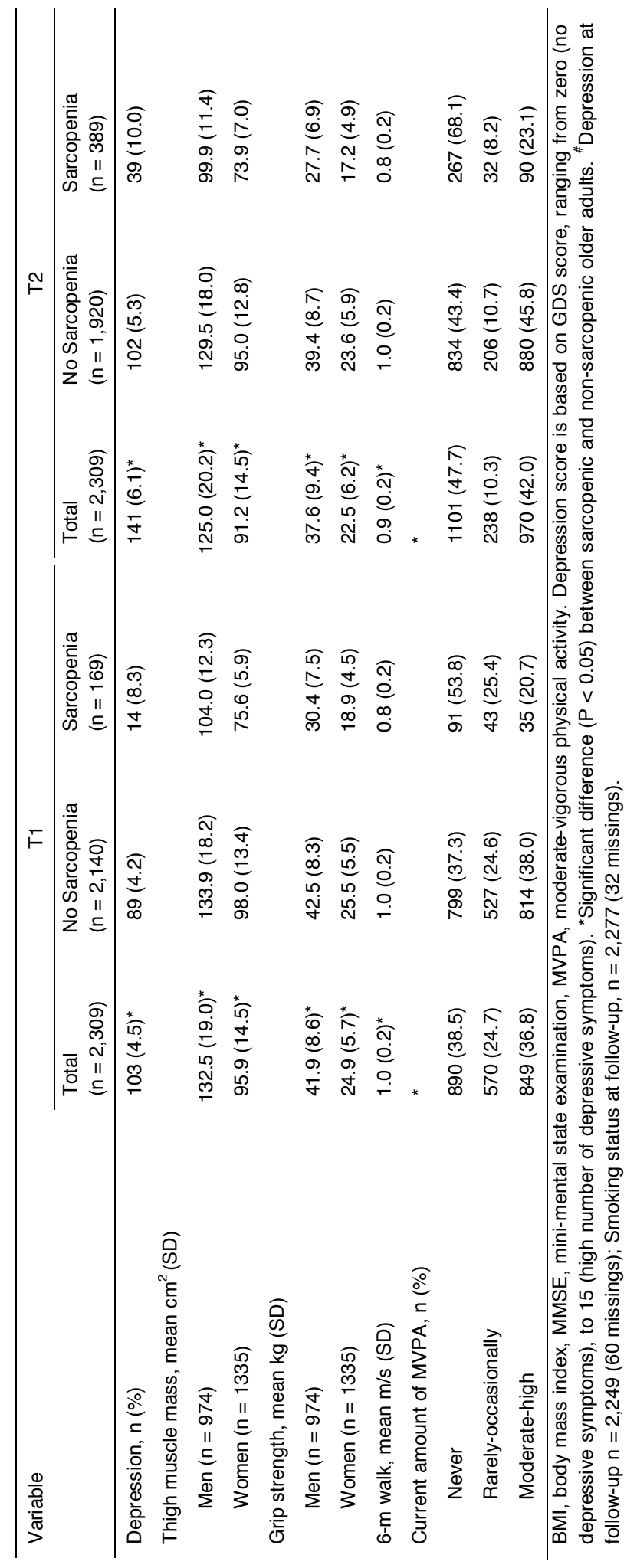




\subsection{Physical Activity in People with and without Sarcopenia}

Multinomial regression indicated that sarcopenic older adults engaged in significantly less MVPA (Table 2). People with sarcopenia at baseline had a lower likelihood $(\mathrm{OR}=0.49$, $95 \% \mathrm{Cl}:$ 0.32-0.76) of having a moderate-high amount of MVPA compared with participants without sarcopenia. People with sarcopenia at baseline also tended to have a lower likelihood $(\mathrm{OR}=0.89,95 \% \mathrm{Cl}: 0.59-1.34)$ of engaging rarely-occasionally in MVPA compared with participants without sarcopenia, but this was not statistically significant.

Table 2 Differences in MVPA between People with and without Sarcopenia

\begin{tabular}{llll}
\hline & $\begin{array}{l}\text { Unadjusted Model } \\
\text { OR }(95 \% \mathrm{Cl})\end{array}$ & $\begin{array}{l}\text { Model 1 } \\
\text { OR }(95 \% \mathrm{Cl})\end{array}$ & $\begin{array}{l}\text { Model } 2 \\
\text { OR }(95 \% \mathrm{Cl})\end{array}$ \\
\hline Rarely-occasionally vs. never (ref) MVPA & O.72 (0.49-1.05) & $0.92(0.61-1.37)$ & $0.89(0.59-1.34)$ \\
Moderate-high vs. never (ref) MVPA & $0.38(0.25-0.56)$ & $0.53(0.35-0.81)$ & $0.49(0.32-0.76)$ \\
\hline
\end{tabular}

Dependent variable is sarcopenia status $(0=$ no sarcopenia, 1 = sarcopenia). Model 1 is adjusted for age, sex, education and marital status. Model 2 further included BMI, smoking status, total number of comorbidities, depressive symptoms, weight loss, and cognitive function. MVPA, moderate-vigorous physical activity.

\subsection{Incidence of Sarcopenia}

As shown in Table 3, the incidence proportion of sarcopenia in participants who never engaged in MVPA, rarely-occasionally engaged in MVPA and participants with a moderate-high amount of MVPA was 14.8\% (118 out of 799), 10.4\% (55 out of 527) and $9.0 \%$ (74 out of 814 ), respectively. Participants who reported a moderate-high amount of MVPA at baseline had a significantly decreased likelihood of incident sarcopenia compared to those who reported never to participate in MVPA (OR: 0.68, 95\% Cl: 0.490.94 ; Table 3, Model 1). Additionally, in model 1 older age was significantly associated with the incidence of sarcopenia. In model 2, next to older age, lower BMI and worse cognitive function were significantly associated with the incidence of sarcopenia.

Sensitivity analyses using the lowest gender-specific $10^{\text {th }}$ percentile for muscle mass showed the same trend, a significant difference was found in the incidence of sarcopenia between participants who never participated in MVPA compared with participants with a moderate-high amount of MVPA (OR 0.64, 95\% Cl: 0.45-0.90; not tabulated).

\section{Discussion}

This study showed that older adults with sarcopenia engaged significantly less in MVPA than their non-sarcopenic peers. Further, the incidence proportion of sarcopenia was significantly lower in the highly active participants, compared with the least active participants.

The incidence proportion found in this study $(9.0-14.8 \%)$ is roughly comparable to the incidence proportion found in two other recent studies performed in community-dwelling older adults. ${ }^{15,16}$ Both studies used the EWGSOP algorithm to define sarcopenia, though slightly different cut-off points were applied. ${ }^{15,16} \mathrm{Kim}$ et al. ${ }^{15}$ found a 4-year sarcopenia incidence proportion of $15.8 \%$ in a community-dwelling population of older women aged 75 years and older. Yu et al. ${ }^{16}$ reported a 4-year incidence proportion of sarcopenia of $7.8 \%$ in a population of 65 years and older, recruited in three Australian cohort studies. Yu et al. ${ }^{16}$ also found that lower physical activity levels were associated with a higher incidence of sarcopenia, though physical activity was not associated with reversibility of sarcopenia. 
However, in an intervention study by Liu et al., ${ }^{31}$ in which sarcopenia was defined as low appendicular lean muscle mass, it was found that a physical activity intervention improved physical performance in both sarcopenic as well as non-sarcopenic older adults. Murphy et al. ${ }^{32}$ showed that in the Health ABC study people with more physical activity were less likely to transition to sarcopenia. A longitudinal study using objectively measured physical activity data, by accelerometer, showed that a greater habitual physical activity delayed the loss of lean mass. ${ }^{33}$ In contrast, in a cross-sectional study by Volpato et al., ${ }^{13}$ no association was found between physical activity and sarcopenia. This may be explained by the method used to assess muscle mass, i.e. bioelectrical impedance, which might have led to an overestimation of muscle mass. ${ }^{13}$ Also, being physically active does not equal immunity to sarcopenia, as suggested in a review by Marcell. ${ }^{34}$ Furthermore, the author questions whether in addition to physiologic factors, sarcopenia might be associated with social issues preventing older adults from taking up exercise. ${ }^{34}$

Table 3 Association of Physical Activity with the Sarcopenia Incidence Proportion over a Five Year Period

\begin{tabular}{|c|c|c|c|c|}
\hline & $\begin{array}{c}\text { Sarcopenia } \\
\text { Incidence (\%) }\end{array}$ & $\begin{array}{c}\text { Unadjusted Model } \\
\text { OR }(95 \% \mathrm{Cl})\end{array}$ & $\begin{array}{c}\text { Model } 1 \\
\text { OR }(95 \% \mathrm{Cl})\end{array}$ & $\begin{array}{c}\text { Model } 2 \\
\text { OR }(95 \% \mathrm{Cl})\end{array}$ \\
\hline \multicolumn{5}{|l|}{ Amount of MVPA at baseline } \\
\hline Never $(n=799)$ & 14.8 & Ref & Ref & Ref \\
\hline Rarely-occasionally $(n=527)$ & 10.4 & $0.67(0.48-0.95)$ & $0.78(0.54-1.12)$ & $0.79(0.54-1.14)$ \\
\hline Moderate-high $(n=814)$ & 9.0 & $0.58(0.42-0.79)$ & $0.68(0.49-0.94)$ & $0.64(0.45-0.91)$ \\
\hline Age & & & $1.21(1.17-1.25)$ & $1.20(1.16-1.24)$ \\
\hline Sex & & & $0.99(0.74-1.33)$ & $1.21(0.89-1.64)$ \\
\hline Education & & & $1.04(0.89-1.22)$ & $1.07(0.90-1.27)$ \\
\hline Marital status & & & $1.06(0.90-1.25)$ & $1.01(0.84-1.20)$ \\
\hline BMI & & & & $0.85(0.82-0.89)$ \\
\hline Smoking status & & & & $1.22(0.98-1.53)$ \\
\hline \# of comorbidities & & & & $1.13(1.00-1.28)$ \\
\hline Depressive symptoms & & & & $1.03(0.95-1.12)$ \\
\hline Weight loss $>5 \mathrm{~kg}$ & & & & $1.31(0.82-2.11)$ \\
\hline Cognitive function & & & & $0.90(0.85-0.96)$ \\
\hline
\end{tabular}

BMI, body mass index; MVPA, moderate-vigorous physical activity; Ref, reference group. Depression symptoms as assessed by the Geriatric Depression Scale, with scores ranging from zero (no depressive symptoms), to 15 (high number of depressive symptoms). Cognitive function was assessed by the MMSE.

Our study supports the idea that physical activity seems to counteract losses of muscle mass, and increasing the level of physical activity might delay the development of sarcopenia. In 2011, Pillard et al. ${ }^{35}$ discussed the idea of prescribing physical activity as a countermeasure for sarcopenia. The paper describes several steps that a medical practitioner can take to encourage physical activity as a medicine, including how to define the physical activity dose. ${ }^{35}$ Both Shephard et al. ${ }^{33}$ and the European Society for Clinical Nutrition and Metabolism (ESPEN) expert group, ${ }^{36}$ recommend daily physical activity for older adults; 15-20 minutes of at least a moderate intensity. The expert group also advises combining physical activity with a diet including 1.0-1.2 $\mathrm{g}$ protein $/ \mathrm{kg}$ body weight/day. ${ }^{36}$ These are first steps in sarcopenia prevention and control. 
Some limitations should be addressed. The prevalence of sarcopenia found in this study is comparable to other studies using the EWGSOP definition in community-dwelling and long-term care populations. ${ }^{3}$ However, the 'real' baseline prevalence of sarcopenia $(12.2 \%$, $n=4,833$ ) was higher than in the analytical sample, because sarcopenic participants were more likely to become lost-to-follow-up. Also, the people that dropped out between the first (T1) and second (T2) examination had on average more comorbidities and more than half never performed MVPA. Since these factors are both likely to increase the risk of developing sarcopenia, the actual incidence of sarcopenia is likely to be higher than shown in this study. CT imaging is seen as one of the gold standards to assess muscle mass, however no official cut-off points for low muscle mass were available, using other cut-off points might affect the outcome. ${ }^{3,37}$ Physical activity was assessed by self-report. This might have led to an overestimation of physical activity levels. ${ }^{38}$ Objective measurement of physical activity could improve the reliability of physical activity data. However, we do believe that self-report gives a fair indication of whether a person is not active at all or highly active. During the five year follow-up, no interim evaluation of physical activity and other measures was performed. It could be possible that events (such as the development of disease or hospitalization) that occurred within these five years have confounded the relationship between incident sarcopenia and physical activity. Although physical activity and exercise are often used interchangeably, in theory they are different concepts. ${ }^{8}$ For this study, one single question was included with regard to physical activity, including both general physical activity as well as exercise; data on reliability and validity of the physical activity questionnaire are unknown. Further, no conclusions can be drawn with regard to the type of physical activity or exercise that contributed mostly to the incidence of sarcopenia.

To conclude, a moderate-high amount ( $>1$ hour per week) of MVPA seems to contribute to counteracting the losses of muscle mass and function. Attention should be paid to increasing physical activity levels in older adults, since this might decrease the incidence of sarcopenia and therefore might prevent the onset of poor health outcomes.

\section{Acknowledgements}

The authors would like to thank all the participants of the AGES-Reykjavik study. We would specially like to thank Melissa E. Garcia for her support with the data handling. Declaration of sources of funding: This work was supported by National Institutes of Health, National Institute on Aging [N01-AG-1-2100], the National Institute on Aging Intramural Research Program, Hjartavernd (the Icelandic Heart Association), and the Althingi (the Icelandic Parliament). 


\section{References}

1. Hairi NN, Cumming RG, Naganathan V, et al. Loss of muscle strength, mass (sarcopenia), and quality (specific force) and its relationship with functional limitation and physical disability: the Concord Health and Ageing in Men Project. J Am Geriatr Soc 2010;58:2055-2062.

2. Rizzoli R, Reginster JY, Arnal JF et al. Quality of life in sarcopenia and frailty. Calcif Tissue Int 2013;93:101120.

3. Cruz-Jentoft AJ, Landi F, Schneider SM et al. Prevalence of and interventions for sarcopenia in ageing adults: a systematic review: report of the International Sarcopenia Initiative (EWGSOP and IWGS). Age Ageing 2014;43:748-759.

4. Fielding RA, Vellas B, Evans WJ et al. Sarcopenia: an undiagnosed condition in older adults: current consensus definition: prevalence, etiology, and consequences. International working group on sarcopenia. $J$ Am Med Dir Assoc 2011;12:249-256.

5. Montero-Fernández N, Serra-Rexach JA. Role of exercise on sarcopenia in the elderly. Eur J Phys Rehabil Med 2013;49:131-143.

6. Landi F, Marzetti E, Martone AM et al. Exercise as a remedy for sarcopenia. Curr Opin Clin Nutr Metab Care 2014;17:25-31.

7. Taylor D. Physical activity is medicine for older adults. Postgrad Med J 2014;90:26-32

8. Chodzko-Zajko W, Proctor DN, Fiatarone Singh MA et al. Exercise and physical activity for older adults. Med Sci Sports Exercise 2009;41:1510-1530.

9. Hallal PC, Andersen LB, Bull FC et al. Global physical activity levels: surveillance progress, pitfalls, and prospects. Lancet 2012;380:247-257.

10. Kim H, Suzuki T, Saito K, Kojima N, Hosoi E, Yoshida H. Long-term effects of exercise and amino acid supplementation on muscle mass, physical function and falls in community-dwelling elderly Japanese sarcopenic women: a 4-year follow-up study. Geriatr Gerontol Int. 2015;16(2):175-81.

11. Scott D, Blizzard L, Fell $\mathrm{J}$ et al. The epidemiology of sarcopenia in community living older adults: what role does lifestyle play? J Cachexia Sarcopenia Muscle 2011;2:125-134.

12. Ryu M, Jo J, Lee $\mathrm{Y}$ et al. Association of physical activity with sarcopenia and sarcopenic obesity in community-dwelling older adults: the Fourth Korea National Health and Nutrition Examination Survey. Age Ageing 2013;42:734-740.

13. Volpato S, Bianchi L, Cherubini A et al. Prevalence and clinical correlates of sarcopenia in communitydwelling older people: application of the EWGSOP definition and diagnostic algorithm. J Gerontol A Biol Sci Med Sci 2013;000-000.

14. Raguso CA, Kyle U, Kossovsky MP, et al. A 3-year longitudinal study on body composition changes in the elderly: role of physical exercise. Clin Nutr 2006;25:573-580.

15. Kim H, Suzuki T, Kim M et al. Incidence and predictors of sarcopenia onset in community-dwelling elderly Japanese women: 4-year follow-up study. J Am Med Dir Assoc 2015;16:85.e81-88.

16. Yu R, Wong M, Leung $\mathrm{J}$ et al. Incidence, reversibility, risk factors and the protective effect of high body mass index against sarcopenia in community-dwelling older Chinese adults. Geriatr Gerontol Int 2014;14:15-28.

17. Scott D, Hayes A, Sanders KM, Aitken D, Ebeling PR, Jones G. Operational definitions of sarcopenia and their associations with 5-year changes in falls risk in community-dwelling middle-aged and older adults. Osteoporos Int. 2014;25(1):187-93.

18. Harris TB, Launer LJ, Eiriksdottir G et al. Age, gene/environment susceptibility: Reykjavik study: multidisciplinary applied phenomics. Am J Epidemiol 2007;165:1076-1087.

19. Cruz-Jentoft AJ, Baeyens JP, Bauer JM et al. Sarcopenia: European consensus on definition and diagnosis: report of the European Working Group on Sarcopenia in Older People. Age Ageing 2010;39:412-423.

20. Bjornsson OJ, Davidsson D, Olafsson H et al. Report ABC XVIII. Health survey in the Reykjavik area: Men. Stages I-III, 1967-1968, 1970-1971 and 1974-1975: participants, invitation, response etc. Reykjavik, Iceland: Icelandic Heart Association, 1979.

21. Bjornsson G, Bjornsson OJ, Davidsson D et al. Report ABC XXIV. Health survey in the Reykjavik area. Women. Stages I-III, 1968-1969, 1971-1972 and 1976-1978: participants, invitation, response etc. Reykjavik, Iceland: Icelandic Heart Association, 1982.

22. Sigurdsson $G$, Aspelund $T$, Chang $M$ et al. Increasing sex difference in bone strength in old age: the Age, Gene/Environment Susceptibility-Reykjavik study (AGES-REYKJAVIK). Bone 2006;39:644-651.

23. Johannesdottir F, Aspelund T, Siggeirsdottir K et al. Mid-thigh cortical bone structural parameters, muscle mass and strength, and association with lower limb fractures in older men and women (AGES-Reykjavik Study). Calcif Tissue Int 2012;90:354-364. 
24. Yu S, Appleton S, Adams R et al. The impact of low muscle mass definition on the prevalence of sarcopenia in older Australians. Biomed Res Int 2014;000-000.

25. Pagotto V, Silveira EA. Methods, diagnostic criteria, cutoff points, and prevalence of sarcopenia among older people. ScientificWorldJournal 2014;000-000.

26. Era $\mathrm{P}$, Rantanen $\mathrm{T}$, Avlund $\mathrm{K}$ et al. Maximal isometric muscle strength and anthropometry in 75-year-old men and women in three Nordic localities. Scand J Med Sci Sports 1994;4:26-31.

27. Ostir GV, Markides KS, Black SA et al. Lower body functioning as a predictor of subsequent disability among older Mexican Americans. J Gerontol A Biol Sci Med Sci 1998;53:M491-495.

28. Yesavage JA, Brink TL, Rose TL et al. Development and validation of a geriatric depression screening scale: a preliminary report. J Psychiatr Res 1982;17:37-49.

29. Almeida OP, Almeida SA. Short versions of the geriatric depression scale: a study of their validity for the diagnosis of a major depressive episode according to ICD-10 and DSM-IV. Int J Geriatr Psychiatry 1999;14:858-865.

30. Folstein MF, Folstein SE, McHugh PR. "Mini-mental state": a practical method for grading the cognitive state of patients for the clinician. J Psychiatr Res 1975;12(3):189-98.

31. Liu CK, Leng X, Hsu FC et al. The impact of sarcopenia on a physical activity intervention: the Lifestyle Interventions and Independence for Elders Pilot Study (LIFE-P). J Nutr Health Aging 2014;18:59-64.

32. Murphy RA, Ip EH, Zhang $Q$ et al. Transition to sarcopenia and determinants of transitions in older adults: a population-based study. J Gerontol A Biol Sci Med Sci 2014;69:751-758.

33. Shephard RJ, Park H, Park S et al. Objectively measured physical activity and progressive loss of lean tissue in older Japanese adults: Iongitudinal data from the Nakanojo study. J Am Geriatr Soc 2013;61:18871893.

34. Marcell TJ. Sarcopenia: causes, consequences, and preventions. J Gerontol A Biol Sci Med Sci 2003;58:M911-916.

35. Pillard F, Laoudj-Chenivesse D, Carnac G et al. Physical activity and sarcopenia. Clin Geriatr Med 2011;27:449-470.

36. Deutz NE, Bauer JM, Barazzoni R et al. Protein intake and exercise for optimal muscle function with aging: recommendations from the ESPEN Expert Group. Clin Nutr 2014;33:929-936.

37. Mijnarends DM, Meijers JMM, Halfens RJG et al. Validity and reliability of tools to measure muscle mass, strength, and physical performance in community-dwelling older people: a systematic review. J Am Med Dir Assoc 2013;14:170-178.

38. Jakicic JM, King WC, Gibbs BB et al. Objective versus self-reported physical activity in overweight and obese young adults. J Phys Act Health 2015;000-000. 


\section{Supplementary Data Chapter 6}

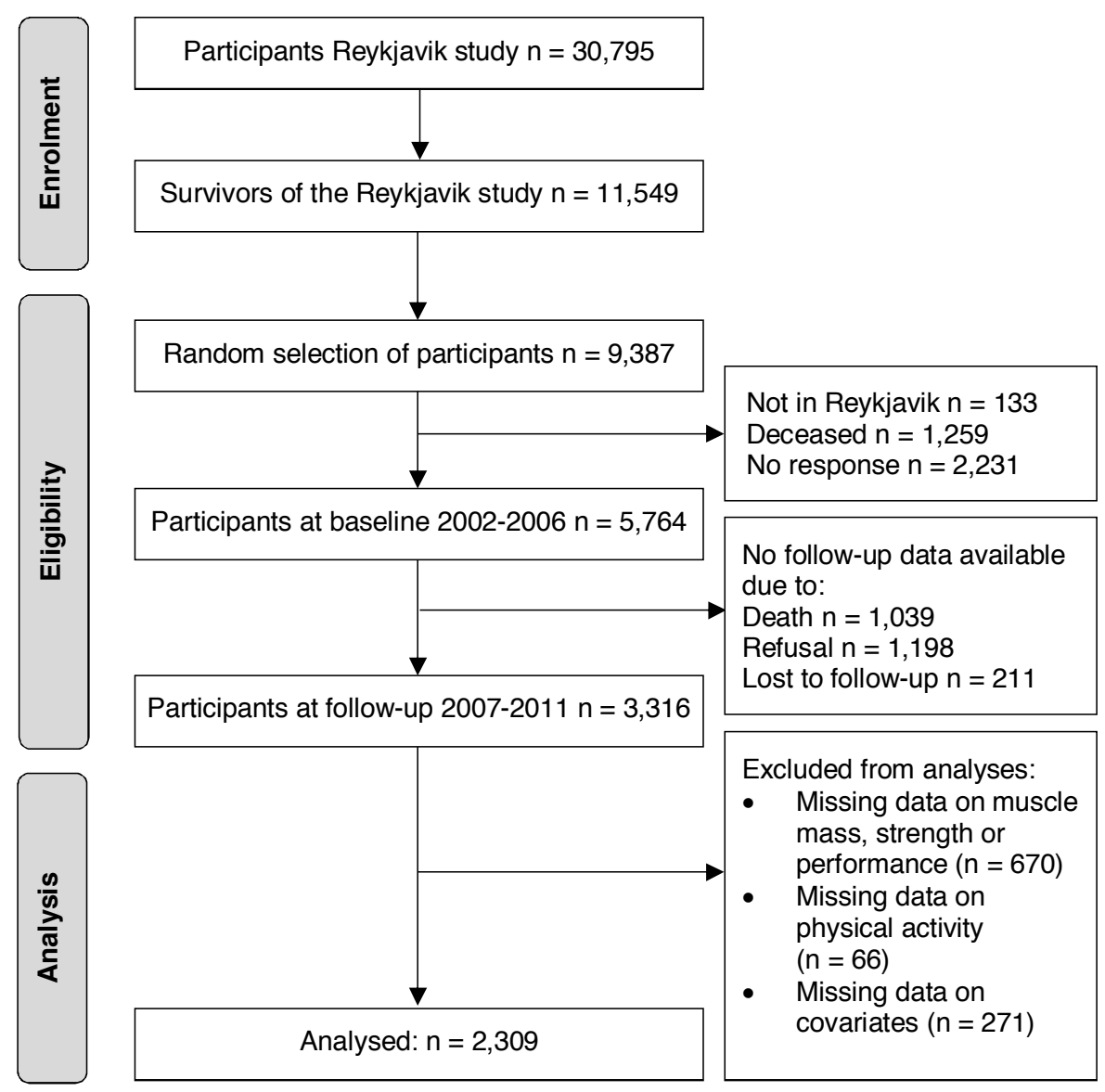

Supplementary Figure 1 Flow diagram of inclusion AGES-Reykjavik Study 


\section{Supplementary Data Chapter 6}

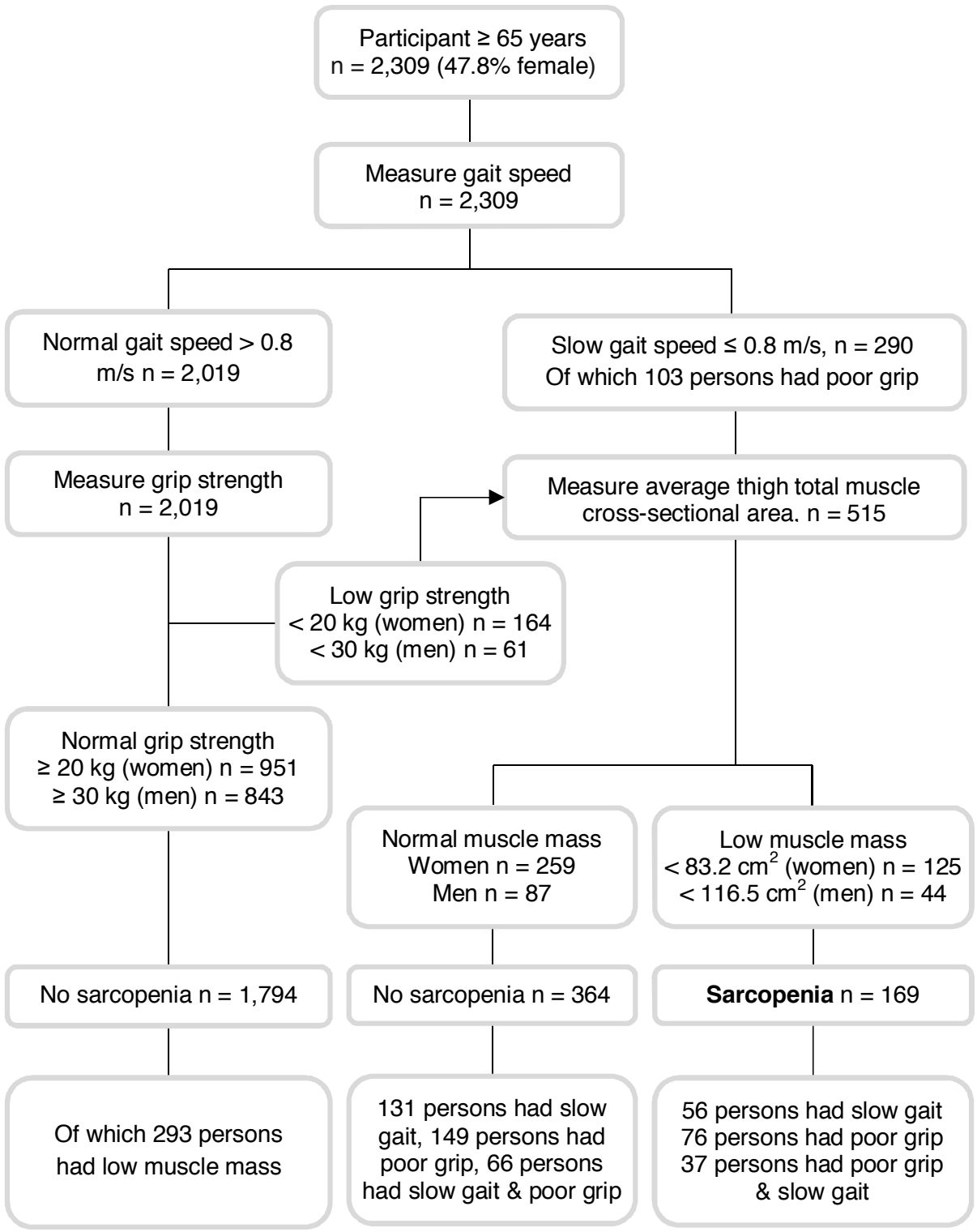

Supplementary Figure 2 Identification of sarcopenia at baseline using the EWGSOP algorithm ${ }^{19}$ 


\section{Supplementary Data Chapter 6}

Supplementary Table 1 Baseline Characteristics of Participants Who Were Excluded From the Analyses

\begin{tabular}{|c|c|c|}
\hline Variable & $\begin{array}{l}\text { Participants with Only Baseline } \\
\text { Data, No Follow-Up Data } \\
\left(n=2,448^{\star}\right)\end{array}$ & $\begin{array}{l}\text { Participants Excluded Because } \\
\text { of Missing Data } \\
\left(n=1,007^{\star \star}\right)\end{array}$ \\
\hline Age, mean y (SD) & $79.7(6.0)$ & $75.7(5.3)$ \\
\hline Women, n (\%) & $1,392(56.9)$ & $599(59.5)$ \\
\hline \multicolumn{3}{|l|}{ Education, n (\%) } \\
\hline Primary & $583(28.6)$ & $217(22.1)$ \\
\hline Secondary & $965(47.4)$ & $502(51.0)$ \\
\hline College/University & $490(24.0)$ & 265 (26.9) \\
\hline \multicolumn{3}{|l|}{ Marital status, n (\%) } \\
\hline Married/living together & $1,059(51.9)$ & $604(61.4)$ \\
\hline Widow or widower & $750(36.8)$ & $261(26.5)$ \\
\hline Divorced & $109(5.3)$ & $59(6.0)$ \\
\hline Single & $121(5.9)$ & $60(6.1)$ \\
\hline BMI, mean $\mathrm{kg} / \mathrm{m}^{2}(\mathrm{SD})$ & $26.7(4.7)$ & $27.5(4.9)$ \\
\hline Comorbidities, mean (SD) & $2.3(1.3)$ & $2.0(1.2)$ \\
\hline Sarcopenia, n (\%) & $350(19.2)$ & $72(10.2)$ \\
\hline \multicolumn{3}{|c|}{ Current amount of MVPA, $n(\%)$} \\
\hline Never & $1,186(58.5)$ & $400(41.6)$ \\
\hline Rarely-occasionally & $409(20.2)$ & $233(24.2)$ \\
\hline Moderate-high & $433(21.4)$ & $329(33.4)$ \\
\hline
\end{tabular}

Presented percentages are valid percentages. ${ }^{*}$ Participants with only baseline data, no follow-up data: BMl, $\mathrm{n}=$ 2,381 (67 missing); Total \# of comorbidities, $n=2,008$ (440 missing); Education, $n=2,038$ (410 missing); Marital status, $n=2,040$ (409 missing); Sarcopenia status, $n=1,819$ (629 missing); Physical activity, $n=2,028$ (420 missing). These participants with only baseline data scored significantly different $(P<0.05)$ on all variables compared with participants that did have follow-up data. ${ }^{\star *}$ Participants excluded because of missing data: BMI, $\mathrm{n}$ $=1,006$ ( 1 missing), Total \# of comorbidities, $n=805$ (202 missing); Education, $n=984$ (23 missing); Marital status, $\mathrm{n}=984$ (23 missing); Sarcopenia status, $\mathrm{n}=705$ (302 missing); Physical activity, $\mathrm{n}=962$ (45 missing). Participants excluded because of missing data scored significantly different $(P<0.05)$ on all variables, except $\mathrm{BMI}$, compared with participants that were included in the analyses. 



\section{CHAPTER 7}

\section{General Discussion}



Sarcopenia is thought to have negative effects on both the individual (health outcomes) as well as the society (health care costs). As sarcopenia is a rather 'new' concept in the research world, many gaps in knowledge exist and screening for sarcopenia is not yet embedded in clinical practice. Among the unanswered questions were e.g.: which measurement tools are valid, reliable, and feasible to assess sarcopenia in a communitydwelling population? What is the prevalence of sarcopenia in community-dwelling older adults receiving professional home care or living in a residential living facility? To what extent does the concept of sarcopenia overlap with frailty? What is the health and economic burden of sarcopenia? What is the effect of general physical activity on the incidence of sarcopenia? As the current focus of governments is on aging in place, increasing our understanding of (the burden of) sarcopenia is relevant. Evidence of a substantial burden strengthens the need for interventions and may support policy decisions with regard to prevention, diagnosis, and treatment. In addition, solid evidence increases political and societal support regarding these interventions, which will be needed for successful implementation of prevention, diagnosis or treatment interventions.

The aim of the research presented in this thesis is to gain more insight in the prevalence, characteristics, and health and economic outcomes of community-dwelling older adults with sarcopenia. This final chapter firstly summarizes the main findings of the studies presented in this thesis. Subsequently, theoretical and methodological considerations are discussed and implications for research and practice are given.

\section{Main Findings}

\subsection{Selecting Tools to Measure Sarcopenia}

The European Working Group on Sarcopenia in Older People (EWGSOP) developed an algorithm for sarcopenia case finding. ${ }^{1}$ This algorithm, which includes the parameters muscle mass, muscle strength, and physical performance, was taken as a starting point for the studies presented in this thesis. The EWGSOP suggested several tools to measure the muscle parameters, ${ }^{1}$ however, no systematic review on the measurement properties of those tools was available. Therefore, in the first study presented in this thesis (Chapter 2), the measurement properties (i.e. validity, reliability) of tools to measure muscle mass, strength, and physical performance in community-dwelling older adults were critically appraised. ${ }^{2}$ For quick assessment of muscle mass, strength, and physical performance among community-dwelling older adults it would be beneficial when tools could be applied in a general practitioner practice or in a home setting. Therefore, also the feasibility of tools in these settings was taken into account.

A total of 62 studies were included in the systematic review, reporting on a wide array of tools that are valid and reliable for measurements of muscle mass (e.g. magnetic resonance imaging), strength (e.g. leg press), and performance (e.g. six minute walk test) in clinical settings. ${ }^{2}$ With regard to muscle mass, no well-validated and reliable tools were found for measurements of muscle mass in a home-setting. The best feasible alternative found was bioelectrical impedance analysis (BIA). Evidence for its validity was found; however, age, sex, and cultural influences may affect its validity. Hence these factors should be considered when using BIA. Furthermore, it is likely that the use of different reference populations and cut-off points for muscle mass have large effects on the outcome. For muscle strength, the handheld dynamometer was found to be valid, reliable, 
and feasible. Aligning protocols to assess grip strength by handheld dynamometry was suggested to improve the comparability of study results. In addition, it may be recommended assessing lower extremity strength where possible, as lower extremity strength is important for functional activities. The Short Physical Performance Battery (SPPB) and gait speed showed good measurement properties with regard to the assessment of physical performance. $^{2}$

In conclusion, several tools are available for valid and reliable measurements of muscle mass, strength, and performance in clinical settings. BIA, handheld dynamometry and gait speed or the SPPB were found to be the most valid, reliable, and feasible in a general practitioner practice or in a home-setting. Research is needed on the reliability of tools to assess muscle mass in an older population.

\subsection{Prevalence and Adverse Outcomes of Sarcopenia}

For chapters 3 to 5 of this thesis, data from the cross-sectional Maastricht Sarcopenia Study (MaSS) was analysed. The MaSS study was performed in community-older adults living 1) independently at home without additional care, 2) at home or in an assisted living facility with professional home care, and 3) in a residential living facility with additional professional nursing care and/or meal service. The total prevalence of sarcopenia found in the study sample was $23.3 \%$. This study revealed that sarcopenia was more prevalent in subjects living in a residential living facility (58.6\%) compared to those receiving home care $(41.5 \%)$ and those living at home without additional care $(12.1 \%)$.

Furthermore, sarcopenia was significantly associated with physical frailty. ${ }^{3}$ Physical frailty was assessed by both the Fried frailty criteria and the FRAIL scale. ${ }^{4,5}$ Subjects were categorized as pre-frail when one or two criteria were scored positive and frail when three or more criteria were scored positive. Physical frailty was present in $8.4 \%$ (Fried criteria) and $9.3 \%$ (FRAIL scale) of the subjects. ${ }^{3}$ As for sarcopenia, there is no full consensus yet on which definition of frailty to use. However, when using the Fried or FRAIL scale criteria and cut-off points for frailty, a majority of the sarcopenic subjects was pre-frail and almost a quarter was frail. Frail older adults had a higher chance of having sarcopenia than people without frailty. Two of the five frailty criteria that were most frequently present in frail older adults were weakness (poor grip strength) and slow walking speed. This information can be useful for clinicians as this study showed that screening older adults on muscle strength and/or mobility may identify not only older adults with sarcopenia, but also older adults with (a risk of) frailty. The two physical frailty scales, the Fried criteria and the FRAIL scale, correlated moderately. This means that the scales cannot be used interchangeably, as they identify partly different subjects as frail.

Sarcopenic subjects had a higher health and economic burden than non-sarcopenic subjects. Regarding the health burden it was found that sarcopenic subjects had more comorbidities, more disability in activities of daily living and a lower quality of life compared with non-sarcopenic subjects. These results indicate that sarcopenia deserves to be referred to as geriatric giant. Furthermore, sarcopenia accounted for an extra annual health care spending of $€ 11168$ per sarcopenic person compared with non-sarcopenic subjects and an extra (although not significant) $€ 6228$ compared with matched controls. The living situation (residential care) was a main driver of costs. This first study on the economic burden of sarcopenia performed in Europe highlights the need for action. 


\subsection{Physical Activity and Incidence of Sarcopenia}

Though many studies reported prevalence rates of sarcopenia, few studies exist on the incidence of sarcopenia. ${ }^{6-8}$ Furthermore, studies on the effect of general physical activity on sarcopenia show inconsistent results. ${ }^{9}$ In chapter 6 , the relation between physical activity and the incidence of sarcopenia was studied. A secondary data analysis using data from the population-based AGES-Reykjavik Study, a large cohort study with five-year follow-up, was performed. It was found that sarcopenic participants less frequently performed moderate to vigorous physical activity than did non-sarcopenic participants. Furthermore, this study shed light on the incidence proportion of sarcopenia over five years. This proportion was lower in the most active individuals $(9.0 \%)$ than in the least active individuals (14.8\%). Older age, lower BMI, and worse cognitive function were associated with higher incidence of sarcopenia. This study showed that in addition to the substantial prevalence of sarcopenia, 1 out of 7 inactive older adults developed sarcopenia in five years' time and 1 out of 11 active older adults developed sarcopenia over five years' time.

\section{Theoretical and Methodological Considerations}

Theoretical and methodological considerations are inherent to scientific research. In each study presented in this thesis limitations particular to that study were addressed. In this section, five overarching theoretical and methodological considerations will be addressed.

\subsection{Defining Sarcopenia}

The coining of the term sarcopenia by Rosenberg in $1989^{10}$ was the beginning of a challenge to find consensus over its definition. Currently several definitions of sarcopenia circulate in the scientific arena (Table 1). Originally the term sarcopenia was used to describe the age-related loss of muscle mass. ${ }^{10}$ However, whether sarcopenia is mere the age-related loss of muscle mass, or that it should be an umbrella term for the low of muscle mass irrespective of its cause (cachexia, physical inactivity, bed rest, malnutrition) has been an issue of debate. ${ }^{11}$ Cruz-Jentoft et al. ${ }^{1}$ raised the idea of using 'primary' sarcopenia to describe the merely age-related low muscle mass, and 'secondary' sarcopenia when one or more other causes, such as malnutrition, physical inactivity or disease, are present. A majority of the studies on sarcopenia (including the studies presented in this thesis) use sarcopenia as umbrella term, because it is difficult to clearly separate the individual aetiology for a low muscle mass. ${ }^{11}$

Another point of discussion around the definition of sarcopenia is whether including mere muscle mass in it definition is satisfactory. Muscle strength and/or physical performance have been put forward to extend the concept of sarcopenia as it has been shown that these muscle parameters relate to muscle mass and may have more clinical relevance than muscle mass alone. ${ }^{21,22}$ However, opponents of this extension of the concept of sarcopenia state that sarcopenia literally means muscle mass and alternative mechanisms may underlie loss of muscle mass and strength. ${ }^{23}$ Therefore loss of muscle strength might better be called dynapenia (dyna = strength, penia = loss). ${ }^{24}$ Studies looking at the agreement between several definitions of sarcopenia have shown that the agreement is low. ${ }^{17,25-27}$ Bijlsma et al. ${ }^{25}$ showed that only one subject out of the 654 included subjects was identified as sarcopenic according to all diagnostic criteria. Dam et 
al. ${ }^{17}$ showed that (positive) agreements between diagnosis of sarcopenia with the FNIH criteria and other criteria ranged between $7-32 \%$.

In the studies presented in this thesis, the recommendations of the European Working Group on Sarcopenia in Older People (EWGSOP) ${ }^{1}$ to define sarcopenia were followed. This means that muscle mass, muscle strength, and physical performance were assessed to identify older adults with sarcopenia. As shown in Chapter 3, choosing to include only muscle mass in its definition would have led to substantial differences in research results, i.e. using muscle mass as sole criterion for sarcopenia leads to a higher prevalence of sarcopenia. Many subjects of the MaSS study had low muscle mass, but normal muscle strength or performance and were therefore not identified as sarcopenic according to the EWGSOP criteria. When the criteria of the International Working Group on Sarcopenia would have been used (i.e. low muscle mass with limited mobility), research results would also have been different, as in the MaSS study several sarcopenic subjects had low muscle mass with poor grip strength, but normal gait speed. As the prevalence of sarcopenia depends on its definition, also the association found between sarcopenia and health and economic outcomes depends on the chosen definition. These results indicate that consensus over a definition is urgently needed to foster developments in the field of sarcopenia regarding research and practice.

Table 1 Definitions and Cut-Off Points for Sarcopenia

\begin{tabular}{|c|c|c|c|}
\hline Definition & Muscle Mass & Muscle Strength & Physical Performance \\
\hline Baumgartner $^{12}$ & $\begin{array}{l}\text { ALM/height }{ }^{2}>2 S D \text { below reference } \\
\text { population; i.e. } 7.26 \mathrm{~kg} / \mathrm{m}^{2}(\mathrm{~m}), 5.45 \mathrm{~kg} / \mathrm{m}^{2} \\
\text { (f) based on anthropometrics }\end{array}$ & - & - \\
\hline Delmonico $^{13}$ & $\begin{array}{l}\text { ALM/height }{ }^{2} \text { under } 20^{\text {th }} \text { percentile; i.e. } 7.25 \\
\mathrm{~kg} / \mathrm{m}^{2}(\mathrm{~m}), 5.67 \mathrm{~kg} / \mathrm{m}^{2}(\mathrm{f}) \text {, based on DXA }\end{array}$ & - & - \\
\hline Janssen $^{14}$ & $\begin{array}{l}\text { 1. Skeletal lean mass } / \text { body mass } \times 100 \% \text { of } \\
1 \text { or more below reference population, } \\
\text { based on BIA } \\
\text { 2. Skeletal lean mass } / \text { height }^{2}<10.75 \\
\mathrm{~kg} / \mathrm{m}^{2}(\mathrm{~m}), 6.75 \mathrm{~kg} / \mathrm{m}^{2}(\mathrm{f}), \text { based on BIA }^{2}\end{array}$ & - & - \\
\hline ESPEN-SIG ${ }^{15}$ & $\begin{array}{l}\text { Muscle mass }>2 S D \text { below mean of young } \\
\text { individuals }\end{array}$ & - & $\begin{array}{l}\text { Gait speed }<0.8 \mathrm{~m} / \mathrm{s} \text { or } \\
\text { reduced physical } \\
\text { performance on other test }\end{array}$ \\
\hline EWGSOP $^{1}$ & $\begin{array}{l}\text { Several cut-off points suggested for DXA } \\
\text { and BIA }\end{array}$ & $\begin{array}{l}\text { Grip strength }< \\
30 \mathrm{~kg}(\mathrm{~m}) \text { and } 20 \\
\mathrm{~kg}(\mathrm{f}) \text { or BMI } \\
\text { specific cut-off } \\
\text { points }\end{array}$ & Gait speed $\leq 0.8 \mathrm{~m} / \mathrm{s}$ \\
\hline $\mathrm{FNIH}^{16,17}$ & $\begin{array}{l}\text { ALM/BMI }<0.789 \text { (men), }<0.512(f) \text {, } \\
\text { based on BIA, DXA, CT }\end{array}$ & $\begin{array}{l}\text { Grip strength }< \\
26 \mathrm{~kg}(\mathrm{~m}) \text { and }< \\
16 \mathrm{~kg}(\mathrm{f})\end{array}$ & (Gait speed $\leq 0.8 \mathrm{~m} / \mathrm{s}^{\star}$ ) \\
\hline IWGS $^{18,19}$ & $\begin{array}{l}\text { ALM/height }{ }^{2} \leq 7.23(\mathrm{~m}), \leq 5.67(\mathrm{f}) \text {, based } \\
\text { on DXA }\end{array}$ & - & Gait speed $<1 \mathrm{~m} / \mathrm{s}$ \\
\hline $\operatorname{SSCWD}^{20}$ & $\begin{array}{l}\text { ALM/height }{ }^{2}>2 S D \text { below the mean of } \\
\text { healthy young adults }\end{array}$ & - & $\begin{array}{l}\text { Gait speed } \leq 1 \mathrm{~m} / \mathrm{s} \text { or }<400 \\
\mathrm{~m} \text { during } 6 \text {-min walk }\end{array}$ \\
\hline
\end{tabular}

Two points that have to be sorted out to find consensus over a definition are 1) agreement over the most important outcome(s), and 2) information on the power of the definition to predict the agreed outcome(s). Cawthon et al. ${ }^{28}$ studied the associations between definitions of sarcopenia (the International Working Group, EWGSOP, FNIH, Baumgartner, Newman) and recurrent falls, hip fractures, functional limitations and mortality in older men. Regarding the EWGSOP definition, it was found that the definition was associated with 
recurrent falls, functional limitations and mortality. ${ }^{28}$ Bianchi et al. ${ }^{29}$ studied the ability of the EWGSOP algorithm to predict disability, hospitalization, and mortality at six and nine years follow-up. They found that the EWGSOP algorithm predicted all three adverse outcomes; but so did low muscle mass and poor grip strength combined (without gait speed) and muscle mass and gait speed combined (without grip strength). ${ }^{29}$ Although these results are promising regarding the predictive validity of the EWGSOP definition, these studies were performed in men only ${ }^{28}$, or assessed muscle mass by $\mathrm{BIA}^{29}$; a confirmation of these results in future research using better validated muscle mass measurements would strengthen the evidence of its predictive validity.

\subsection{Measuring Sarcopenia}

While the challenge of finding a consensus definition of sarcopenia has not yet been solved another challenge awaits: which measurement tools and cut-off points should be used to identify older adults with sarcopenia? In the review presented in this thesis (Chapter 2), multiple tools to measure muscle mass, muscle strength, and physical performance were evaluated. It has been pointed out that the choice of a measurement tool depends on the setting of the evaluation, e.g. in clinical practice or in a home-setting. Depending on the setting and study population, costs, exposure to radiation, rate of injuries, duration of the measurement, muscle soreness, ease of administration, acceptability to patients, portability, and ability to perform the test were among the factors stated to the influence the feasibility of the measurement. ${ }^{2}$ In the MaSS study (Chapters 3 5) sarcopenia was assessed during a home visit. In this way we hoped to reduce participation bias by also enabling less healthy older adults (e.g. with mobility difficulties) to participate. The disadvantage of assessment in a home-setting is that not all tools are feasible in this setting. For example, for muscle mass the BIA was used, which can be seen as the most valid device for assessment of muscle mass in a home setting; however, it might have overestimated the amount of muscle mass. ${ }^{30}$ This means that in reality the prevalence of sarcopenia might be higher than was found in de MaSS study. In the AGESReykjavik Study (Chapter 6) subjects were invited for several clinic visits, allowing the measurement of muscle parameters with more advanced techniques such as computed tomography (CT). Especially for muscle mass, assessment in a clinical setting provides more valid results; however, for screening purposes this might be unfeasible to apply due to the higher costs involved.

Another consideration regarding the choice of measurement tool is whether to use a performance-based tool (such as handheld dynamometry to assess grip strength) and/or a questionnaire. In the MaSS study, sarcopenia was assessed using performance based tools, while frailty was assessed by both performance based tools and a questionnaire. ${ }^{3}$ With respect to frailty, the Fried criteria and the FRAIL scale partly identified different subjects as frail. This could be explained by the possibility that subjects overestimate their abilities in a questionnaire; however, it may also be explained by the fact that the questions of the FRAIL scale concerned slightly different topics than the Fried criteria, e.g. illnesses is included in the FRAIL scale but not the Fried criteria. Although objective measurement might reduce the risk of overestimation of abilities, a questionnaire is quick and inexpensive thereby making it practical for screening purposes. An example of a brief sarcopenia questionnaire is the SARC- $\mathrm{F}^{31}$ and first results show that the questionnaire is internally consistent and valid. ${ }^{32}$ More research is needed to compare the outcomes of this 
questionnaire with performance based measurements. A combination of a questionnaire (e.g. for screening) and performance based tools (e.g. for in-depth assessment of at risk individuals) could also be considered. Moreover, advanceladis in technology, such as smartphone-based $\mathrm{BI}^{33}$ or infrared sensors for unobtrusive in-home measurement of gait speed $^{34}$, might stimulate (self-)assessment of muscle parameters in the future.

Choosing a measurement tool is a trade-off between the ideal world and what is feasible. The question is to what extent the extra investments (costs, human resources etc.) of muscle parameter assessment in a clinical setting weigh against the extra quality of the measurement (validity, reliability, accessibility, etc.) compared to assessment in a general practitioners (GP) practice or home-setting. With the current knowledge, gait speed and/or grip strength seems to have the best 'price/quality ratio' and should, where possible, be assessed in a GP practice or at home, after which further assessment in a clinical setting may take place when indicated.

\subsection{Cut-off Points}

Where the choice of a measurement tool is mainly guided by the setting of evaluation and available resources, the choice of cut-off points should incorporate considerations on study population (age, ethnicity etc.) and measurement tool. Firstly, the characteristics of the population under study should be taken into account when applying cut-off points. Important characteristics are among others age, sex and ethnicity. In the MaSS study (Chapters 3-5), the cut-off points for BIA suggested by the EWGSOP were chosen, as these cut-off points were tested in an older Caucasian population. Most subjects of the MaSS were Caucasian; however, a few subjects were Asian. It has been shown that when applying the EWGSOP or the IWG criteria to Asian subjects, slow gait speed and low handgrip strength were 2-4 times higher than when using the lowest $20^{\text {th }}$ percentile method. However, as Asian cut-off points were not presented by the EWGSOP, the same cut-off point was used for all subjects. As there were only few Asian subjects (of whom three out of six were sarcopenic) it is unlikely that the results are highly influenced by this.

Secondly, as shown in Table 1, for all three muscle parameters a variety of cut-off points are used in current research. The EWSGOP presents several cut-off points for muscle mass assessed by BIA and dual energy X-ray absorptiometry (DXA), which are all based on absolute muscle mass (muscle mass divided by height squared). In addition to muscle mass, (appendicular) lean mass (i.e. total body mass without fat mass and bone mineral mass) and fat free mass (i.e. total body mass without fat mass) are used in sarcopenia research. ${ }^{35}$ Cheung et al. ${ }^{36}$ found that absolute lean mass was predictive of mortality; however, lean mass divided by BMI was an even stronger predictor. Bijlsma et al. ${ }^{37}$ showed that relative muscle mass (total or appendicular lean mass as percentage of body mass) was associated with physical performance, while absolute muscle mass was not. This should be taken into account when applying these cut-off points. Finding consensus over cut-off points will improve comparability of studies. Furthermore, the EWGSOP provides cut-off points for BIA and DXA, but not for MRI, CT, and other tools for assessing muscle mass. For these other tools one could choose a cut-off point of two standard deviation (2SD) below the mean of young adults or the lowest sex-specific $20^{\text {th }}$ percentile of the study population. However, for the 2SD method, a (young, healthy) reference population needs to be available. An issue when using the lowest sex-specific $20^{\text {th }}$ percentile of the study population, which was used in Chapter 6, is that the cut-off 
point is derived from the muscle mass of the total study population. That means that no matter how high or low the muscle mass of the study sample is, $20 \%$ of the subjects will always be considered to have low muscle mass. In the absence of generally accepted cutoff points these ways of selecting a cut-off point are the best available alternatives. However, using large cohort studies to establish sex-specific cut-off points that are predictive of sarcopenia-related health-risks, such as disability, is of major importance. This also counts for cut-off points for muscle strength and physical performance.

A third point of consideration when choosing a cut-off point applies to the BIA measurement. A BIA device sends an electrical current through the body of the subject and subsequently displays a resistance and reactance value. These values have to be converted into amount of the skeletal muscle mass (or fat-free mass, lean mass). Several formulas have been presented to make the conversion to muscle mass. These formulas include e.g. resistance, height, sex and age (formula by Janssen et al. ${ }^{38}$ ), height, resistance, weight and reactance ${ }^{39}$ or formulas that are device specific (based on unknown variables). ${ }^{40}$ It will be clear that different formulas will yield different outcomes. For example, Sipers et al. ${ }^{40}$ compared the Janssen formula with the Maltron formula and found that the prevalence of sarcopenia highly depended on which formula was used. Although those differences were acknowledged, it was felt that using the Janssen formula ${ }^{38}$ in the MaSS study was appropriate as it was the only BIA formula provided by the EWGSOP and cut-off points for low muscle mass (based on their predictive validity of disability) were established. ${ }^{1,14}$

\subsection{Study Design}

This thesis includes studies using two different study designs, a cross-sectional design (chapters 3-5) and a population-based cohort study with five-year follow-up (chapter 6). Both designs have advantages and disadvantages. In a cross-sectional design exposure and outcome are measured at one time point, thereby providing a snapshot of the outcome at a particular time. ${ }^{41}$. This design is relatively inexpensive and loss to follow up is not of concern. This design is often used to assess the prevalence of a health outcome, as the sample is usually taken from the whole population. ${ }^{42} \mathrm{~A}$ shortcoming of the cross-sectional design is that it does not allow for making causal inference. Therefore, associations made should be interpreted with caution, as they might be attributed to bias instead of causal association. ${ }^{43}$ Furthermore, as this design provides a snapshot on one time point, it may be that outcomes differ when the study is repeated at another point in time. ${ }^{42}$ In the MaSS study several variables may be prone to seasonal influences, like nutritional intake, physical activity and quality of life. Data collection of the MaSS study was spread over all four seasons (May 2013 - Feb 2014), therewith reducing potential seasonal effects of these variables on the outcome. In addition, exploratory analysis showed that sarcopenia status (main outcome) and living situation (important driver of costs) did not depend on the season in which the home visit was performed.

In a population-based cohort study subjects are selected on the basis of a shared characteristic, such as year of birth, geographic area or occupation. A strength of this type of study is that subjects are followed over time, making it possible to assess causality as exposure occurs prior to outcome. ${ }^{44} \mathrm{~A}$ cohort study is the best way to measure incidence and natural history of a disease. ${ }^{45}$ Disadvantages of a population-based cohort design are that they are time consuming, might incur high costs, and the design is prone to high loss 
to follow-up. In the AGES-Reykjavik Study (Chapter 6) $58 \%$ of the initial baseline sample participated at follow-up. Subjects that were lost to follow-up significantly differed from subjects that did not drop out (selection bias) regarding among others age, level of physical activity, and sarcopenia status. Furthermore, the time span between measurements was five years, during which no interim evaluation was performed. Events that occurred within these five years might have influenced the association found between sarcopenia and physical activity.

\subsection{Sample and Selection}

Regarding both the MaSS study and the AGES-Reykjavik study sample bias should be kept in mind. Bias can be defined as "a systematic difference between study measurements and the true population values", ${ }^{46}$ and may refer to 1) selection bias, 2) information bias (observer bias, recall bias, etc.) and 3) confounding. ${ }^{43}$

Firstly, possible selection bias in both study designs will be addressed. Are those included in the sample systematically different from the ones not included? If yes, then it is a matter of selection bias. ${ }^{46}$ For the MaSS study, the municipality of Maastricht was asked to provide a random sample of older adults living in Maastricht, as selecting subjects via a health care provider (which was done for the pilot study) had proven to be difficult. By asking the municipality to provide a random sample the likelihood of addressing a representative sample was high. Selection bias was therewith partly prevented. Another issue affecting the representativeness of the sample is the response rate. It was known beforehand that nonresponse is a common issue in large (cross-sectional) studies, ${ }^{42}$ therefore several strategies were implemented in an attempt to limit nonresponse, for example by publishing an articles in a local newspaper and newsletter of care facility, informing managers of assisted living and residential living facilities, distributing flyers at these facilities and pharmacies, and creating a website. Despite this, only $15 \%$ of the potential subjects responded. Collecting data about non-responders and telephone prompting were not allowed by the Medical Ethics Committee who approved the MaSS study. Older adults with a poorer physical condition might be less inclined to participate than older adults in better physical condition. ${ }^{3}$ This means that a healthier group might have been included and hence the sample might not have been fully representative. Therefore, prudence is called for when generalizing the results to the whole population. In addition, the eligibility criteria of the study might have further affected the generalizability of the results. Subjects had to be able to endure a two-hour home visit and due to safety reasons older adults suffering from severe disease(s) were excluded. It could however be argued that when these (severely ill) older adults were included, the prevalence of sarcopenia would be higher than currently reported. Furthermore, as stated before, by performing home visits we hoped to reach older adults with a poor physical condition as well, thereby limiting the chances of jeopardizing the representativeness of the study sample. The fact that the sarcopenia prevalence found in the MaSS study is comparable to other studies investigating the prevalence of sarcopenia and the similarity of the MaSS subjects demographics (age, sex) compared to the total Dutch population may be seen as indications that the results are representative. Looking at the AGES-Reykjavik Study, the response rate was higher than the MaSS study but still only $35 \%$ of the selected participants participated at baseline and follow-up, and subjects that were lost to follow-up significantly differed from subjects that did not drop out, as stated in the previous section. 
However, as for the MaSS study, eradicating selection bias would probably have strengthened the association found (i.e. between incidence of sarcopenia and physical activity) as older adults having a poorer physical condition (having a higher change of developing sarcopenia) were more likely to become lost to follow-up.

Secondly, is there a systematic difference in the measurement of study parameters between observers or between study groups ${ }^{46}$ If so, then information bias is present (including observer bias, recall bias, etc). In both the MaSS study and the AGES-Reykjavik Study observer bias was kept as low as possible by developing and discussing standard operating procedures. In the MaSS study these procedures were additionally tested by two trained data collectors in a pilot study. During the data collection of the pilot study both data collectors were present at the home visit, one as assessor and one as observer, to ensure conformity of data collection. This procedure was repeated three and six months after the data collection had started. Recall bias was not applicable for many variables, as the questions or measurements reflected the day of the measurement itself (e.g. 'how would you rate your own health today'). However, exceptions existed, such as for selfreported physical activity, weight loss and health care utilization. Although subjects might remember specific forms of (health care related) information for a long period, the measurement period is ideally no longer than three months. ${ }^{47}$ Most of the relevant questions fell within the recall period of three months, with time frames ranging from the past week (e.g. frailty questions) to the past year (e.g. weight loss). Where possible, questions that were eligible for recall bias were supported by information noted down in the subject's agenda or calendar (MaSS Study) or in patients records (AGES-Reykjavik).

Thirdly, confounding may occur in the analysis when an association is found between two variables, which in reality results from another variable not included in the analysis. ${ }^{46}$ In the MaSS study, age, sex and BMI were included as covariates in the models (Chapters 3 and 4) or a matched sample was used (Chapter 5) to reduce this type of bias. In the AGES-Reykjavik Study several potential confounders were added to the analytical models as well. However, there is still a chance that variables not included in the model, such as interim events or physical activity level throughout life, may have influenced the results.

In both the MaSS and AGES-Reykjavik Study some form of bias may have crept in, as fully ruling out bias is very hard. However, several measures were in place to minimize bias and therefore the results from these studies are thought to be plausible.

\section{Implications}

This thesis has shown that plenty of valid and reliable measurement tools and cut-off points are available to identify older adults with sarcopenia. The need for identification of older adults with sarcopenia was supported by the substantial prevalence of sarcopenia and its health and economic burden found. Herewith, this thesis adds to the evidence that there is a need for prevention, early diagnosis, and intervention with regard to sarcopenia. This section elaborates on the research and practical implications that can be made based on the studies presented in this thesis and in the light of existing literature.

\subsection{Research}

This thesis has shown that many tools to measure muscle mass, muscle strength, and physical performance exist. No information was found on the reliability of tools to assess muscle mass in an older population; further research should look into this. Furthermore for 
multiple tools many cut-off points were available and it was found that protocols for the assessment of grip strength differ. It is of first importance to agree on a universally accepted definition and attune cut-off points to identify older adults with sarcopenia. To obtain appropriate cut-off points for each muscle parameter (muscle mass, muscle strength and physical performance) a first option is to establish reference populations. When establishing reference populations, several subgroups (age, sex, and ethnicity) should be taken into account. It should be noted that this point is currently given attention by the Special Interest Group on Sarcopenia, operating within the European Union Geriatric Medicine Society, who is putting effort into combining data from several sarcopenia studies. A second option is to search for clinically relevant cut-off points for each muscle parameter, based on the ability of the cut-off point to predict adverse outcomes. This could be done by performing area under the curve analyses using longitudinal data, as this type of analysis allows finding an optimal cut-off point to distinguish whether a person is at risk of (an) adverse outcome(s) or not. This type of analysis was performed by e.g. Alley et al., ${ }^{48}$ who investigated clinically relevant cut-off points for grip strength. Next to the study of Alley et al. ${ }^{48}$ plenty of other studies investigated the ability of low muscle mass, poor muscle strength and poor physical performance, alone or combined, to predict adverse outcomes. ${ }^{29,} 36,49$ It can be recommended to bundle these studies in a systematic review and, if possible, perform a meta-analysis to obtain an overview of the adverse outcomes predicted by each muscle parameter/cut-off point. If such a review was performed other muscle parameters might be included as well, such as muscle power, which has been shown to be a strong predictor of physical performance. ${ }^{50}$ Based on the results of such a review, and in close collaboration with experts in the field, appropriate cut-off points can be decided upon.

This thesis and previous literature ${ }^{51,52}$ show that the prevalence of sarcopenia in both the community as well as in care settings (residential care, nursing homes) is considerable. Furthermore it has been shown that the incidence of sarcopenia is $6 \%$ lower in active older adults compared with inactive older adults. Thus, stimulating exercise in older adults will likely yield positive rewards regarding sarcopenia prevention and treatment. However, to be able to justify an intervention, intervention endpoints should be specified. ${ }^{31,32}$ Endpoints of interventions targeted at sarcopenia depend on the nature of the intervention (preventive or therapeutic) and should incorporate considerations on, amongst others, clinical significance, reproducibility, responsiveness, and feasibility. ${ }^{53,54}$ Some studies have shed light on the influence of a six month resistance exercise intervention combined with nutritional support on muscle parameters, ${ }^{55,56}$ however, long-term studies on the effects of an intervention program on adverse outcomes are scarce. ${ }^{57}$ Suggested intervention endpoints are mobility disability, ADL dependency, recurrent falls, hospitalization or mortality as they are clinically relevant. Further research should focus on identifying relevant endpoints and meaningful changes in these endpoints; taking into account the different settings in which sarcopenia is present (community-dwelling, nursing home, hospital). Mortality may be a good endpoint in nursing homes, but may be less valuable as endpoint in community-dwelling older adults. A promising initiative regarding intervention endpoints is the "Sarcopenia \& Physical Frailty in Older People: Multicomponent Treatment Strategies (SPRINT-T)" initiative, which will be the first (two year) interventional clinical trial in Europe for frail and sarcopenic older adults. ${ }^{58}$ This study provides a unique opportunity 
to examine intervention effects in the long run and can further elicit whether combining sarcopenia and frailty screening is profitable.

Finally, this thesis has shown that sarcopenic older adults made more use of health care, leading to higher costs, than their non-sarcopenic peers. As a next step regarding to the economic burden of sarcopenia it can be recommended to incorporate costeffectiveness analysis in the evaluation of intervention programs aimed at the prevention or treatment of sarcopenia.

\subsection{Practice}

The results in this thesis show that according to the EWGSOP definition the prevalence and incidence of sarcopenia in older adults is substantial. Sarcopenia was shown to be associated with physical frailty, disability in activities of daily living, lower quality of life and higher costs of care. Despite the mounting evidence on the burden of sarcopenia coming from the studies presented in this thesis and other literature ${ }^{59,60}$ in current clinical practice screening of individuals at risk of sarcopenia does not take place yet. Older adults deserve a helping hand in the fight against muscle decay and support to prolong their independency. The Dutch Ministry of Welfare, Health and Sport endorses an increase in health care problems due to the aging of the population. ${ }^{61}$ One focus of the Dutch Ministry, as well as Ministries in many other European countries is therefore on prevention targeted at keeping older adults healthy, independent, and autonomous (also referred to as healthy aging, aging in place), and ensure their participation in society. ${ }^{61}$ Prevention of sarcopenia perfectly fits within this mission; however, several challenges have to be overcome to implement sarcopenia screening in current prevention programs.

Absence of a universally accepted definition, lack of clarity about specific treatment options, pharmaceutical interest, and public awareness hamper translation of research findings into practice. ${ }^{62}$ The World Health Organization (WHO) could play a role herein, as they manage the International Classification of Diseases and Related Health Problems (ICD) database. ${ }^{63}$ This database is "the standard diagnostic tool for epidemiology, health management and clinical purposes". ${ }^{63}$ ICD codes are used by health care providers, health information managers, policymakers, insurers, patient advocacy organizations etcetera, and are used for reimbursement, resource allocation, and decision making purposes. ${ }^{63}$ The importance of an ICD code was acknowledged by the Alliance for Aging Research, and they have undertaken steps to establish such a diagnosis code for sarcopenia. ${ }^{64}$ In the meantime, it can be recommended to increase awareness about sarcopenia, its consequences, and ways to counteract the loss of muscle mass and function among health care providers and the public via multiple channels (e.g. television, newspaper, specialist journal), and promote inclusion of sarcopenia education in relevant trainings. Once an ICD code is available, it is suggested to incorporate prevention of sarcopenia in existing health programs aimed at e.g. exercise, healthy diet and fall prevention.

Then general practitioners, nurse practitioners, physiotherapists, occupational therapists, and geriatricians could play a key role in identifying older adults (at risk of) with sarcopenia and advice on prevention and treatment. As has been shown in this thesis, the prevalence of sarcopenia was higher in older adults receiving home care or living in residential care, compared to community-dwelling older adults living independently. Therefore, home care services and residential care facilities should also be target of awareness raising campaigns. Furthermore, other researchers have suggested combining 
screening for sarcopenia with frailty ${ }^{65}$ or osteoporosis ${ }^{66}$ for respectively screening or treatment purposes. Research presented in this thesis has shown that by assessing hand grip strength and gait speed, a large amount of the frail older adults were identified. So screening for sarcopenia could also contribute to the identification of older adults with frailty. 


\section{References}

1. Cruz-Jentoft AJ, Baeyens JP, Bauer JM, et al. Sarcopenia: European consensus on definition and diagnosis: report of the European Working Group on Sarcopenia in Older People. Age Ageing 2010;39:412-423.

2. Mijnarends DM, Meijers JMM, Halfens RJG, et al. Validity and reliability of tools to measure muscle mass, strength, and physical performance in community-dwelling older people: a systematic review. J Am Med Dir Assoc 2013;14:170-178.

3. Mijnarends DM, Schols JM, Meijers JM, et al. Instruments to assess sarcopenia and physical frailty in older people living in a community (care) setting: similarities and discrepancies. J Am Med Dir Assoc 2015;16:301308.

4. Fried LP, Tangen CM, Walston J, et al. Frailty in older adults: evidence for a phenotype. J Gerontol A Bio Sci Med Sci 2001;56:M146-156.

5. Morley JE, Malmstrom TK, Miller DK. A simple frailty questionnaire (FRAIL) predicts outcomes in middle aged African Americans. J Nutr Health Aging 2012;16:601-608.

6. Kim H, Suzuki T, Kim M, et al. Incidence and predictors of sarcopenia onset in community-dwelling elderly Japanese women: 4-year follow-up study. J Am Med Dir Assoc 2015;16:85.e81-88.

7. Yu R, Wong M, Leung J, Lee J, Auyeung TW, Woo J. Incidence, reversibility, risk factors and the protective effect of high body mass index against sarcopenia in community-dwelling older Chinese adults. Geriatr Gerontol Int 2014;14:15-28.

8. Scott D, Hayes A, Sanders KM, Aitken D, Ebeling PR, Jones G. Operational definitions of sarcopenia and their associations with 5-year changes in falls risk in community-dwelling middle-aged and older adults. Osteoporos Int 2014;25:187-193.

9. Scott D, Blizzard L, Fell J, Jones G. The epidemiology of sarcopenia in community living older adults: what role does lifestyle play? J Cachexia Sarcopenia Muscle 2011;2:125-134.

10. Rosenberg IH. Summary comments. Am J Clin Nutr 1989;50:1231-1233.

11. Cederholm T. Challenges of defining sarcopenia: status report of the EUGMS Working Group on Sarcopenia. 110th Abbott Nutrition Research Conference, 23-25 June 2009. Columbus, Ohio, 2009.

12. Baumgartner RN, Koehler KM, Gallagher D, et al. Epidemiology of sarcopenia among the elderly in New Mexico. Am J Epidemiol 1998;147:755-763.

13. Delmonico MJ, Harris TB, Lee JS, et al. Alternative definitions of sarcopenia, lower extremity performance, and functional impairment with aging in older men and women. J Am Geriatr Soc 2007;55:769-774.

14. Janssen I, Baumgartner RN, Ross R, Rosenberg IH, Roubenoff R. Skeletal muscle cutpoints associated with elevated physical disability risk in older men and women. Am J Epidemiol 2004;159:413-421.

15. Muscaritoli M, Anker SD, Argiles J, et al. Consensus definition of sarcopenia, cachexia and pre-cachexia: joint document elaborated by Special Interest Groups (SIG) "cachexia-anorexia in chronic wasting diseases" and "nutrition in geriatrics". Clin Nutr 2010;29:154-159.

16. Studenski SA, Peters KW, Alley DE, et al. The FNIH sarcopenia project: rationale, study description, conference recommendations, and final estimates. J Gerontol A Biol Sci Med Sci 2014;69:547-558.

17. Dam TT, Peters KW, Fragala M, et al. An evidence-based comparison of operational criteria for the presence of sarcopenia. J Gerontol A Biol Sci Med Sci 2014;69:584-590.

18. Fielding RA, Vellas B, Evans WJ, et al. Sarcopenia: an undiagnosed condition in older adults: current consensus definition: prevalence, etiology, and consequences. International working group on sarcopenia. J Am Med Dir Assoc 2011;12:249-256.

19. Newman $A B$, Kupelian V, Visser $M$, et al. Sarcopenia: alternative definitions and associations with lower extremity function. J Am Geriatr Soc 2003;51:1602-1609.

20. Morley JE, Abbatecola AM, Argiles JM, et al. Sarcopenia with limited mobility: an international consensus. $J$ Am Med Dir Assoc 2011;12:403-409.

21. Newman $A B$, Kupelian V, Visser $M$, et al. Strength, but not muscle mass, is associated with mortality in the Health, Aging and Body Composition Study cohort. J Gerontol A Biol Sci Med Sci 2006;61:72-77.

22. Visser M, Goodpaster BH, Kritchevsky SB, et al. Muscle mass, muscle strength, and muscle fat infiltration as predictors of incident mobility limitations in well-functioning older persons. J Gerontol A Biol Sci Med Sci 2005;60:324-333.

23. Mitchell WK, Williams J, Atherton P, Larvin M, Lund J, Narici M. Sarcopenia, dynapenia, and the impact of advancing age on human skeletal muscle size and strength: a quantitative review. Front Physiol 2012;3:260.

24. Clark BC, Manini TM. Sarcopenia \# dynapenia. J Gerontol A Biol Sci Med Sci 2008;63:829-834.

25. Bijlsma AY, Meskers CG, Ling CH, et al. Defining sarcopenia: the impact of different diagnostic criteria on the prevalence of sarcopenia in a large middle aged cohort. Age 2013;35:871-881. 
26. Pagotto V, Silveira EA. Applicability and agreement of different diagnostic criteria for sarcopenia estimation in the elderly. Arch Gerontol Geriatr 2014;59:288-294.

27. Lee WJ, Liu LK, Peng LN, Lin MH, Chen LK. Comparisons of sarcopenia defined by IWGS and EWGSOP criteria among older people: results from the I-Lan longitudinal aging study. J Am Med Dir Assoc 2013;14:528.e521-527.

28. Cawthon PM, Blackwell TL, Cauley J, et al. Evaluation of the usefulness of consensus definitions of sarcopenia in older men: results from the observational osteoporotic fractures in men cohort study. J Am Geriatr Soc 2015;63(11):2247-59.

29. Bianchi L, Ferrucci L, Cherubini A, et al. The predictive value of the EWGSOP definition of sarcopenia: results from the InCHIANTI study. J Gerontol A Biol Sci Med Sci 2015;71(2):259-64.

30. Beaudart C, Reginster JY, Slomian J, et al. Estimation of sarcopenia prevalence using various assessment tools. Exp Gerontol 2015;61:31-37.

31. Malmstrom TK, Morley JE. SARC-F: a simple questionnaire to rapidly diagnose sarcopenia. J Am Med Dir Assoc 2013;14:531-532.

32. Malmstrom TK, Miller DK, Simonsick EM. SARC-F: a symptom score to predict persons with sarcopenia at risk for poor functional outcomes. J Cachexia Sarcopenia Muscle 2015; in press.

33. Choi A, Kim JY, Jo S, et al. Smartphone-based bioelectrical impedance analysis devices for daily obesity management. Sensors (Basel) 2015;15:22151-22166.

34. Hayes TL, Hagler S, Austin D, Kaye J, Pavel M. Unobtrusive assessment of walking speed in the home using inexpensive PIR sensors. Conf Proc IEEE Eng Med Biol Soc 2009;51:7248-7251.

35. Bosy-Westphal A, Muller MJ. Identification of skeletal muscle mass depletion across age and BMI groups in health and disease: there is need for a unified definition. Int J Obes 2015;39:379-386.

36. Cheung CL, Lam KS, Cheung BM. Evaluation of cutpoints for low lean mass and slow gait speed in predicting death in the National Health and Nutrition Examination Survey 1999-2004. J Gerontol A Biol Sci Med Sci 2016;71(1):90-5.

37. Bijlsma AY, Meskers CG, Van den Eshof N, et al. Diagnostic criteria for sarcopenia and physical performance. Age 2014;36:275-285.

38. Janssen I, Heymsfield SB, Baumgartner RN, Ross R. Estimation of skeletal muscle mass by bioelectrical impedance analysis. J Appl Physiol (Bethesda, Md : 1985) 2000;89:465-471.

39. Genton L, Karsegard VL, Kyle UG, Hans DB, Michel JP, Pichard C. Comparison of four bioelectrical impedance analysis formulas in healthy elderly subjects. Gerontology 2001;47:315-323.

40. Sipers WMWH, Meijers JMM, Van Dijk RB, Halfens RJG, Schols JMGA. Impact of different diagnostic criteria on the prevalence of sarcopenia in an acute care geriatric ward. $J$ Frailty Aging 2014;3:222-229.

41. Grimes DA, Schulz KF. An overview of clinical research: the lay of the land. Lancet 2002;359:57-61.

42. Levin KA. Study design III: Cross-sectional studies. Evid Based Dent 2006;7:24-25.

43. Grimes DA, Schulz KF. False alarms and pseudo-epidemics: the limitations of observational epidemiology. Obstet Gynecol 2012;120:920-927.

44. Levin KA. Study design IV. Cohort studies. Evid Based Dent 2006;7:51-52.

45. Grimes DA, Schulz KF. Cohort studies: marching towards outcomes. Lancet 2002;359:341-345.

46. Levin KA. Study design II. Issues of chance, bias, confounding and contamination. Evid Based Dent 2005;6:102-103.

47. Hakkaart-van Roijen L, Tan SS, Bouwmans CAM. Handleiding voor kostenonderzoek: methoden en standaard kostprijzen voor economische evaluaties in de gezondheidszorg: geactualiseerde versie 2010. Diemen: CVZ, 2011.

48. Alley DE, Shardell MD, Peters KW, et al. Grip strength cutpoints for the identification of clinically relevant weakness. J Gerontol A Biol Sci Med Sci 2014;69:559-566.

49. Bischoff-Ferrari HA, Orav JE, Kanis JA, et al. Comparative performance of current definitions of sarcopenia against the prospective incidence of falls among community-dwelling seniors age 65 and older. Osteoporos Int 2015;26(12):2793-80.

50. Bean JF, Kiely DK, Herman S, et al. The relationship between leg power and physical performance in mobility-limited older people. J Am Geriatr Soc 2002;50:461-467.

51. Cruz-Jentoft AJ, Landi F, Schneider SM, et al. Prevalence of and interventions for sarcopenia in ageing adults: a systematic review: report of the International Sarcopenia Initiative (EWGSOP and IWGS). Age Ageing 2014;43:748-759.

52. Morley JE, Anker SD, Von Haehling S. Prevalence, incidence, and clinical impact of sarcopenia: facts, numbers, and epidemiology-update 2014. J Cachexia Sarcopenia Muscle 2014;5:253-259. 
53. Studenski S. What are the outcomes of treatment among patients with sarcopenia? J Nutr Health Aging 2009;13:733-736.

54. Vellas B, Fielding R, Miller R, et al. Designing drug trials for sarcopenia in older adults with hip fracture: a task force from the International Conference on Frailty and Sarcopenia Research (ICFSR). Journal Frailty Aging 2014;3:199-204.

55. Strandberg E, Edholm P, Ponsot E, et al. Influence of combined resistance training and healthy diet on muscle mass in healthy elderly women: a randomized controlled trial. J Appl Physiol (Bethesda, Md : 1985) 2015;119:918-925.

56. Tieland M, Dirks ML, Van der Zwaluw N, et al. Protein supplementation increases muscle mass gain during prolonged resistance-type exercise training in frail elderly people: a randomized, double-blind, placebocontrolled trial. J Am Med Dir Assoc 2012;13:713-719.

57. Pahor M, Guralnik JM, Ambrosius WT, et al. Effect of structured physical activity on prevention of major mobility disability in older adults: the LIFE study randomized clinical trial. JAMA 2014;311:2387-2396.

58. Sarcopenia \& Physical fRailty in older people: multi-componenT Treatment strategies. Why an innovative study in Geriatrics? [S.I.]: SPRINTT, 2015. Accessed via:

http://www.mysprintt.eu/?, October 2015.

59. Janssen I, Shepard DS, Katzmarzyk PT, Roubenoff R. The healthcare costs of sarcopenia in the United States. J Am Geriatr Soc 2004;52:80-85.

60. Beaudart C, Rizzoli R, Bruyere O, Reginster JY, Biver E. Sarcopenia: burden and challenges for public health. Arch Public Health 2014;72:45.

61. Harbers MM. Preventie gericht op ouderen samengevat. Volksgezondheid Toekomst Verkenning, Nationaal Kompas Volksgezondheid, versie 4.17 edn. Bilthoven: Rijksinstituut voor Volksgezondheid en Milieu, 2014.

62. Bijlsma AY, Meskers CG, Westendorp RG, Maier AB. Chronology of age-related disease definitions: osteoporosis and sarcopenia. Ageing Res Rev 2012;11:320-324.

63. World Health Organization. International Classification of Diseases (ICD). Geneva: W.H.O., 2015. Accessed via: http://www.who.int/classifications/icd/en/, October 2015.

64. Bens CA. Establishing an ICD-10 code for sarcopenia. Volume 15 slides: Alliance for Aging Research; Aging in Motion, 2015, PowerPoint presentation.

65. Cruz-Jentoft AJ, Michel JP. Sarcopenia: a useful paradigm for physical frailty. Eur Geriatr Med 2013;4:102105.

66. Reginster JY, Beaudart C, Buckinx F, Bruyere O. Osteoporosis and sarcopenia: two diseases or one? Curr Opin Clin Nutr Metab Care 2016;19(1):31-6. 

Chapter 8

Valorisation 
The research in this thesis sheds light on the prevalence of sarcopenia and has identified various characteristics, health, and economic outcomes of community-dwelling older adults with sarcopenia. This chapter will assess the scientific results that have emerged from the research in relation to their importance for society. In this chapter respectively the relevance of the study results, target groups for dissemination of results, activities (to be) undertaken, and future directions will be discussed.

\section{Relevance}

More than 600 skeletal muscles are the driving spirit of the human body. ${ }^{1}$ Stand straight, keep balance, walk, run, bend over, scratch your knee, get dressed, go shopping, carry a bag, you name it. Those actions are all possible because of our skeletal muscles. When the muscles are healthy and function normally, one might not realize all the tasks that they perform. But when muscle mass and function decrease, difficulties may arise in performing activities of daily living and as a result quality of life and autonomy may decrease while the risk of care dependency and subsequent institutionalization increases.

Currently, in the Netherlands, older adults with difficulties in performing activities of daily living are eligible to receive home care, or may qualify for housing in a residential living facility. However, due to governmental regulation residential living facilities will dissolve soon and older adults will be more and more empowered to live independently as long as possible (also called 'aging in place'). Nevertheless, this also corresponds to the wish of the majority of older adults themselves, who prefer to stay at home as long as possible. Aging in place has several advantages for older adults, such as preservation of their personal network and environmental landmarks. ${ }^{2}$ In addition, aging in place is thought to reduce the burden of health care services and has therefore attracted attention of most western governments. Sarcopenia may threaten the trend towards aging in place, considering its association with difficulties performing activities of daily living and institutionalization. Insight in the prevalence of sarcopenia, its characteristics, health and economic outcomes is of importance to 1) know which community-dwelling older adults are at risk of sarcopenia, and 2) to know what are the target areas for a tailored-made approach to prevent/treat sarcopenia and contribute to a sustainable, affordable health care system. The results of the studies in this thesis provide guidance for a psychometrically sound measurement of sarcopenia, and they show that the prevalence and incidence of sarcopenia in several subgroups of community-dwelling older adults and the associated health care costs are substantial. Moreover they help to understand the link between sarcopenia and frailty and confirm the association between sarcopenia and disability in activities of daily living.

\section{Target Groups}

Dissemination of research findings to target groups such as older adults, (older) patients, health care professionals, policy makers etcetera enables them to benefit optimally from the new knowledge. It gives them a hand in exploring possibilities to prevent exposure of unnecessary risks and unnecessary healthcare expenditure. ${ }^{3}$ The results of this thesis are of interest to several target groups, as explained below. 


\subsection{Older Adults}

Sarcopenia occurs in older adults living in the community, but also hospital patients and nursing homes resident are at risk of sarcopenia. Furthermore, younger adults that are temporarily immobile due to disease or injury might also face loss of muscle mass. Many of them will have never heard of sarcopenia, as the translation of sarcopenia research from science to practice has not yet been established. Informing these people (and their informal care givers) about the development, causes and consequences of sarcopenia will help them to recognize it and become aware that there are ways to delay the onset and progression of sarcopenia.

\subsection{Health Care Professionals}

Health care professionals working with people with (a risk of) sarcopenia such as nursing staff, home care workers, physiotherapists, general practitioners, nurse practitioners, occupational therapists, geriatricians and dieticians, can in the future help to identify older adults with (a risk of) sarcopenia. Also, health care professionals working with frail older adults, or older adults with osteoporosis should be attentive to sarcopenia. Chapter two of this thesis provides relevant information on the validity and reliability of tools that are feasible to screen for sarcopenia in older adults. Health care professionals may use these tools to identify older adults with (a risk of) sarcopenia. Although so far no consensus approach or national guidelines to treat sarcopenia are available, older adults identified with low muscle mass and/or function can be advised to start an exercise program or participate in a physical activity stimulating activity. ${ }^{4}$ In addition, fitness centres could play a preventive or curative role by providing facilities and a welcoming environment for older adults to exercise. They could also function as 'walk-in' for support with (self-) monitoring of health by older adults. Regarding nursing homes, recent research showed that nursing home residents are lying down or are seated for about $90 \%$ of the time. ${ }^{5} \mathrm{~A}$ mind-set shift within nursing staff from 'take good care and so take over tasks of the resident' to 'let residents do it themselves where possible' could contribute to more physical activity in this setting. Supplementation of specific nutrients (protein, vitamins, etc.) could be valuable as well, especially when combined with an exercise component. ${ }^{6}$ Furthermore, educating older adults about proper nutrition may further empower people to take responsibility for their own process of healthy (muscle) aging.

\subsection{Industry}

The studies in this thesis show that especially in residential living facilities the prevalence of sarcopenia is substantial. Bearing in mind that for older adults living in these facilities resistance exercise might not always be feasible, nutritional supplementation or pharmacological agents may be of support in reducing functional decline. ${ }^{7}$ In 2015 , a taskforce made up of researchers, leaders from the pharmaceutical and nutritional industries, and representatives from non-profit organizations came together to discuss issues relating to drugs for frailty and sarcopenia. ${ }^{8}$ The results of this thesis support the option of combining treatment for sarcopenia and frailty, as has been shown that the two frailty criteria that were mostly present in frail older adults were weakness (poor grip strength) and slow walking speed, therewith showing much ground in common with sarcopenia. 
In addition to the pharmaceutical and nutritional industries, advancements in technology are of interest for older adults with sarcopenia. For example, using a smartphone for selfmonitoring of physical activity with direct feedback and goal setting has been shown effective in increasing physical activity levels in older adults with chronic obstructive pulmonary disease and diabetes. ${ }^{9}$ This new technology might also be suitable for counteracting (the negative consequences of) sarcopenia.

\subsection{Health Insurance Companies}

The results presented in this thesis demonstrate that sarcopenic older adults imply a considerable economic burden for health care. Interventions to prevent or delay the onset or progression of sarcopenia might lead to health benefits and subsequently reduce health care costs. At this moment health insurance companies are on the sideline, as sarcopenia is not officially recognized as a geriatric syndrome in Dutch health care. However, in the near future sarcopenia will have its own ICD-10 code, and will thereupon be visible for all stakeholders in health care. The Dutch Healthcare Authority obliges health care providers to register ICD-10 codes indicating the disease(s) of their patients. In the Netherlands health care providers do not have to forward the ICD-10 codes to the health insurance companies yet. However, the existence of an ICD-10 code will facilitate reimbursement, resource allocation, and decision making regarding future drug, nutritional or exercise treatment. By stimulating early identification and treatment of sarcopenia, health insurance companies could contribute to a reduction of the health and economic burden of sarcopenia.

\subsection{Policy Makers}

Dutch municipalities could contribute to awareness raising and counteracting sarcopenia as part of their role in aging in place. The municipality has the responsibility to advise and inform their inhabitants about possibilities for aging in place. ${ }^{10}$ On top of that they could provide a safe and challenging environment and stimulate the organization of (social) activities to improve physical activity.

\section{Activities/Products}

Public awareness is a key feature when trying to translate research into practice. ${ }^{11}$ Several activities were undertaken to inform the target groups about sarcopenia and the study results. Before the start of the MaSS study a special website was launched, including information on the study procedures, but also links to general information about sarcopenia. In addition, an interview on sarcopenia was given to a local newspaper. Information about sarcopenia and the MaSS study have been disseminated to pharmacies and residential living facilities, and the latter facilities also placed a short summary of the results in their newsletters. Participants of the MaSS study received a brief overview of their individual scores on muscle strength, physical performance and nutritional status. Participants furthermore received a Dutch summary of the final research findings. A short preventive message based on the current evidence base was added to this summary. In addition the research findings have been presented at several national and international geriatric and gerontology conferences. The results of this thesis can furthermore be spread to relevant health care provider associations and associations for older adults. 
Maastricht University offers bachelor students in Health Sciences a course in which sarcopenia is discussed. As these students might become future health care providers or employees at health insurance companies, informing this group is of importance. The particular studies in this thesis might be added to the resources provided to students.

\section{Future Directions}

The research in this thesis has contributed to unravelling the burden of sarcopenia in community dwelling older persons, and provides information on tools to identify older adults with sarcopenia. Now it is time to put the money where the mouth is. Advancements in the field of sarcopenia lag because of the absence of a universally accepted definition (including cut-off points) of sarcopenia. With this in mind, coming to a consensus definition followed by registration of an ICD-10 code is urgently needed to progress from the stage of sarcopenia research and awareness raising to acceptance and adoption of sarcopenia screening and treatment by the clinical community. Only then this geriatric giant will receive the attention it needs.

This thesis provides information on tools to identify older adults with sarcopenia, which can be used for screening purposes. Initiatives such as the SPRINT-T initiative are undertaken to identify proper strategies to counteract sarcopenia. ${ }^{12}$ After proven effective, these interventions can be tested for feasibility in health care practice. Also the acceptance of new technologies to stimulate physical activity could be explored, such as bicycles for 24 persons. Cycling is a habit of many Dutch people, and these 2-4 person bicycles enable older adults to exercise in a safe way, if needed with an informal care giver or nursing staff as driver. However, as it will take some time to explore these opportunities, in the meantime disseminating information about sarcopenia to relevant target groups is of importance. 


\section{References}

1. Guyton AC, Hall JE. Textbook of medical physiology. 11th ed. Philadelphia: Elsevier Saunders, 2005.

2. Luppa M, Luck T, Weyerer S, Konig HH, Brahler E, Riedel-Heller SG. Prediction of institutionalization in the elderly: a systematic review. Age Ageing 2010;39:31-38.

3. Grimshaw JM, Eccles MP, Lavis JN, Hill SJ, Squires JE. Knowledge translation of research findings. Implement Sci 2012;7:50.

4. Bosaeus I, Rothenberg E. Nutrition and physical activity for the prevention and treatment of age-related sarcopenia. Proc Nutr Soc 2015;1:1-7.

5. Den Ouden MD, Bleijlevens MH, Meijers JM, et al. Daily (in)activities of nursing home residents in their wards: an observation study. J Am Med Dir Assoc 2015;16:963-968.

6. Tieland M, Dirks ML, Van der Zwaluw N, et al. Protein supplementation increases muscle mass gain during prolonged resistance-type exercise training in frail elderly people: a randomized, double-blind, placebocontrolled trial. J Am Med Dir Assoc 2012;13:713-719.

7. Rolland Y, Onder G, Morley JE, Gillette-Guyonet S, Abellan van Kan G, Vellas B. Current and future pharmacologic treatment of sarcopenia. Clin Geriatr Med 2011;27:423-447.

8. Cesari M, Fielding R, Benichou $\mathrm{O}$, et al. Pharmacological interventions in frailty and sarcopenia: report by the International Conference on Frailty and Sarcopenia Research Task Force. The J Frailty Aging 2015;4:114-120.

9. Van der Weegen S, Verwey R, Spreeuwenberg M, Tange H, Van der Weijden T, De Witte L. It's LiFe!: mobile and web-based monitoring and feedback tool embedded in primary care increases physical activity: a cluster randomized controlled trial. J Med Internet Res 2015;17:e184.

10. Rijksoverheid. Langer zelfstandig wonen ouderen. Available from:

https://www.rijksoverheid.nl/onderwerpen/ouderenzorg/inhoud/ouderen-langer-zelfstandig-wonen, last access January 2016.

11. Green LA, Seifert CM. Translation of research into practice: why we can't "just do it". J Am Board Fam Pract 2005;18:541-545.

12. Sarcopenia \& Physical fRailty in older people: multi-componenT Treatment strategies. Why an innovative study in Geriatrics? [S.I.]: SPRINTT, 2015. Available from: http://www.mysprintt.eu/, last access January 2016. 




\section{Summary}

\section{Samenvatting \\ Dankwoord}

\section{About the Author \\ Publications}

Abbreviations 



\section{Summary}

The human body is composed of more than 600 skeletal muscles, accounting for about $40 \%$ of body weight. Skeletal muscles help you to stand straight, keep balance, walk, run, get dressed, bend over, go shopping, carry a bag, scratch your knee, and so on. After about 30 years of age, muscle mass and function slowly start to decrease. The older you get, the more muscle you lose. When muscle mass and function fall below a certain threshold, the person in question may experience mobility difficulties, loss of independence, a lower quality of life and an increased risk of morbidity and mortality.

In 1989 Rosenberg coined the term sarcopenia, to describe the loss (Greek: penia) of muscle (Greek: sarx). Sarcopenia has been proposed as a new geriatric giant, a frequently occurring geriatric syndrome affecting the lives of a growing number of older adults. As sarcopenia is a rather 'new' concept in the research world, many gaps in knowledge exist and screening for sarcopenia is not yet embedded in clinical practice. The purpose of this thesis was to increase our understanding of the prevalence, characteristics, and health and economic outcomes of community-dwelling older adults with sarcopenia. The data used within this thesis was collected as part of the cross-sectional Maastricht Sarcopenia Study (MaSS; chapters 3-5) and the population-based Age, Gene/Environment, SusceptibilityReykjavik Study (AGES-Reykjavik; chapter 6). This section summarizes all studies described in this thesis.

Chapter 1 gives an introduction about sarcopenia, discussing its mechanisms, current knowledge on its burden and ways to identify and counteract sarcopenia. Additionally several gaps in knowledge within sarcopenia research are presented. The chapter ends with some background information regarding the data sources and the aims and outline of the thesis.

Chapter 2 describes the results of a systematic review on the measurement properties (i.e. validity, reliability) and feasibility of tools to measure muscle mass, strength, and physical performance in community-dwelling older adults. Muscle mass, strength and physical performance were chosen as the European Working Group on Sarcopenia in Older People (EWGSOP) recommended to include these three muscle parameters in the identification of older adults with sarcopenia. Sixty-two studies were included in the systematic review, reporting on a wide array of tools that are valid, reliable and feasible for measurements of muscle mass (e.g. magnetic resonance imaging), strength (e.g. leg press), and performance (e.g. six minute walk test) in clinical settings. Bioelectrical impedance analysis (BIA), handheld dynamometry and gait speed or the short physical performance battery (SPPB) were found to be the most valid, reliable, and feasible in a general practitioner practice or in a home-setting. However, regarding muscle mass no well-validated and reliable tools were found for this setting.

Chapter 3 reports on the prevalence and characteristics of sarcopenic older adults who participated in the MaSS study. This study included 247 community-dwelling older adults living in Maastricht. Data was collected during a single 1-2 hour home visit, including measurements of height, weight, muscle mass, muscle strength, physical performance, comorbidities, cognitive function, physical activity, nutritional status, frailty, functional 
status, and health care utilization. In the MaSS study, the prevalence of sarcopenia was $12.1 \%, 41.5 \%$ and $58.6 \%$ in respectively older adults living 1 ) independently at home without additional care, 2) at home or in an assisted living facility with professional home care, and 3 ) in a residential living facility. Most sarcopenic older adults had low muscle mass in combination with poor grip strength.

Chapter 4 explores the association between sarcopenia and physical frailty (MaSS data). Frail older adults (about $9 \%$ of the study population) were more often sarcopenic compared to non-frail older adults. In addition, a majority of the sarcopenic subjects was pre-frail and almost a quarter was frail. Two of the five frailty criteria that were most frequently present in frail older adults were weakness (poor grip strength) and slow walking speed. Therefore, screening older adults on muscle strength and/or walking speed may identify both older adults with (a risk of) sarcopenia and older adults with (a risk of) frailty. The two physical frailty scales, the Fried criteria and the FRAIL scale, correlated moderately, i.e. they identify partly different subjects as frail.

Chapter 5 examines the health and economic burden of older adults with sarcopenia (MaSS data). Sarcopenic older adults had more comorbidity, were more disabled in activities of daily living and had a lower quality of life compared with non-sarcopenic older adults. Furthermore, sarcopenic older adults presented higher costs of care, which were mainly attributed to the living situation (residential living facility versus independently living and home care).

Chapter 6 reports on the relation between physical activity and the incidence of sarcopenia in participants from the population-based AGES-Reykjavik Study. The AGES-Reykjavik Study is a large cohort study with 5-year follow-up. The examinations consisted of several clinic visits and included numerous measurements on vascular, neurocognitive, and musculoskeletal health and questionnaires on physical, psychological, and social health. A secondary data-analysis showed that sarcopenic older adults less frequently performed moderate to vigorous physical activity than did non-sarcopenic older adults. Regarding the incidence proportion of sarcopenia over five years' time: 1 out of 7 inactive older adults and 1 out of 11 active older adults developed sarcopenia.

Chapter 7 discusses the main findings of the studies presented in this thesis, and reflects on the theoretical and methodological considerations. The chapter concludes with implications for research and practice.

Chapter 8 concentrates on the societal value that the (scientific) knowledge that emerged from the studies has. 




\section{Samenvatting}

Het menselijk lichaam bestaat uit meer dan 600 skeletspieren, die samen ongeveer $40 \%$ van het lichaamsgewicht uitmaken. Skeletspieren stellen je in staat om rechtop te kunnen staan, balans te houden, te lopen, rennen, aankleden, buigen, boodschappen doen, een tas te dragen, je knie krabben en ga zo maar door. Na het 30ste levensjaar nemen de spiermassa en spierfunctie langzaam af. Hoe meer jaren er verstrijken, hoe meer verlies van spiermassa er optreedt. Wanneer de spiermassa en functie onder een bepaalde drempelwaarde komen, kan de betreffende persoon moeite ervaren met de mobiliteit en zelfstandigheid, een lagere kwaliteit van leven ervaren en heeft de persoon een hogere kans op ziekte en sterfte.

In 1989 heeft Rosenberg de term sarcopenie geïntroduceerd om het verlies van spiermassa en functie te beschrijven. De term sarcopenie is gebaseerd op de Griekse woorden 'sarx' (vlees, spier) en 'penia' (verlies). Sarcopenie wordt ook wel gezien als een nieuwe geriatrische reus, een veelvoorkomend geriatrisch syndroom dat het leven van ouderen (negatief) beïnvloed. Sarcopenie is een nog relatief nieuw begrip in de onderzoekswereld, en er zijn dan ook nog veel hiaten in de wetenschappelijke kennis omtrent sarcopenie. Ook wordt in de klinische praktijk nog niet standaard gescreend op sarcopenie. Het doel van dit proefschrift was om meer inzicht te krijgen in de prevalentie, kenmerken en gezondheids- en economische uitkomsten van thuiswonende ouderen met sarcopenie. Om dit doel te bereiken zijn gegevens verzameld in de cross-sectionele Maastrichtse Sarcopenie Studie (MaSS; hoofdstuk 3-5) en is een secundaire data-analyse uitgevoerd op data van de Age, Gene/Environment, Susceptibility-Reykjavik Study (AGESReykjavik; hoofdstuk 6).

Hoofdstuk 1 geeft een introductie over sarcopenie. In dit hoofdstuk komen de onderliggende mechanismen, de belasting van sarcopenie voor zowel mens als maatschappij en manieren om sarcopenie te identificeren en aan te pakken aan bod. Daarnaast wordt ingegaan op de nog ontbrekende kennis rondom sarcopenie. Als laatste wordt in dit hoofdstuk een korte toelichting gegeven op de gebruikte databronnen en zijn de doelstellingen van het proefschrift beschreven.

Hoofdstuk 2 beschrijft de resultaten van een systematisch review naar de validiteit, betrouwbaarheid en uitvoerbaarheid van verschillende meetinstrumenten om spiermassa, spierkracht en fysiek functioneren te meten bij thuiswonende ouderen. Deze componenten zijn gekozen op basis van aanbevelingen van de Europese Werkgroep Sarcopenie bij Ouderen (EWGSOP). De EWGSOP adviseert deze drie componenten te gebruiken bij het identificeren van ouderen met sarcopenie. De 62 geïncludeerde studies rapporteren over een grote range aan meetinstrumenten die valide, betrouwbaar en uitvoerbaar zijn in een klinische setting. Daarnaast bleken bio-impedantie, een hand-dynamometer en loopsnelheid of een korte fysieke functie batterij (SPPB) het meest valide, betrouwbaar en uitvoerbaar in een huisartsenpraktijk of thuis. Echter er zitten wel wat haken en ogen aan de validiteit van de bio-impedantie meting in een oudere populatie en er zijn geen studies gevonden die de betrouwbaarheid van deze meting hebben onderzocht. 
Hoofdstuk 3 doet verslag van de gevonden prevalentie van sarcopenie en de kenmerken van de deelnemers van de MaSS studie. Aan deze studie hebben 247 thuiswonende ouderen deelgenomen. De gegevens zijn verzameld door middel van een 1 à 2 uur durend huisbezoek, waarin onder andere lengte, gewicht, spiermassa, spierkracht, fysiek functioneren, ziekten, cognitieve status, fysieke activiteit, voedingsstatus en zorggebruik zijn gemeten. In de MaSS studie was de prevalentie van sarcopenie $12.1 \%, 41.5 \%$ en $58.6 \%$ in respectievelijk 1) thuiswonende ouderen zonder zorg, 2) ouderen met thuiszorg of wonend in een aanleunwoning, en 3 ) ouderen in een verzorgingshuis. De meeste sarcopene ouderen hadden een lage spiermassa gecombineerd met lage spierkracht.

Hoofdstuk 4 verkent de associatie tussen sarcopenie en kwetsbaarheid (MaSS data). Kwetsbare ouderen (ongeveer 9\%) waren vaker sarcopeen dan niet kwetsbare ouderen. Daarnaast voldeed een meerderheid van de sarcopene ouderen aan 1 of 2 criteria voor kwetsbaarheid, en was een kwart van de sarcopene ouderen daadwerkelijk kwetsbaar (3 of meer criteria van kwetsbaarheid aanwezig). Twee van de meest voorkomende criteria van kwetsbaarheid waren een lage knijpkracht en lage loopsnelheid. Knijpkracht en loopsnelheid kunnen daarom mogelijk gebruikt worden voor het opsporen van zowel sarcopene ouderen als kwetsbare ouderen. De twee gebruikte meetinstrumenten voor kwetsbaarheid waren matig gecorreleerd, dat wil zeggen dat ze gedeeltelijk dezelfde, maar gedeeltelijk andere ouderen aanmerkten als kwetsbaar.

Hoofdstuk 5 onderzoekt de gezondheids- en economische belasting van sarcopenie voor mens en maatschappij (MaSS data). Sarcopene ouderen hadden meer ziekten, waren meer beperkt in activiteiten van het dagelijks leven en hadden een lagere kwaliteit van leven in vergelijking met niet-sarcopene ouderen. Sarcopene ouderen hadden daarnaast hogere zorgkosten, voornamelijk veroorzaakt door hun woonsituatie (verzorgingshuis ten opzichte van thuiswonend zonder zorg of thuiszorg).

Hoofdstuk 6 beschrijft de relatie tussen fysieke activiteit en de incidentie van sarcopenie in deelnemers van het AGES-Reykjavik bevolkingsonderzoek. In dit onderzoek zijn deelnemers tweemaal gemeten, met een tussenperiode van 5 jaar. De metingen zijn verricht gedurende verscheidene bezoeken aan een kliniek, en omvatten onder andere vasculaire, neurocognitieve en spieronderzoeken, en vragenlijsten over fysieke, psychologische en sociale gezondheid. Een secundaire data-analyse liet zien dat sarcopene ouderen minder vaak deelnamen aan matig tot intensieve fysieke activiteit vergeleken met niet-sarcopene ouderen. Gedurende de 5 jaar onderzoek ontwikkelde 1 op de 7 inactieve ouderen, en 1 op de 11 actieve ouderen sarcopenie.

Hoofdstuk 7 is de algemene discussie, waarin de belangrijkste resultaten van het proefschrift worden samengevat en theoretische en methodologische overwegingen worden beschreven. Afsluitend worden implicaties van de resultaten van het proefschrift voor zowel onderzoek als praktijk gegeven.

Hoofdstuk 8 concentreert zich op de maatschappelijke waarde die de opgedane wetenschappelijke kennis heeft. 




\section{Dankwoord}

Dan ineens is het zover, mijn proefschrift is af! lk ben erg dankbaar voor alle steun, motiverende woorden, gezelligheid en afleiding, die mij de afgelopen jaren naar deze eindstreep hebben gebracht. Een aantal mensen wil ik hiervoor in het bijzonder bedanken.

Allereerst de mensen die deelgenomen hebben aan de MaSS studie. Een groot deel van dit proefschrift zou niet tot stand zijn gekomen zonder jullie inzet. Bedankt voor jullie gastvrijheid, geduld, enthousiasme en de vele goede verhalen! Ik heb oprecht genoten van de huisbezoeken.

Mijn promotieteam, Prof. Dr. Jos Schols, Dr. Ruud Halfens en Dr. Judith Meijers, bedankt voor de fijne samenwerking, de vele inhoudelijke discussies, jullie continue vertrouwen, jullie openheid en de vrijheid die jullie me gegeven hebben. Ik bewonder jullie hart voor de zorg en ik had me geen beter team kunnen wensen!

Jos, wat heb jij ontzettend veel energie! Als je op kantoor was, kwam je altijd wel even binnenlopen. Zodra de klink van mijn deur naar beneden ging, kwam de spraakwaterval al op gang en die hield pas op nadat je was vertrokken en de deur allang dicht was. Wát ik ook wilde vragen, je was altijd bereikbaar en hebt me altijd gemotiveerd en geïnspireerd om door te gaan. Jouw optimisme, gedrevenheid en kennis hebben me geholpen enorme stappen te maken in de afgelopen jaren.

Ruud, als een geluk bij een ongeluk werd jij, (nu ga ik geen 'u' meer zeggen hoor... ()) na wat omwegen, mijn bachelor scriptiebegeleider. Het is mij erg goed bevallen en ik mocht meteen blijven voor een paar weken vakantiewerk, dus ik geloof dat de klik wederzijds was. Na het afronden van mijn master in Amsterdam, heb je me overtuigd om terug te komen naar Maastricht. Ik was niet van plan om weer te verhuizen naar Maastricht en wilde ook niet promoveren! Achteraf ben ik heel blij, dat ik de door jouw geboden kans toch heb aangepakt! Je betrokkenheid, nuchterheid en kalmte hebben me geholpen met beide benen op de grond te blijven en het zijn daarnaast perfecte eigenschappen gebleken om de soms wilde plannen van Jos iets te neutraliseren... (-).

Judith, 3x zwangerschapsverlof, een verhuizing en een combi baan. Met jou maak je van alles mee. Gelukkig kun je goed plannen, iets wat je mij ook altijd hebt aangemoedigd om te doen. Met je heldere feedback, epidemiologische achtergrond en helikopterview, wist je me altijd in de juiste richting te sturen!

I would like to thank the members of the assessment committee: Prof. Dr. R.A. de Bie, Prof. Dr. O. Bruyère, Prof. Dr. C.P.G.M. de Groot, Prof. Dr. A.M.W.J. Schols and chairman Prof. dr. G.I.J.M. Kempen, for their invested time and efforts to read and evaluate this thesis.

Yvette, Sjors en Sovianne, bedankt voor jullie bijdrage in de verschillende fases van het project en jullie flexibiliteit wat betreft de overleg-locaties!

Gemeente Maastricht (Marcel Dautzenberg, Rob Starren, Paul Hinssen, Paul-Philip Lemmens), locatie managers van de Maastrichtse verzorgingshuizen, Roel Herben, Frank Guldemond en Gezondheidscentrum Van Kleef, dank voor jullie hulp bij het rekruteren van 
deelnemers! Rachele Arends, dank voor uw bereidwilligheid om medische achterwacht te zijn.

Fabienne Hameleers, leden van de METC en het CTCM (Maud Wasserman, Tine Horsten, Arno Škrabanja), bedankt voor het meedenken, jullie kritische blik en de vele informatie die ik van jullie ontvangen heb.

Loe en Loe, bedankt voor het wegwijs maken in de wereld van het lab. Loe D. het was altijd een plezier om na een huisbezoek de vele trappen te beklimmen naar de $4 \mathrm{e}$ verdieping van het MUMC+ om de buisjes bloed bij je af te geven, wetende dat je ons met een lach stond op te wachten $:-$. Ook wil ik Jaap Bakker en Jörgen Bierau van de afdeling Klinische Genetica bedanken voor hun inzet voor de MaSS Studie.

Collega's van de vakgroep HSR, bedankt voor jullie collegialiteit en de fijne samenwerking de afgelopen jaren! Ik heb altijd met veel plezier op de vakgroep gewerkt. LPZ-ers Suzanne, Saskia, Esther, Noémi, Armand en Jacques, bedankt voor jullie interesse en de gezellige chitchats! Fitri, we've both gone through some hard times, but it was a relief to have such a friendly Indonesian PhD ally to share the good and bad times! Vivian, Nora, Sanne en Yasemin, zonder jullie als kamergenotes was het een stuk minder gezellig geweest! Sanne, met jou heb ik het langst een kamer gedeeld. Je bent een creatieveling en optimist in hart en nieren, het was fijn om alles met je te kunnen bespreken! De wetenschap, statistiek, maatschappelijke issues, het nieuws, reizen, verhuizen naar het noorden.... soms moesten we even een praatpauze inlassen om verder te werken ;-). Hanneke, Irma, Mirre, Nienke en Ramona, bedankt voor jullie enthousiaste inzet tijdens (de voorbereidingen van) het EDCNS congres, good memories! (Oud) HSR buurvrouwen Basima, Tanja, Marla en Inge, bedankt voor de fijne kamer/Menza/gang/keuken gesprekken! Bart, wat heb jij mij vaak aan het lachen gemaakt! Bedankt voor de fijne herinneringen aan de etentjes, poolavondjes, bezochte bandjes, muziektips en natuurlijk onze bijzondere reis. Marianne, je stond altijd klaar en hebt met veel geduld al mijn mailtjes afgehandeld, super! Brigitte, Suus, Willy-An en Arnold bedankt voor jullie ondersteuning in verschillende fases van het project. An, cảm ơn for the nice conversations en succes met je cursus Nederlands! Walther, niet werkzaam bij HSR, maar er wel met enige regelmaat te vinden, bedankt voor je input bij de projectgroep overleggen en tussendoor!

Elles, mijn partner in (MaSS) crime, je bent een kei! Het was ontzettend fijn om met je samen te werken en onze vele huisbezoek/levenservaringen te kunnen delen. Je bent een harde werker, altijd optimistisch, betrokken en proactief. Je hebt zelfs je vader aangeboden voor een pre-pilot huisbezoek (bedankt meneer Lenaerts!). Daarnaast ben je gewoon heel gezellig, ik ga onze terrasjes/koffietjes/etentjes missen!

Collega's van de BHV, met jullie was er altijd wel wat te beleven. Even een brandje blussen, theatrale optredens, alarmbellen, geluids- en filmopnames, of gezellig een hapje eten. Dank jullie wel voor de waardevolle aanvulling op mijn PhD tijd! 
I very much enjoyed participating in the Doctoral Programme Nursing Science. The trips to Berlin and Graz were a welcome distraction of routine work. The constructive feedback during the meetings and the in-between talks (en partie en français, merci Birgit et Friederike!) enabled me to put things into perspective and resulted in new insights. Silvia, Daniela and Sandra I will miss our Indian dinners, your stories and the famous German gummy bears! Barbara, you stand for hospitality and lots of fun in Bern (-). Christa, Theo and other PhD fellows, thanks a lot and good luck with your PhDs/the life after!

I would like to thank all co-authors for their contributions to the several chapters of this thesis. In particular I would like to thank Dr. Cruz Jentoft. Your work has inspired me and l've very much appreciated your input during my project. Luc, bedankt voor alle wijze adviezen m.b.t. de metingen van spiermassa en functie. Frans, bedankt voor je waardevolle statistische ondersteuning! Silvia Evers, ik heb veel van je geleerd over kostenstudies, dank daarvoor! Annemarie Koster, bedankt voor de brainstormsessies, je scherpe feedback op mijn stukken en natuurlijk het overdragen van je enthousiasme voor de NIA!

Dr. Harris, alias queen of aging. Thank you for your hospitality and valuable insights before, during and after my internship at the NIA. Martine, Elisa, Ilse, Mitchel and Osorio, you made the lab into a living playground of science. Thanks for all the candy, chocolate, teas, games, muscular pains, dinners and outings! Also thanks to Dr. Launer, Tad, Armilda, Victoria, Melissa, Jennifer, Robert, Jacob, Eric, Caroline, Julia, and Phyllis for patiently answering my questions and making me feel at home.

Dhr. Rodenburg en Garance Jacquot, bedankt voor jullie steun en inzichten in de laatste maanden van mijn $\mathrm{PhD}$ traject.

Good friends are like stars, you don't always see them but you know they are always there. Annoek, Ite, Sandra, Marissa, Ellen, Tamara, Liske, Janneke, Jarl en Stef, voor jullie ging ik altijd graag terug naar het midden des lands! :) Jullie zorgden ervoor dat ik letterlijk en figuurlijk even afstand kon nemen van het werk. Lidwien, kom je ook snel naar het midden des lands, zodat we onze gezellige rtl-4 avondjes kunnen voortzetten? Federica, sono contenta di avere un amico come te! Annelien, misschien wel het verst weg van allemaal, maar soms stond je zomaar ineens op de stoep, zelfs in DC. Bedankt voor je inspirerende vriendschap! Minka, als mede-PhD'er konden we samen heerlijk klagen over vertragingen en andere onzin. Bedankt voor je luisterend oor en de leuke avondjes uit! Willem, Desiree, Niek en Jeanette, bedankt voor de gezellige Maastrichtse volleybal/film/terras avonden!

Sandra, wat hebben wij veel meegemaakt de afgelopen 25 jaar! (jubileum! Hint...) Waar het begon met schommelen op een tractorband, urenlang monopolie spelen, logeerpartijtjes, nachtbraken, een eigen bedrijfje runnen, samen sporten, looking for squirrels (ok, nu wat minder...), klussen en weekendjes weg, hebben we sinds kort ook discussies over de wetenschap en onderzoeksvoorstellen. Ik heb onwijs veel bewondering voor je leervermogen en creativiteit en lig steeds weer in een scheur om je humor. Bedankt voor alles, ik voel me vereerd dat je als paranimf aan mijn zijde wilt staan! 
Lieve opa's en oma's. Helaas maken jullie deze dag niet meer mee. Toch wil ik jullie hier even noemen, jullie waren geweldig! Opa M., ik heb uw advies opgevolgd, heel erg bedankt, it was worth it!

Ooms, tantes, nichtjes, neefjes en aanhang. Bedankt voor jullie meeleven met het onderzoek en de welkome afleiding in de Belgische Ardennen, op de skipiste, (bij jullie) thuis, tijdens de familietoernooien, bbq's en kerstdiners!

Herman, Aly, Linda, Tim, Sem en Jorick, inmiddels kom ik alweer meer dan drie jaar bij jullie over de vloer en ik hoop dat daar nog heel veel jaren bij komen. Bedankt voor jullie goede zorgen!

Lieve pap en mam, ik heb respect voor de manier waarop jullie in het leven staan. Jullie hebben me laten zien dat je samen alles aan kunt en ondanks de soms zware tijden in de kleine dingen geluk kunt vinden. Jullie hebben me altijd gesteund en gestimuleerd om te doen wat me gelukkig maakt. Als ik het even niet meer wist, kon ik altijd bij jullie aankloppen. Bedankt dat jullie altijd voor mij klaar staan, jullie zijn the best!

Jordy, Guido en Tjeerd, mijn lieve (schoon)broers! Nu mijn promotie bijna is afgerond hoop ik jullie weer wat vaker te zien. Jordy, jij hebt mijn blik op de wereld verrijkt en laten zien dat anders zijn soms moeilijk, maar vooral ook heel bijzonder is. Jij leert me wat echt belangrijk is in het leven. Tjeerd, fijn om zo'n avonturier in ons gezin te hebben! Guido, van jongs af aan heb ik opgekeken tegen mijn grote broer, ondanks dat je het af en toe heel leuk vond om mij te plagen, te laten schrikken of te klagen dat ik te hard mee blèrde met mijn walkman. Ik ben blij met zo'n fijne broer als jij en vind het super dat je als paranimf naast me zal staan!

Lieve Jeroen, mijn maatje, mijn prins op het struik-etende paard. Waar we ook zijn, bij jou voel ik me thuis. Je oneindige geduld, begrip, openheid, rust, relativeringsvermogen en oplossingsgerichtheid hebben me enorm geholpen als mijn hoofd weer eens overliep van allerlei (on)zinnige zaken. Bedankt dat je me hebt geholpen om alles eruit te halen wat erin zit! $\mathrm{Nu}$ is het tijd om het PhD hoofdstuk af te sluiten en onze reis samen voort te zetten. I can't wait! 




\section{About the Author}

Donja Marita Mijnarends was born on February 1st 1987 in Zelhem, the Netherlands. She attended secondary school (VWO) at Ulenhof College in Doetinchem. In 2006 she started with the bachelor General Health Sciences at Maastricht University, with a major in Health Care Studies and a minor Bio-regulation. After completing her bachelor degree in 2009, she moved to Amsterdam where she followed the master International Public Health at the VU University, Amsterdam, the Netherlands. She wrote her master thesis at the Medical Committee Netherlands - Vietnam in Hanoi, Vietnam. The thesis focused on sustainability criteria for community-based rehabilitation programs in Vietnam.

After obtaining her master's degree in 2010, she returned to Maastricht University (Department of Health Services Research), where she started as a research assistant on a ZonMw funded project aimed at improving the quality of nutritional care. In 2011 she started her PhD trajectory under supervision of Prof. dr. Jos Schols, dr. Ruud Halfens, and dr. Judith Meijers, which has resulted in this thesis. During her PhD trajectory she participated in the PhD Program Nursing Science, jointly organized by Maastricht University, the Medical University of Graz (Austria) and Charité Universitätsmedizin Berlin (Germany). In addition, she was coorganizer (2011) and chair (2014) of the European Doctoral Conference in Nursing Science. In the final year of her PhD, she performed a three month internship at the National Institutes of Health, National Institute on Aging, Bethesda,

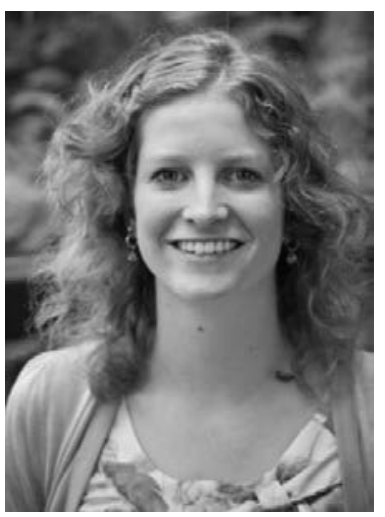
USA. 



\section{Publications}

\section{International refereed journals}

- DM Mijnarends, JMGA Schols, RJG Halfens, JMM Meijers, YC Luiking, S Verlaan, SMAA Evers. Burden-of-Illness of Dutch Community-Dwelling Older Adults with Sarcopenia: Health Related Outcomes and Costs. Eur Geriatr Med 2016; Epub ahead of print , http://dx.doi.org/10.1016/j.eurger.2015.12.011.

- DM Mijnarends, A Koster, JMGA Schols, JMM Meijers, RJG Halfens, V Gudnason, G Eiriksdottir, K Siggeirsdottir, S Sigurdsson, PV Jonsson, O Meirelles, TB Harris. Physical Activity and Incidence of Sarcopenia: The Population-Based AGES-Reykjavik Study. Submitted.

- DM Mijnarends, RJG Halfens, JMGA Schols, FES Tan, ELA Lenaerts, S Verlaan, YC Luiking, JMM Meijers. Prevalence and Characterization of Sarcopenia in Older People Living in the Community. Submitted.

- S ter Borg, LCPGM de Groot, DM Mijnarends, JHM de Vries, S Verlaan, S Meijboom, YC Luiking, JMGA Schols. Differences in Nutrient Intake and Biochemical Nutrient Status Between Sarcopenic and Non-Sarcopenic Older Adults - Results from the Maastricht Sarcopenia Study. J Am Med Dir Assoc 2016; Epub ahead of print, doi: http://dx.doi.org/10.1016/j.jamda.2015.12.015.

- DM Mijnarends, JMGA Schols, JMM Meijers, FES Tan, S Verlaan, YC Luiking, JE Morley, RJG Halfens. Instruments to Assess Sarcopenia and Physical Frailty in Older People Living in a Community (Care) Setting: Similarities and Discrepancies. J Am Med Dir Assoc 2015;16(4):301-8.

- $\quad$ S ter Borg, S Verlaan, DM Mijnarends, JMGA Schols, LCPGM de Groot, YC Luiking Macronutrient Intake and Inadequacies of Community-Dwelling Older Adults, A Systematic Review. Ann Nutr Metab 2015;66(4):242-55

- S ter Borg, S Verlaan, J Hemsworth, DM Mijnarends, JMGA Schols, YC Luiking, LCPGM de Groot. Micronutrient Intakes and Potential Inadequacies of CommunityDwelling Older Adults: A Systematic Review. Br J Nutr 2015;113(8):1195-206.

- D Schoberer, DM Mijnarends, M Fliedner, RJG Halfens, C Lohrmann. Quality of Austrian and Dutch Falls-Prevention Information: A Comparative Descriptive Study. Health Education Journal 2015; 1-15.

- DM Mijnarends, JMM Meijers, RJG Halfens, S ter Borg, YC Luiking, S Verlaan, D Schoberer, AJ Cruz Jentoft, LJC van Loon, JMGA Schols. Validity and Reliability of Tools to Measure Muscle Mass, Strength, and Physical Performance in CommunityDwelling Older People: A Systematic Review. J Am Med Dir Assoc 2013;14(3):170-8.

- JMM Meijers, RJG Halfens, DM Mijnarends, H Mostert, JMGA Schols. A Feedback System to Improve the Quality of Nutritional Care. Nutrition 2013;29(7-8):1037-41.

- DM Mijnarends, D Pham, K Swaans, WH Van Brakel, EP Wright. Sustainability Criteria for CBR Programmes - Two Case Studies of Provincial Programmes in Vietnam. Disability, CBR and Inclusive Development Journal 2011; Vol 22, No.1, doi 10.5463/DCID.v22i2.54. 


\section{National refereed journals}

- WMWH Sipers, DM Mijnarends, JMGA Schols. Sarcopenie. Ned Tijdschr Tandheelkd 2013;120(5):236-9.

\section{Conference contributions}

- EUGMS, Rotterdam, the Netherlands (2014). Quality of Life is decreased in Community-Dwelling Older People with Sarcopenia (poster). Published in: Eur Geriatr Med; Vol 5: S1 p.189.

- ESPEN, Geneva, Switzerland (2014). Sarcopenic community-dwelling older persons are more disabled in (instrumental) activities of daily living compared to their nonsarcopenic peers (poster). Published in: Clin Nutr; Vol 33: S1 p.S36.

- International Conference on Frailty and Sarcopenia Research, Barcelona, Spain (2014). Assessment of Sarcopenia in Community-dwelling Older People: Evaluation of the EWGSOP Consensus Definition Criteria (poster). JFA, Vol 3: 1, p.67.

- IAGG World Congress of Gerontology and Geriatrics, Seoul, South Korea (2013). Rationale and design of a cross-sectional study of the prevalence, characterization and health and economic consequences of sarcopenia in community-dwelling older people in the Netherlands (symposium). J Nutr Health Aging; 17 (suppl. 1): S245.

- Geriatriedagen, Den Bosch, the Netherlands (2013). Sarcopenie screening: welke meetinstrumenten zijn het meest valide en betrouwbaar? (poster).

- $\quad$ EUGMS, Brussels, Belgium (2012). Assessing sarcopenia in community-dwelling older people in a home-setting: a systematic review (poster). Published in: Eur Geriatr Med; Vol 3:S1 p S59.

- European Doctoral Conference in Nursing Science, Graz, Austria (2012). Psychometric properties of tools to assess sarcopenia in community-dwelling older people: a systematic review (oral presentation).

- ESPEN, Barcelona, Spain (2012). Psychometric properties of tools to assess sarcopenia in community-dwelling older people: a systematic review (poster). Published in: Clin Nutr; Vol 7: S 09/2012 p.52-53.

- European Doctoral Conference in Nursing Science, Maastricht, the Netherlands (2011). Valid, reliable and feasible assessment of sarcopenia in community-dwelling elderly: a systematic review (oral presentation).

- International Conference on Sarcopenia Research, Toulouse, France (2011). Identification and characterization of community-dwelling elderly with sarcopenia - a study protocol (poster). Published in: J Nutr Health Aging; Vol 15: S p.511.

- CAPHRI research day, Maastricht, the Netherlands (2011). Identification and characterization of community-dwelling elderly with sarcopenia in the Netherlands (poster). 




\section{Abbreviations}

ADL Activities of daily living

AGES Age, Gene/Environment, Susceptibility (Reykjavik Study)

ALM Appendicular lean mass

AUC Area under the curve

BIA Bioelectrical impedance analysis

BMI Body mass index

CHEERS Consolidated Health Economic Evaluation Reporting Standards

$\mathrm{Cl} \quad$ Confidence interval

CIRS Cumulative illness rating scale

COSMIN Consensus-based standards for the selection of health status measurement instruments

CT Computed tomography

DXA Dual energy $x$-ray absorptiometry

ESPEN-SIG European Society of Parenteral and Enteral Nutrition Special Interest Groups

EWGSOP European Working Group on Sarcopenia in Older People

FNIH Foundation for the National Institutes of Health Sarcopenia Project

GARS Groningen Activity Restriction Scale (or: modified gait abnormality rating scale)

GDS Geriatric Depression Scale

HHD Handheld dynamometry

IADL Instrumental activities of daily living

ICC Intraclass correlation coefficient

IWGS International Working Group on Sarcopenia

LBW Lean body weight

LEPB Lower extremity performance battery

LOA Limits of agreement

MaSS Maastricht Sarcopenia Study

MAT Mobility assessment tool

MMSE Mini-mental state examination

MRI Magnetic resonance imaging

MVPA Moderate-vigorous physical activity

$\mathrm{NZa} \quad$ Nederlandse Zorgautoriteit (Dutch Healthcare Authority)

OR Odds ratio

POMA Performance-oriented mobility assessment

PPT Physical performance test

PRISMA Preferred Reporting Items for Systematic Reviews and Meta-Analyses

QoL Quality of life

ROM Range of motion

TBW Total body water

SD Standard deviation

SEM Standard error of measurement

SF Short form

SMI Skeletal muscle index

SPPB Short physical performance battery

SSCWD Society of Sarcopenia, Cachexia and Wasting Disorders

STS Sit-to-stand

TUG Timed up and go

UEPB Upper extremity performance battery

4-C model 4 compartment model

6-MW Six minute walk test 


$\{\{\}$ ing 